Hergen Schultze

Einfache Modelle für komplexe Biomembranen 



\author{
Dissertation \\ zur Erlangung des Doktorgrades \\ der Mathematisch-Naturwissenschaftlichen Fakultäten \\ der Georg-August-Universität zu Göttingen
}

\title{
Einfache Modelle für komplexe Biomembranen
}

\author{
vorgelegt von \\ Hergen Schultze \\ aus Hannover
}

Göttingen, 2003

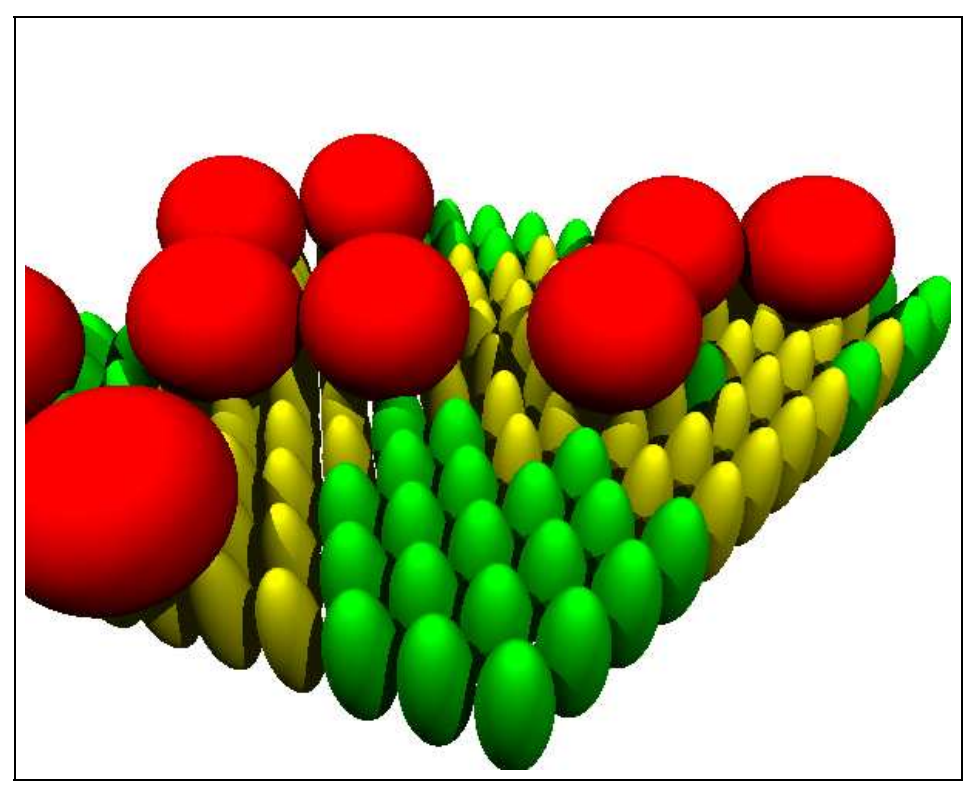


D 7

Referent: Prof. Dr. Reiner Kree

Koreferentin: Prof. Dr. Annette Zippelius

Tag der mündlichen Prüfung: 6. Oktober 2003 


\section{Kurzreferat}

Biomembranen versteht man als komplexe zweidimensionale Fluide, die aus Proteinen und Lipiden bestehen. In dieser Arbeit werden möglichst einfache molekulare Modelle zur Beschreibung der thermodynamischen Eigenschaften von Biomembranen entwickelt, angewendet und diskutiert. Die Modelle geben Aufschluss über laterale Strukturen und charakterisieren diese als Cluster oder Domänen („Rafts“). Den Ausgangspunkt bildet ein Gittergas (Ising-Modell) mit temperaturabhängigem Feld zur Beschreibung der Zustandsänderungen der Lipide in einer einzelnen flachen Membran. Die Proteine werden als zusätzliche Komponenten des Gitters in das Modell integriert. Die wesentlichen Aspekte der Untersuchung bestehen erstens in der Unterscheidung von peripheren und integralen Komponenten in einem Mehrschicht-Modell und zweitens in der Charakterisierung von weichen ausgedehnten Komponenten. Das Clusterverhalten kleiner Komponenten kann durch eine Mittlere-Feld-Approximation inklusive Nachbarschafts-Korrelationen (ClusterVariationsverfahren) ausreichend beschrieben werden. Das Modell der Lipidmembran mit ausgedehnten Adsorbaten wird einerseits analytisch auf ein effektives Lipidsystem mit Mehrteilchen-Kopplung abgebildet und andererseits durch Monte-Carlo-Simulation auf ein Proteinsystem mit effektiver Paar-Wechselwirkung. Beide Ansätze zeigen gegenüber der Wechselwirkung im Ausgangsmodell eine neue Kooperativität. Tatsächlich kann in Simulationen eine Entmischung des Gesamtsystems in einen bedeckten und unbedeckten Bereich aufgrund der Fluktuationen im Lipidsystem nachgewiesen werden. Die Grenzfläche zwischen den Phasen ist ungewöhnlich rau, was sich in einem statischen Skalenexponenten äußert, der signifikant größer ist als für typische zweidimensionale Modelle. Die erfolgreiche Anpassung der Modell-Parameter an Experimente zeigt, dass die Vorstellung von peripheren Proteinen, die mit mehr Lipiden wechselwirken als sie bedecken, realistisch ist. Die Diskussion schließlich führt zu einem Modell, das nur mit Hilfe der inneren Zustände der Komponenten die Krümmung der äußeren Membran-Oberfläche beschreibt. 



\section{Abstract}

Biomembranes are complex two-dimensional fluids consisting of proteins and lipids. In this work, simple molecular models are developed, applied and discussed to describe the thermodynamic properties of biomembranes. These models explain lateral structures and characterise them as clusters or domains ("rafts"). The starting point is a lattice gas (IsingModel) with a temperature-dependent field to describe the conformation changes of the lipids in a single flat membrane. The proteins are included in the model as additional lattice components. The main topics of this study are firstly the differences between peripher and included components in a multi layer model and secondly the characterisation of soft extended components. The clustering of small components can be described by a mean field approximation with next neighbour correlations (cluster variation method). The model of lipid membranes with expanded adsorbates is mapped on the one hand analytically onto an effective lipid system with multi particle coupling, and on the other hand with Monte-Carlo-Simulation onto a protein system with effective pair interaction. Both approaches show a new cooperativity compared to the interactions in the starting model. Computer simulations presented in this work show a segragation of adsorbates due to the fluctuations in the lipid system. The boundary layer between the phases in remarkably rough which leads to an increased static scale exponent compared to typical two-dimensional models. The successful fitting of the model parameters to experiments shows that peripheral proteins can be viewed as interacting with more lipids than they cover. The discussion finally leads to a model, that describes the curvature of the membrane surface in terms of the internal degrees of freedom of the membrane components. 



\section{Inhaltsverzeichnis}

Kurzreferat $\quad$ v

$\begin{array}{ll}\text { Abstract } & \text { vii }\end{array}$

1 Modellierung von Biomembranen 1

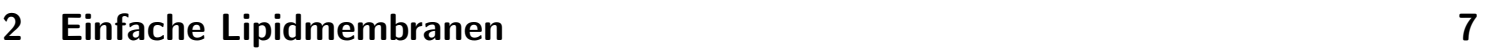

3 Lipidmembranen mit kleinen Komponenten $\quad 35$

4 Lipidmembranen mit großen Komponenten $\quad 59$

5 Diskussion und Einordnung der Arbeit $\quad 93$

6 Zusammenfassung der Ergebnisse 109

A Programm zur Berechnung der Mittlere-Feld-Approximation 113

B Programm zur Monte-Carlo-Simulation nach Metropolis 117

$\begin{array}{lr}\text { Literaturverzeichnis } & 129\end{array}$

$\begin{array}{lr}\text { Symbolverzeichnis } & 142\end{array}$

$\begin{array}{lr}\text { Stichwortverzeichnis } & 143\end{array}$

$\begin{array}{lr}\text { Danksagung } & 147\end{array}$

$\begin{array}{lr}\text { Lebenslauf des Autors } & 149\end{array}$ 



\title{
1 Modellierung von Biomembranen
}

\author{
Inhaltsangabe
}

1.1 Biomembranen aus physikalischer Sicht $\ldots \ldots \ldots \ldots \ldots$

1.2 Motivation und Gliederung der Arbeit . . . . . . . . . 4

Biomembranen sind quasi zweidimensionale komplexe Fluide, bestehend aus Polymeren ganz unterschiedlicher Struktur und Größe (zur Einführung siehe z. B. Alberts u. a., 1994). Ihre Hauptbestandteile sind Lipide und Proteine: Bei Lipiden handelt es sich um etwa 2,5 nm lange amphiphile Moleküle mit zwei Kohlenwasserstoffketten und einer Kopfgruppe. Proteine sind sehr lange Ketten (bis zu einige tausend Segmente) aus verschiedenen Aminosäuren, die sich zu stabilen räumlichen Gebilden formen (zur biochemischen Struktur der Moleküle siehe z. B. Stryer, 1995). Die Moleküle sind zu einer flexiblen Doppelschicht aggregiert, in der die Lipid-Doppelschicht den Kern ausmacht (das Leitbild der meisten Membran-Modelle findet sich in Singer und Nicolson, 1972; Jain und White, 1977). Die Proteine sind in diese Schicht entweder eingelagert oder an eine der beiden Seiten adsorbiert und können mehr oder weniger frei diffundieren. Im Zellinneren ist die Biomembran mit dem Cytoskelett der Zelle verbunden, einem reversiblen Polymernetzwerk aus Actin und anderen Proteinen (zur physikalischen Charakterisierung siehe Tempel u. a., 1996). Die äußere Seite der Membran ist von der Glycocalix belegt, einer Schicht aus Zuckergruppen, die entweder an die Kopfgruppen der Lipide oder die integralen Proteine gebunden sind (eine physikalische Einführung findet sich in Sackmann, 1995). Die gesamte Biomembran besitzt eine Dicke von bis zu $50 \mathrm{~nm}$, die Zellen bzw. Zellkompartimente können zwischen $100 \mathrm{~nm}$ und $10 \mu \mathrm{m}$ groß sein (elektronenmikroskopische Aufnahmen finden sich z. B. in Luftig und McMillan, 1983).

\subsection{Biomembranen aus physikalischer Sicht}

Aus physikalischer Sicht ergibt sich ein äußerst komplexes Bild der Biomembran. So fungiert sie global gesehen zur Abgrenzung der Zelle als biochemischen Reaktionsraum und bewirkt durch selektiven Teilchentransport ein Konzentrationsgefälle bezüglich der meisten Moleküle und Ionen. Die elektrischen Eigenschaften (die Biomembran bildet eine Art Kondensator in einem Potentialgradienten) dienen der Signalübermittlung, die auch chemisch vermittelte Pfade enthält, die über spezifische Bindungen von Liganden an Rezeptoren in und an der Biomembran ausgelöst und reguliert werden. Die Membran besitzt den Charakter einer zweidimensionalen Flüssigkeit mit verschwindend niedriger Oberflächenspannung und deshalb dominierender Krümmungs-Energie. Das hat zur Folge, dass Zellen ganz unterschiedliche Formen annehmen können.

Die Biomembran ist ein komplexes Gemisch aus hunderten von verschiedenen Lipidsorten unterschiedlicher chemischer Struktur und Kettenlänge und aus hunderten 
von verschieden Proteinen ganz unterschiedlicher Größe und Bindung mit der LipidDoppelschicht. Die Lipide und Proteine sind nicht gleichmäßig in der Membran verteilt: Erstens unterscheiden sich Innen- und Außenseite in der Zusammensetzung und zweitens bilden sich laterale, d. h. flächige, Strukturen.

Obwohl spezielle biochemische Funktionen fast ausschließlich mit Proteinen als funktionelle Einheiten direkt in Verbindung gebracht werden, ist die Lipidmatrix kein passives Medium. So werden manche Lipide als Kofaktoren für bestimmte Proteinfunktionen identifiziert (Zidovetzki, 1997). Ein oft diskutierter Effekt der Lipidmembran beruht darauf, dass Proteine erst in einem Komplex aus mehreren Bestandteilen funktionieren und diese Aggregation reversibel ist und von äußeren Bedingungen wie Temperatur oder Salzgehalt abhängt. Ein besonders instruktives Beispiel für Proteinaggregation und -funktion zeigt Burger (1997).

Verschiedene experimentelle Befunde deuten auf die angesprochenen lateralen Strukturen hin. Die Arbeiten von Simons und Ikonen (1997) und andere haben den Begriff Floß (engl. raft) für diese Strukturen in die Diskussion eingebracht. Ursprünglich war - mit einem weniger blumigen Wort - von Sortierung die Rede (Simons und van Meer, 1988). Der Gedanke, dass es mehr oder weniger geordnete Bereiche gibt, die sich als metastabile Gebilde in der Biomembran bewegen, ist bereits einige Jahre nach der Entwicklung des FlüssigMosaik-Modells durch Singer und Nicolson (1972) als Platten-Modell von Jain und White (1977) veröffentlicht worden. Der mit dem Begriff Floß bezeichnete Ansatz fokussiert auf die Strukturierung der Lipidschicht, die sich aus dem beobachteten Mischungsverhalten der Komponenten ergibt. Unabhängig von diesen Untersuchungen findet man auch bezüglich der Proteine laterale Organisation (siehe z. B. Varma und Mayor, 1998). Sehr instruktive Elektronenmikroskop-Aufnahmen, in denen man die Aggregation von Proteinen direkt sehen kann, finden sich bereits in da Silva (1987); Sackmann u.a. (1987). Eine aktuell diskutierte Frage ist, ob die Proteine den existierenden Strukturen in der Lipidmembran folgen oder sie eventuell erst bilden (aktuelle Übersichtsartikel zum Thema " Rafts"' finden sich z. B. in Pike, 2003; Vereb u. a., 2003). In biologischen Membranen darf man darüber hinaus die strukturierende Wirkung des Cytoskeletts nicht außer Acht lassen (Suzuki u. a., 2000; Fujiwara u. a., 2002).

Die Physik versucht den Gegenstand ihrer Untersuchung mit Hilfe von Experimenten zu definierten Bedingungen und mathematischen Modellen zu beschreiben. Das hat einerseits zur Folge, dass sowohl die experimentelle als auch die theoretische Modellierung einen reduktionistischen Ansatz verfolgen. Andererseits müssen die aus unterschiedlichen Ansätzen folgenden Überlegungen und Sichtweisen miteinander in Einklang gebracht werden, um sie erstens zu überprüfen und um zweitens ein Gesamtbild des untersuchten Systems zu gewinnen.

Experimentell gelten die reinen Lipidmembranen als gute Modellsysteme zum Verständnis von Biomembranen. Sie lassen sich technisch in sehr unterschiedlichen Geometrien und Versuchsaufbauten relativ einfach herstellen. Beispielhaft genannt seien an dieser Stelle die Lipidvesikel: Dies sind kugelförmige geschlossene Lipid-Doppelschichten, die sich bei geringen Lipid-Konzentrationen in Wasser spontan bilden. Versetzt man diese Lipidmembranen gezielt mit einer Sorte von Proteinen, kann man die molekularen Wechselwirkungen studieren. Im Vordergrund steht die Frage, welche Effekte generisch für Biomembranen und welche speziell für eine Sorte von Proteinen oder Lipiden typisch sind. Auf diese Art und Weise tastet man sich ausgehend von einkomponentigen Systemen zu immer komplexeren Mischungen als Modellsysteme für Biomembranen voran (zur 


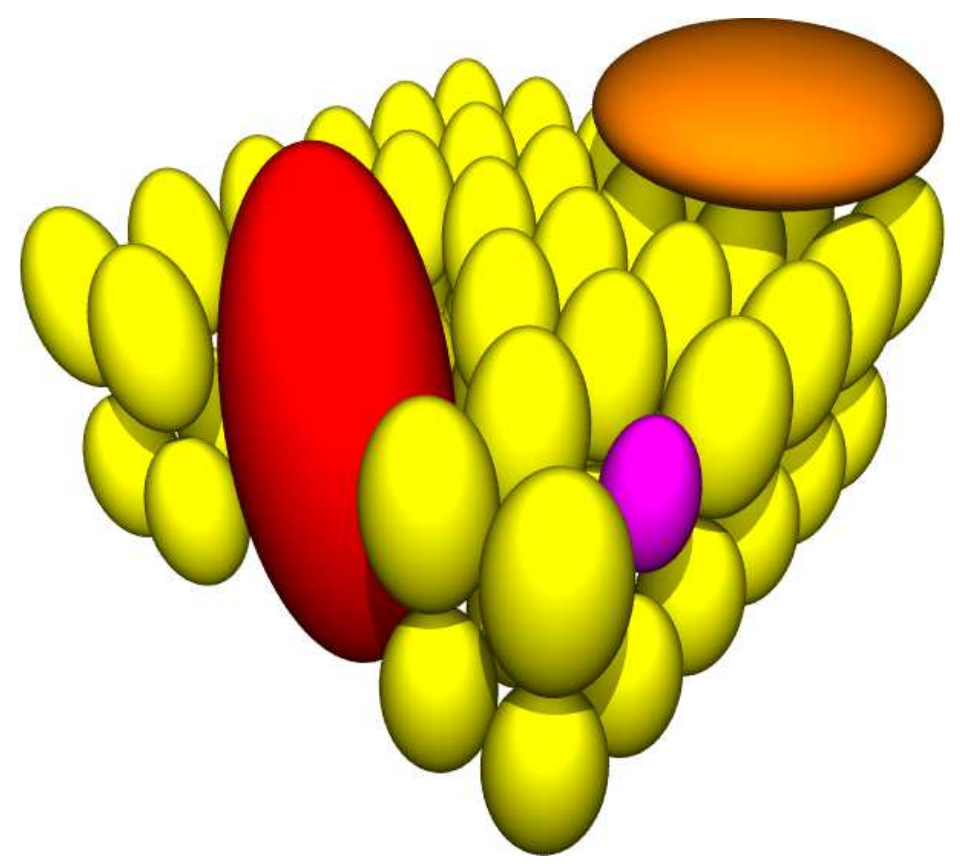

Abbildung 1.1: Flüssig-Mosaik-Modell nach Singer und Nicolson (1972). Übliche Darstellung des molekularen Aufbaus einer Biomembran: Doppelschicht aus Lipiden (gelb bzw. hell), kleine Einlagerungen wie Cholesterin (magenta bzw. dunkel), große eingelagerte Proteine oder Proteinkomplexe (rot bzw. sehr dunkel) und zuletzt adsorbierte Proteine (braun bzw. wenig dunkel). Die Proteine bilden häufig größere Komplexe.

Struktur von Modell-Membranen siehe z. B. Chapman, 1984; Gennis, 1989; Epand, 1997). Die experimentellen Methoden reichen von Druck-Fläche-Isothermen und Fluoreszenzbzw. Atomkraftmikroskopie an Langmuir-(Blodgett)-Monoschichten über kalorimetrische und spektroskopische Untersuchungen an Vesikelsuspensionen und lamellaren Stapeln bis hin zu Messungen an einzelnen Molekülen über die Fluoreszenz-Korrelations-Methode oder mit optischen Pinzetten.

Untersuchungen (in erster Linie durch Röntgenbeugung) der einzelnen MembranBestandteile auf ihre molekulare Struktur hin haben zu einem detaillierten Wissen über den Aufbau von Lipiden und manchen Proteinen geführt. Die komplexe dreidimensionale Struktur großer Proteine ist nur mit Hilfe von aufwändigen Methoden messbar. Ein Ansatz der Modellierung startet mit diesem Wissen über die atomare Struktur und stellt das System so detailliert wie möglich in Molekulardynamik-Simulationen (abgekürzt MD) dar. Allerdings begrenzt die verfügbare Computerleistung die Simulationen auf Systeme aus ein oder zwei Proteinen, einigen hundert Lipiden und einer dünnen Wasserschicht, die über einige Nanosekunden beobachtet werden können. Für thermodynamische Untersuchungen ist das System zu klein und die Zeit zu kurz.

Phänomenologische Modelle setzen gleich auf den Skalen der Phänomene an und beinhalten in diesem Zusammenhang meist eine kontinuierliche Fläche und darauf definierte Teilchendichten. Die freie Energie dieser Theorien mit ihren Parametern lassen sich an Experimente anpassen, jedoch nicht mikroskopisch herleiten.

Andere Ansätze, die ausgehend von der mikroskopischen Struktur das theoretische Modell der Membran soweit in seiner Auflösung bezüglich Längen- und Zeitskalen vergröbern 
bis es handhabbar für analytische Näherungen oder Computersimulationen wird, liegen zwischen den oben beschriebenen Methoden. Sie füllen die Lücke zwischen der atomaren Struktur und dem thermodynamischen Verhalten des Systems. Diese Ebene der Modellierung lässt sich durch die Darstellung des Flüssig-Mosaik-Modells veranschaulichen (siehe Abbildung 1.1). Die Lipide und Proteine sind Bestandteile des Modells, ihre innere Struktur und äußere Form wurde jedoch stark vereinfacht. In diesem Sinne sind die molekularen Wechselwirkungen bereits eine vergröberte Sicht auf die atomare Struktur. Dieser Ansatz erlaubt die Formulierung eines statistischen Modells, das sowohl analytisch als auch durch Simulationen handhabbar ist. Genau wie von experimenteller Seite tastet sich die theoretische Formulierung ausgehend von der einkomponentigen Lipidmembran zu komplexeren Mischungen vor, um ein Bild von den generischen Effekten von Biomembranen zu gewinnen. Der Vorteil der theoretischen molekularen Modellierung liegt neben der Berechenbarkeit darin, dass die Darstellung nun systematisch weiter vergröbert werden kann. Dafür wird beispielsweise ein effektives Proteinsystem formuliert, das die Lipide nicht mehr explizit enthält. Auf diese Weise lässt sich das unter Umständen sehr komplexe Phasenverhalten des Gemisches quantitativ besser untersuchen. Anschließend an diese molekularen Ansätze stellt sich beispielsweise die Frage, wie man in geeigneter Weise von der molekularen Struktur der Membran auf ihre äußere Form schließen kann.

In dieser Arbeit sollen die generischen strukturellen Eigenschaften von Membranen und ihre thermischen Abhängigkeiten untersucht werden. Die hier aufgeworfenen physikalischen Fragestellungen gehören zum Gebiet der statistischen Physik kondensierter Materie. Doch darf man kondensierte Materie nicht mit Festkörpern verwechseln. Neben der Komplexität in Zusammensetzung und Struktur spielt die Tatsache, dass es sich um weiche Materie handelt, eine wesentliche Rolle (eine umfangreiche Einführung in die Physik weicher Materie findet sich z. B. in Chaikin und Lubensky, 1995). Das Zusammenspiel innerer Freiheitsgrade der großen Moleküle und der intermolekularen Wechselwirkung charakterisieren dieses Gebiet der Physik, in dem die Biomembran ein spezielles und besonders faszinierendes Objekt ist.

\subsection{Motivation und Gliederung der Arbeit}

Das Ziel dieser Arbeit ist die effektive Modellierung der Biomembran als komplexes Fluid bestehend aus Lipiden und Proteinen. Besonders wichtig ist die Beschreibung der ProteinLipid-Wechselwirkung und ihrer Auswirkungen auf das System der Lipide bzw. das der Proteine. Die Aufgabe umfasst die theoretische Untersuchung, Charakterisierung und Erklärung von Strukturbildung in Biomembranen. Nicht die systematische Analyse des Parameterraums und mögliche Anpassungen an verschiedene Experimente stehen im Vordergrund, sondern das Verständnis der Effekte bezüglich qualitativer Abhängigkeiten von Modellveränderungen und -erweiterungen. Ausgangspunkt der Modellierung ist die reine Lipidmembran, deren thermodynamische Eigenschaften durch die inneren Konformationsfreiheitsgrade der Lipide dominiert werden. Leitbild der weiteren Modellierung von Gemischen mit Proteinen ist die Tatsache, dass Proteine wesentlich größer als die Lipide und im Vergleich zu ihnen starr sind. In Kapitel 2 werden chemisch und physikalisch kontrollierte Modellsysteme vorgestellt, der Ansatz der Modellierung erläutert und in die Methoden eingeführt. Die Ergebnisse der Arbeit finden sich in Kapitel 3 (kleine Komponenten) und Kapitel 4 (große Komponenten). Im letzten Kapitel 5 werden der hier verfolgte Ansatz sowie dessen Ergebnisse in den Kontext der aktuellen Forschung gesetzt und diskutiert. 
Die Resultate der vorliegenden Arbeit führen zu einem Hinweis, wie die Organisation der Biomembran in begrenzte und stabile Bereiche auch verstanden werden kann. Der Ausblick stellt eine Möglichkeit zur Berechnung der gekrümmten Membran-Fläche aus dem Modell der inneren Molekülfreiheitsgrade vor. 



\title{
2 Einfache Lipidmembranen
}

\author{
Inhaltsangabe
}

2.1 Lipidaggregate in Wasser . . . . . . . . . . . . 9

2.2 Phasenübergänge in Topologie, Form und Struktur . . . . . . 11

2.3 Molekulare Modelle und effektive Wechselwirkung . . . . . . 14

2.4 Ausgangsmodell für die Lipidmembran . . . . . . . . . . 17

2.5 Referenzsystem Ising-Modell . . . . . . . . . . . . . 21

2.6 Referenzmethoden Mittleres-Feld und Monte-Carlo . . . . . 28

2.7 Vergleich mit dem Experiment . . . . . . . . . . 32

In diesem Kapitel wird die einfache Lipidmembran - der Grundbaustein jeder Biomembran - beschrieben. Das Verständnis der Lipidmembran ist die Voraussetzung zur Behandlung komplexerer Systeme, die in den beiden nachfolgenden Kapiteln behandelt werden.

Die Definition, welche Moleküle als Lipide bezeichnet werden, ist nicht ganz einheitlich. In der chemischen Literatur werden damit umfassend alle Fette, Öle und fettähnliche Stoffe beschrieben (Lexikonredaktion, 1995). In dieser Arbeit sollen darunter aber einschränkend nur Moleküle verstanden werden, die aus zwei hydrophoben Fettsäureketten und einer hydrophilen Kopfgruppe bestehen, verbunden durch eine Glycerin-Gruppe. Diese sind die Hauptbestandteile der Lipidschicht von Biomembranen. Wegen ihrer amphiphilen Eigenschaft bilden sie in wässriger Lösung meist dicht gepackte Aggregate, auf die später noch detaillierter eingegangen wird. In diesem Zusammenhang ist zu beachten, dass immer von Lipiden in Aggregaten die Rede sein wird, auch wenn Eigenschaften der einzelnen Moleküle betrachtet werden.

In den Abbildungen 2.1 und 2.2 sind Phospholipide dargestellt. Die Bilder sind aus Molekulardynamik-Simulationen von Lipid-Doppelschichten in Wasser gewonnen (Heller u. a., 1993). In der zitierten Simulation werden verschiedene thermodynamische Phasen nachvollzogen. Die Lipide in den beiden Abbildungen unterscheiden sich lediglich in ihrem Konformationszustand. Dieser ist charakteristisch für die verschiedenen Phasen.

Zunächst erkennt man die beiden Kohlenwasserstoff-Ketten, die typischerweise aus 15 Kohlenstoffatomen bestehen. Daran schließt sich der polare und damit hydrophile Teil des Moleküls an. Dieser beginnt erst nach der Glycerin-Gruppe im oberen Drittel des Moleküls, die quasi das Rückgrat des Moleküls bildet. Die Ketten sind mit 1,8 nm ungefähr doppelt so lang wie die Kopfgruppe. Die chemische Klasse der Kopfgruppe und die Länge der Ketten definieren die Bezeichnung des Moleküls. In Aggregaten sind die Moleküle meist mehr oder weniger gestreckt, dabei lagern sich die hydrophoben Ketten zusammen und die Köpfe wechselwirken mit dem Wasser. 


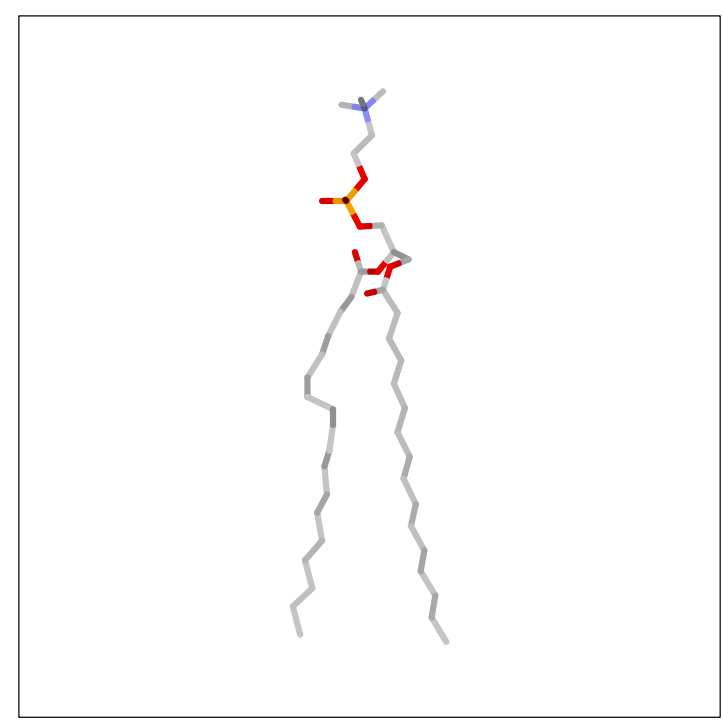

(a) Bindungen als Stäbchen dargestellt

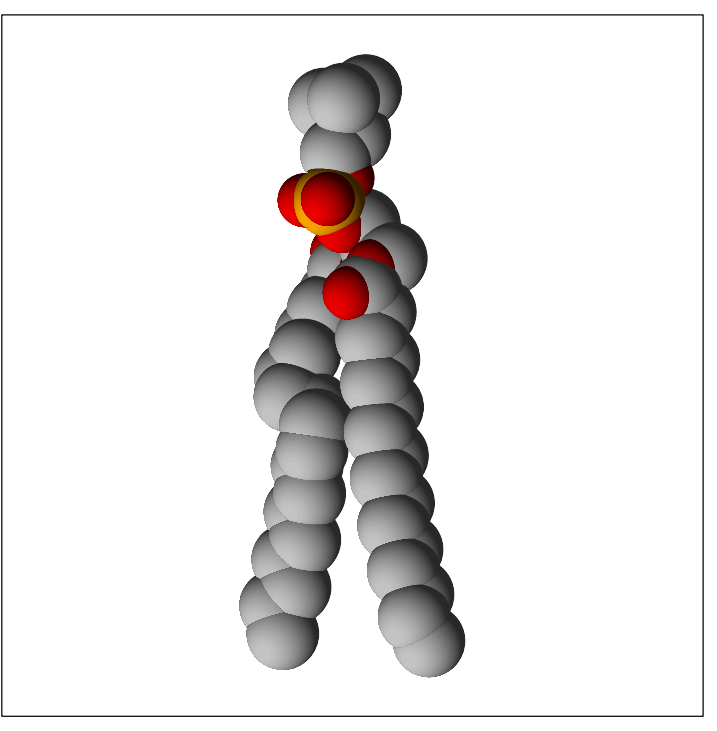

(b) Atome als Kugeln dargestellt

Abbildung 2.1: Phospholipid im gestreckten Zustand. Die Bilder sind nach Daten aus MolekularDynamik-Simulationen von Lipid-Doppelschichten und Wasser erstellt (Heller u. a., 1993). In der zitierten Arbeit wird zwischen zwei Tieftemperatur-Phasen, kristallin und gel, unterschieden. Zur Verdeutlichung der Argumentation ist ein Molekül der stärker geordneten kristallinen Phase gezeigt.

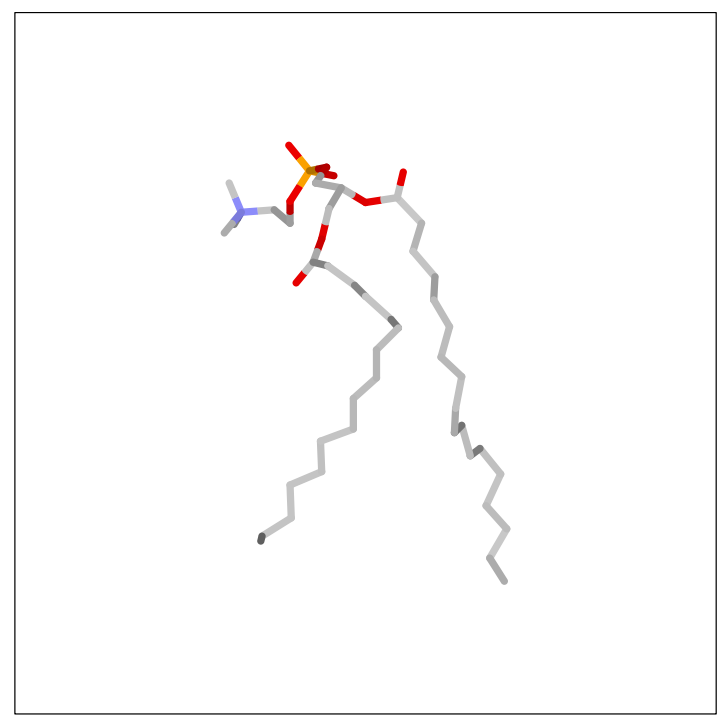

(a) Bindungen als Stäbchen dargestellt

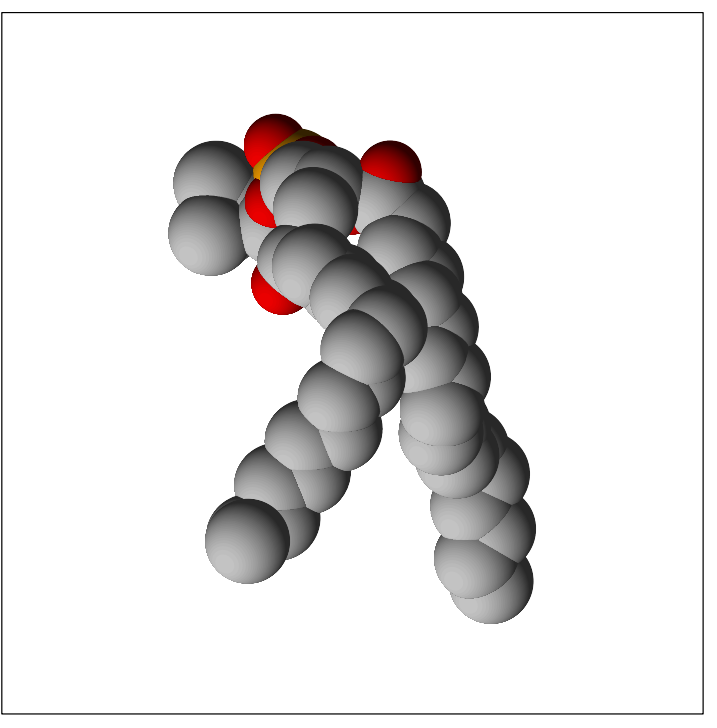

(b) Atome als Kugeln dargestellt

Abbildung 2.2: Phospholipid im gefalteten Zustand, der typisch für die Hochtemperatur-Phase ist. Die Quelle für die Daten ist die gleiche wie in Abbildung 2.1. 
Im folgenden Abschnitt soll zunächst von den angesprochenen Aggregaten die Rede sein. Darauf aufbauend werden einige der Phasenübergänge vorgestellt, die man an solchen Systemen beobachtet (die Phasen von Mischungen aus Lipid und Wasser werden auch lyotrope Phasen genannt). Die Modellierung wird eingeleitet mit allgemeinen Bemerkungen zum Konzept der effektiven Wechselwirkung. In einem eigenen Abschnitt werden die Referenzmethoden der Untersuchung grundsätzlich vorgestellt. Dieses Kapitel wird abgeschlossen mit einer Darstellung, wie grundsätzlich aus dem Experiment die Parameter des Modells bestimmt werden können.

\subsection{Lipidaggregate in Wasser}

Zunächst sollen Mischungen aus Wasser und Lipiden betrachtet werden, in denen die Lipide viele verschiedene Aggregate ausbilden, je nach Sorte und Konzentration des Lipides. Bei sehr niedrigen Konzentrationen bilden sich zunächst Mizellen. Dies sind kugelbzw. röhrenförmige Ansammlungen, in denen die Ketten der Lipide zueinander zeigen und die Köpfe zum Wasser. In einem sehr breiten Bereich mittlerer Konzentrationen bilden sich Doppelschichten aus. Die Ränder dieser Schichten müssen sich auf irgendeine Art und Weise schließen, um den hydrophoben Teil dem Wasser zu entziehen. Dabei bilden sich als stabile Phase im einfachsten Fall quasi unendlich ausgedehnte lamellare Schichten, die am Rand geschlossen sind. In der Mitte der Doppelschicht zeigen die Ketten wieder zueinander, die Köpfe wenden sich zu beiden Seiten der Schicht dem Wasser zu. Dies ist auch das Bauprinzip der Lipidschicht von Biomembranen. Bei sehr hohen Dichten von Lipid in Wasser bilden sich die inversen mizellaren Phasen, in denen das Wasser in kleinen kugel- oder röhrenförmigen Volumina zusammengefasst ist (siehe z. B. Seddon und Templer, 1995; Adam u. a., 1995).

Diese Arbeit beschränkt sich auf isolierte zweidimensionale Aggregate und gilt damit für Konzentrationsbereiche, in denen sich Doppelschichten ausbilden. Die Lipid-Doppelschicht ist ein gutes Modellsystem zum Verständnis von Biomembranen. Bezüglich ihrer physikalischen Eigenschaften finden sich in der Literatur einige ausführliche Übersichtsartikel (siehe z.B. Bloom u. a., 1991). Die meiste Ähnlichkeit zur Membran einer Zelle weisen sicherlich Lipidvesikel auf. Das sind Doppelschichten, die sich zu Kugeln geschlossen haben. Häufig sind mehrere Schichten zwiebelartig ineinander zu multilamellaren Vesikeln verschachtelt. Lipidvesikel bilden sich in wässriger Lösung spontan. Bernardes (1996) konnte die Aggregation von Vesikeln in einer Monte-Carlo-Simulation eines mikroskopischen Modells auch theoretisch nachvollziehen, Goetz und Lipowsky (1998) haben die Aggregation von Lipiden in Wasser zu einer Doppelschicht in einer Molekular-Dynamik-Simulation beschrieben. Solche unpräparierten Systeme sind aber aus drei Gründen nicht so geeignet zur weiteren thermodynamischen Charakterisierung: erstens sind sie nicht stabil bei einer Zerfallszeit von Stunden oder Tagen, zweitens ist die Zahl der Lamellen sehr unterschiedlich und drittens ist die Größenverteilung der Vesikel sehr breit. Zumindest die beiden letzten Punkte kann man durch die Extrusion der Suspension durch einen Filter, der aus einem Polymernetzwerk mit definierter Porengröße besteht, verbessern. Dabei drückt man die Vesikel mehrmals durch Poren eines Durchmessers von etwa $100 \mathrm{~nm}$ und erhält eine Suspension aus unilamellaren Vesikeln mit einer relativ scharfen Größenverteilung bei einem Durchmesser, der etwa der Porengröße entspricht. Führt man diesen Herstellungsprozess bei relativ geringen Lipid-Konzentrationen durch, so erhält man Suspensionen, in denen die Vesikel wenig miteinander wechselwirken und eine Lebensdauer von Tagen 
haben. Sie gelten als gute Modellsysteme für biologische Membranen. Eine gründliche theoretische Beschreibung von Vesikelsuspensionen aus Sicht der statistischen Physik findet sich in Morse und Milner (1995). Zur Untersuchung im optischen Mikroskop lassen sich einzelne sehr große unilamellare Vesikel (engl. giant unilamellar vesicles, GUV) mit einem Durchmesser von bis zu $100 \mu$ m präparieren (Akashi u. a., 1996).

Neben Vesikeln gibt es andere, physikalisch eventuell besser kontrollierte, ModellMembranen. Drei Systeme sollen kurz angesprochen werden:

Langmuir-Monoschichten Das physikalisch wohl am besten kontrollierte Lipidsystem ist die Langmuir-Monoschicht (Langmuir, 1917). Die Lipide werden dabei auf eine Wasseroberfläche aufgebracht. Wegen ihres amphiphilen Charakters bilden sie eine monomolekulare Schicht an der Wasser/Luft-Grenzfläche, die Köpfe im Kontakt mit Wasser und die Ketten möglichst davon getrennt. Die Oberfläche des Wassertrogs wird nun mit Hilfe eines Schiebers, einer Langmuir-Waage, variiert. Über eine Feder wird die Rückstellkraft, der laterale Druck, geregelt und die Fläche gemessen. Der ganze Aufbau wird zusätzlich thermisch geregelt, so dass die Zustandsgrößen Teilchenzahl, Druck bzw. Fläche und Temperatur unter Kontrolle sind. An den so präparierten Lipidschichten lassen sich eine Reihe von strukturellen Phasenübergängen studieren. Gute Übersichtsartikel sind Möhwald (1990); Kaganer u. a. (1999), besonders interessante räumliche Strukturen finden sich in Knobler (1990); McConnell (1991).

Lamellare Stapel aus Doppelschichten Spontan bilden sich in Wasser die oben angesprochenen multilamellaren Vesikel. Thermodynamisch stabil sind aber erst weit ausgedehnte Strukturen von Doppelschichten, die lamellaren Stapel. Sie werden üblicherweise nicht aus der Lipid-Wasser-Suspension gebildet, sondern in einem technischen Verfahren aus einer Lösung von Lipid in hydrophoben Lösungsmittel auf ein Substrat aufgebracht und nachträglich hydratisiert. Die so hergestellten Doppelschichten liegen in etwa parallel zueinander und sind bis auf Störungen eben. Sie besitzen einen definierten Abstand zueinander, der bei einer geringen Wasserkonzentration vom Hydratisierungsgrad abhängt und ab einer bestimmten Konzentration einen Gleichgewichtswert einnimmt. Diese Aggregatform ist thermodynamisch stabil. Ihre Strukturen und unterschiedlichen thermischen Phasen sind seit vielen Jahren ausführlich untersucht und weiter aktueller Forschungsgegenstand.

Es wurde auch auf andere Weise versucht, einzelne Lipidschichten experimentell zu präparieren und zu beobachten. Kurz erwähnt werden sollen die abgestützten Monobzw. Doppelschichten. In gewisser Weise vermitteln die Oligostapel, bestehend aus einigen (etwa zehn) Doppelschichten, zwischen den lamellaren Stapeln und den Einzelschichten.

Unterstützte Einzelschichten Streift man Langmuir-Monoschichten an einer geeigneten festen Oberfläche ab, so haften die Lipidketten an ihr und die Moleküle immobilisieren (zur sogenannten Langmuir-Blodgett-Technik siehe z. B. Knobler und Schwartz, 1999). Die Hoffnung ist, dass damit der Zustand der originalen Monoschicht erhalten bleibt. Die so abgestützte Monoschicht kann nun z. B. im Atomkraftmikroskop untersucht werden, in dem Höhenprofile gemessen werden. Hydrophilisiert man die Festkörperoberfläche vor diesem Prozess, so kann man auf die erste Monoschicht, deren Köpfe dann an die Oberfläche binden, eine zweite aufbringen, deren Köpfe dem wässrigen Medium zugeneigt sind. So erhält man eine unterstützte Doppelschicht, die 
mit den gleichen Methoden untersucht werden kann (eine andere Technik zum Aufbringen von einzelnen Lipid-Doppelschichten aus einer Vesikelsuspension beschreibt McKiernan u. a., 1997).

\subsection{Phasenübergänge in Topologie, Form und Struktur}

Im weiten Feld von Lipidaggregaten in Wasser gibt es einen ganzen Zoo von verschiedenen Phasen. Um den Überblick zu bewahren, wird zwischen Übergängen in der Topologie des Aggregates, der Form der Schichten und der Struktur, das heißt der Beschaffenheit auf molekularer Ebene, unterschieden. Zu den ersten beiden Kategorien soll nur kurz etwas gesagt werden. Die weitere Arbeit beschäftigt sich mit strukturellen Phasen (eine Übersicht über das Phasenverhalten von Lipidmembranen findet sich z. B. in Epand, 1997).

Mit Phasenübergängen in der Topologie sind einerseits die Übergänge zwischen verschiedenen Lipidaggregaten gemeint, beispielsweise von hexagonal angeordneten Röhrenmizellen zu lamellaren Stapeln von Doppelschichten und andererseits die topologische Umwandlung einzelner Vesikel, z. B. von einer Kugel in einen Torus (siehe z. B. Klösgen, 2001). Bei Phasenübergängen in der Form meint man die verschiedenen Gestalten, die Vesikel annehmen können. Auch wenn sie topologisch die Form einer Kugel haben, so können sie je nach äußeren Bedingungen wie Oblaten oder Prolaten oder sogar wie Untertassen aussehen. In dieser Arbeit sollen diese beiden Effekte ausgeblendet werden. Man stelle sich immer eine flache (Doppel-) Schicht aus Lipiden vor, die nicht mit anderen wechselwirkt.

In verschiedenen Lipidsystemen sind eine Reihe von Phasenübergängen beobachtet worden. Diese unterscheiden sich sowohl in der thermischen Signatur als auch in ihrer räumlichen Struktur und Ordnung. Der Versuch, für das thermische Phasenverhalten von verschiedenen Lipidsorten in unterschiedlichen Aggregatformen eine einheitliche Klassifikation zu finden, ist nur für einen einzigen Übergang - den sogenannten Hauptübergang ansatzweise gelungen. Die anderen Übergänge unterscheiden sich erheblich je nach Lipidsorte oder Aggregatform oder sind in manchen Systemen gar nicht beobachtet worden.

Im Folgenden sind die im Zusammenhang mit dem Hauptübergang gebräuchlichsten Begriffe für die beiden Phasen, abhängig von der untersuchten Aggregatform, aufgeführt:

Langmuir-Monoschichten: Man spricht hier vom Phasenübergang „flüssig kondensiert" zu „flüssig expandiert“. Bei tieferen Temperaturen oder höheren Drücken folgen dann verschiedene „kristalline“ Phasen und bei hohen Temperaturen (niedrigen Drücken) die „gasförmige“ (Albrecht u. a., 1978).

Lamellare Stapel: Die Hochtemperatur-Phase „lamellar flüssig kristallin“ $\left(L_{\alpha}\right)$ geht in die Phase „lamellar gel“ $\left(L_{\beta}\right)$ oder die „Ripple Phase“ $\left(P_{\beta}\right)$ über. Bei weiterer Erniedrigung der Temperatur folgt die „kristalline“ Phase $\left(L_{c}\right)$ (Doniach, 1980).

Vesikel: Hier haben sich die Bezeichnungen „flüssig kristallin“ bzw. „fluid“ und „gel“ für die Phasen am Hauptübergang eingebürgert. Eine „Ripple-Phase“ beobachtet man manchmal auch hier (Mouritsen, 1991).

Da die Namen für die Phasen im Falle der Monoschichten am ehesten das mikroskopische Bild des Modells beschreiben, soll im Folgenden von expandiert und kondensiert im Rahmen des Hauptübergangs gesprochen werden, auch wenn die Analyse in erster Linie auf Vesikel abzielt. Der bevorzugte Zustand der Lipidmoleküle in diesen Phasen wird 
als gefaltet bzw. gestreckt bezeichnet. Den Hauptübergang versteht man im Wesentlichen als einen kooperativen Übergang der inneren Molekülfreiheitsgrade ausgehend von einem Grundzustand $\mathrm{zu}$ einem hoch entarteten und deshalb entropisch begünstigten angeregten Zustand. Im Grundzustand sind die Moleküle gestreckt, weil die Rotationsisomere der Bindungen (insbesondere der C-C-Bindungen der Ketten) nicht angeregt sind. Die Moleküle sind starr. Werden die Rotationsfreiheitsgrade angeregt, so faltet und verkürzt sich das Molekül und es wird flexibler. Weil die Ketten wesentlich mehr mögliche Konformationen annehmen können als die Kopfgruppe, ist in diesem Zusammenhang häufig von Kettenschmelzen die Rede. Die Teilchendichte innerhalb der Membran verändert sich nicht ausreichend, d.h. die Membran gewinnt an Fläche und verliert an Dicke. Experimentelle Ergebnisse zum Flächenbedarf von Lipidmolekülen, und damit verbunden auch zur Dicke der Membran, differieren von Studie zu Studie sehr stark (eine konkrete Messung des Flächenbedarfs einiger Lipidsorten mit Hilfe von Röntgenbeugung findet sich z. B. in Costigan u.a., 2000). Beispielsweise werden bezüglich des häufig untersuchten Lipides DPPC bei einer bestimmten Temperatur jenseits des Hauptübergangs Werte zwischen 0,56 und $0,72 \mathrm{~nm}^{2}$ angegeben (Nagle und Tristram-Nagle, 2001). Mit dem Flächenbedarf von DPPC in der Tieftemperatur-Phase von $0,48 \mathrm{~nm}^{2}$ resultiert ein Unterschied bezüglich des gestreckten und des gefalteten Zustands von 0,08 bis $0,24 \mathrm{~nm}^{2}$, d. h. die Unsicherheit ist sehr groß (einen Überblick der Methoden und Ergebnisse struktureller Untersuchungen von Lipidmembranen bietet z. B. Nagle und Tristram-Nagle, 2000).

Beim Studium der Literatur und der Diskussion unter Forschern muss man feststellen, dass die experimentellen Ergebnisse zum Hauptübergang von Lipidmembranen ein verwirrendes Bild zeigen. Zum einen unterscheiden sich die Ergebnisse bezüglich der Aggregatform der Lipide (Monoschichten, lamellare Doppelschichten oder unilamellare Vesikel) erheblich. Aber auch unterschiedliche experimentelle Methoden an ein und derselben Aggregatform deuten auf verschiedene Charakteristika des Phasenübergangs:

Langmuir-Monoschichten: Unstetiger Übergang mit kritischem Endpunkt Der Phasenübergang, gemessen üblicherweise durch Druck-Fläche-Isothermen, ist bei mittleren Drücken und Temperaturen unstetig und weist ein ausgedehntes Koexistenzgebiet auf, ganz ähnlich zum Gas-Flüssig-Übergang des Van-der-Waals-Gases. Bei höheren Temperaturen und Drücken endet diese Phasenübergangslinie in einem kritischen Punkt, ab dem der Übergang stetig ist.

Multilamellare Phasen: Phasenübergang 1. Ordnung Die Dicke der Doppelschichten ist eine übliche strukturelle Größe, die mit Hilfe von Röntgenbeugung oder Neutronenstreuung (Lemmich u. a., 1996b) gemessen wird. Am Hauptübergang in multilamellaren Stapeln zeigt diese Hysterese-Effekte, ein deutliches Anzeichen für einen Phasenübergang 1. Ordnung. Des Weiteren kann man zwei Dicken in der gleichen Messung identifizieren, was eine Koexistenz von verschiedenen Phasen anzeigt. Die spezifische Wärme zeigt ein scharfes Maximum. Die Koexistenz von Phasen und die Ursache für Domänenbildung wird beispielsweise in Jain (1983) diskutiert. Trotzdem liefert das Verhalten der Dicke am Übergangspunkt, das sogenannte „anormale Anschwellen“, Anlass zu Diskussionen (siehe z. B. Hoenger u. a., 1994). So sprechen Nagle u. a. (1998) z. B. sogar von einem „kritischen“ Verhalten der Schichtdicke.

Hauptbeitrag durch Kettenschmelzen Die aus kalorimetrischen Messungen abgeschätzte latente Wärme ist mit $14 \mathrm{k}_{\mathrm{B}}$ pro Molekül relativ groß (im Vergleich zu $1 \mathrm{k}_{\mathrm{B}}$ bei smektischen Flüssigkristallen) und führte zu der Aussage, dass es die inneren Zustände 
sein müssen (Kettenschmelzen), die den Übergang treiben und nicht das Auflösen der zweidimensionalen Gitterordnung oder der Orientierung der Molekülachsen, die unterhalb des Hauptübergangs sichtbar sind (Doniach, 1980).

Ordnungsparameter bleibt stetig Der üblicherweise identifizierte Ordnungsparameter für die Lipidketten (die Kettenordnung wird repräsentiert durch die mittlere Projektion der C-C-Bindungen auf eine zuvor definierte Achse oder ähnliche Parameter, die die Ansisotropie messen) steigt stark an, macht aber keinen Sprung - wie man es bei einem Phasenübergang 1. Ordnung erwartet, sondern bleibt stetig. Dieser Anstieg korreliert mit dem Maximum in der spezifischen Wärme (Riske u. a., 2002).

Die mittlere Molekülordnung der Membran sollte ein nicht erhaltener Ordnungsparameter sein, ähnlich der Magnetisierung im Ferromagneten. Des Weiteren beobachtet man starke Fluktuationen am Übergang. Beispielsweise nimmt die oben angesprochene Dicke der Doppelschicht am Übergang ein Maximum ein, welches anormales Anschwellen genannt wird.

Unilamellare Vesikel: Kritischer Phasenübergang In Suspensionen aus unilamellaren Vesikeln (niedrige Lipiddichte) ist kritisches Verhalten zu beobachten. Halstenberg u.a. (2003) haben die Daten der Ultraschallspektroskopie erfolgreich an theoretische Berechnungen zur binären kritischen Entmischung anpassen können. Dazu muss angemerkt werden, dass die kritische Mode - der Parameter, der den kritischen Übergang treibt - nicht widerspruchsfrei identifiziert ist. In der Theorie entspricht er dem (erhaltenen) Dichteunterschied der binären Verbindung. Dieses Bild passt nicht zu den oben erläuterten Ergebnissen.

Andere Observablen sind kontinuierlich Der Übergang in kalorimetrischen Größen (spezifische Wärme) von Vesikel-Suspensionen ist stark verbreitert, so dass man an einem Phasenübergang im strikten Sinne zweifeln kann (siehe z. B. Schrader u. a., 2002). Nach Aussage der Experimentatoren ist die Auflösung der Kalorimeter besser als die Breite der Übergangslinien.

Fluoreszenzmikroskopie an verwandten Systemen Mit Hilfe von Fluoreszenzmarkern, die sich bevorzugt in Bereichen der einen Lipidphase anreichern, könnte man im Prinzip die Phasen - und vor allem ihre Struktur im Übergangsbereich - abbilden. Leider sind Experimente dieser Art nur an Lipiden verwandten Molekülen in einem Langmuir-Monoschicht-Aufbau bekannt, so dass sie keine direkte Abbildung der hier untersuchten Phasen darstellen (Qiu u. a., 1991). Doch zeigt sich in den verwandten Systemen eine klare Entmischung in zwei Komponenten im Bereich des Übergangs, jedoch keine kritische wie im Fall der Schallexperimente angenommen.

Direkte Beobachtung durch Atomkraftmikroskopie Es gibt leider zur Zeit nur eine Technik, die beiden Phasen des Hauptübergangs direkt sichtbar zu machen: Lipidschichten werden dabei auf ein festes Substrat aufgebracht, dabei immobilisiert und anschließend im Atomkraftmikroskop untersucht. Die unterschiedlichen Höhen der Monoschicht werden als Gebiete mit gestreckten oder gefalteten Lipiden interpretiert (McKiernan u.a., 2000). Eine Analyse der Größenverteilung der Gebiete durch Nielsen u.a. (2000) zeigt ein Skalieren über zwei Größenordnungen, was als Hinweis für kritisches Verhalten gedeutet wird. Bei der Interpretation muss aber bedacht werden, welche invasiven Nebenbedingungen der experimentelle Aufbau für die Lipide bedeutet. Warum sich die abgestützten Schichten genau so verhalten soll- 
ten wie Langmuir-Monoschichten bei einer ganz bestimmten Temperatur und einem ganz bestimmten lateralen Druck, ist eine der vielen Ungereimtheiten.

All diese Beobachtungen haben zur Folge, dass in einschlägigen Arbeiten Formulierungen wie „schwach 1. Ordnung“ oder „prekritisch“ zur Charakterisierung des Phasenübergangs gebraucht werden, die aber letztendlich die Natur des Übergangs auch nicht aufklären.

Aus theoretischer Sicht ist die Lipidmembran quasi zweidimensional mit einem Ordnungsparameter, der keine Symmetrie aufweist und nicht erhalten sein sollte. Wenn der Hauptübergang durch die Ordnung der inneren Freiheitsgrade der Lipide, insbesondere der Kettenordnung, bestimmt ist, sieht man keinen Grund, warum diese variable molekulare Eigenschaft im Mittel über das System erhalten sein sollte. Das bedeutet, dass man generischer Weise entweder einen Phasenübergang 1. Ordnung oder einen kontinuierlichen Übergang erwartet. Dies zeigt eine Landau-Entwicklung der freien Energie ohne die übliche Symmetrie der Spins (zur Landau-Entwicklung findet sich etwas in vielen Büchern zur statistischen Physik, z. B. in Pathria, 1996). In zwei Dimensionen gibt es außerdem prinzipielle Beschränkungen bezüglich der Identifizierung einer langreichweitigen Ordnung, welches den Nachweis eines eventuellen unstetigen Übergangs erschwert (Kosterlitz und Thouless, 1973).

Für diese Arbeit wird die Frage, ob der Hauptübergang unstetig oder kontinuierlich ist, undogmatisch gehandhabt. Die Alternativen werden diskutiert und bei der Anpassung von Experimenten wird sich auf einen pragmatischen Standpunkt gestellt, der es erlaubt, die Parameter des Modells an die Daten von Vesikelsuspensionen anzupassen. Bevor das Modell der Lipidmembran entwickelt wird, soll die prinzipielle Herangehensweise aus Sicht der theoretischen Physik erläutert werden.

\subsection{Molekulare Modelle und effektive Wechselwirkung}

Das Konzept der statistischen Physik des Gleichgewichts beruht auf der Beschreibung des Mikrozustands durch die Identifizierung der zugänglichen Freiheitsgrade des betrachteten Systems, deren Randbedingungen und der Abhängigkeit der Energie von diesen Variablen. Ist das Modell erst durch eine mikroskopische Hamiltonfunktion und die Wahl des Ensembles definiert, so folgt auf sicherem Terrain die Arbeit an der Lösung des Problems: die Berechnung der Zustandssumme. Die statistische Physik ist als ein Grundpfeiler der theoretischen Physik wohl etabliert, trotzdem sei auf ein paar grundlegende Bücher hingewiesen (Fließbach, 1995; Landau und Lifschitz, 1987; Reif und Muschik, 1987). Für die weitere Darstellung sei die kanonische Gesamtheit der zugänglichen mikroskopischen Freiheitsgrade $\{n\}$ gewählt. Mit dem bekannten Boltzmann-Faktor (Boltzmann, 1909) schreibt sich die Zustandssumme $\mathcal{Z}$ in Abhängigkeit der Hamiltonfunktion $\mathcal{H}$ und der inversen Temperatur $\beta$ wie folgt:

$$
\mathcal{Z}=\sum_{\{n\}} \exp [-\beta \mathcal{H}(\{n\})]
$$

Die Modellierung des Mikrozustandes geht einher mit einer möglichst systematischen Vergröberung der Darstellung. Häufig ist man nicht an allen Freiheitsgraden des Systems interessiert, sondern nur an einigen wenigen. In diesem Fall erweist sich das Konzept der effektiven Wechselwirkung als nützlich, welches in diesem Abschnitt beschrieben wird. Es zeigt auf, dass man - im Prinzip ohne Näherungen - von einer Beschreibung des 
kompletten Mikrozustands durch eine partielle Summation über einige Freiheitsgrade zu einem effektiven vergröberten Modell des Systems gelangt. Die konkrete Berechnung der Zustandssumme bzw. der freien Energie ${ }^{1} \mathcal{F}=-T \log [\mathcal{Z}]$ kann grundsätzlich zwei Wegen folgen: erstens der weitgehend analytischen Berechnung unter approximativen Annahmen oder zweitens der möglichst genauen Berechnung mit Hilfe numerischer Verfahren.

In dieser Arbeit soll bezüglich der Modellierung ein Weg beschritten werden, der einerseits die molekulare Struktur der Biomembran mit einbezieht, also nicht über die Moleküle hinaus vergröbert, aber andererseits handhabbar in analytischen Näherungen und statistischen Simulationen bleibt, also die atomare Struktur nur in effektiven Größen berücksichtigt.

Zur Darstellung des Konzepts soll von einem System aus zwei verschiedenen Sorten von Teilchen die Rede sein. Sie werden durch Besetzungszahlen beschrieben, die jeweils eine Eigenschaft (oder Zustand) der Teilchen repräsentieren. Sie nehmen den Wert eins an, wenn dieser Zustand angenommen wird, und sonst den Wert null. Im Folgenden bestehe das System aus den Teilchen $\{n\}$ und $\{N\}$ (beispielsweise Lipiden und Proteinen), wobei die Besetzungszahlen $n_{i}$ bzw. $N_{i}$ gleich eins sind, wenn sich ein Teilchen der entsprechenden Sorte am Ort $i$ befindet. Man sortiere die Beiträge der Teilchen zur Hamiltonfunktion zunächst entsprechend der Abhängigkeit von den Besetzungszahlen:

$$
\mathcal{H}(\{n\},\{N\})=\mathcal{H}_{11}(\{n\})+\mathcal{H}_{12}(\{n\},\{N\})+\mathcal{H}_{22}(\{N\})
$$

Die Zustandssumme kann man nun exakt umformen und man erhält ein effektives System, das nur noch durch die eine Gruppe von Freiheitsgraden definiert wird. In diesem Fall soll nach den Freiheitsgraden der Teilchen $\{n\}$ aufgelöst werden:

$$
\begin{aligned}
\mathcal{Z} & =\sum_{\{n\}}\left(\exp \left[-\beta \mathcal{H}_{11}(\{n\})\right] \sum_{\{N\}} \exp \left[-\beta\left(\mathcal{H}_{12}(\{n\},\{N\})+\mathcal{H}_{22}(\{N\})\right)\right]\right) \\
& =: \sum_{\{n\}} \exp \left[-\beta \mathcal{H}^{\text {eff. }}(\{n\})\right]
\end{aligned}
$$

Man sagt, die Freiheitsgrade der Teilchen $\{N\}$ werden aussummiert und bezeichnet als effektive Hamiltonfunktion den folgenden Ausdruck:

$$
\mathcal{H}^{\text {eff. }}(\{n\})=\mathcal{H}_{11}(\{n\})-T \log \left[\sum_{\{N\}} \exp \left[-\beta\left(\mathcal{H}_{12}(\{n\},\{N\})+\mathcal{H}_{22}(\{N\})\right)\right]\right]
$$

Der Grund für die gezeigte Umformung besteht darin, dass die effektive Hamiltonfunktion 2.4 formal nur noch von $\{n\}$ abhängig ist. Praktisch wird die Zustandssumme über die anderen Freiheitsgrade meist approximativ ausgeführt (zum Konzept der effektiven Wechselwirkung siehe Likos, 2001; Löwen, 2002). Eine übliche Methode besteht darin,

\footnotetext{
${ }^{1}$ Die Temperatur ist auch nur eine Energie und wird folglich auch in solchen Einheiten gemessen. Damit ist die Boltzmann-Konstante $\mathrm{k}_{\mathrm{B}}=1$. Der natürliche Logarithmus bekommt natürlich den Namen log.
} 
die effektive Hamiltonfunktion in Abhängigkeiten der miteinander wechselwirkenden Teilchen $\{n\}$ zu entwickeln:

$$
\begin{aligned}
\mathcal{H}^{\text {eff. }}(\{n\}) & =\mathcal{H}_{\text {Volumen }}^{\text {eff. }}+\mathcal{H}_{\text {Feld }}^{\text {eff. }}\left(n_{i}\right)+\mathcal{H}_{\text {Paar }}^{\text {eff. }}\left(n_{i}, n_{j}\right)+\ldots \\
& =C+\sum_{i} H_{i} n_{i}+\sum_{i, j} U_{i j} n_{i} n_{j}+\ldots
\end{aligned}
$$

Das ist so zu verstehen, dass der Volumen-Term nicht von der Konfiguration der betrachteten Freiheitsgrade (wohl aber von den thermodynamischen Parametern) abhängt, der Feld-Term linear mit den Freiheitsgraden der Teilchen (an den Orten $i$ ) geht und der Paar-Term die Zweiteilchen-Wechselwirkung der Teilchen $i$ und $j$ enthält. Höhere Terme werden häufig vernachlässigt. In allen diesen Termen stecken die Einflüsse des gesamten Systems der Teilchen $\{n\}$ und $\{N\}$ und alle sind potenziell relevant für das thermodynamische Verhalten. Die direkte Wechselwirkung $\mathcal{H}_{11}$ der betrachteten Komponenten ist in diesem Zusammenhang unproblematisch und wird daher aus der Betrachtung ausgeblendet. Der Paar-Term in Gleichung 2.5 wird effektive Wechselwirkung genannt. Ein übliches Vorgehen zur näherungsweisen Berechnung dieses Beitrags besteht darin, das System auf zwei Teilchen der interessierenden Sorte $\{n\}$ an den Orten $i$ und $j$ zu beschränken. Daneben existieren weiterhin alle anderen Teilchen $\{N\}$, die man aus der Betrachtung eliminieren möchte. Das Modellsystem (bezeichnet mit dem Index $N+2$ ) ist demnach wie folgt definiert:

$$
\mathcal{Z}_{N+2}=\sum_{i, j} \sum_{\{N\}} \exp \left[-\beta \mathcal{H}_{N+2}\right]
$$

Die effektive Wechselwirkung in diesem System schreibt sich dann wie folgt als partiell (d. h. nicht über die Teilchenorte $i, j$ ) ausgeführte Zustandssumme:

$$
\exp \left[-\beta \mathcal{H}^{\text {eff. }}(i, j)\right]:=\sum_{\{N\}} \exp \left[-\beta \mathcal{H}_{N+2}(\{N\}, i, j)\right]
$$

Dieses Verfahren beschreibt grundsätzlich den von Teilchen der zweiten Sorte vermittelten Beitrag zur Paar-Wechselwirkung $\mathcal{H}_{\text {Paar }}^{\text {eff. }}$ der ersten Sorte (siehe Gleichung 2.5). Das Modellsystem stellt im Grenzfall niedriger Dichten der Teilchen $\{n\}$ eine gute Approximation an die effektive Wechselwirkung des Gesamtsystems dar. Der Volumen- und der Feld-Term sind im $N+2$-System konstant.

In dem so definierten Modellsystem lässt sich die Paar-Korrelationsfunktion $g(i, j)$ zu festen Teilchenpositionen $i$ und $j$ durch die effektive Wechselwirkung ausdrücken:

$$
g(i, j)=\frac{1}{\mathcal{Z}_{N+2}} \exp \left[-\beta \mathcal{H}^{\text {eff. }}(i, j)\right]
$$

Man prüft weiterhin einfach nach, dass das Potential der mittleren Kräfte der Differenz zwischen freien Energien des Gesamtsystems mit zwei Teilchen an den Orten $i, j$ und der des Systems mit unendlich entfernten Teilchen entspricht. Im Kontinuum lässt sich die auf diese Weise beschriebene effektive Wechselwirkung als Potential der mittleren Kräfte (engl. potential of mean forces) interpretieren, denn es gilt folgender leicht nachzuprüfender Zusammenhang:

$$
-\nabla_{j} \mathcal{H}^{\text {eff. }}(i, j)=\left\langle-\nabla_{j} \mathcal{H}_{N+2}\right\rangle_{\{N\} ; i, j \text { fest }}
$$


Die Interpretation als Potential der mittleren Kräfte ist erstens anschaulich und zweitens aus technischer Sicht sinnvoll, weil sich freie Energien durch Computersimulationen nur schwierig bestimmen lassen, Mittelwerte von Observablen (wie in Gleichung 2.9) dagegen direkt zugänglich sind. Die Verteilung der Abstände (und damit die Korrelationsfunktion) von Teilchen ist experimentell messbar, entweder direkt (bei Kolloiden ist das der Fall, siehe Rudhardt u. a., 1998) oder über die Streufunktion (für den theoretischen Zusammenhang siehe z. B. Nägele, 2002).

Im Rahmen dieser Arbeit wird an einigen Stellen explizit von der Methode der effektiven Wechselwirkung Gebrauch gemacht. Aber bereits der Einstieg und die Formulierung des Modells für die Lipidmembran kann in diesem Kontext verstanden werden, auch wenn die Darstellung dort weniger formal ist.

\subsection{Ausgangsmodell für die Lipidmembran}

Die Lipid-Doppelschicht definiert die Fläche der Membran. Der Ausgangspunkt der Modellierung ist die reine Lipidmembran, also ohne Proteine und sonstige Komponenten. Für dieses System wird ein Modell gewählt, welches möglichst viele generische thermodynamische Eigenschaften von Lipidmembranen enthält, aber gleichzeitig möglichst weit analytisch zu handhaben ist. Zuerst wird der Hauptübergang auf Basis des in der statistischen Physik wohlbekannten Gittergas-Modells, für das es gesicherte Ergebnisse gibt, beschrieben. In späteren Kapiteln der Arbeit werden vor allem die Einflüsse zusätzlicher Komponenten in einem dafür erweiterten Modell untersucht.

Das Modell soll molekular sein, das heißt die Lipide als Teile des Systems auffassen. Damit grenzt es sich zunächst von allen Modellen kontinuierlicher Flächen ab, die mit zweidimensionalen Teilchendichten arbeiten (bezüglich der theoretischen Modellierung der inneren Struktur von Lipidmembranen findet sich eine Einführung bereits in Pink, 1984). Bezüglich der molekularen Details soll soweit vergröbert werden, dass das Lipid nur als Teilchen mit einigen wenigen Eigenschaften (inneren Freiheitsgraden) beschrieben wird. Damit kann über die Vorgänge auf Skalen von weniger als einigen Nanometern, auf denen Molekular-Dynamik-Simulationen operieren, nichts mehr ausgesagt werden. Obwohl eine systematische Vergröberung der Komplexität des Lipidmoleküls (siehe die Abbildungen 2.1 und 2.2) ausgehend von der atomaren Struktur hier nicht unternommen wird, muss trotzdem entschieden werden, welche Aspekte in das Modell eingehen sollen.

Die Moleküle besitzen zunächst einen Schwerpunkt und die mit ihm verbundene Bewegung. Man muss dabei unterscheiden zwischen der lateralen Diffusion innerhalb der Schicht, der Bewegung senkrecht zur Membran, dem Wechseln von einer Schicht zur anderen (Flip-Flop genannt) und dem Verlassen des Lipidaggregats in die (wässrige) Lösung. Diese Bewegungen werden als äußere Freiheitsgrade bezeichnet. Die Teilchenzahl in der Lipidschicht kann in guter Näherung als konstant angenommen werden, da die Flip-Flop-Raten mit einer typischen Zeit von einigen Tagen sehr gering und die Dissoziationsraten wegen der sehr niedrigen Konzentration (etwa $10^{-7}$ ) von einzelnen Lipiden in Wasser (der sogenannten kritischen Mizellen-Konzentration) ebenfalls äußerst gering sind (Jain und White, 1977; Roelofsen und Op den Kamp, 1987). Die laterale Diffusions-Konstante der Lipide innerhalb der Schicht ist dagegen mit etwa $1 \mu \mathrm{m}^{2} / \mathrm{s}$ relativ groß (Sackmann, 1978), die der Proteine etwa um den Faktor hundert kleiner.

Die inneren Freiheitsgrade resultieren aus dem komplexen Aufbau des Lipids. Die Kopfgruppe und die Kohlenwasserstoff-Ketten können viele verschiedene Konformationen an- 


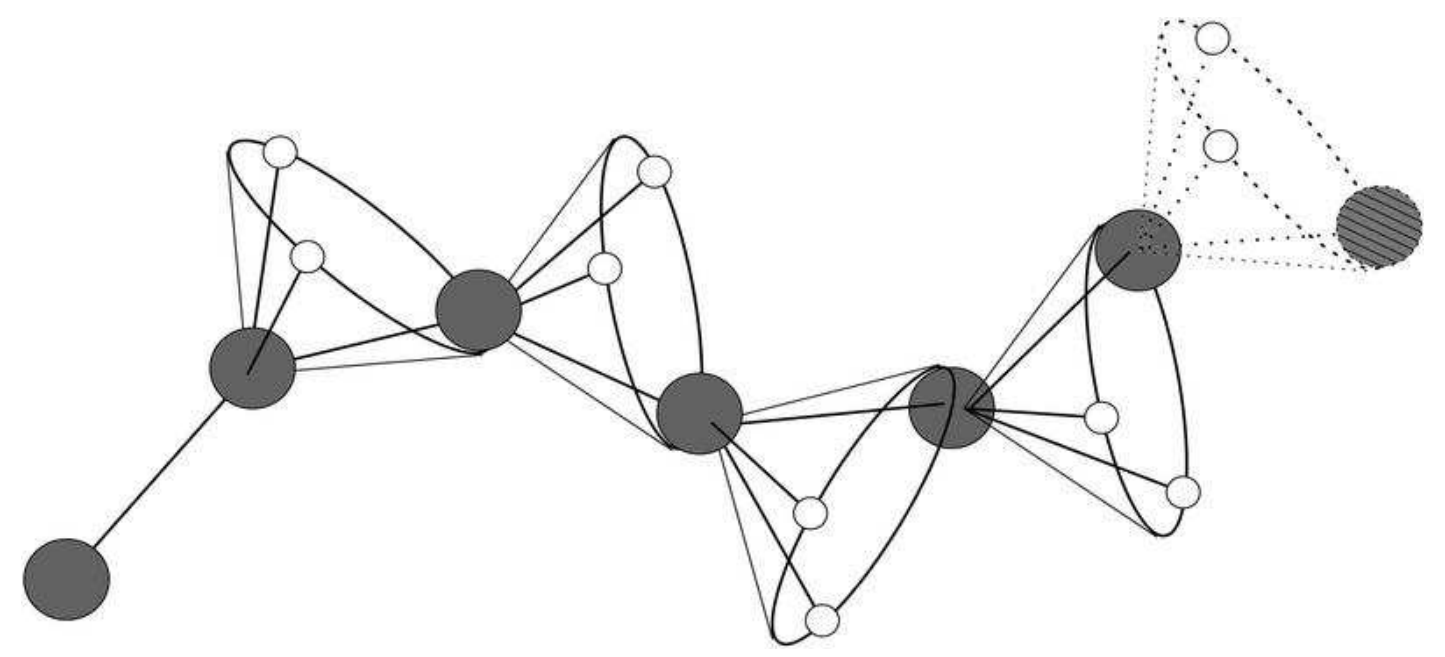

Abbildung 2.3: Schematische Darstellung der Rotationskonformationen einer KohlenwasserstoffKette, mit freundlicher Genehmigung von Ralph Behrends, Göttingen. Um jede Kohlenstoffbindung gibt es drei energetisch bevorzugte Rotationswinkel.

nehmen. Man betrachte zur Vereinfachung nur die Kohlenwasserstoff-Kette: Die Ketten der Lipide sind einfache lineare Polymere. Jede Bindung zweier Kohlenstoffatome besitzt einen Rotationsfreiheitsgrad. Die Länge der Bindung und der Winkel zur nächsten Bindung sind vergleichsweise fest. Die Rotationen von Kettensegmenten führen zu verschiedenen Konformationen der Kette. Die sterischen Hinderungen durch die benachbarten Kohlenwasserstoff-Gruppen führen, betrachtet man den Winkel einer Bindung relativ zur vorhergehenden, zu einem Rotationspotential, das ein globales Minimum und zwei Nebenminima aufweist (z. B. Kapitel 10 in Flory, 1992). Die Konfiguration, die dem globalen Minimum entspricht, nennt man trans, die beiden anderen gauche. Die Anregungsenergien liegen im Bereich der thermischen Energie (z. B. Kapitel 2 in Gennis, 1989). Den Rotationsfreiheitsgrad kann man demnach auf drei diskrete Einstellungen vergröbern (siehe Abbildung 2.3). Das heißt aber auch, dass bei einer Anzahl von typischerweise $3^{2 \times 14}$ Zuständen (für eine typische Länge der Ketten von 15 Kohlenstoffatomen) das einzelne Lipidmolekül zu einem statistisch behandelbaren System wird. Eine gute Einführung in die Physik einfacher linearer Ketten findet sich beispielsweise in Sturm (1991), eine umfangreiche Darstellung in Doi und Edwards (1988).

Betrachtet man Lipide im Aggregat, so kann man bezüglich der Konformationsfreiheitsgrade verschiedene Gruppen von Zuständen energetisch unterscheiden. Im Grundzustand bei niedrigen Temperaturen sind fast alle Rotationswinkel beim energetisch bevorzugten Wert. Aufgrund der Tatsache, dass sich die Moleküle in einem dichten Aggregat befinden, die Moleküle also möglichst ideal gepackt werden müssen, sind einige wenige Bindungen verdreht. Nahezu alle Lipide des Aggregates sind im gleichen Konformationszustand, der als gestreckt bezeichnet wird. Ein Lipid in diesem Zustand ist in Abbildung 2.1 gezeigt. Bei höheren Temperaturen werden die Bindungswinkel angeregt. Es resultieren viele verschiedene ungeordnete Zustände. Ein beliebiger Schnappschuss eines solchen gefalteten Zustands ist in Abbildung $2.2 \mathrm{zu}$ sehen. Fasst man die meisten angeregten Zustände in diesen gefalteten zusammen, so ergibt sich eine Entartung von etwas unter $3^{2 \times 14}$ pro Lipid. 
Dieses grobe Bild eines Zweizustands-Modells der Lipide geht auf Raman- und InfrarotSpektroskopie zurück (siehe z. B. Verma und Wallach, 1984; Amey und Chapman, 1984). Dabei ist zu beachten, dass spektroskopisch etwa neun verschiedene gestreckte Zustände mit wenigen angeregten Bindungen zu unterscheiden sind, die also einen geringen Entartungsgrad besitzen. Darüber hinaus beobachtet man aber auch, dass die Übergangszeiten von einem wenig angeregten Zustand in einen anderen wesentlich kürzer sind als die von einem der Grundzustände in den hoch angeregten (Pink u. a., 1981; Gennis, 1989).

Für die Thermodynamik des zu entwickelnden Modells ist die Aufteilung in viele ähnliche Zustände bei tiefen Temperaturen nicht entscheidend. Getrieben wird der Hauptübergang durch den hohen Entartungsgrad des angeregten Lipidzustands. Man stellt aber leicht fest, dass ein nicht kooperativer Übergang eines wie hier zunächst beschriebenen Systems aus nicht wechselwirkenden Lipiden, der ausschließlich durch die innere Entropie der Lipide getrieben wird, eine Breite von mindestens zehn Kelvin hätte. Weil der in Lipidmembranen beobachtete Phasenübergang wesentlich enger ist, muss die kooperative Wechselwirkung der Lipide eine wesentliche Rolle spielen. Doch zunächst zur Formalisierung des hier dargestellten Szenariums.

Die Lipidmoleküle seien im Wärmeaustausch mit dem Lösungsmittel, daher berechnet man die kanonische Zustandssumme $\mathcal{Z}$, zunächst die eines Teilchens. Der Zustandsraum sei diskret im Sinne der oben beschriebenen Konformationen der Ketten:

$$
\begin{aligned}
\mathcal{Z}_{\text {Lipid }} & =\sum_{\text {Lipid }} \exp \left[-\beta \mathcal{H}_{\text {Lipid }}\right] \\
& \approx D_{s} \exp \left[-\beta E_{s}\right]+D_{f} \exp \left[-\beta E_{f}\right] \\
& =\exp \left[-\beta\left(E_{s}-T S_{s}\right)\right]+\exp \left[-\beta\left(E_{f}-T S_{f}\right)\right]
\end{aligned}
$$

Die Temperatur $T$ wird in Energieeinheiten gemessen (die Boltzmann-Konstante ist eins) und $\beta$ bedeutet wie üblich $1 / T$. Der Index $s$ bezeichnet den Grundzustand (stretched oder gestreckt) und $f$ den angeregten Zustand (folded oder gefaltet). Der Parameter $D=$ $\log S$ bezeichnet die Entartung und $S$ demnach die innere Entropie eines Zustands des Moleküls. Dessen Energie wird mit $E$ bezeichnet. Diese Formulierung ist Ausdruck der Tatsache, dass es sich bei Lipiden um große Moleküle mit vielen Freiheitsgraden und bei der Beschreibung um eine effektive handelt.

Die Gleichung 2.10 wird durch Einführung der Besetzungszahl $n^{L}$ (der Index $L$ steht für Lipid) vereinfacht. Dabei ist $n^{L}$ null im gestreckten und eins im gefalteten Zustand und die Zustandssumme erstreckt sich über alle Werte der Besetzungszahl. Die neuen Parameter ergeben sich aus den Differenzen der obigen mit Index $f$ und $s$ :

$$
\begin{aligned}
n^{L} & = \begin{cases}1 & \text { wenn Lipid gefaltet } \\
0 & \text { sonst }\end{cases} \\
\mathcal{Z}_{\text {Lipid }} & =\sum_{n^{L} \in\{0,1\}} \exp \left[-\beta(E-T S) n^{L}\right]
\end{aligned}
$$

Führt man nun die Ausdrücke für alle Moleküle der Lipidmembran zusammen, so erhält man folgende Gleichung für denjenigen Teil der effektive Hamiltonfunktion, der von den 
Beiträgen der einzelnen nicht wechselwirkenden Lipide herrührt. Die Moleküle werden mit einem Index $i$ durchnummeriert:

$$
\mathcal{H}_{\text {Lipide }}=(E-T S) \sum_{i} n_{i}^{L}
$$

Weitere Auswirkungen der inneren Konformationen (Dipol, Molekülachse) sollen in diesem Modell unberücksichtigt bleiben. Jedoch soll eine äußere Eigenschaft der Moleküle indirekt berücksichtigt werden: ihr Flächenbedarf.

Da man nicht bei einzelnen Molekülen, sondern nur in einem Aggregat vom Flächenbedarf sprechen kann, ist hiermit bereits der erste Beitrag zur Wechselwirkung angesprochen. Man versteht darunter üblicherweise die Gesamtfläche der Membran geteilt durch die Teilchenzahl, oder geometrisch ausgedrückt die Projektion des Lipidvolumens auf die Grenzfläche zwischen dem hydrophoben und dem hydrophilen Bereich. Wenn die Rotationsfreiheitsgrade der Ketten angeregt werden, verkürzt sich die Länge des Moleküls und es wird notwendigerweise breiter, denn das Volumen bzw. die Dichte verändert sich nicht im gleichen Maße. Bei dieser Vergrößerung muss Arbeit gegen die anderen Teilchen im Aggregat geleistet werden. Nimmt man die Membran im Hinblick auf diesen Effekt als homogene Fläche an, so führt man zur Flächenänderung einen ihr konjugierten lateralen Druck ein. Im Rahmen des Zweizustands-Modells der Lipide ist der Flächenbedarf $A$ mit der Besetzungszahl $n^{L}$ gekoppelt:

$$
\mathcal{H}_{\text {Druck }}=\pi A \sum_{i} n_{i}^{L}
$$

Man kann diesen Term auch als Beschreibung der molekularen Wechselwirkung in einer Mittlere-Feld-Formulierung ansehen (Marčelja, 1974). Das betrachtete Ensemble ist demnach das Folgende: Die Lipid-Teilchenzahl ist konstant, die mittlere Besetzungszahl aber nicht. Mit ihr fluktuiert auch die Gesamtfläche der Membran. Der konjugierte Parameter zum mittleren Zustand ist das enthalpische Feld $H=E+\pi A$. Die Membran ist an ein Wärmebad (das wässrige Lösungsmittel) gekoppelt, die Zustände sind also kanonisch verteilt.

Unter vielen möglichen Wechselwirkungen der Lipide untereinander und mit dem Wasser ist diejenige die wichtigste, die die Aggregation der Lipidschichten bewirkt, die sogenannte hydrophobe Wechselwirkung: Die Kopfgruppen der Lipide sind im Allgemeinen polar oder sogar geladen. Daher wechselwirken sie günstig mit dem wässrigen Lösungsmittel, sie sind hydrophil. Die Kohlenwasserstoff-Ketten dagegen sind unpolar, also hydrophob. Sie gewinnen keine Energie durch Kontakt mit dem Wasser. Das Wasser wiederum bevorzugt auch aus entropischen Gründen die Kopfgruppen, da sich nur dort Wasserstoff-Brücken ausbilden können (siehe z. B. Tanford, 1973; Adam u. a., 1995). Zusammengefasst bedeutet das, dass Lipide in Wasser die Ketten aneinanderlagern und die Köpfe die Grenzfläche zum Wasser bilden, und dass Teilchen mit unterschiedlich langen hydrophoben Bereichen in der Membran ungünstig miteinander wechselwirken, sich also abstoßen.

Im hier zu entwickelnden Modell soll die Existenz von Lipidschichten bereits angenommen werden. Die Lipidschicht wird als zweidimensionales Gittergas formuliert. Dazu wird ein Dreiecksgitter eingeführt, auf dessen Gitterplätzen sich die Teilchen befinden können. Die Gitterkonstante gibt damit einen Mindestabstand, den harten Kern der Teilchen, vor. Dieser beschreibt die sterische Hinderung der Moleküle auf einfache Weise. Die Konnektivität des Gitters ist nicht relevant, solang darauf geachtet wird, keine Größen zu 
messen, die von der Struktur explizit abhängen. Das Dreiecksgitter beschreibt die dichteste Packung von Scheiben in zwei Dimensionen und ist daher für die Beschreibung der Lipidmembran angemessen, wenn man von einer (parallel zur Oberfläche der Membran) symmetrischen Massenverteilung der Lipidmoleküle ausgeht. Genau diese dichte Packung von Scheiben soll zunächst zur Vereinfachung für die Lipidschicht in allen Phasen angenommen werden. Im Sinne des Gittergases betrachten wir also den Grenzfall einer dichten Flüssigkeit. Die Teilchendichte kommt erst in der Erweiterung des Modells im nächsten Kapitel als Parameter in das Modell wieder hinein. Im Sinne des oben beschriebenen unterschiedlichen Flächenbedarfs der Lipide in den beiden Zuständen ist der mittlere Lipidzustand äquivalent zu einer (lateralen) Dichte.

Alle weiteren Wechselwirkungen, wie die elektrische, polare oder sonstige, werden mit der hydrophoben Wechselwirkung in einem Energieterm zusammengefasst, der nur von den zuvor eingeführten zwei inneren Zuständen (gestreckt oder gefaltet) abhängen soll. Darüber hinaus sollen nur nächste Nachbarn miteinander wechselwirken. Der Beitrag zur Hamiltonfunktion stellt sich damit wie folgt dar:

$$
\begin{gathered}
\mathcal{H}_{\text {Wechselwirkung }}=K_{L L} \sum_{\langle i, j\rangle} n_{i}^{L} n_{j}^{L} \\
K_{L L}<0
\end{gathered}
$$

Die spitzen Klammern um Indizes $\langle i, j\rangle$ bezeichnen grundsätzlich Indexpaare von nächsten Nachbarn auf dem Gitter. Das Vorzeichen der Wechselwirkungs-Konstante $K_{L L}$ wird so gewählt, dass sich homogen geordnete Phasen bilden können, d. h. negativ. Fügt man nun Gleichung 2.12 und Gleichung 2.14 zusammen, so erhält man das komplette Zweizustands-Modell für die einfache Lipidmembran:

$$
\mathcal{H}_{\text {Lipidmembran }}=K_{L L} \sum_{\langle i, j\rangle} n_{i}^{L} n_{j}^{L}+(H-T S) \sum_{i} n_{i}^{L}
$$

Frühe Darstellungen dieses Modells für den Hauptübergang von Lipidmembranen finden sich in Caille u. a. (1978); Doniach (1978); Pink u. a. (1980) und etwas verklausuliert bereits in Marčelja (1974). Abbildung 2.4 zeigt, wie man sich das Modell vorstellen kann. Alle weiteren symbolhaften Abbildungen dieser Arbeit sind auf diese Weise aufgebaut, so sollen gelbe (helle) Symbole die gestreckten Lipide und grüne (dunkle) Symbole die gefalteten Lipide repräsentieren. Hilfreich für die Analyse und Interpretation des Modells ist der Hinweis, dass das hier beschriebene Gittergas äquivalent zum Ising-Modell des Ferromagnetismus ist.

\subsection{Referenzsystem Ising-Modell}

Die Hamiltonfunktion in Gleichung 2.15 lässt sich statt in Besetzungszahlen auch mit Spin-Variablen $s^{L}$ schreiben, die die Werte \pm 1 einnehmen:

$$
s_{i}^{L} \equiv 2 n_{i}^{L}-1
$$

Die Äquivalenz zum Ising-Modell (Ising, 1925) mit äußerem Magnetfeld ist unmittelbar ersichtlich. Die Kopplung $K_{L L}$ ist ferromagnetisch gewählt. Nicht miteinander wechselwirkende Lipide entsprechen demnach dem Paramagneten im äußeren Feld. Das hier beschriebene Modell ist also darauf ausgelegt, in seiner Ausgangsversion das einfachst mögliche 


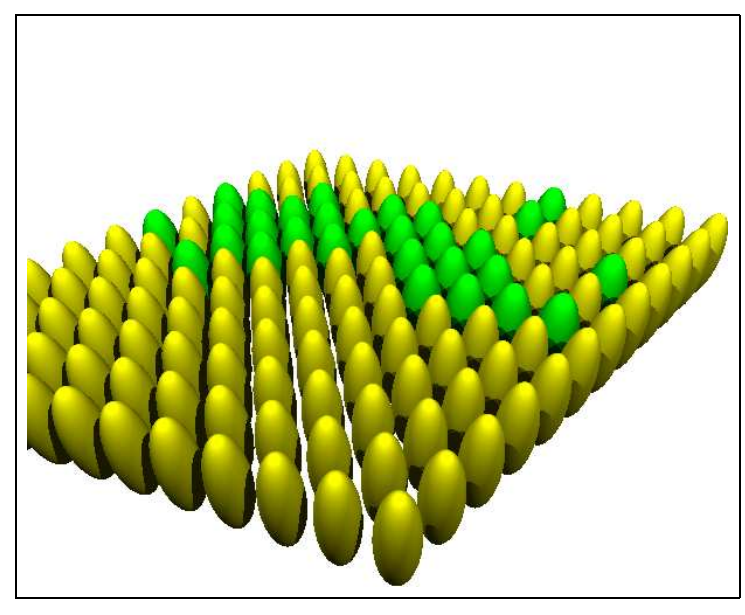

(a) Dreidimensionale Seitenansicht

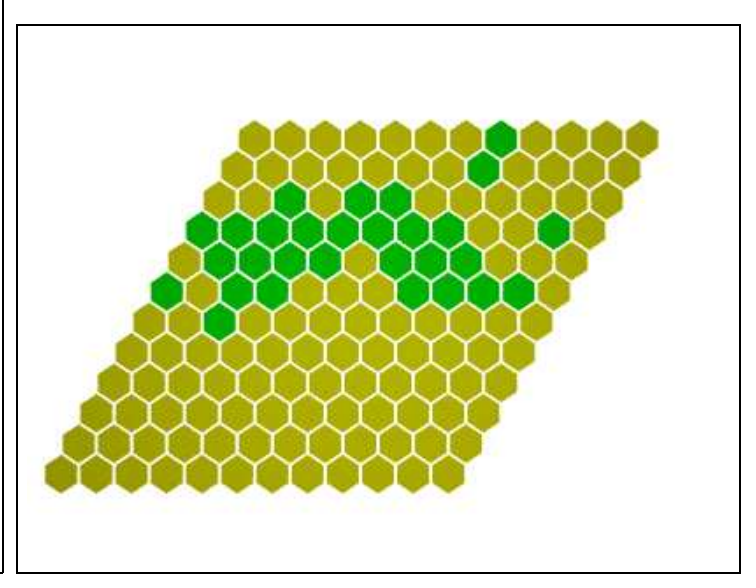

(b) Zweidimensionale Aufsicht

Abbildung 2.4: Schnappschuss des Modells einer Lipidmembran als Zweizustands-Gittergas. Die Ellipsoide bzw. Hexagone repräsentieren die Lipide, gelb (hell) für den gestreckten und grün (dunkel) für den gefalteten Zustand. Die Teilchen bilden ein zweidimensionales Dreiecksgitter und haben dementsprechend jeweils sechs Nachbarn.

System (die pure Lipidmembran) mit dem einfachst möglichen Modell zu beschreiben, das einen Phasenübergang erlaubt. In dieser Arbeit wird aber konsequent die Notation des Gittergases mit Besetzungszahlen statt der des Ising-Modells mit Spins benutzt. Die übliche symmetrische Formulierung des Ising-Modells ist im vorliegenden Fall von Nachteil, da die Lipidzustände keine derartige Symmetrie aufweisen, sie könnte also in die Irre führen. Die fehlende Symmetrie kann in der Sprache des Ising-Modells auch anders ausgedrückt werden: Es gibt immer ein äußeres Feld.

Fundierte theoretische Einführungen zum Thema Phasenübergänge finden sich zum Beispiel jeweils in den ersten Kapiteln von Baxter (1982) sowie Lavis und Bell (1999). In den erwähnten Büchern findet man darüber hinaus einige analytische Ergebnisse zu den in dieser Arbeit verwendeten Modellen. So ist das zweidimensionale Ising-Modell ohne äußeres Feld exakt gelöst (Onsager, 1944).

Aus der Äquivalenz ist auch sofort der Ordnungsparameter ersichtlich. Es ist im Fall des Ferromagneten die Magnetisierung und hier die mittlere Besetzungszahl der Lipide:

$$
m:=\left\langle n_{i}^{L}\right\rangle \in[0,1]
$$

Doch muss man bezüglich der Phasen klar vom Ferromagnetismus unterscheiden. Der Wert $m=0$ entspricht der kondensierten Phase und $m=1$ der expandierten. Diese Phasen sind im Ferromagnetismus nicht zu unterscheiden, es sind beides in diesem Sinne geordnete Phasen, nur mit unterschiedlichen Vorzugsrichtungen der Spins aufgrund eines externen Feldes. Der Ordnungsparameter $m$ des Modells beschreibt den mittleren Lipidzustand. Aus der mikroskopischen Begründung des Modells folgt, dass er so etwas wie die mittlere Ordnung der Lipidketten repräsentieren muss. Nun ist im Zusammenhang mit der Kettenordnung in der Literatur ein mikroskopisch definierter Ordnungsparameter (üblicherweise mit $S$ bezeichnet) eingeführt, der direkt mit Hilfe der Kernspinresonanz gemessen wer- 
den kann. Dieser misst die mittlere Orientierung der Kohlenstoffbindungen und kann für jedes Kettensegment einzeln bestimmt werden. Es ist bekannt, dass die so ermittelte Kettenordnung zu den Enden der Ketten hin abnimmt und neben vielen Parametern auch von der chemischen Klasse der Kopfgruppe abhängt (Thurmond und Lindblom, 1997). Mit diesem experimentellen Parameter existiert ein vergleichbares Gegenstück zur mittleren Besetzungszahl $m$. Aus der Interpretation des Flächenbedarfs eines Lipids in einem bestimmten Zustand folgt, dass der Ordnungsparameter auch für die Gesamtfläche der Membran steht. Ein Ensemble, in dem sich der Ordnungsparameter frei einstellt, entspricht also der Vorstellung, dass die Membran-Fläche bei konstantem lateralen Druck frei fluktuiert.

Das Phasendiagramm des Ising-Modells ist wohlbekannt. Ungewöhnlich und zugleich entscheidend für dessen Eigenschaften ist die Temperaturabhängigkeit der effektiven Hamiltonfunktion mit dem Feld $H-T S$ aus Gleichung 2.15. In der üblichen Darstellung, in der das äußere Feld gegen Temperatur bzw. die inverse Kopplungs-Konstante aufgetragen ist, muss beachtet werden, dass Feld und Temperatur über den Entropieparameter $S$ linear gekoppelt sind. Bei einem relativ großen Wert von $S$ verläuft eine Trajektorie steigender Temperatur im Phasendiagramm (siehe Abbildung 2.5) steil von links oben nach rechts unten. Der Übergang ähnelt deshalb eher dem Feldübergang des Ising-Ferromagneten als dessen temperaturgetriebenen Übergang. Der Phasenübergang 1. Ordnung findet bei einem bestimmten Wert des äußeren Feldes unterhalb einer kritischen Temperatur statt (auch kritischer Punkt genannt). Die fehlende Symmetrie der Gittergas-Formulierung schlägt sich in einem Wert ungleich null für dieses Feld nieder.

Das Modell kennt drei verschiedene temperaturgetriebene Übergänge, die für verschiedene Werte des äußeren Feldes (Parameter $H$ und $S$ ) auftreten können:

- Phasenübergang 1. Ordnung bei niedrigen Temperaturen (bzw. entsprechenden FeldParametern),

- Phasenübergang 2. Ordnung (kritisch) bei einer ganz bestimmten Temperatur, der kritischen,

- Kontinuierlicher Übergang bei hohen Temperaturen.

Welche Art des Übergangs, d.h. welche Region des Phasendiagramms, den Hauptübergang von Lipidmembranen am ehesten beschreibt, wird im Folgenden diskutiert, denn die Charakteristika des Hauptübergangs der Lipide unterscheiden sich stark je nach Aggregatform und Präparation des Wasser-Lipid-Systems.

Langmuir-Monoschichten In Langmuir-Monoschichten kann man den Hauptübergang sowohl durch die Temperatur als auch durch den äußeren lateralen Druck treiben. Die experimentellen Fakten sprechen deutlich für einen Phasenübergang 1. Ordnung, der in einem kritischen Punkt endet. Die Natur des Übergangs jenseits des kritischen Punktes ist nicht eindeutig geklärt, die Annahme einer Linie kritischer Punkte (Albrecht u. a., 1978) hat sich offensichtlich nicht bestätigt. Die Phasenübergangslinie in der Auftragung Druck gegen Temperatur ist für nicht zu kleine Drücke eine Gerade mit bestimmter Steigung.

Zu Diskussionen über die Ordnung des Übergangs hat geführt, dass die Koexistenzlinien (z. B. in der Darstellung Druck gegen Fläche) nicht eben sind. Albrecht u. a. (1978) haben daraus geschlossen, dass nur endlich viele Moleküle jeweils kooperativ am Übergang beteiligt sind und haben eine sehr kleine Zahl von etwa 100 Teilchen abgeschätzt. Später wurde 


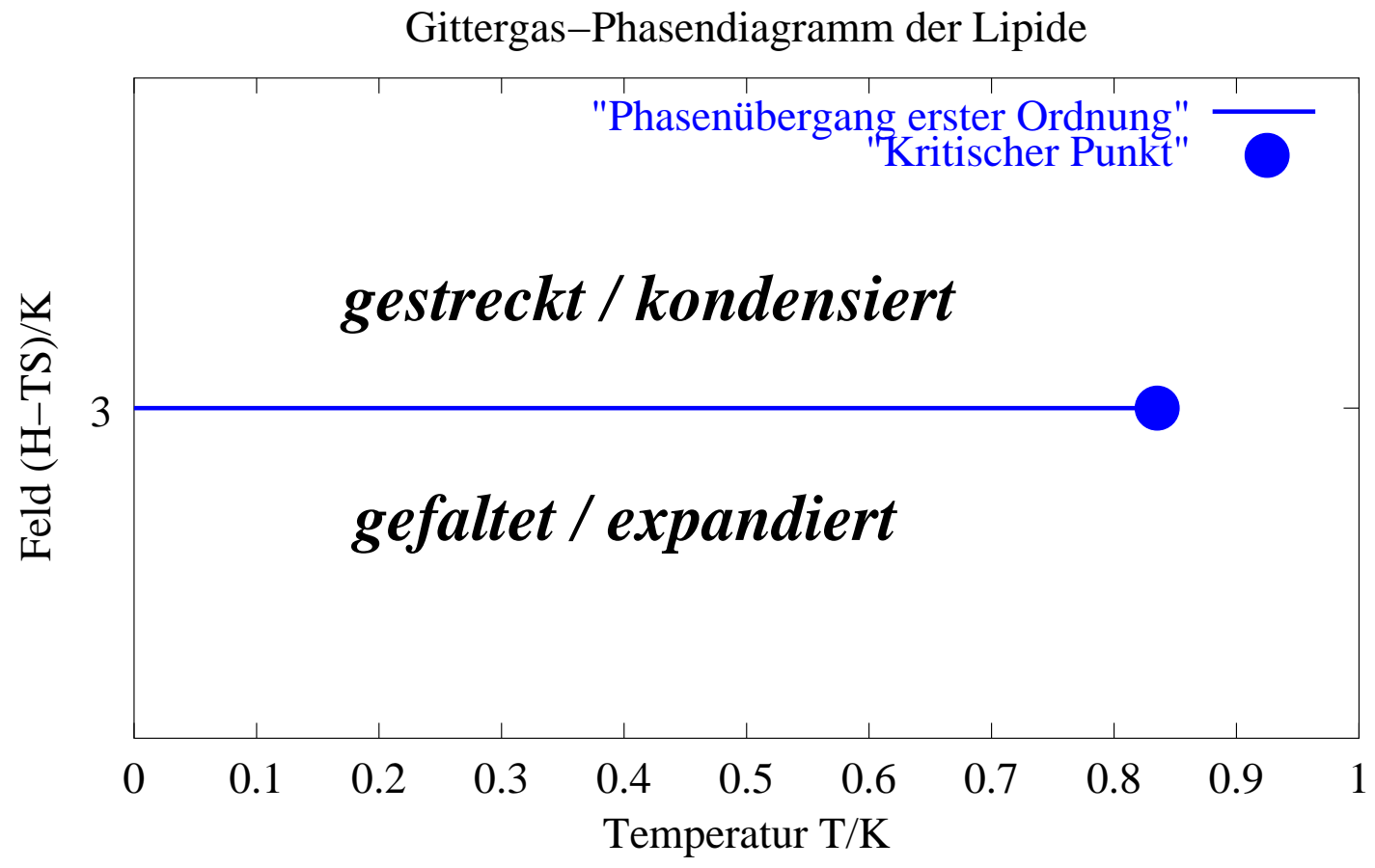

\begin{abstract}
Abbildung 2.5: Skizze des Phasendiagramms des Zweizustands-Modells mit möglichen Phasen und Übergängen. Wegen des entropischen Beitrags zum Feld führt eine Erhöhung der Temperatur vom Bereich links oben in den Bereich rechts unten. Daher entsprechen die Lipidphasen „gestreckt/kondensiert" bzw. „gefaltet/expandiert" den Ising-Phasen bei unterschiedlichem Vorzeichen des äußeren Feldes. Die Größen sind auf die Kopplungs-Konstante normiert. Ein Phasendiagramm mit konkreten Werten für die Modellparameter findet sich in Abbildung 2.6.
\end{abstract}

der Koexistenzbereich direkt beobachtet: Die Abbildungen von Fluoreszenzmikroskopen an Lipiden verwandten Molekülen (Qiu u. a., 1991), zeigen im Allgemeinen ein Wachstum von etwa kreisrunden Domänen, die wesentlich größer sind als die im oben erwähnten Artikel abgeschätzten. Die Domänen verweilen in einem Stadium unvollständiger Phasentrennung, dessen Ursache aber letztendlich nicht klar ist, zumal eine Ausbildung solcher Domänen für binäre Flüssigkeiten durchaus erwartet wird (Yeomans, 2000) und man so etwas auch bei Vesikeln aus Lipid-Mischungen beobachtet.

Unter der Annahme eines Phasenübergangs 1. Ordnung fällt die Interpretation des Phasendiagramms im Rahmen des theoretischen Modells leicht. Der laterale Druck ist im Parameter $H$ enthalten und die Steigung der Phasenübergangslinie im Parameter $S$. Die Wechselwirkung $K_{L L}$ bestimmt die Lage der Gerade und des kritischen Endpunkts (siehe Abschnitt 3.2). Auch den Phasenübergang von gasförmig zu flüssig kann man in das Modell integrieren.

Lamellare Phasen Der Hauptübergang in Schichtsystemen zeigt sich als Phasenübergang 1. Ordnung. Die spezifische Wärme zeigt ein äußerst enges und stark ausgeprägtes Maximum. Die daraus abgeleitete latente Wärme beträgt etwa $14 \mathrm{k}_{\mathrm{B}}$ pro Molekül (Doniach, 1980). Die Dicke der Schichten, etwa durch Röntgenstrukturmessungen bestimmt, nimmt in einem engen Temperaturbereich stark zu. Der genaue Verlauf der Kurve gibt Anlass zu Diskussionen über anormales Anschwellen am Übergangspunkt, die Hysterese bezüglich 
Aufheizen und Abkühlen spricht aber für das Szenarium eines unstetigen Phasenübergangs.

Die Frage, ob die Schichten als gekoppelt oder einzeln zu betrachten sind, hängt von der untersuchten Eigenschaft ab. Für den Hauptübergang wird im Allgemeinen angenommen, dass es sich um unabhängige Schichten handelt, wenn man die Schichtsysteme bis zu ihrem jeweiligen Gleichgewichtsabstand hydratisiert. Das Bild ist nicht so vollständig wie das im Falle der Monoschichten. Den lateralen Druck kann man nicht direkt variieren, aber zumindest den Salzgehalt der Lösung und den osmotischen Druck auf das Schichtsystem. Systematische Untersuchungen, die idealerweise in einem Phasendiagramm münden, das man mit dem der Monoschichten oder dem des Gittergas-Modells vergleichen könnte, sind nicht bekannt.

Publizierte Phasendiagramme für multilamellare Stapel von Lipid-Doppelschichten beschreiben die Abhängigkeit von Temperatur und Wassergehalt des Systems (eine Zusammenfassung bezüglich der Lipidsorte Phosphatidylcholine bzw. einen umfassenden Index von Phasendiagrammen bieten Koynova und Caffrey, 1998, 2002). Für Wasserkonzentrationen unterhalb von $20 \%$ erkennt man eine deutliche Abhängigkeit der Übergangstemperatur von der Konzentration und ein breites Koexistenzgebiet der beiden Phasen. Die Übergangstemperatur ist unabhängig oberhalb eines Wassergehalts von $20 \%$. Jedoch verkompliziert sich die Situation, weil die expandierte Phase $L_{\alpha}$ nicht direkt in die kondensierte $L_{\beta}$ übergeht, sondern zunächst in die „Ripple-Phase“ $P_{\beta}$. In der „Ripple-Phase“ sind die Ketten der Lipide, ähnlich wie in der kondensierten Phase, gestreckt, die Schwerpunkte der Moleküle bilden aber zusätzlich ein wellenartiges Höhenprofil aus. Eine Koexistenz von $L_{\beta}$ und $P_{\beta}$ ist ebenfalls beobachtet worden.

Unilamellare Vesikel Man gehe davon aus, dass die Suspensionen mit einer geringen Konzentration von Lipiden (weniger als 0,1\%) hergestellt wurden, und die Vesikel daher als wechselwirkungsfrei und ausreichend stabil angesehen werden können. Der Hauptübergang, gemessen z.B. in der Signatur der spezifischen Wärme, hat bei solchen Systemen immer eine endliche Breite in der Größenordnung von einem Kelvin. Die Übergangswärme, bestimmt als das Integral $\int \mathrm{d} T C(T)$ über die spezifische Wärme, beträgt mit etwa $10 \mathrm{k}_{\mathrm{B}}$ zwar weniger als im Fall lamellarer Stapel, aber wesentlich mehr als bei smektischen Flüssigkristallen. Anzeichen für einen Übergang 1. Ordnung (Hysterese) gibt es nicht. Da der laterale Druck in Vesikeln experimentell nicht kontrolliert werden kann, fällt die Zuordnung in das Phasendiagramm des theoretischen Modells nicht leicht. Verschiedene Erklärungen sind denkbar:

Experimentelle Unschärfe Dieser Punkt kann nach Aussage einiger Experimentatoren ausgeschlossen werden. Nach ihrer Aussage ist die Auflösung z. B. der Kalorimeter besser als die Breite des Übergangs. Andere geben dagegen an, dass die Maxima in ihrer Form nicht verlässlich sind, d. h. nicht wirklich punktweisen Messungen entsprechen (aus Diskussionen u. a. mit T. Heimburg und T. Salditt).

Endliche Größe des Systems Die Größe der Lipidaggregate ist wahrscheinlich nicht entscheidend. Es ist keine klare Größenabhängigkeit berichtet und die Anzahl der Lipide in einem Vesikel ist nicht auffällig klein. Verdeutlicht wird das durch eine Abschätzung: Die kleinsten Vesikel haben einen Radius von etwa $100 \mathrm{~nm}$. Das macht eine Fläche von etwa $4 \times 10^{-14} \mathrm{~m}^{2}$. Bei einem Flächenbedarf von etwa $(0,7 \mathrm{~nm})^{2}=$ $5 \times 10^{-19} \mathrm{~m}^{2}$ ergeben sich $10^{5}$ Teilchen pro Vesikel. Die in dieser Arbeit ausgeführten 
Computersimulationen z. B. zeigen ab $10^{3}$ bis $10^{4}$ Teilchen keine Abhängigkeiten mehr von der Systemgröße.

Fehlende thermische Stabilität Die Vesikel-Suspensionen sind nur metastabil. Bei konstanten Bedingungen halten sie sich Stunden bis Tage. Aber insbesondere im Übergangsbereich sind strukturelle Umwandlungen beobachtet worden. Das reicht von Veränderungen der Form bis hin zur Auflösung der Vesikeltopologie. Trotzdem können die Vesikel bei geeigneten experimentellen Bedingungen (vor allem bei geringer Dichte der Vesikel in Lösung) auch den Hauptübergang unbeschadet überstehen. Auch die Größenverteilung kann sehr schmal gehalten werden. Die Szenarien, die von unterschiedlichen experimentellen Gruppen beobachtet werden, unterscheiden sich zum Teil drastisch. Natürlich wird das einfache Gittergas-Modell überstrapaziert, wenn Umwandlungen der Vesikelform die Thermodynamik des Systems bestimmen.

Endliche Krümmung Aus vielen experimentellen Untersuchungen und theoretischen Modellen weiß man, dass die Lipidmembranen krümmungsdominierte Flächen sind. Die Krümmungs-Energie eines kleinen Vesikels von $100 \mathrm{~nm}$ Radius lässt sich mit $40 \mathrm{k}_{\mathrm{B}} T$ abschätzen, wobei man ein Krümmungsmodul von $\kappa=10 \mathrm{k}_{\mathrm{B}} T$ annimmt. Die Fluktuationen der äußeren Form sollten demnach nur klein sein. Dennoch ist der relative Unterschied in der Krümmungs-Energie pro Fläche oder Teilchen zwischen den beiden Schichten der Lipidmembran mit etwa 0,1 nicht unbedingt vernachlässigbar, wobei ein innerer Krümmungsradius von $100 \mathrm{~nm}$ und eine Dicke der Doppelschicht von $5 \mathrm{~nm}$ angenommen wird.

Intrinsische Gründe, d.h. Lipid-Wechselwirkung Die Erfahrung der Experimentatoren spricht also am ehesten für einen, wenn auch schmalen und von starken Fluktuationen bestimmten, kontinuierlichen Übergang. Die Wechselwirkungen sind dabei so, dass der Übergang bei typischen experimentellen Bedingungen kontinuierlich verläuft.

Letztendlich ergibt sich aus Sicht des Modells eine pragmatische Erklärungsmöglichkeit für die Einordnung in das Phasendiagramm, wenn man intrinsische Gründe für einen kontinuierlichen Übergang annimmt. Denn das Phasendiagramm in Abbildung 2.5 zeigt neben dem Übergang 1. Ordnung auch einen Bereich von Parametern, für die der Übergang kontinuierlich ist. Eine tiefere Begründung, warum der im Modell enthaltene unstetige Übergang bei Vesikeln nicht beobachtet wird, bleibt jedoch aus.

Es muss angemerkt werden, dass es experimentelle Befunde gibt, die in ihrer Observablen einen kritischen Übergang zeigen. Dabei handelt es sich um Ultraschallspektroskopie, deren Messungen mit dem Verhalten von binären kritisch entmischenden Systemen in Zusammenhang gebracht werden (Halstenberg u.a., 2003). Dazu kann nur gesagt werden, dass der Ordnungsparameter $m$ des in der vorliegenden Arbeit betrachteten Modells nach Gleichung 2.15 in dieser Weise unvereinbar mit dem Szenarium binärer Entmischung ist, da die mittlere Lipid-Besetzungszahl keine Erhaltungsgröße darstellt.

Der auch im Rahmen dieses Modells existierende kritische Übergang erscheint unwahrscheinlich als Szenarium für die Lipidmembran. Die Parameter des Systems müssten schon ganz bestimmte Werte annehmen, um einen Übergang genau durch den kritischen Punkt zu ermöglichen. Schon eine geringe Änderung der äußeren Parameter müsste das System aus dem kritischen Bereich heraustreiben. Das wird jedoch nicht beobachtet. Eine Symmetrie wie beim Ising-Ferromagnet (oder der Landau-Entwicklung der freien Energie für 
kritische Übergänge), die das System auf genau einer Linie im Phasendiagramm fixiert, gibt es im Lipidsystem nicht, d.h. in der Sprache des Ising-Modells: der feldfreie Ferromagnet wäre hier ein Kuriosum.

Biologische Membranen Etwas vereinfacht gesagt liegt die Motivation des Modells in der Vorstellung, dass die Lipide in einfachen Membranen aufgrund ihrer inneren Freiheitsgrade einerseits sehr viele verschiedene Konformationen annehmen können, andererseits aber energetisch eine Art Grundzustand und ein Band angeregter Zustände der Lipide ausgezeichnet sind. Es sind diese hoch entarteten inneren Zustände, die die Thermodynamik des Systems bestimmen. Überträgt man dieses Bild auf Biomembranen, so stellt man sich vor, dass die Lipide natürlicherweise einen ungeordneten Zustand, den gefalteten, annehmen. Andere geordnetere Zustände sind aber möglich und tatsächlich beobachtet man einen sehr verbreiterten Übergang nahe physiologischer Temperaturen auch bei biologischen Membranen (Bach, 1984). Manche Lipidmembranen mit biologischer Zusammensetzung (das sind Lipidmembranen, für die man die Lipide aus biologischen Membranen extrahiert und daraus z. B. Vesikel gebildet hat) zeigen eine Signatur, die der reiner Vesikelsuspensionen sehr ähnlich ist. Ausführlich untersucht ist die Membran des Bakteriums E. Coli: Messungen des Ordnungsparameters finden sich beispielsweise in Watts und Spooner (1991), solche der spezifischen Wärme in White u.a. (2000). Nun ist die physiologische Relevanz des Hauptübergangs stark umstritten. Es gibt nur ein Bakterium, bei dem man den Übergang als natürliches Phänomen beobachtet haben will. Allerdings muss die Relevanz nicht im Übergang selbst liegen, sondern kann allein in der Eigenschaft der Lipide, ihren Zustand ändern zu können, begründet sein. So findet man Hinweise darauf, dass die Membranen von biologische Organismen so zusammengesetzt sind, dass sie den Hauptübergang vermeiden, z. B. ist der Anteil ungesättigter Fettsäuren in der Membran von E. Coli von der Temperatur abhängig, in der es sich entwickelt (de Kruijff u. a., 1997). Der innere Zustand der Lipide und damit die Eigenschaften der ganzen Membran kann durch äußere Einwirkungen, also durch Adsorbate und Einlagerungen, beeinflusst werden. Die Kooperativität der Lipide und ihre Tendenz, homogene Phasen zu bilden, tritt nun in Konkurrenz zur Mischung der adsorbierten oder eingelagerten Komponenten. Das heißt, ein zuvor homogenes, aber durch Fluktuationen gekennzeichnetes System, kann durch die Wechselwirkung mit neuen Komponenten eventuell strukturiert werden. Für dieses Bild scheint das Zweizustands-Modell der Lipide jenseits des kritischen Punktes ein vielversprechender Startpunkt zu sein, um die Effekte zu verstehen, die gerade aufgrund der Mischung aus Lipiden und Proteinen geschehen. Insofern relativiert sich die zuvor dargestellte Diskussion des Hauptübergangs.

Nach eingehender Recherche und Gesprächen sowie Untersuchungen des Modells hat sich die Motivation für diese Arbeit von der genauen Klärung des Hauptübergangs hin zur Untersuchung generischer Effekte in Biomembranen entwickelt. Zur Beschreibung des Hauptübergangs sind eventuell Erweiterungen bezüglich der Modellierung der molekularen Struktur notwendig. Die zentrale Frage der weiteren Modellierung lautet: Inwiefern können zusätzliche Komponenten durch ihre Wechselwirkung mit der Lipidmembran zu (stabiler) Strukturbildung führen und wie hängt dieser Effekt vom Typ der Wechselwirkung ab? Technisch gesehen wird die Untersuchung von der Frage geleitet: Findet man eine effektive vergröberte Formulierungen des Modells, die Einsicht in die Ursachen der Strukturbildung verschafft? 


\subsection{Referenzmethoden Mittleres-Feld und Monte-Carlo}

In dieser Arbeit werden zwei grundsätzlich verschiedene Methoden angewandt. Zum einen die analytisch orientierte Mittlere-Feld-Methode (abgekürzt MF, engl. mean field), die die freie Energie des Systems durch einen analytisch handhabbaren Ausdruck approximiert und zum anderen die Monte-Carlo-Methode (abgekürzt MC), die den Zustandsraum mit Hilfe einer bestimmten Wahl von Stichproben, die auf dem Computer simuliert werden, abschätzt.

Mittlere-Feld-Approximation nach Variationsansatz Es gibt viele verschiedene Formulierungen der Mittlere-Feld-Approximation. Hier soll vom allgemeinen Prinzip des Variationsansatzes ausgegangen werden. Nach dem thermodynamischen Variationsprinzip ist diejenige Verteilung $P$ die (kanonische) Gleichgewichtsverteilung, die die freie Energie $\mathcal{F}$ minimiert:

$$
\mathcal{F}=\min _{P}\left\{\langle\mathcal{H}\rangle_{P}-T \mathcal{S}_{P}\right\}
$$

Dabei ist $\langle\mathcal{H}\rangle_{P}$ die innere Energie des Systems, $\langle\ldots\rangle_{P}$ der Erwartungswert in der Verteilung $P$ und $\mathcal{S}_{P}=-\langle\log P\rangle_{P}$ die Entropie dieser Verteilung. Die bekannte Lösung dieser Gleichung ist die Boltzmann-Verteilung $P=\exp [-\beta \mathcal{H}]$, siehe z. B. Kapitel 1 in Parisi (1998).

Bei einer Approximation nach Variationsansatz definiert man eine möglichst einfache Klasse von Verteilungen, z. B. parametrisierte, und minimiert dann innerhalb der Klasse, um eine approximative freie Energie nach Gleichung $2.18 \mathrm{zu}$ erhalten. Die MittlereFeld-Näherung besteht nun darin, dass man annimmt, die Verteilung hänge nur von den Mittelwerten der Besetzungszahlen ab:

$$
P=P\left(\left\langle n_{j}^{L}\right\rangle\right)=P(m)
$$

Mit dieser Wahl ist gleichzeitig entschieden, dass nur homogene Phasen untersucht werden können. Die Entropie schreibt sich in diesem Fall einfach als die Mischungsentropie idealer Gase. Im Fall einer einfachen Lipidmembran bedeutet die Näherung konkret, dass die freie Energie nur in Abhängigkeit eines Parameters $m$ minimiert werden muss. Diese Minimalbedingung ist gleichzeitig die Bestimmungsgleichung (auch SelbstkonsistenzBedingung genannt) für die mittlere Besetzungszahl, den Mittlere-Feld-Parameter:

$$
\partial_{m}\left[\langle\mathcal{H}\rangle_{P}-T \mathcal{S}_{P}\right]=0
$$

Die Optimierung muss im konkreten Fall numerisch geschehen. Dafür bieten sich einfache Algorithmen aus Press u.a. (1992) an. In Kapitel 3 wird die Mittlere-FeldApproximation angewandt und erweitert. Allgemein ist es so, dass der Typ der Ordnung in die Wahl der zu optimierenden Verteilung bereits eingeht. Wegen der Vernachlässigung der Fluktuationen durch die Wahl der Verteilung, einzig abhängig von der mittleren Besetzungszahl, bricht die Approximation an einem kritischen Punkt, der von Fluktuationen dominiert ist, zusammen. Weit weg vom kritischen Punkt ist sie sehr verlässlich.

Monte-Carlo-Simulation mit Metropolis-Algorithmus Die Technik der Monte-CarloSimulation ist relativ alt und geht bis in die Anfänge der Computer zurück (zur Einführung siehe z. B. Allen und Tildesley, 1986). Sie ist in vielen verschiedenen Büchern ausführlich 
beschrieben. Als eine Einführung in die Computersimulation sei auf Kinzel und Reents (1998) verwiesen, eine detailliertere Darstellung der Monte-Carlo-Methode findet sich in Binder und Heermann (1997). Im Allgemeinen geht es darum, eine Größe mit Hilfe einer in bestimmter Art und Weise zufälligen Wahl von Stichproben (engl. sampling) abzuschätzen, die sich ansonsten nur schwierig oder gar nicht berechnen lässt. Bezüglich der Erzeugung von (Pseudo-) Zufallszahlen auf einer deterministischen Maschine wie dem Computer sei auf die oben erwähnte Literatur verwiesen (z. B. Kapitel 5 in Kinzel und Reents, 1998).

Um die Erwartungswerte und Fluktuationen thermodynamischer Observablen im Gleichgewicht zu bestimmen, muss das Ensemble-Mittel in einer gewissen Verteilung ausgeführt werden. Wirklich alle möglichen Mikrozustände und die damit verbundenen Gewichte zu berechnen, dauert auch mit Hilfe des Computers viel zu lang. Man ist darauf angewiesen, die thermodynamischen Größen aufgrund der Kenntnis eines endlichen Satzes von Zuständen abzuschätzen. Die thermodynamische Verteilungsfunktion ist in der Regel stark zentriert auf einen engen Bereich um den Gleichgewichtswert (siehe Bücher über statistischen Physik wie z. B. Reif und Muschik, 1987). Eine rein zufällige Wahl der Stützstellen für die Schätzung wäre also sehr ineffektiv. Damit ist das Problem bereits umrissen: Finde eine Vorgehensweise, die erstens sicherstellt, dass nur die Mikrozustände ausgewählt werden, die ein großes Gewicht in der Verteilungsfunktion haben, d. h. gewichtete Stichproben (engl. importance sampling) entnommen werden, und zweitens gewährleistet, dass die Mikrozustände mit ihrer Häufigkeit aus dem Gleichgewichtsensemble des Systems gezogen werden. Die Monte-Carlo-Methode beruht daher auf folgenden Voraussetzungen:

1. Der (zugängliche) mikroskopische Zustandsraum ist bekannt. Im einfachsten Fall sind alle Freiheitsgrade definiert und das System ist ergodisch.

2. Die Hamiltonfunktion in Abhängigkeit der mikroskopischen Freiheitsgrade ist gegeben.

3. Ein Generator, der möglichst unkorrelierte Pseudo-Zufallszahlen liefert, liegt vor.

Grundsätzlich lautet die Strategie: Starte mit einem Mikrozustand hohen Gewichts und verändere diesen nur lokal (im Sinne des Zustandsraums) in solch einer Art und Weise, dass erstens das Gewicht groß bleibt und zweitens der Zustand des Systems in das Gleichgewicht relaxiert. Dabei ist die zentrale Eigenschaft einer solchen lokalen Vorschrift, dass sie die Detaillierte Balance erfüllt. Damit ist einfach der folgende Zusammenhang für die Übergangswahrscheinlichkeit $p(j \leftarrow i)$ von einem Zustand $i$, der mit der Wahrscheinlichkeit $p(i)$ angenommen wird, in einen Zustand $j$ gemeint. Dieser muss für jede mögliche Zustandsänderung des Algorithmus erfüllt sein:

$$
p(j \leftarrow i) p(i)=p(i \leftarrow j) p(j)
$$

Stellt der Algorithmus sicher, dass die bedingte Wahrscheinlichkeit, von einem bestimmten Zustand in einen anderen zu wechseln genauso hoch ist wie der umgekehrte Vorgang, so führt dieser sicher in das Gleichgewicht. Wie lang dieser Vorgang dauert, kann aus diesen Überlegungen aber nicht geschlossen werden. Zunächst bietet sich im kanonischen Ensemble an, die Übergangswahrscheinlichkeiten so zu wählen, dass ihr Verhältnis dem 
Boltzmann-Faktor (Boltzmann, 1909) bezüglich der Energiedifferenz der Zustände entspricht:

$$
\frac{p(j \leftarrow i)}{p(i \leftarrow j)}=\exp [-\beta(\mathcal{H}(j)-\mathcal{H}(i))]
$$

Damit hat man bezüglich der Übergangswahrscheinlichkeiten immer noch einige Freiheiten. Diese können z. B. dazu genutzt werden, um besonders effektive Schritte zu definieren oder physikalisch realistische, die einen Anknüpfungspunkt der Computer-Zeit an die reale ermöglichen. Die am weitesten verbreitete Strategie, die Stichproben auszuwählen, ist der Metropolis-Algorithmus, der auch in dieser Arbeit verwendet wird (Metropolis u. a., 1953). Er definiert die Übergangswahrscheinlichkeiten wie folgt:

$$
p(j \leftarrow i)=\min \{1, \exp [-\beta(\mathcal{H}(j)-\mathcal{H}(i))]\}
$$

Man erzeugt also aus einem geeigneten Anfangszustand immer wieder neue nach der gegebenen Wahrscheinlichkeit in Gleichung 2.23 und die Observablen ergeben sich als Mittelwerte über die durch die Stichproben gewonnen Einzelmessungen. Um den Einfluss der Systemränder zu minimieren, führt man üblicherweise periodische Randbedingungen ein. Das bedeutet, dass die Teilchen am oberen Rand des Systems mit denen am unteren Rand wechselwirken, genauso die Teilchen am rechten mit denen am linken Rand. Im Folgenden wird die Messung, also die Bestimmung der thermodynamischen Observablen, und deren Auswertung genauer beschrieben.

Die Werte für die Kopplungs-Parameter in der Hamiltonfunktion sind so zu verstehen, dass sie Energiebeiträge von Teilchenpaaren sind. Formalisiert wurde dies durch Wechselwirkungs-Umgebungen jeder Teilchenspezies mit den anderen. Dementsprechend ist die Summe über die Gitterplätze zu berechnen. In der Simulation werden genau diese Paare mit Hilfe von Wechselwirkungs-Umgebungen gezählt. Man erhält im ersten Schritt also Mittelwerte der Besetzungszahlen, die Nachbarschafts-Wahrscheinlichkeiten und daraus die innere Energie. Alle anderen Observablen lassen sich daraus bestimmen, wie etwa die spezifische Wärme:

$$
C=\frac{\left\langle\mathcal{H}^{2}\right\rangle-\langle\mathcal{H}\rangle^{2}}{N T^{2}}
$$

Zur Umsetzung der Monte-Carlo-Simulationen wurde im Rahmen dieser Arbeit das Programm lipflip entwickelt, welches im Anhang B näher beschrieben ist. Die Vorgehensweise zur Bestimmung der Mittelwerte soll in den nächsten Stichpunkten näher erläutert werden:

Mittelwerte und Erwartungswerte der Observablen Ein Messwert einer Observablen errechnet sich aus dem Mikrozustand des Systems durch Mittelung über alle Plätze des Gitters und über eine möglichst große Zahl von unabhängigen Instanzen des Zustands (Ensemble-Mittel). Die Anzahl von Instanzen, die zum Ensemble-Mittel herangezogen werden, wird im Programm lipflip als $N_{\text {ext }}$ bezeichnet. Die Zahl von Messwerten, aus der dann die Messkurve konstruiert wird, ist $N_{\text {exp }}$.

Relaxation in das Gleichgewicht Der Algorithmus braucht eine gewisse Anzahl von Durchläufen, um aus dem Anfangszustand in das Gleichgewicht zu gelangen. Die Dauer dieser Relaxation ist von vornherein nicht bekannt und muss im konkreten 
Fall gemessen werden. Dabei ist zu beachten, dass verschiedene Observablen unterschiedliche Relaxationszeiten besitzen können. Deshalb wird im Programm lipflip die Relaxation anhand eines ganzen Satzes von Observablen protokolliert. Erst wenn alle Werte einen bis auf Fluktuationen unveränderten Wert angenommen haben, kann man davon ausgehen, dass sich das System im Gleichgewicht befindet. In der Berechnung der Observablen wird dies durch eine minimale Zahl von Läufen $N_{\text {min }}$ berücksichtigt, deren Ergebnisse nicht mit in die Berechnung der Erwartungswerte eingehen.

Korrelationen Die Mittelwerte der Observablen sind von Durchlauf zu Durchlauf korreliert. Das liegt daran, dass nicht jeder Mikrozustand neu geraten wird, sondern aus dem letzten durch lokale Veränderungen gewonnen wird. Dieser Einfluss kann von Hand behoben werden, indem der Wert $N_{\text {int }}$ gesetzt wird, der angibt, wieviele Durchläufe unberücksichtigt bleiben, bis die nächste Einzelmessung aufgenommen wird. Der Ensemble-Mittelwert einer beliebigen Observablen $\mathcal{A}$ ergibt sich demnach folgendermaßen:

$$
\langle\mathcal{A}\rangle=\frac{1}{N_{\text {ext }}-N_{\text {min }}} \sum_{j=N_{\text {min }}}^{N_{\text {ext }}} \mathcal{A}\left(i=j \times N_{\text {int }}\right)
$$

Der Einfluss der Korrelationen kann sicherer automatisch durch Einteilung der Rohdaten korrigiert werden, wie im nächsten Punkt beschrieben wird.

Dateneinteilung Durch Einteilung der Einzelmesswerte in geeignete Blöcke und eine getrennte Mittelung innerhalb dieser Blöcke, können neue, nun unkorrelierte, „Einzelmessungen“ erzeugt werden. Der Fachbegriff dafür heißt Data Blocking. In einem ersten Schritt muss aus den Rohdaten deren Korrelationszeit (Zeit im Sinne von MC-Durchläufen) bestimmt werden. Die Blockgröße wird dann wesentlich größer als diese Korrelationszeit gewählt und stellt so sicher, dass die Blöcke voneinander unabhängig sind. Diese Datenanalyse ist aufwändig und verlangsamt das Programm, weshalb sie meist nur eine Kontrollfunktion einnimmt.

Geeignete Observablen Selbstverständlich werden die Mittelwerte der Zustände (Besetzungszahlen) als Ordnungsparameter gemessen. Darüber hinaus werden die Nachbarschaften, in der Simulation definiert über die Wechselwirkungs-Umgebungen, hinsichtlich der mittleren Zustände analysiert. Aus der Standardabweichung der Besetzungszahlen folgt die Suszeptibilität und entsprechend aus der der inneren Energie die spezifische Wärme. Spezielle Größen wie die Lage der Grenzlinie und deren Breite werden ebenfalls bestimmt. Eine komplette Auflistung findet sich in der Dokumentation des Projektes mit dem Namen BioMemMod, welche sich neben allen Quelltexten und Rohdaten auf der beigelegten CD-ROM befindet.

Schnappschüsse und Filme Zu einem bestimmten Zeitpunkt (nach einer gewissen Anzahl von MC-Durchläufen) wird der Zustand des Systems in geeigneter Weise abgespeichert und als Schnappschuss dargestellt. Verbindet man solche Bilder so erhält man einen Film, der die MC-Dynamik am bzw. bei der Relaxation in das Gleichgewicht zeigt. 


\subsection{Vergleich mit dem Experiment}

Die Temperatur wird in dieser Arbeit meistens in Energieeinheiten ausgedrückt. Das hat zur Folge, dass die Boltzmann-Konstante gleich eins ist. Als Energieeinheit wird $\mathrm{cal} / \mathrm{mol}$ (Kalorien pro Mol) gewählt, die Gas-Konstante, die zwischen Energie und Temperatur vermittelt, ist in diesem Fall etwa gleich zwei. Damit entspricht eine Temperatur von $300 \mathrm{~K}$ ungefähr $600 \mathrm{cal} / \mathrm{mol}$.

Die spezifische Wärme ist proportional zur Krümmung (2. Ableitung) der freien Energie bzw. zu den Fluktuationen der inneren Energie (siehe Gleichung 2.24) und deshalb gut geeignet, (Phasen-) Übergänge zu detektieren. Das experimentelle Signal einzelner Membranen ist aber viel zu schwach. Man ist auf Suspensionen von Lipidaggregaten mit Wasser angewiesen. Dabei ist zu beachten, dass die Wechselwirkungen der Vesikel untereinander nicht in jedem Fall vernachlässigbar klein sind. Wie in den Abschnitten 2.2 beschrieben wurde, zeigt der Hauptübergang, gemessen an Vesikel-Suspensionen, eine charakteristische endliche Breite. Mögliche Ursachen wurden in Abschnitt 2.5 angesprochen. Hier soll davon ausgegangen werden, dass es intrinsische Ursachen gibt, die einen kontinuierlichen Übergang zur Folge haben. Im Rahmen des untersuchten Modells wird dies nachvollzogen, indem eine geeignete Region des Phasendiagramms gewählt wird. Die Modell-Parameter für den Hauptübergang des reinen Lipidsystems werden in drei Schritten an die experimentellen Daten angepasst:

Übergangsenthalpie Der Hauptübergang ist mit einem Eintrag an Enthalpie in das System, der Übergangsenthalpie $H_{\mathrm{m}}$, verbunden. Genau diesen misst die spezifische Wärme, die selbst als Ableitung nach der Temperatur definiert ist. Nach der Hamiltonfunktion des Modells in Gleichung 2.15 ist diese einfach durch zwei Parameter gegeben:

$$
H_{\mathrm{m}}=\int \mathrm{d} T C(T)=-3 K_{L L}+H
$$

Übergangstemperatur Die Temperatur des Übergangs wird als Lage des Maximums der spezifischen Wärme bestimmt. Geht man davon aus, dass sich der kontinuierliche Übergang bei einer Temperatur $T_{\mathrm{m}}$ ereignet, für die der gleiche Zusammenhang gilt wie für die Linie von 1. Ordnung-Phasenübergängen, so erhält man:

$$
\left(H-T_{\mathrm{m}} S\right)=3 K_{L L} \Rightarrow S=\frac{H_{\mathrm{m}}}{T_{\mathrm{m}}}
$$

Übergangsbreite Damit lassen sich $H$ und $S$ aus den beiden obigen Gleichungen berechnen, einen Wert für die Kopplung $K_{L L}$ vorausgesetzt. Diesen muss man durch Vergleich der Kurvenformen anpassen, am besten an die Halbwertsbreite $\Delta T_{1 / 2}$ des Übergangsmaximums.

Aus den experimentellen Größen $H_{\mathrm{m}}, T_{\mathrm{m}}$ und $\Delta T_{1 / 2}$ folgen demnach die drei Parameter des Modells $H, S$ und $K_{L L}$.

In Abbildung 2.6 ist das Phasendiagramm und die Lage des Hauptübergangs als Ergebnis einer solchen Anpassung beispielhaft für eine Suspension aus unilamellaren Vesikeln gezeigt. Man findet, dass die Übergangstemperatur etwa $10 \%$ von der kritischen entfernt liegt. 


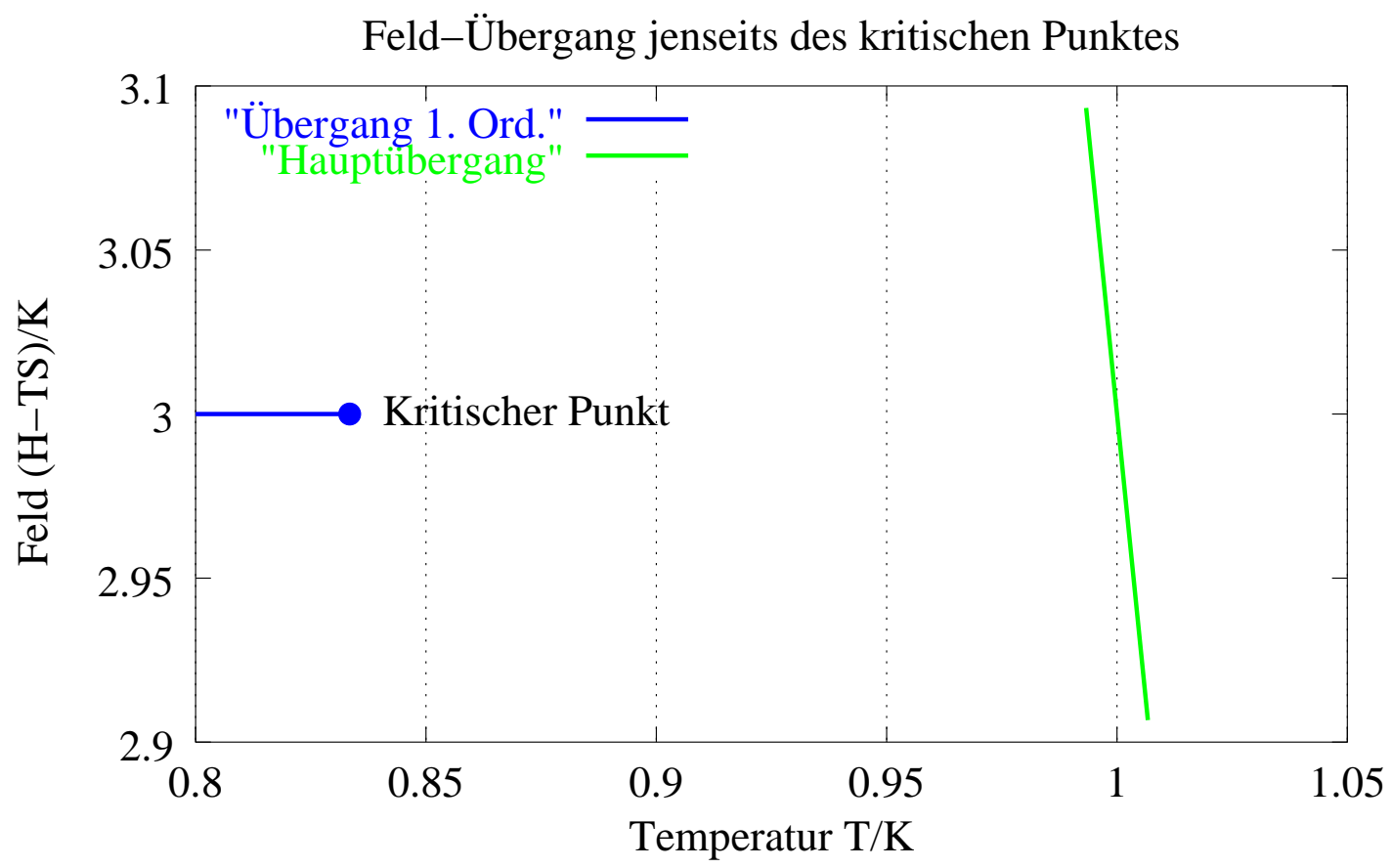

Abbildung 2.6: Phasendiagramm mit konkreten Parameterwerten, die typisch für unilamellare Vesikel sind. Die Linie, der bei Erhöhung der Temperatur gefolgt wird, ist eingezeichnet. Sie liegt jenseits des kritischen Punktes. Die Werte entsprechen den in Abb. 4.19 gezeigten Schnappschüssen. Vergleiche das prinzipielle Phasendiagramm in Abbildung 2.5.

Quantitativ unterscheiden sich die Übergänge von verschiedenen Lipidsorten und die von unilamellaren oder multilamellaren Vesikeln zum Teil deutlich. Deshalb soll sich in den meisten Fällen, in denen es um das prinzipielle Verhalten von Lipidmembranen geht, auf typische Parameter bezogen werden. Als typisch werden die folgenden Übergangsgrößen für unilamellare Lipidvesikel bezeichnet (eine Einführung in die Kalorimetrie von Modell- und Biomembranen findet sich in Bach, 1984):

$$
\begin{aligned}
H_{\mathrm{m}} & =6 \mathrm{kcal} / \mathrm{mol} \\
T_{\mathrm{m}} & =600 \mathrm{cal} / \mathrm{mol} \\
\Delta T_{1 / 2} & \approx 1 \mathrm{cal} / \mathrm{mol}
\end{aligned}
$$

Die Übergangstemperatur und -enthalpie sind beispielsweise annähernd linear von der Kettenlänge der Lipide abhängig (Lewis und McElhaney, 2000). Die Breite des Übergangs hängt von der Aggregatform und eventuell von der Präparation des Systems ab. Passt man nach der oben beschriebenen Prozedur die Parameter des Modells an die experimentellen Daten an, so erhält man als Ergebnis im Fall der Mittlere-Feld-Approximation mit Nachbarschaften die folgenden Werte:

$$
\begin{aligned}
H & =7425 \mathrm{cal} / \mathrm{mol} \\
S & =10 \\
K_{L L} & =-475 \mathrm{cal} / \mathrm{mol}
\end{aligned}
$$


Die Anpassungen von Monte-Carlo-Simulationen führen auf einen anderen Wert für die Kopplungs-Konstante und folglich auch für das enthalpische Feld:

$$
\begin{aligned}
H & =7875 \mathrm{cal} / \mathrm{mol} \\
S & =10 \\
K_{L L} & =-625 \mathrm{cal} / \mathrm{mol}
\end{aligned}
$$

Die Form der Übergangskurven in Experiment, Approximation und Simulation unterscheidet sich im Wesentlichen dadurch, dass der Untergrund, also das Gewicht der Schultern des Maximums, in der Approximation besonders hoch ist. Als Folge dessen ist das Maximum selbst nicht so hoch. Bezüglich des Experiments muss angemerkt werden, dass die Null-Linie einfach durch Abschneiden der Kurven außerhalb der Maxima definiert wird, eine breite Schulter also bereits durch die Messmethode unterdrückt würde. 


\title{
3 Lipidmembranen mit kleinen Komponenten
}

\author{
Inhaltsangabe
}

3.1 Modell mit peripheren Komponenten . . . . . . . . . 36

3.2 Modell mit integralen Komponenten . . . . . . . . . . . 37

3.3 Mittlere-Feld-Approximation mit Nachbarschaften . . . . . 40

3.4 Strukturelle Information und Clusterbildung . . . . . . . . 46

3.5 Integrale und periphere Komponenten im Vergleich . . . . . 50

3.5.1 Zufallsfeld der Adsorbate erzeugt homogenen Beitrag . . . . . . . 51

3.5.2 Bekannte Mittlere-Feld-Lösung des Dreizustands-Modells . . . . 54

3.6 Beispiel: Multilamellare Vesikel aus DMPC und Cholesterin . 56

Das bisher beschriebene Modell für die Lipidmembran, ein zweidimensionales dicht gepacktes Gittergas mit zwei möglichen Zuständen auf jedem Platz, soll nun um zusätzliche Membran-Komponenten erweitert werden. Neue Komponenten können dabei andere Lipide, Sterole wie Cholesterin oder Proteine bzw. Peptide sein. Typisch für Biomembranen sind die großen Unterschiede in der Form und Stabilität der Bestandteile.

Funktionelle Komplexe bestehen meist aus Proteinen. Sie sind wesentlich größer als Lipide und wegen ihrer Tertiärstruktur auch starrer. Konformationsänderungen sind meist nicht thermisch, sondern chemisch angeregt. Die Bestandteile von Proteinen - kürzere Aminosäureketten, die meist stabile Sekundärstrukturen wie $\alpha$-Helizes bilden - nennt man Peptide. Darüber hinaus werden globale thermische, strukturelle und mechanische Eigenschaften der Biomembran auch von kleinen Komponenten wie Cholesterin (siehe Abbildung 3.1) bestimmt. Wegen ihrer starren Kohlenwasserstoff-Ringe besitzen Sterole wenige Konformationsfreiheitsgrade. Deshalb sollen sie auch nicht, wie in manch chemischer Literatur üblich, zur Gruppe der Lipide gezählt werden.

Zunächst wird sich in diesem Kapitel auf kleine Komponenten, die in etwa die Größe von Lipiden besitzen, d. h. im Modell einen Gitterplatz einnehmen, beschränkt. Als eine solche Komponente kann man sich Cholesterin (ist etwas kleiner als ein Lipid) oder kleine Peptide (sind etwas größer als Lipide) vorstellen. Auf größere Komponenten wird im folgenden Kapitel 4 eingegangen.

Das Modell mit kleinen Komponenten wird sowohl für Einlagerungen als auch Adsorbate so formuliert, dass sich bekannte Modelle der statistischen Physik ergeben. So kann erstens der Anschluss an den Stand der theoretischen Modellierung sichergestellt werden und zweitens der Wert dieser effektiven molekularen Modelle für die Interpretation verschiedener Eigenschaften von Biomembranen und konkreter Experimente an Modellmembranen geprüft werden. Der Schwerpunkt liegt in diesem Kapitel auf dem Vergleich 


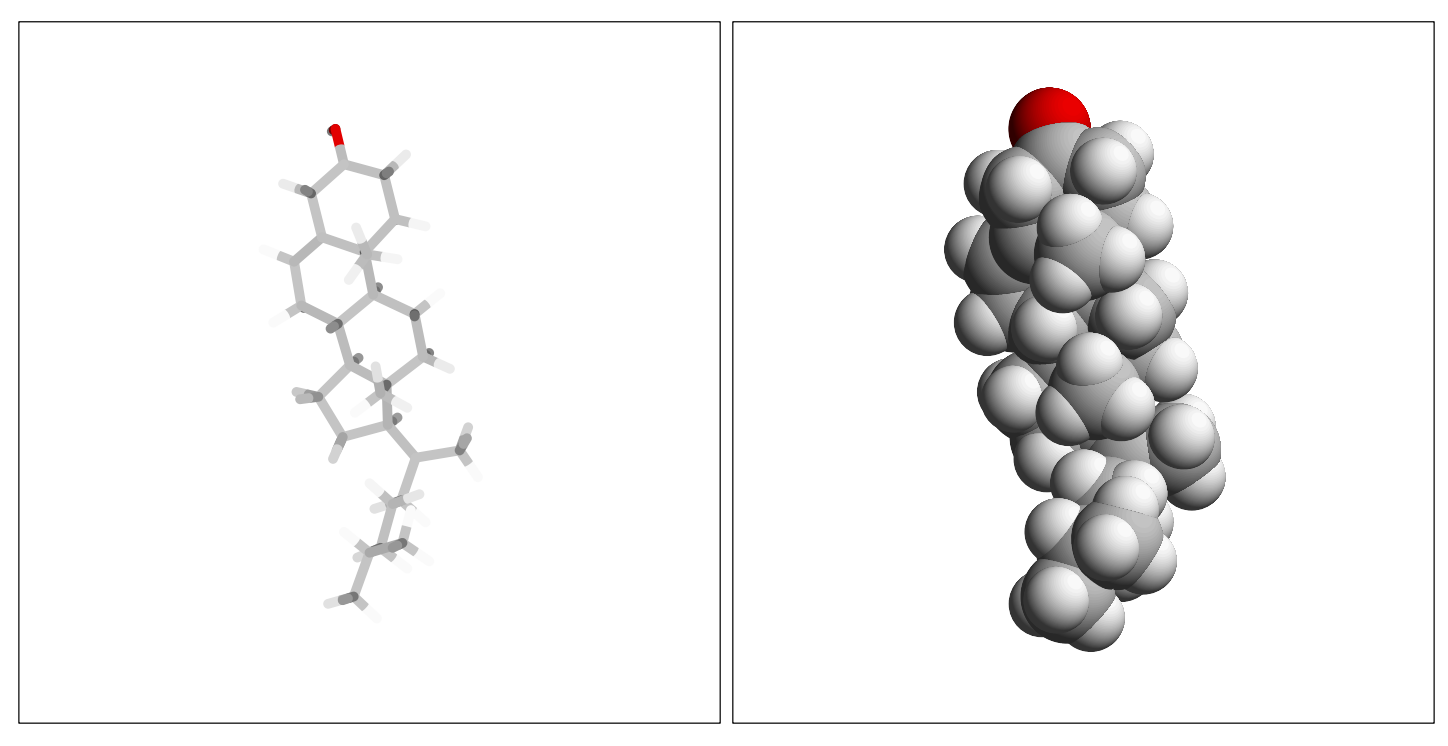

$\begin{array}{ll}\text { (a) Bindungen als Stäbchen dargestellt } & \text { (b) Atome als Kugeln dargestellt }\end{array}$

Abbildung 3.1: Cholesterin gehört zur Gruppe der Sterole, welche typische starre Kohlenwasserstoff-Ringe, eine sehr kleine polare Kopfgruppe und eine kurze Kohlenstoffkette besitzen.

eingelagerter und adsorbierter Komponenten sowie der Frage nach der Güte analytischer Approximationen im Vergleich zu Monte-Carlo-Simulationen.

\subsection{Modell mit peripheren Komponenten}

Im Fall peripherer Komponenten führt man neben der vorhandenen Lipidschicht eine zweite Schicht mit dem gleichen Gitter und der Besetzungszahl $n^{P}$ ein. Sie gibt an, ob ein Gitterplatz von einem Adsorbat bedeckt ist oder nicht. Die Teilchen auf dem zweiten Gitter wechselwirken lokal mit denen auf dem ersten, das heißt es gibt einen Beitrag zur Energie nur dort, wo ein Adsorbat auf einem Lipid liegt. Die Wechselwirkungs-Energie unterscheidet sich je nach innerem Zustand des Lipids (gestreckt oder gefaltet). Die resultierende Hamiltonfunktion schreibt sich demnach wie folgt:

$$
\begin{aligned}
n^{P}= & \left\{\begin{aligned}
1 & \text { wenn Platz bedeckt } \\
0 & \text { sonst }
\end{aligned}\right. \\
\mathcal{H}_{\text {peripher }}= & K_{L L} \sum_{\langle i, j\rangle} n_{i}^{L} n_{j}^{L}+(H-T S) \sum_{i} n_{i}^{L} \\
& +K_{L P} \sum_{i} n_{i}^{L} n_{i}^{P}\left(+K_{P P} \sum_{\langle i, j\rangle} n_{i}^{P} n_{j}^{P}\right)
\end{aligned}
$$

Die direkte Protein-Protein-Wechselwirkung, also der letzte eingeklammerte Term in Gleichung 3.1, wird im Kontext kleiner Adsorbate vernachlässigt. Die Adsorbate wirken unter dieser Annahme auf die Lipide wie ein zufälliges lokales Feld und besitzen keinen 
eigenen Phasenübergang. Die Verteilung des induzierten Feldes ist durch die Protein-LipidWechselwirkung rückgekoppelt an die Lipidzustände und insbesondere nicht eingefroren sondern thermisch.

In Abbildung 3.2(a) ist die Membran mit kleinen Komponenten bildhaft gezeigt. Die Bewegung in der Schicht der Adsorbate ist unabhängig von der Lipidschicht. Die in dieser Arbeit gewählte Form der Darstellung des Systems ist in Abbildung 3.3 vorgestellt. Man erkennt das Dreiecksgitter der Lipidschicht, das dicht gepackt mit Lipiden im gestreckten oder gefalteten Zustand (unterschiedliche Farben) ist und das Gitter der Adsorbate, das üblicherweise in geringer bis mittlerer Dichte mit Proteinen besetzt ist.

\subsection{Modell mit integralen Komponenten}

Für die zusätzliche Membran-Komponente, d. h. den dritten Zustand, den ein Gitterplatz annehmen kann, wird eine neue Besetzungszahl $n^{I}$ (für integrale Komponente) eingeführt, anstatt der Besetzungszahl $n^{L}$ einen neuen möglichen Wert zu geben. Das erhöht die Klarheit vor allem deswegen, weil die neuen Zustände unter Umständen an spezielle Nebenbedingungen geknüpft sind, die nicht für die Lipide gelten. So wird z. B. häufig eine konstante Konzentration von Einlagerungen angenommen und eine Umwandlung ausgeschlossen. Der Wert von $n^{I}$ ist eins, wenn sich ein eingelagertes Teilchen am Gitterplatz befindet und sonst null. Die Lipidbesetzungszahl $n^{L}$ muss im ersten Fall null sein. Die möglichen Zustände an einem Gitterplatz sind in der Übersicht:

1. Lipid im gestreckten Zustand: $n^{L}=0, n^{I}=0$

2. Lipid im gefalteten Zustand: $n^{L}=1, n^{I}=0$

3. Eingelagerte Komponente: $n^{L}=0, n^{I}=1$

Die resultierende Hamiltonfunktion schreibt sich wie folgt:

$$
\begin{aligned}
\mathcal{H}_{\text {integral }}= & K_{L L} \sum_{\langle i, j\rangle} n_{i}^{L} n_{j}^{L}+(H-T S) \sum_{i} n_{i}^{L} \\
& +K_{L I} \sum_{\langle i, j\rangle} n_{i}^{L} n_{j}^{I}+K_{I I} \sum_{\langle i, j\rangle} n_{i}^{I} n_{j}^{I}
\end{aligned}
$$

Die Wechselwirkung der Lipide mit der zusätzlichen Komponente kann ganz unterschiedliche Ursachen haben, z. B. die sterische Hinderung der Ketten oder/und Kopfgruppen, elektrostatische Kräfte durch Ladungen oder Dipole und die hydrophobe Wechselwirkung wegen unterschiedlicher Längen der Moleküle. Deshalb ist die Nächste-Nachbar-Wechselwirkung vom Betrag und Vorzeichen ad hoc unbestimmt und in manchen Fällen eventuell nicht ausreichend.

Die wichtigsten Unterschiede von Gleichung 3.2 zu den Adsorbaten aus Gleichung 3.1 sind die ausschließlich lokale Wechselwirkung der Adsorbate mit den Lipiden und die vernachlässigte Wechselwirkung der Adsorbate untereinander.

Für die Interpretation der Wechselwirkungs-Energien ist zu beachten, dass in der hier vorgestellten Formulierung bereits die Nebenbedingung eines komplett mit Teilchen besetzten Gitters eingeflossen ist. Die Besetzungszahl $n^{s}$ für den gestreckten Zustand ist 


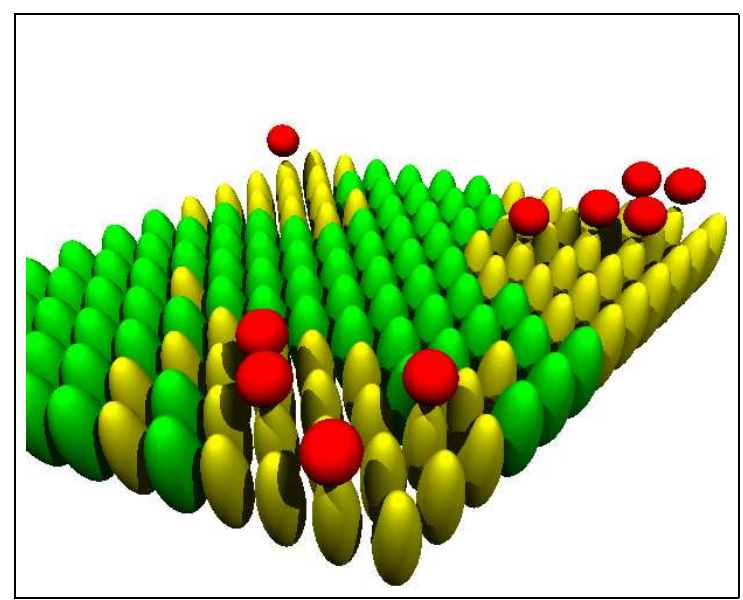

(a) Lipidmembran mit kleinen Adsorbaten

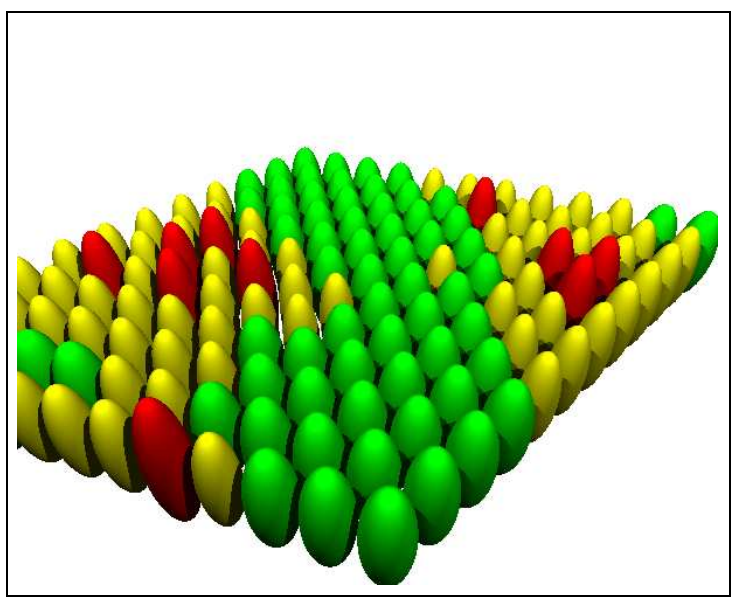

(b) Lipidmembran mit kleinen Einlagerungen

Abbildung 3.2: Anschauliche Darstellung des Modells einer Lipidmembran mit kleinen Komponenten durch eine dreidimensionale Seitenansicht auf das komplette System. Die Lipide sind durch gelbe (helle) und grüne (dunkle) Ellipsoide dargestellt. Die Adsorbate bzw. Einlagerungen sind rot (etwas dunkler).

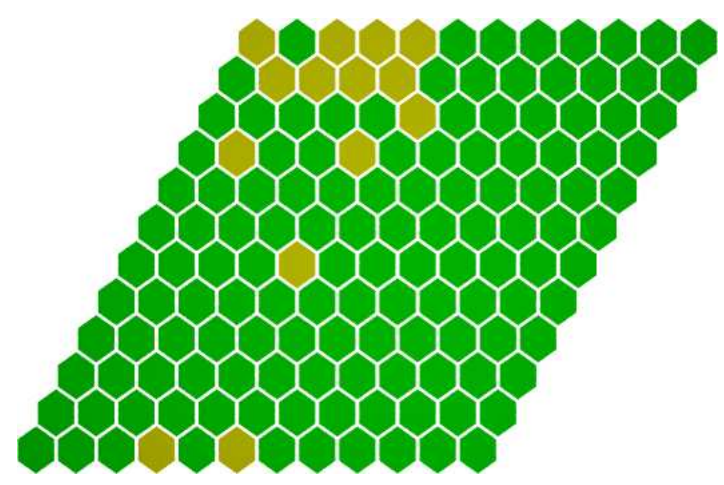

(a) Zweidimensionale Aufsicht auf Lipide

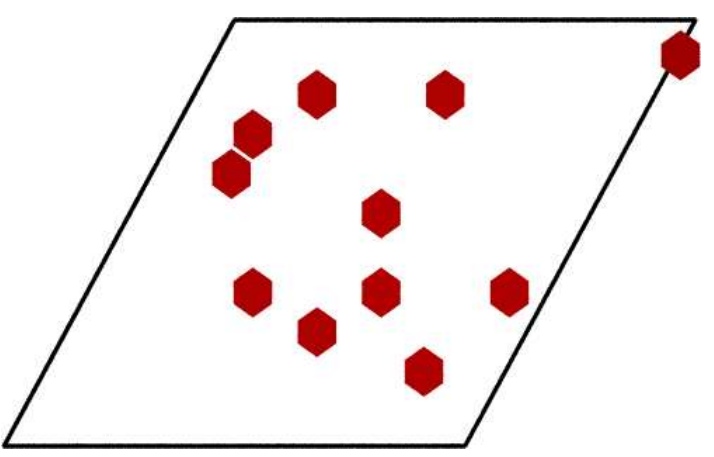

(b) Zweidimensionale Aufsicht auf Adsorbate

Abbildung 3.3: Schnappschuss einer Lipidmembran mit kleinen Adsorbaten. Die gestreckten Lipide sind gelbe (helle), die gefalteten grüne (dunkle) Hexagone. Die Form der Teilchen korrespondiert mit dem Dreiecksgitter, auf dem sie liegen, denn sie haben sechs Nachbarn. Die Proteine sind rote (sehr dunkle) Hexagone im rechten Bild. 
mit Hilfe der folgenden Nebenbedingung durch die anderen Besetzungszahlen ausgedrückt worden:

$$
\begin{array}{rll}
n_{j}^{f}+n_{j}^{s}+n_{j}^{I}=1 & \forall j & \text { (Einlagerungen) } \\
n_{j}^{f}+n_{j}^{s}=1 & \forall j & \text { (Adsorbate) }
\end{array}
$$

Statt des gefalteten Zustands $n^{f}$ ist vereinfachend nur vom Lipidzustand $n^{L} \equiv n^{f}$ die Rede. Möchte man die Einträge der Kopplungen mikroskopisch motivieren, so ist Gleichung 3.3 von Bedeutung. Man sollte von der ursprünglichen Formulierung mit drei verschiedenen Besetzungszahlen ausgehen und die eine explizit eliminieren. Dies führt auf die im Folgenden zusammengefasste Abbildung von Kopplungen und Feldern im Fall eingelagerter bzw. adsorbierter Komponenten. Die Felder der Komponenten sind im Fall variabler Teilchenzahl als chemische Potentiale zu sehen.

\section{Einlagerungen}

$$
\begin{aligned}
& \left(\begin{array}{ll}
K_{I I} & K_{I L} \\
& K_{L L}
\end{array}\right)=\left(\begin{array}{l|c}
K_{i i}+K_{s s}-2 K_{i s} & K_{i f}+K_{s s}-K_{s f}-K_{i s} \\
& K_{f f}+K_{s s}-2 K_{s f}
\end{array}\right) \\
& \left(\begin{array}{c}
H_{I} \\
H_{L}
\end{array}\right)=\left(\begin{array}{c}
H_{i}-H_{s}-6 K_{s s}+6 K_{i s} \\
H_{f}-H_{s}-6 K_{s s}+6 K_{s f}
\end{array}\right)
\end{aligned}
$$

\section{Adsorbate}

$$
\begin{aligned}
& \left(\begin{array}{cc}
K_{P P} & K_{P L} \\
& K_{L L}
\end{array}\right)=\left(\begin{array}{l|c}
K_{p p} & K_{p f}-K_{p s} \\
& K_{f f}+K_{s s}-2 K_{s f}
\end{array}\right) \\
& \left(\begin{array}{c}
H_{P} \\
H_{L}
\end{array}\right)=\left(\begin{array}{c}
H_{p}+K_{p s} \\
H_{f}-H_{s}-6 K_{s s}+6 K_{s f}
\end{array}\right)
\end{aligned}
$$

Die Wahl der ursprünglichen Kopplungs-Konstanten auf der rechten Seite der Gleichungen werden von mikroskopischen Überlegungen geleitet wie der Frage, ob die hydrophoben Längen der Teilchen zusammenpassen (engl. hydrophobic matching). Falls diese nicht passen, wird jeder Kontakt von nicht gleich langen hydrophoben Bereichen aufgrund des angenommenen Kontaktes mit dem umgebenen Wasser energetisch bestraft. Aus diesen Überlegungen wird aber auch deutlich, wie vorsichtig man bei der Interpretation der Kopplungen sein muss, denn erstens wird das Lösungsmittel gar nicht explizit im Modell berücksichtigt und zweitens ist wohlbekannt, dass es sich beim hydrophoben Effekt nicht um eine in erster Linie energetische Frage handelt, sondern um eine entropische. Aus Überlegungen zur Molekülstruktur können also höchstens Hinweise zu den Kopplungen gewonnen, aber keine quantitativen Schlussfolgerungen gezogen werden. Dafür wäre eine systematische Vergröberung nötig, ausgehend von den Molekülen inklusive des Lösungsmittels.

Lipidmembran mit variabler Dichte Die integrale Komponente kann auch als "Loch" aufgefasst werden. Damit ist die Teilchendichte der Lipide in der Membran variabel und man kehrt in gewisser Hinsicht wieder zum bekannten Gittergas-Modell für Flüssigkeiten zurück, wobei nun aber die Teilchen zwei unterschiedliche Zustände annehmen können, die darüber hinaus energetisch mit der Teilchendichte gekoppelt sind. Der Flächenbedarf 
der Membran pro Teilchen setzt sich nun aus der Dichte $1-\left\langle n^{I}\right\rangle$ und dem inneren Zustand $\left\langle n^{L}\right\rangle$ zusammen:

$$
A_{\text {Membran }}=A_{L}\left(1-\left\langle n^{I}\right\rangle\right)+A\left\langle n^{L}\right\rangle
$$

Der laterale Druck $\pi$, die konjugierte Größe zum Flächenbedarf, besteht dementsprechend aus zwei Komponenten: einmal wirkt er auf die Zustandsvariable $n^{L}$ (das ist ein Beitrag zum enthalpischen Feld $H$ ) und zum anderen wie ein Feld (oder chemisches Potential) auf die Löcher. Ausgehend von der Hamiltonfunktion in Gleichung 3.2 kann man die Energie folgendermaßen schreiben:

$$
\begin{gathered}
\mathcal{H}_{\text {Langmuir }}=K_{L L} \sum_{\langle i, j\rangle} n_{i}^{L} n_{j}^{L}+(E-\pi A-T S) \sum_{i} n_{i}^{L}+\left(\pi-\pi_{c}\right) A_{L} \sum_{i} n_{i}^{I} \\
+K_{L I} \sum_{\langle i, j\rangle} n_{i}^{L} n_{j}^{I}+K_{I I} \sum_{\langle i, j\rangle} n_{i}^{I} n_{j}^{I} \\
\frac{\partial\langle\mathcal{H}\rangle}{\partial A}=-\pi
\end{gathered}
$$

Man beachte, dass es in der Gittergas-Formulierung zwei verschiedene Sichtweisen auf die Felder geben kann. Zum einen betrachtet man sie als Beiträge von Druck und Temperatur zu einem effektiven Feld, welches den Phasenübergang treibt. Äquivalent dazu ist die Beschreibung im großkanonischen Ensemble, in dem die chemischen Potentiale den Phasenübergang treiben. In beiden Bildern bestimmen die Werte der Kopplungs-Konstanten, von welchem Typ der Übergang ist.

\subsection{Mittlere-Feld-Approximation mit Nachbarschaften}

Im Fall der kleinen Komponenten, insbesondere der kleinen Einlagerungen, erweist sich die Mittlere-Feld-Approximation als sehr nützlich, weil sie erstens leicht handhabbar und zweitens zur Bestimmung homogener thermodynamischer und struktureller Größen ausreichend ist. Die MF-Approximation zeigt bereits ein komplexes Phasenverhalten und kann in Bereichen, die nicht in der Nähe eines kritischen Punktes liegen, auch gute quantitative Ergebnisse erzielen. Da in dieser Arbeit besonders die räumlichen Strukturen interessieren, wird die einfache Approximation, in der lediglich die Information über den mittleren Gitterplatz-Zustand steckt, um die Nachbarschafts-Verhältnisse erweitert. Sofern man nur Wechselwirkungen über Nächste-Nachbar-Kontakte annimmt, wird der Ausdruck für die innere Energie exakt; die Entropie wird weiterhin abgeschätzt.

In der Literatur wird dies oft als Cluster-Variationsverfahren oder ähnlich bezeichnet. Einen guten Einstieg in die Thematik bietet das Buch von Lavis und Bell (1999). Eine systematische Entwicklung in der Größe der Cluster findet sich bei Suzuki und Katori (1986); Suzuki (1986). Die Herangehensweise von Kikuchi (1951) entspricht am ehesten der im Folgenden erläuterten Entwicklung der Approximation. In einer auf Nachbarschaften begrenzten Formulierung ist dieses Verfahren auch als Bethe-Peierls-Methode bekannt (Bethe, 1935; Peierls, 1935; Weiss, 1948).

Mit der in dieser Arbeit verwendeten Bezeichnung Mittlere-Feld-Approximation mit Nachbarschaften (kurz MF+N) soll ausgedrückt werden, dass es sich dabei um eine direkte Erweiterung der bekannten MF-Approximation handelt. Eine Einführung in die MittlereFeld-Approximation als Variationsansatz findet sich in Abschnitt 2.6 der vorliegenden 
Arbeit. Die folgende Darstellung bezieht sich ganz allgemein auf ein Gittergas mit einem Satz von Besetzungszahlen $n_{i}^{\alpha}$, wobei $\alpha$ die chemische Spezies bzw. den inneren Zustand charakterisiert und $i$ den Gitterplatz bezeichnet. Die spitzen Klammern um Indizes bedeuten, dass über nächste Nachbarn summiert wird. Die Hamiltonfunktion lautet dann wie folgt:

$$
\mathcal{H}_{\text {Gittergas }}=\sum_{\alpha, \beta} \sum_{\langle i, j\rangle} K_{\alpha \beta} n_{i}^{\alpha} n_{j}^{\beta}+\sum_{\alpha} \sum_{i}\left(H_{\alpha}-T S_{\alpha}\right) n_{i}^{\alpha}
$$

Für die Mittlere-Feld-Näherung nimmt man zunächst eine homogene Verteilung (Index MF) an. Diese soll mit einem Satz $p$ von Variablen parametrisiert werden. Die Variablen beinhalten in der erweiterten Approximation mit Nächste-Nachbar-Kontakten weiterhin die mittleren Besetzungszahlen (auch MF-Parameter genannt) der als äquivalent angenommenen Gitterplätze:

$$
p^{\alpha}:=\left\langle n_{i}^{\alpha}\right\rangle_{\mathrm{MF}}
$$

Darüber hinaus sollen die gemittelten Produkte von benachbarten Besetzungszahlen, die Nachbarschafts-Wahrscheinlichkeiten, in die Verteilung eingehen:

$$
p^{\alpha \beta}:=\left\langle n_{i}^{\alpha} n_{j}^{\beta}\right\rangle_{\mathrm{MF}}
$$

Die Mittelwerte hängen nicht mehr vom Gitterplatz $i$ ab. Die Parameter der Verteilung müssen gewissen Nebenbedingungen genügen: Ein Platz muss mit einem Teilchen besetzt sein, die Nachbarschafts-Wahrscheinlichkeiten (auch Cluster-Parameter genannt) müssen mit den mittleren Besetzungszahlen konsistent sein und die Wahrscheinlichkeit ist symmetrisch bezüglich der Besetzung der beiden Gitterplätze:

$$
\begin{aligned}
\sum_{\alpha} p^{\alpha} & =1 \\
\sum_{\beta} p^{\alpha \beta} & =p^{\alpha} \quad \forall \alpha \\
p^{\alpha \beta} & =p^{\beta \alpha}
\end{aligned}
$$

Die Nebenbedingungen reduzieren die Anzahl der Parameter auf einen geringeren Satz unabhängiger. Die redundanten Parameter folgen direkt aus den obigen Bedingungen. Im Fall integraler Komponenten (Gleichung 3.2) bleiben von drei $p^{\alpha}$ und neun $p^{\alpha \beta}$ mit sieben Nebenbedingungen (Gl. 3.14, dreimal Gl. 3.15 und dreimal Gl. 3.16) fünf unabhängige (zwei $p^{\alpha}$ und drei $p^{\alpha \beta}$ ) Parameter übrig - vier bei fester Konzentration der Einlagerungen. Die Hamiltonfunktion der Lipidmembran mit Adsorbaten (Gleichung 3.1) betrachte man als eine Funktion von vier Besetzungszahlen (für die Zustände gestreckt unbedeckt, gestreckt bedeckt, gefaltet unbedeckt und gefaltet bedeckt). Damit kommt man auf neun unabhängige Parameter im Fall peripherer Komponenten - acht bei festem Bedeckungsgrad.

Für den Fall fester Teilchenzahl von Einlagerungen bzw. Adsorbaten ist der Zusammenhang zwischen den Parametern der Approximation in den Tabellen 3.1 und 3.2 als Gleichungssystem dargestellt. Die rechte äußere Spalte mit den Konzentrationen ist die rechte Seite des Gleichungssystems. Alle anderen Spalten stehen für Summanden, die die linke Seite der Gleichungen ergeben. Die erste Zeile in Tabelle 3.1 liest sich beispielsweise als $p_{1}+p_{2}=1-\phi$. Parameter in Fettdruck geben an, dass diese als unabhängig für die 


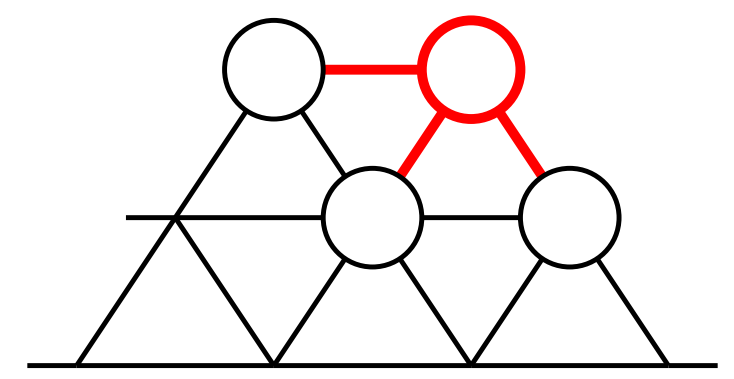

Abbildung 3.4: Skizze zur Erläuterung der Mittlere-Feld-Approximation mit Nachbarschaften. Zur Ermittelung der Entropie wird das Gitter sukzessive aufgebaut. Der rote Gitterplatz soll mit einem Zustand neu besetzt werden. Man fragt dabei nach den Wahrscheinlichkeiten für die Besetzung der Plätze allein und nach den Wahrscheinlichkeiten der Paare und vernachlässigt alle weiteren Korrelationen.

konkreten Rechnungen gewählt werden. Alle anderen lassen sich mit Hilfe des Gleichungssystems aus diesen ableiten.

Die weitere Herleitung der freien Energie ist mit dem vollen Satz von Parametern formuliert, da sich das Ergebnis so symmetrischer darstellt. Die obigen Bestimmungsgleichungen für die abhängigen Parameter bleiben als Nebenbedingungen der Theorie erhalten.

Die innere Energie wird in dieser Approximation nur durch die Wahl der Verteilung approximiert, der Ausdruck ist ansonsten exakt im Sinne der Nächste-Nachbar-Wechselwirkung:

$$
\langle\mathcal{H}\rangle_{\mathrm{MF}}=\sum_{\alpha, \beta} K_{\alpha \beta} p^{\alpha \beta}+\sum_{\alpha}\left(H_{\alpha}-T S_{\alpha}\right) p^{\alpha}
$$

Nun muss die Entropie in Abhängigkeit der Parameter $p^{\alpha \beta}$ und $p^{\alpha}$ der Verteilung bestimmt werden. Man berechnet die Anzahl der Möglichkeiten, Instanzen des Gitters aus der Menge der möglichen (Mikro-) Zustände zu bilden. Dazu stelle man sich das Gitter schrittweise aufgebaut vor und betrachte das Hinzufügen eines Gitterplatzes mit seinem Zustand, wie in Abbildung 3.4 angedeutet.

Ein (neues) Paar von Gitterplätzen besitzt die möglichen Konfigurationen $\alpha, \beta$. Die Anzahl $W$ von Möglichkeiten, diese Zustände über ein Ensemble von $L$ Instanzen zu verteilen, beträgt:

$$
W=W_{\text {Paar }}=\frac{L !}{\Pi_{\alpha, \beta}\left(p^{\alpha \beta} L\right) !}
$$

Wären die Gitterplätze unabhängig voneinander, so ergäbe sich für die Anzahl $W$ von Möglichkeiten der folgende Ausdruck:

$$
W=W_{\text {Platz }}^{2}=\left(\frac{L !}{\Pi_{\alpha}\left(p^{\alpha} L\right) !}\right)^{2}
$$

Der neu einzuführende Korrekturfaktor $G$, der im Weiteren als Hilfsgröße verwendet wird, ist definiert als die Korrelation der Plätze, die von Gleichung 3.18 nach 3.19 vernachlässigt wurde:

$$
W_{\text {Paar }}=W_{\text {Platz }}^{2} G_{\text {Paar }}
$$




\begin{tabular}{|ccc|ccc|ccc||c|}
\hline$s$ & $f$ & $i$ & & & & & & & \\
\hline$p_{1}$ & $\mathbf{p}_{\mathbf{2}}$ & $p_{3}$ & $p_{11}$ & $p_{12}$ & $\mathbf{p}_{\mathbf{2 2}}$ & $p_{13}$ & $\mathbf{p}_{\mathbf{2 3}}$ & $\mathbf{p}_{\mathbf{3 3}}$ & \\
\hline \hline 1 & 1 & 0 & 0 & 0 & 0 & 0 & 0 & 0 & $1-\phi$ \\
0 & 0 & 1 & 0 & 0 & 0 & 0 & 0 & 0 & $\phi$ \\
\hline-1 & 0 & 0 & 1 & 1 & 0 & 1 & 0 & 0 & 0 \\
0 & -1 & 0 & 0 & 1 & 1 & 0 & 1 & 0 & 0 \\
0 & 0 & -1 & 0 & 0 & 0 & 1 & 1 & 1 & 0 \\
\hline
\end{tabular}

Tabelle 3.1: MF- und Cluster-Parameter bei fester Zahl kleiner Einlagerungen: Nebenbedingungen aus der dichten Packung des Gitters, der festen Konzentration $\phi$ an Einlagerungen und der Konsistenz der Nachbarschafts-Wahrscheinlichkeiten. Die Buchstaben $s, f$ und $i$ geben den Bezug zu den Besetzungszahlen des gestreckten und des gefalteten Zustands bzw. zur integralen Komponente an. Fette Buchstaben zeigen an, welche Parameter als unabhängig gewählt werden. Die Tabelle liest sich als Gleichungssystem, die erste Zeile z. B. als $p_{1}+p_{2}=1-\phi$.

\begin{tabular}{|cc|cc|cccc|ccc|cccc||c|}
\hline$s$ & $f$ & $\bar{s}$ & $\bar{f}$ & & & & & & & & & & \\
\hline$p_{1}$ & $\mathbf{p}_{\mathbf{2}}$ & $p_{3}$ & $\mathbf{p}_{\mathbf{4}}$ & $p_{11}$ & $p_{12}$ & $\mathbf{p}_{\mathbf{2 2}}$ & $p_{33}$ & $p_{34}$ & $\mathbf{p}_{\mathbf{4 4}}$ & $\mathbf{p}_{\mathbf{1 3}}$ & $\mathbf{p}_{\mathbf{1 4}}$ & $\mathbf{p}_{\mathbf{2 3}}$ & $\mathbf{p}_{\mathbf{2 4}}$ & \\
\hline \hline 1 & 1 & 0 & 0 & 0 & 0 & 0 & 0 & 0 & 0 & 0 & 0 & 0 & 0 & $1-\theta$ \\
0 & 0 & 1 & 1 & 0 & 0 & 0 & 0 & 0 & 0 & 0 & 0 & 0 & 0 & $\theta$ \\
\hline-1 & 0 & 0 & 0 & 1 & 1 & 0 & 0 & 0 & 0 & 1 & 1 & 0 & 0 & 0 \\
0 & -1 & 0 & 0 & 0 & 1 & 1 & 0 & 0 & 0 & 0 & 0 & 1 & 1 & 0 \\
0 & 0 & -1 & 0 & 0 & 0 & 0 & 1 & 1 & 0 & 1 & 0 & 1 & 0 & 0 \\
0 & 0 & 0 & -1 & 0 & 0 & 0 & 0 & 1 & 1 & 0 & 1 & 0 & 1 & 0 \\
\hline
\end{tabular}

Tabelle 3.2: MF- und Cluster-Parameter bei fester Zahl kleiner Adsorbate: Nebenbedingungen aus der dichten Packung des Gitters, des festen Grads der Bedeckung $\theta$ und der Konsistenz der Nachbarschafts-Wahrscheinlichkeiten. Die Buchstaben $s$ und $f$ bezeichnen die Zustände von unbedeckten Lipiden, $\bar{s}$ und $\bar{f}$ die Zustände von bedeckten. Fette Buchstaben zeigen an, welche Parameter als unabhängig gewählt werden. Die Tabelle liest sich als Gleichungssystem, die erste Zeile z. B. als $p_{1}+p_{2}=1-\theta$. 
Man betrachte nun ein großes System aus $N$ Plätzen mit jeweils $\nu$ Nachbarn (im hier immer diskutierten Fall des Dreiecksgitters $\nu=6$ ) und vernachlässige alle Korrelationen von Clustern, die größer als ein Paar sind:

$$
W_{N}=W_{\text {Platz }}^{N} G_{\text {Paar }}^{\nu N / 2}
$$

In einem exakten Ausdruck für $W_{N}$ stünden Korrekturfaktoren bis zur Ordnung $N$. Aus der Formulierung der letzten Gleichungen ist ersichtlich, dass die gleiche Prozedur sukzessive für beliebig große Nachbarschaften verallgemeinert werden kann. Im Rahmen dieser Arbeit soll es aber bei nächsten Nachbarn bleiben. Man ersetze nun die Hilfsgröße $G$ in Gleichung 3.21 wieder durch die Definition aus Gleichung 3.20 und erhält die Anzahl der Konfigurationen auf dem Gitter der Größe $N$ :

$$
W_{N}=W_{\text {Platz }}^{(1-\nu) N} W_{\text {Paar }}^{\nu N / 2}
$$

Nun lasse man $L$ und $N$ beliebig groß werden und wende die Stirlingsche Formel (Bronstein und Semendjajew, 1991) auf Gleichung 3.21 an, und man erhält die Entropie des Systems:

$$
\mathcal{S}_{\mathrm{MF}}=\frac{1}{N} \log W_{N}=(1-\nu) \sum_{\alpha} p^{\alpha} \log p^{\alpha}+\frac{\nu}{2} \sum_{\alpha, \beta} p^{\alpha \beta} \log p^{\alpha \beta}
$$

Die freie Energie und damit alle thermodynamischen Funktionen bestimmt man durch Minimierung des durch Gleichung 3.17 und 3.23 gegebenen Ausdrucks in Abhängigkeit der Mittlere-Feld- und Cluster-Parameter:

$$
\mathcal{F}=\min _{p^{\alpha \beta}, p^{\alpha}}\left\{\langle\mathcal{H}\rangle_{\mathrm{MF}}-T \mathcal{S}_{\mathrm{MF}}\right\}
$$

Für diese Prozedur wurde im Rahmen dieser Arbeit das Programm kikmean entwickelt, das in Anhang A) dokumentiert ist. Es findet mit dem Verfahren konjugierter Gradienten im fünf- bzw. neundimensionalen Parameterraum der $p^{\alpha}$ und $p^{\alpha \beta}$ das Minimum und berechnet alle gewünschten Größen. Natürlich lassen sich von der freien Energie in Gleichung 3.24 alle Ableitungen bilden, so dass für die Berechnung, beispielsweise der spezifischen Wärme, keine weitere Näherung als die Ungenauigkeit der Minimierungsprozedur hinzukommt.

Es ist bekannt, dass das kritische Verhalten in der MF+N-Approximation weiter „MFartig“" ist, also alle Approximationen mit endlich großen Nachbarschaften zu derselben Klasse gehören. Hier geht es aber auch nicht um die Beschreibung des kritischen Punktes, weil er im Hinblick auf die Lipidmembranen aus den in Abschnitt 2.5 erwähnten Gründen uninteressant ist. Grundsätzlich ließen sich mit der erläuterten Mittlere-FeldApproximation mit Nachbarschaften auch Phasen mit Nahordnung charakterisieren, die durch die einfache MF-Näherung nicht beschrieben werden. Die Frage nach möglichen neuen Phasen soll hier aber nicht gestellt werden.

Im Folgenden geht es darum, unkritische thermodynamische Observablen quantitativ zu bestimmen und zu zeigen, inwiefern diese Approximation ausreicht, die experimentellen Befunde nachzuvollziehen oder zu verstehen. Dabei bringt die Berücksichtigung der Nachbarschaften für die globalen Größen wie die spezifische Wärme kaum einen Gewinn in Bereichen des Phasendiagramms, wo die MF-Approximation bereits gut ist. Vor allem aber beinhaltet sie neue Information über die lokale Struktur der Membran. So können 


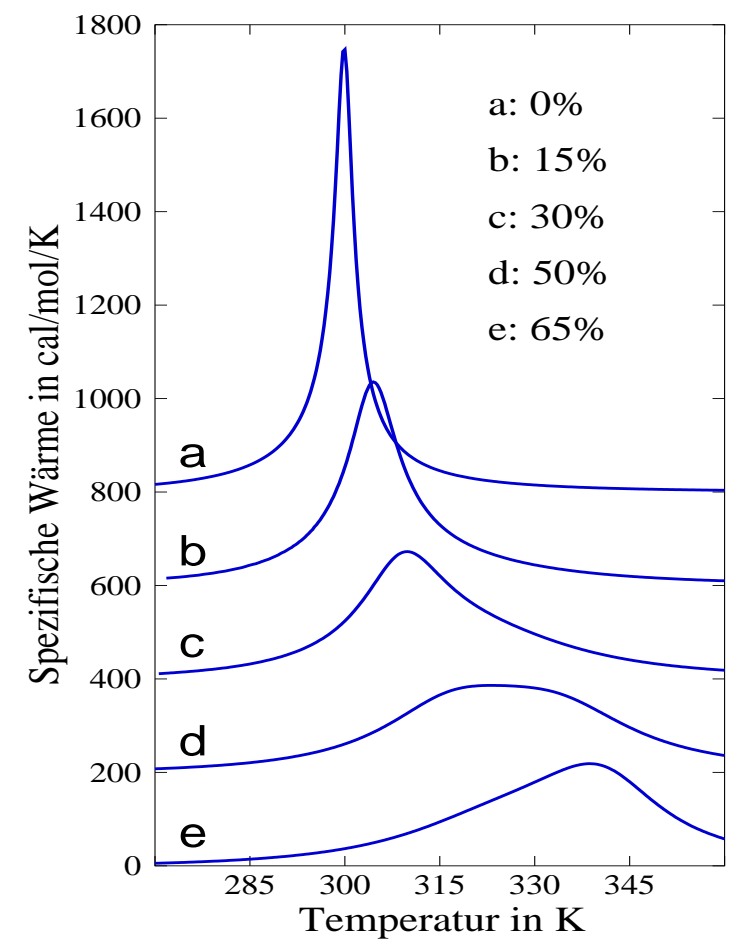

(a) Spezifische Wärme

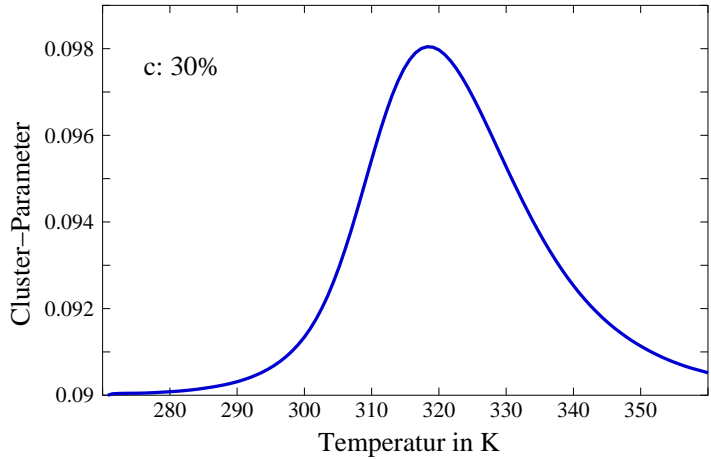

(b) Protein-Protein-Cluster-Parameter

\begin{abstract}
Abbildung 3.5: Lipidmembran mit verschiedener Konzentration von hypothetischen kleinen Adsorbaten. Angewandt wurde die Mittlere-Feld-Approximation mit Nachbarschaften. (Ohne die Berücksichtigung der Nachbarschaften ergeben sich in der spezifischen Wärme lediglich Änderungen in der Höhe des Maximums. Der erwartete „Cluster-Parameter" wäre konstant gleich $\theta^{2}$, also gleich 0,09 bei $30 \%$ Bedeckung.) Parameter: $H=9680 \mathrm{cal} / \mathrm{mol}, S=14, K_{L L}=430 \mathrm{cal} / \mathrm{mol}$, $K_{P L}=1500 \mathrm{cal} / \mathrm{mol}$.
\end{abstract}

mit den Cluster-Parametern Fragen nach den lokalen Umgebungen von Teilchen einer bestimmten Spezies beantwortet werden. Genau dies birgt ein großes Potenzial bei der Untersuchung biologisch relevanter Fragestellungen.

Inspiriert u. a. durch die Arbeit von Heimburg und Biltonen (1996) wird in der vorliegenden Arbeit zunächst der Frage nachgegangen, inwieweit die einfache Mittlere-FeldApproximation ausreicht, um die beobachteten und mit Monte-Carlo-Simulationen untersuchten Charakteristika des Hauptübergangs von Lipidmembranen mit Adsorbaten zu beschreiben. Der Hauptübergang wird in der oben zitierten Arbeit kalorimetrisch ausgemessen, an diese Daten werden dann die Parameter der ebenfalls durchgeführten Monte-CarloSimulation qualitativ angepasst. Ziel der Autoren ist es, die beobachteten Asymmetrien in den Übergangskurven nachzuvollziehen und mit mikroskopischen Eigenschaften des Systems in Verbindung zu bringen. Als Resultat präsentieren sie asymmetrische Übergangskurven in der Größenordnung der experimentellen Verläufe (aber ohne die Möglichkeit, die Kurven quantitativ anzupassen) und einen Parameter, der das Clusterverhalten misst und zeigt, dass die Adsorbate genau im Übergangsbereich klumpen. Das hängt wiederum mit der ungeordneten Struktur des Systems bezüglich der Lipidzustände in diesem Bereich zusammen. 
Das Ergebnis der Bemühungen, in dieser Arbeit im Rahmen der MF-Approximation qualitative Übereinstimmungen mit dem Experiment und der Simulation zu erzielen, ist in Abbildung 3.5(a) zu sehen. Die Kurvenformen der spezifischen Wärme entsprechen sehr genau den in der Literatur gezeigten Ergebnissen aus Computersimulationen. Jedoch musste die Protein-Lipid-Kopplung in der Approximation so stark gewählt werden, dass sich die Verschiebung und die Breite der Kurven, sprich die Skalierung der Temperaturachse, fast um einen Faktor zehn unterscheiden. Bezüglich der Frage der Clusterbildung muss zunächst die Wahrscheinlichkeit, ein Adsorbat neben einem anderen zu finden aus Tabelle 3.2 abgelesen werden:

$$
p:=p_{33}+2 p_{34}+p_{p 44}=\theta-p_{13}-p_{14}-p_{23}-p_{24}
$$

Das Ergebnis in Abbildung 3.5(b) zeigt, abgesehen von deutlichen quantitativen Unterschieden, starke qualitative Übereinstimmungen mit den Computersimulationen aus der Literatur. So zeigt auch die MF+N-Approximation eine Klumpung der Proteine im Bereich des Lipid-Übergangs. Im Unterschied zur oben zitierten Arbeit wurden die Adsorbate hier als klein angenommen (dort besetzen sie 19 Plätze). Vergleicht man die beiden Methoden, so stellt sich heraus, dass man die Effekte im Rahmen der Mittlere-Feld-Approximation mit Nachbarschaften qualitativ nachvollzieht, sie quantitativ aber falsch abschätzt.

\subsection{Strukturelle Information und Clusterbildung}

Da das System im Rahmen dieser Approximation als homogen angenommen wird, folgt, dass nur über das gesamte System gemittelte Größen bestimmt werden können. In den Parametern der Approximation, den Wahrscheinlichkeiten $p^{\alpha}$ und $p^{\alpha \beta}$, steckt strukturelle Information über die Phasen. Die Cluster-Parameter zeigen, ob die Komponenten sich gut durchmischen oder nicht (in diesem Fall bilden sie Anhäufungen oder Cluster). Der Fall idealer Mischung wird durch folgende Parameterwerte beschrieben:

$$
p^{\alpha \beta}=p^{\alpha} p^{\beta} \quad \forall \alpha, \beta
$$

Ist der Cluster-Parameter gegenüber Gleichung 3.26 deutlich erhöht, so spricht man von Clusterbildung der beteiligten Komponenten $\alpha$ und $\beta$.

Welche Art von Information man mit Hilfe dieser Methode gewinnen kann, welche qualitative Verbesserung dies zur üblichen Mittlere-Feld-Näherung ist und inwieweit die Ergebnisse auch quantitativ Bedeutung haben, soll das folgende Beispiel erläutern.

Das gewählte Szenarium beschreibt eine Lipidmembran bei typischen Parametern für unilamellare Vesikel mit kleinen integralen Komponenten bei geringer Konzentration, die sowohl mit gestreckten als auch mit gefalteten Lipiden repulsiv wechselwirken, Lipide im gefalteten Zustand jedoch doppelt so stark abstoßen wie solche im gestreckten. Die resultierende Tendenz der Einlagerungen zur Aggregation ist durch eine abstoßende Wechselwirkung unterdrückt. Dahinter steckt das Bild kleiner integraler Peptide, die länger als die Lipidmembran sind und daher gestreckte Lipide in der Nachbarschaft bevorzugen. Die Abstoßung der Peptide untereinander könnte auf eine effektive Ladung zurückgehen.

Zunächst betrachtet man die globalen Parameter, die auch in der Approximation ohne Nachbarschaften zugänglich sind und versucht, aus ihnen Information über das Mischungsverhalten zu gewinnen. Die Cluster-Parameter sind durch die Produkte der Dichten der jeweiligen Zustände gegeben. Für die Wahrscheinlichkeit von Peptid-Peptid- 
Nachbarschaften ergibt sich konstant $\phi^{2}=0,0009$, diejenigen für Nachbarschaften aus Peptid und einem der Lipidzustände folgen dem mittleren Lipidzustand. Die beiden „ClusterParameter" sind in Abbildung 3.6(a) gezeigt. In Abbildung 3.6(b) ist gezeigt, dass die spezifische Wärme in diesem Parameterbereich keine besondere Struktur aufweist.

Die MF-Approximation mit Nachbarschaften liefert die Cluster-Parameter direkt aus der Minimierung der freien Energie, unabhängig von den mittleren Besetzungszahlen. Abbildung 3.6 zeigt die Ergebnisse: In Abbildung 3.6(c) ist die Wahrscheinlichkeit dargestellt, neben einem Protein ein Lipid in einem bestimmten Zustand zu finden und daneben in Abbildung 3.6(d) die Wahrscheinlichkeit, dass sich neben einem Protein wieder ein Protein befindet gezeigt. Zunächst ist der Cluster-Parameter bezüglich der Protein-ProteinKorrelation im Gegensatz zur einfachen MF-Approximation nicht konstant. Er steigt im Bereich des Hauptübergangs an, ausgehend von einem Wert, der nur knapp über dem der idealen Mischung liegt. Die Erklärung ist sofort einsichtig, denn die Wechselwirkung der Proteine ist so gewählt, dass sie die gefalteten Lipide der expandierten HochtemperaturPhase ablehnen. Sie tendieren daher zur Klumpung und vermindern die Anzahl von Kontakten mit Lipiden.

Bemerkenswerter sind die Protein-Lipid-Cluster-Parameter. Sie zeigen, dass bei Temperaturen weit jenseits des Hauptübergangs in der expandierten Lipidphase die Wahrscheinlichkeit, neben einem Protein ein gestrecktes Lipid zu finden weiterhin größer ist als die für ein gefaltetes Lipid. Das bedeutet, dass sich die Umgebung der Proteine von der globalen Lipidphase unterscheidet. Die Proteine schaffen sich ihre bevorzugte Lipidumgebung. Auf diese Art liest man aus der analytischen Theorie homogener Phasen mikroskopische Aussagen heraus. Die spezifische Wärme unterscheidet sich übrigens fast nicht in MF- oder $\mathrm{MF}+\mathrm{N}$-Approximation.

Um die Qualität der analytischen Approximationen abschätzen zu können, wird das oben erwähnte Szenarium auch auf dem Computer simuliert. Die Ergebnisse sind bis auf numerische Fehler und die möglichen Einflüsse der endlichen Systemgröße exakt im Sinne des Modells. Da in beiden Varianten der Mittlere-Feld-Näherung in erster Linie die Wechselwirkung der Lipide stark vereinfacht approximiert wird, kann man die absoluten Werte der Kopplungs-Parameter nicht mit der Simulation vergleichen. Deshalb wird für die Simulation ein Wert angenommen, der in seinen Auswirkungen auf den Phasenübergang des Systems, gemessen in der Halbwertsbreite des Übergangs, vergleichbar ist. Als Kopplungs-Konstante der Lipide mit den Proteinen wird dann wie oben einfach die Hälfte des Wertes der Lipid-Kopplung angenommen. Die Kopplung der Proteine untereinander wird gleich null gesetzt. Das Ergebnis ist in Abbildung $3.7 \mathrm{zu}$ sehen.

Alle Cluster-Parameter folgen qualitativ dem Verlauf der Kurven aus der $\mathrm{MF}+\mathrm{N}$ Approximation (vergleiche Abbildung 3.7 mit 3.6) und bestätigen damit die analytischen Rechnungen. Insbesondere zeigt der Vergleich mit der Approximation ohne Nachbarschaften (siehe Abbildung 3.6), dass die Erweiterung der Approximation die Bevorzugung der gestreckten Lipide durch die Proteine in der Phase der gefalteten Lipide richtig beschreibt. Eine erwähnenswerte Diskrepanz betrifft den Absolutwert des Protein-Cluster-Parameters. Dieser wird durch die Approximation unterschätzt.

Verständlich wird die Diskrepanz in den MC- und MF+N-Daten, wenn man sich das simulierte System näher betrachtet. In Abbildung 3.8 sind Schnappschüsse des Gesamtsystems aus Lipiden und Proteinen vor und nach dem Hauptübergang gezeigt. Man sieht, dass die Annahme eines homogenen Systems nur noch bedingt gilt. Jenseits des Hauptübergangs ist eine Clusterbildung zu erkennen, deren charakteristische Länge unter der 


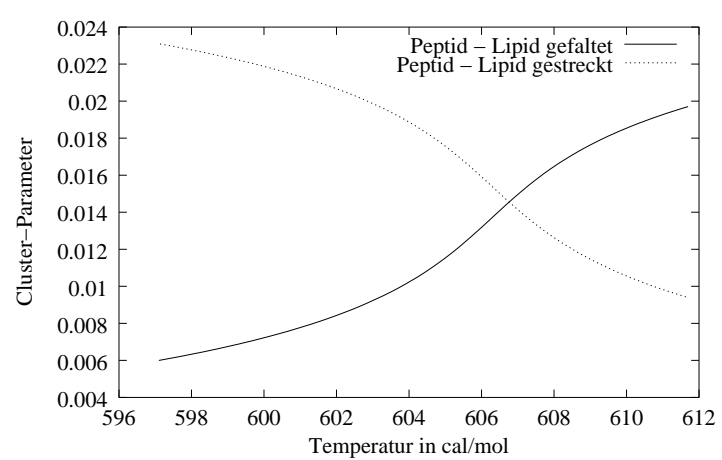

(a) Peptid-Lipid-,,Cluster-Parameter" unter Kenntnis der MF-Näherung ohne Nachbarschaften.

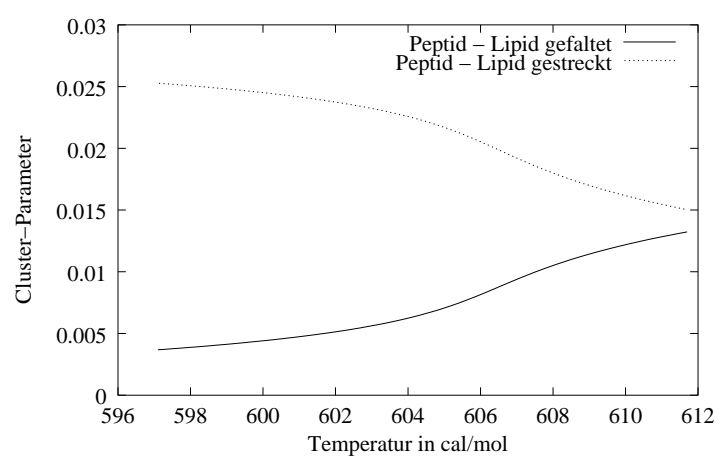

(c) Peptid-Lipid-Cluster-Parameter in $\mathrm{MF}+\mathrm{N}-$ Approximation.

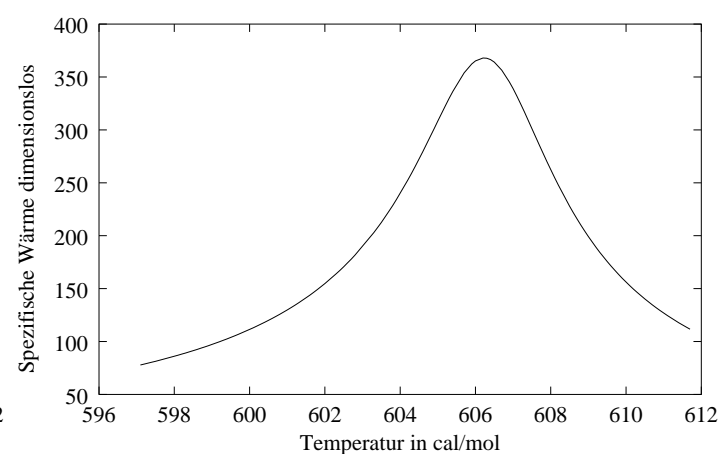

(b) Die spezifische Wärme unterscheidet sich kaum in MF- oder MF+N-Approximation.

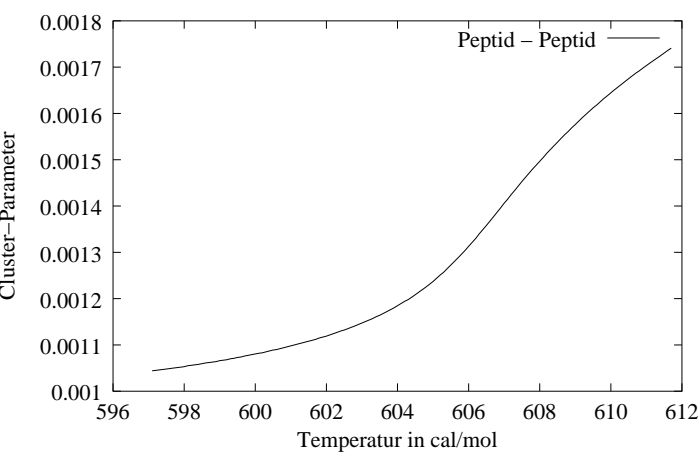

(d) Peptid-Peptid-Cluster-Parameter in $\mathrm{MF}+\mathrm{N}$-Approximation.

Abbildung 3.6: Hypothetische kleine lange Peptide in einer Lipidmembran. Spezifische Information aus der Mittlere-Feld-Approximation ohne und mit Nachbarschaften Parameter: $H=$ $7425 \mathrm{cal} / \mathrm{mol}, S=10, K_{L L}=-475 \mathrm{cal} / \mathrm{mol}, K_{I L}=237,5 \mathrm{cal} / \mathrm{mol}, K_{I I}=0, \phi=0,03$.

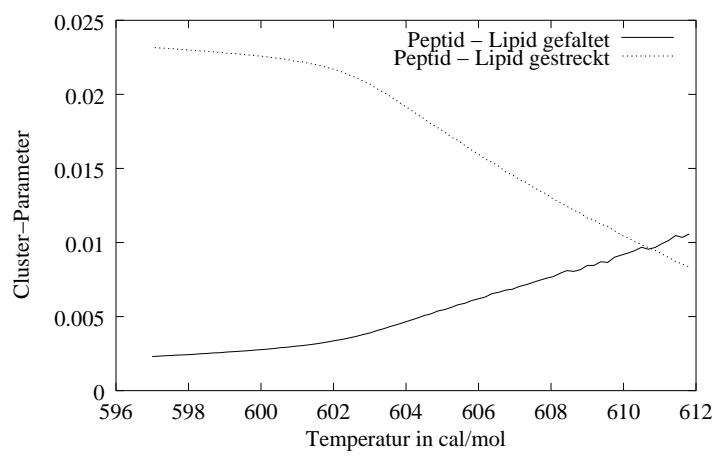

(a) Peptid-Lipid-Cluster-Parameter.

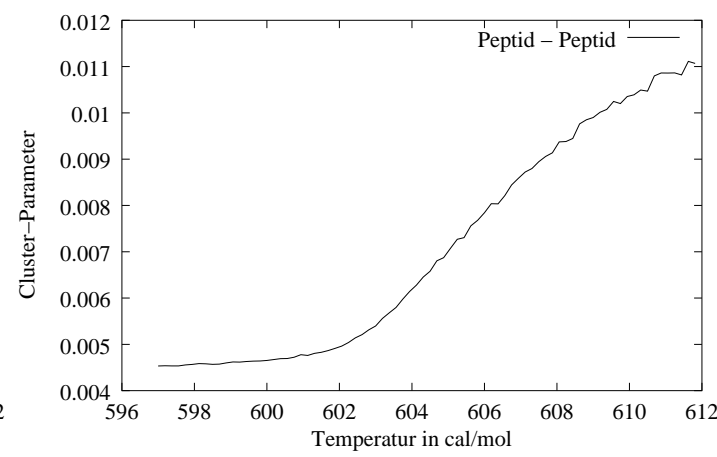

(b) Peptid-Peptid-Cluster-Parameter.

Abbildung 3.7: Monte-Carlo-Simulation hypothetischer Peptide in einer Lipidmembran. Parameter: $L=80, H=7875 \mathrm{cal} / \mathrm{mol}, S=10, K_{L L}=-625 \mathrm{cal} / \mathrm{mol}, K_{L I}=312,5 \mathrm{cal} / \mathrm{mol}, K_{I I}=0$, $\phi=0,03$. 


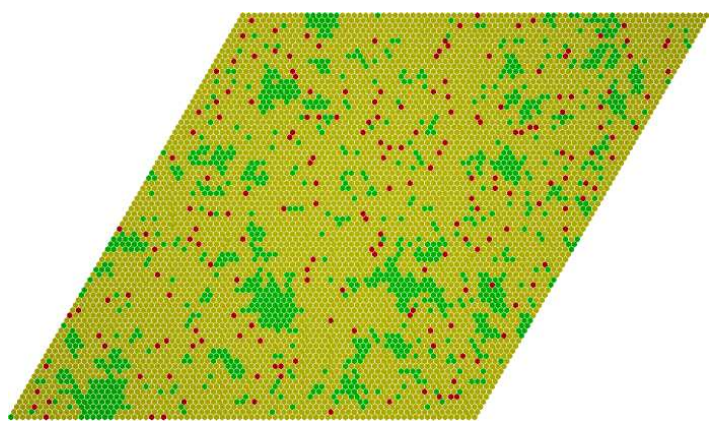

(a) $T=602 \mathrm{cal} / \mathrm{mol}<T_{m}$

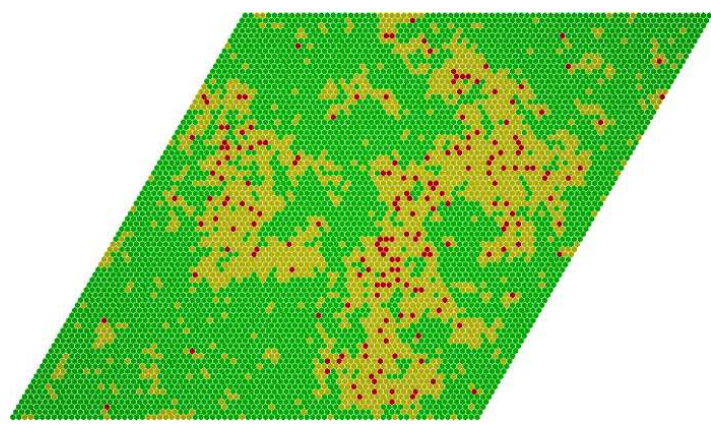

(b) $T=610 \mathrm{cal} / \mathrm{mol}>T_{m}$

Abbildung 3.8: Schnappschüsse von Monte-Carlo-Simulationen. Die integralen Proteine (rot bzw. sehr dunkel) bevorzugen gestreckte Lipide (gelb bzw. hell) und bewirken Umgebungen solcher Lipide selbst in der expandierten Lipidphase (grün bzw. dunkel). Die Parameter entsprechen denen aus Abbildung 3.7. Die Randbedingungen sind periodisch.

Ausdehnung des Systems liegt aber auch deutlich größer ist als der Abstand zwischen nächsten Nachbarn. Es handelt sich damit wahrscheinlich um eine lokale (instabile) Strukturbildung und noch nicht um globale Entmischung der Komponenten. Damit ist auch umrissen, wo die Grenzen der analytischen Approximation liegen: Sie behandelt Vorgänge auf der Ebene der Teilchen-Paare korrekt und liefert Aussagen über das globale Phasenverhalten. Bezüglich Vorgängen auf Längenskalen zwischen der Gitterkonstante und der Systemgröße reagiert sie nicht.

Als weiteres Szenarium sollen kleine periphere Komponenten betrachtet werden, die schwach an die Lipidmembran unilamellarer Vesikel binden. Die Lipidparameter sind die gleichen wie zuvor und die Protein-Lipid-Kopplung $K_{L P}$ beträgt $200 \mathrm{cal} / \mathrm{mol}$, die Adsorbate bevorzugen also die gestreckten Lipide mit einer Energiedifferenz von einem Drittel der thermischen (bei einer Übergangstemperatur von $600 \mathrm{cal} / \mathrm{mol}$ ). In Abbildung 3.9(a) ist die Wahrscheinlichkeit aufgetragen, ein Paar von Adsorbaten zu finden. Sie berechnet sich in der MF-Approximation mit Nachbarschaften aus $p=\theta-p_{13}-p_{14}-p_{23}-p_{24}$, welches aus den beiden letzten Gleichungen in Tabelle 3.2 folgt. Ohne das Wissen über die Nachbarschaften läge der Wert konstant bei $p=\theta^{2}$. Im Einsatz der Abbildung ist die zugehörige spezifische Wärme gezeigt. Sie zeigt keinerlei besondere Struktur. Man sieht, dass der Cluster-Parameter ein (allerdings sehr schmales) Maximum genau im Bereich des Übergangs ausbildet. Die Ausprägung des Maximums lässt sich durch den Wert der Kopplung verändern.

In Abbildung 3.9(b) sind korrespondierende Ergebnisse aus Monte-Carlo-Simulationen gezeigt. Die Lipid-Parameter stimmen bis auf die - an die Breite des Übergangs angepasste - Kopplungs-Konstante überein, die Protein-Lipid-Kopplung beträgt ebenfalls $200 \mathrm{cal} / \mathrm{mol}$ und die Adsorbate bedecken einen Platz. Das qualitative Verhalten entspricht genau dem der Approximation mit Nachbarschaften, jedoch ist der absolute Wert des ClusterParameters höher.

Zusammenfassend kann man feststellen, dass die MF-Approximation mit Nachbarschaften gegenüber der ohne Nachbarschaften neue strukturelle Information beinhaltet, die durch MC-Simulationen qualitativ und zum Teil auch quantita- 


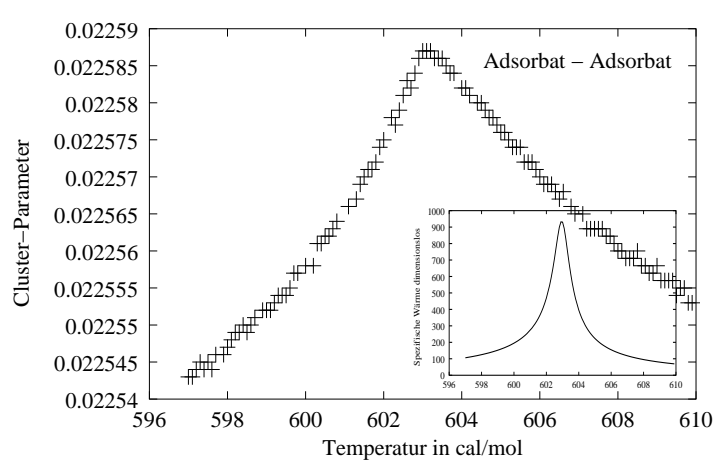

(a) Adsorbat-Adsorbat-Cluster-Parameter in Mittlere-Feld-Näherung mit Nachbarschaften. Ohne die Kenntnis von Nachbarschaften würde man konstant $\theta^{2}=0,0225$ erwarten. Im Einsatz ist die spezifische Wärme gezeigt.

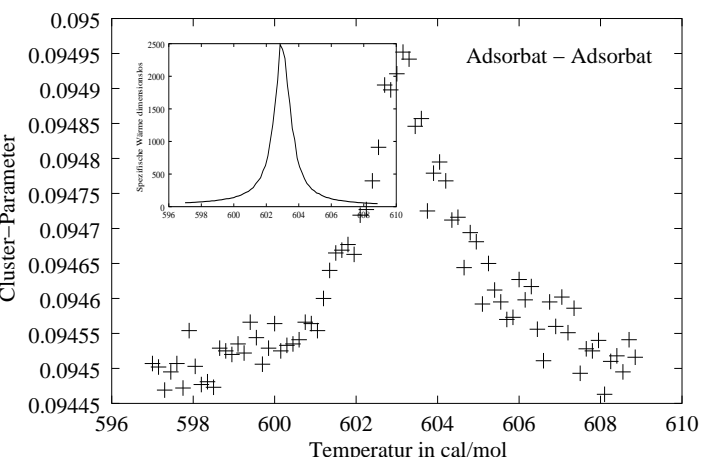

(b) Adsorbat-Adsorbat-Cluster-Parameter aus korrespondierender MC-Simulation. Im Einsatz ist die spezifische Wärme gezeigt.

\begin{abstract}
Abbildung 3.9: Lipidmembran mit hypothetischen kleinen Adsorbaten. Der Bedeckungsgrad ist konstant bei $\theta=0,15$. Links sind die Ergebnisse der $\mathrm{MF}+\mathrm{N}$-Approximation und rechts die der MC-Simulation gezeigt. Parameter: $L=80, H=7875 \mathrm{cal} / \mathrm{mol}, S=10, K_{L L}=-625 \mathrm{cal} / \mathrm{mol}$, $K_{L P}=200 \mathrm{cal} / \mathrm{mol}$.
\end{abstract}

tiv bestätigt werden können. Ihre Grenze erreicht die Approximation, wenn Komponenten stark aggregieren, dann unterschätzt sie die Cluster-Wahrscheinlichkeit. Das liegt an der Annahme homogener Phasen, die im Bereich von Aggregation oder Entmischung zusammenbrechen muss.

Experimentell zugänglich sind die Cluster-Parameter oder Nächste-Nachbar-Wahrscheinlichkeiten im Prinzip über die Kernspinresonanz-Spektroskopie (NOESY NMR), wobei zwischen verschiedenen chemischen Spezies, aber wohl nicht zwischen unterschiedlichen inneren Zuständen der Lipide, unterschieden werden kann (siehe Huster und Gawrisch, 2001).

\title{
3.5 Integrale und periphere Komponenten im Vergleich
}

Die übliche Messgröße zur Identifizierung des Hauptübergangs an Lipidmembranen ist die spezifische Wärme. Anhand eines Beispiels mit für Vesikelsuspensionen typischen Werten soll gezeigt werden, dass die im Allgemeinen beobachteten Veränderungen in den kalorischen Messungen durch zusätzliche Komponenten nicht empfindlich dafür sind, ob es sich dabei um kleine integrale oder periphere Komponenten handelt. Es kann aber in Schnappschüssen gezeigt werden, dass das Verhalten des Systems in den beiden Fällen äußerst verschieden sein kann.

Dafür startet man bei typischen Werten für die Lipidmembran und erzeugt in den Simulationen mit kleinen Komponenten spezifische Wärmen, die typisch für experimentelle Kurven sind. Bei geringen Dichten der zusätzlichen Komponente soll die Verschiebung des Hauptübergangs nur klein sein, sich aber eine starke Verbreiterung und Abflachung des Maximums ergeben. Die Werte für die mikroskopischen Kopplungs-Konstanten der peri- 
pheren und integralen Komponenten müssen dabei nicht unbedingt vergleichbar sein, da die Wirkung der Komponenten im Modell je nach ihrer Lage (in oder auf der Lipidschicht) sehr unterschiedlich ist (siehe auch Gleichungen 3.4 und 3.6).

Die Wechselwirkungs-Parameter, bzw. der Energieeintrag in das Lipidsystem durch die zusätzlichen Komponenten, und die Teilchendichte seien gleich. Die makroskopische Observable der spezifischen Wärme weisen keine deutlichen Unterschiede auf, wie die Abbildungen 3.10 und 3.11 jeweils im linken Teil zeigen. Man beachte, dass sich der absolute Wert eines Kurvenmaximums im Experiment nur vergleichsweise ungenau bestimmen lässt. Das Phasenverhalten jedoch ist komplett unterschiedlich, wie die Schnappschüsse jeweils im rechten Teil der Abbildungen verdeutlichen.

Die Membran mit integralen Komponenten entmischt in eine Phase, die reich an Lipiden im gefalteten Zustand ist. Sie klumpen nicht eng zusammen, weil die gewählten Parameter eine effektive Abstoßung der Komponenten beinhalten. Der Verlauf der spezifischen Wärme unterscheidet sich kaum von dem im Fall peripherer Komponenten. Die Eigenschaft einer mehr oder weniger asymmetrischen Übergangskurve besitzen beide Szenarien.

\subsubsection{Zufallsfeld der Adsorbate erzeugt homogenen Beitrag}

Die zur Hamiltonfunktion aus Gleichung 3.1 gehörige Zustandssumme summiert über die Besetzungszahlen $n^{L}$ der Lipide und $n^{P}$ der Proteine. Letztere kann man für obiges Modell der kleinen Adsorbate exakt ausführen und erhält ein effektives Lipidsystem, in dem der Einfluss der Proteine in die Lipid-Parameter eingeflossen ist.

Die zu Gleichung 3.1 gehörige kanonische Zustandssumme schreibt sich wie folgt:

$$
\begin{gathered}
\mathcal{Z}=\sum_{\left\{n^{L}\right\}} \exp \left[-\beta\left(K_{L L} \sum_{\langle i, j\rangle} n_{i}^{L} n_{j}^{L}+(H-T S) \sum_{i} n_{i}^{L}\right)\right] \times \\
\sum_{\left\{n^{P}\right\}} \exp \left[-\beta\left(K_{P L} \sum_{i} n_{i}^{P} n_{i}^{L}\right)\right]
\end{gathered}
$$

Man beachte, dass der innere Teil der Zustandssumme, die Summe über die Proteinzustände, noch von den Lipidzuständen abhängt und demzufolge auch Bestandteil der äußeren Summation wird. Dieser innere Teil wird im Folgenden exakt ausgeführt. Dafür geht man in das großkanonische Ensemble der Adsorbate, führt also ein chemisches Potential $\mu$ ein und verliert die Nebenbedingung fester Teilchenzahl. Das Vorzeichen des chemischen Potentials ist dabei so definiert, dass die Teilchen Energie bei der Adsorption gewinnen, wenn $\mu$ positiv ist. Ziel ist es, einen Ausdruck zu erlangen, der die Protein- 


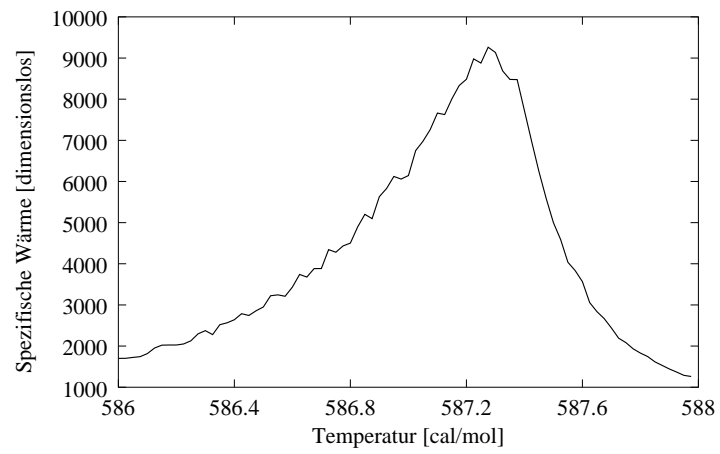

(a) Spezifische Wärme mit Einlagerungen

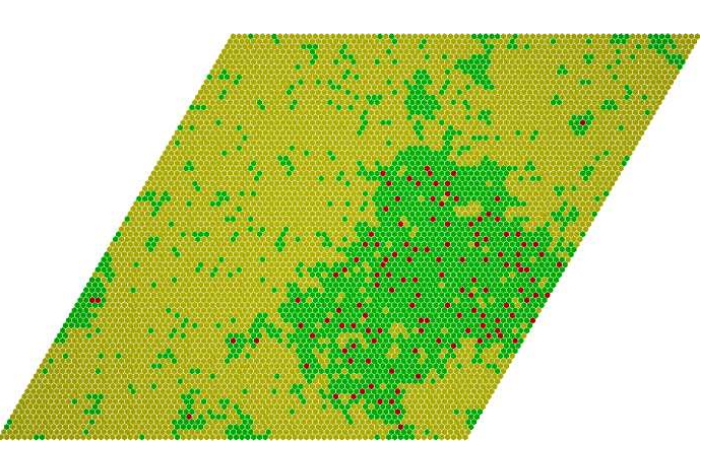

(b) Schnappschuss mit Einlagerungen bei $T=$ $586 \mathrm{cal} / \mathrm{mol}$

Abbildung 3.10: Kleine Einlagerungen führen zu einem komplexen Phasenverhalten mit Entmischungsszenarien und Untergitterordnung. Die Einlagerungen sind rot (sehr dunkel), die Lipide grün (dunkel) und gelb (hell). Parameter: $K_{L L}=-611 \mathrm{cal} / \mathrm{mol}, H=19473 \mathrm{cal} / \mathrm{mol}, S=30$, $K_{L I}=-1222 \mathrm{cal} / \mathrm{mol}, \phi=0,02, L=80$ (Schnappschuss für $L=40$ ).

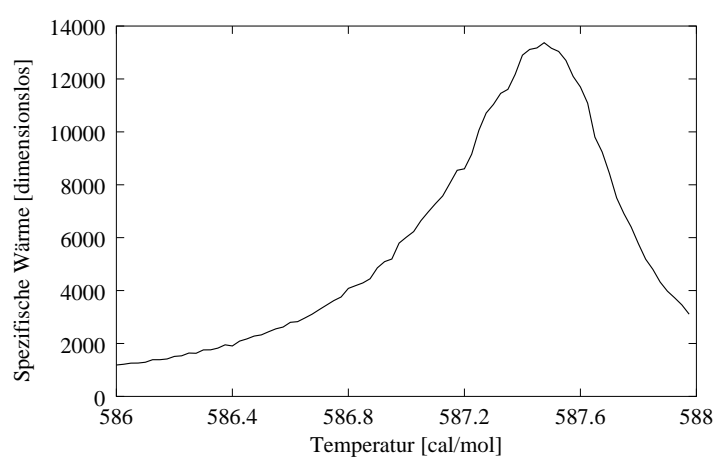

(a) Spezifische Wärme mit Adsorbaten

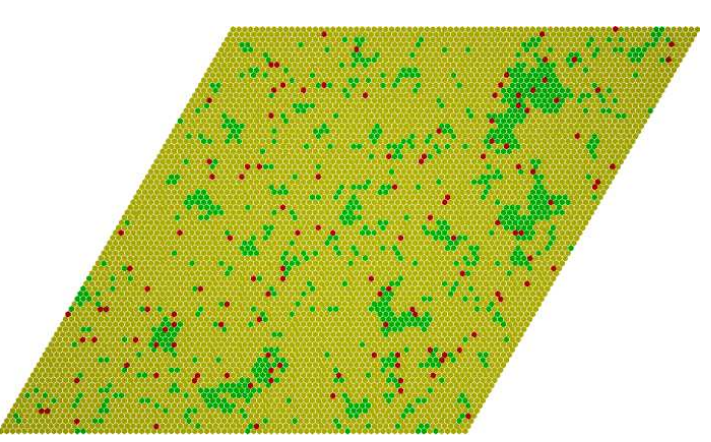

(b) Schnappschuss mit Adsorbaten bei $T=$ $586 \mathrm{cal} / \mathrm{mol}$

Abbildung 3.11: Kleine Adsorbate beeinflussen das System nur lokal und es bleibt homogen. Die Adsorbate sind rot (sehr dunkel) und ausnahmsweise mit der Lipidschicht (grün bzw. dunkel und gelb bzw. hell) in einem Bild dargestellt. Parameter: $K_{L L}=-611 \mathrm{cal} / \mathrm{mol}, H=19473 \mathrm{cal} / \mathrm{mol}$, $S=30, K_{L P}=-1222 \mathrm{cal} / \mathrm{mol}, \theta=0,02, L=80$ (Schnappschuss für $L=40$ ). 


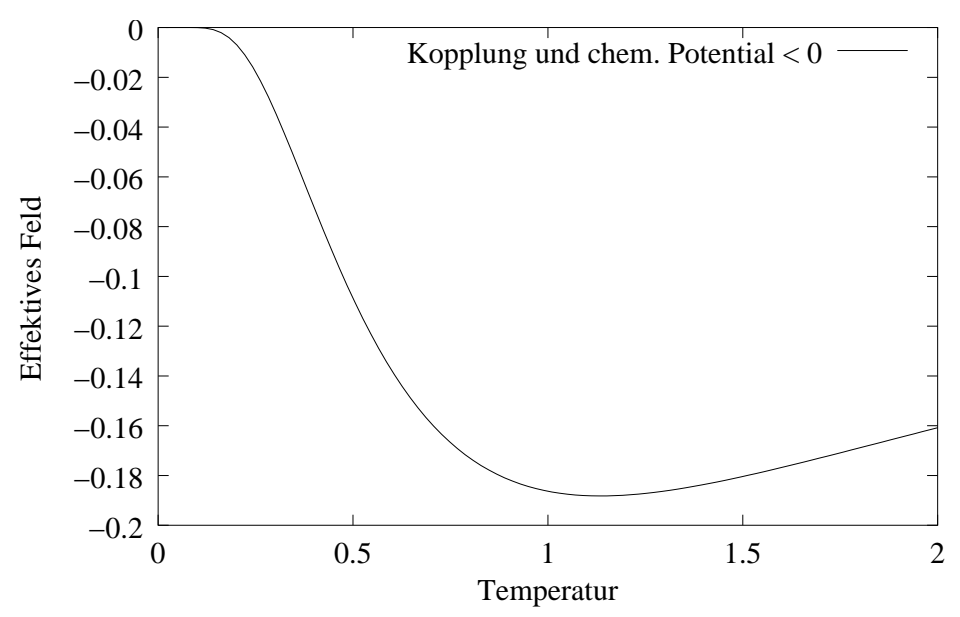

Abbildung 3.12: Durch kleine Adsorbate induziertes effektives Feld. Alle Energien sind dimensionslos gewählt und die Parameter $K_{P L}$ und $\mu$ sind jeweils gleich -1 .

zustände nicht mehr enthält und diesen als Boltzmann-Faktor zu schreiben. Der Exponent wird dann als Beitrag zur effektiven Hamiltonfunktion interpretiert:

$$
\begin{aligned}
\mathcal{Z}_{\text {Adsorbate }} & =\sum_{n_{1}^{P}} \cdots \sum_{n_{N}^{P}} \exp \left[-\beta\left(K_{P L} \sum_{i} n_{i}^{P} n_{i}^{L}-\mu \sum_{i} n_{i}^{P}\right)\right] \\
& =\prod_{i} \sum_{n^{P}=\{0,1\}} \exp \left[-\beta\left(K_{P L} n^{P} n_{i}^{L}-\mu n^{P}\right)\right] \\
& =\prod_{i}\left\{1+\exp \left[-\beta\left(K_{P L} n_{i}^{L}-\mu\right)\right]\right\} \\
& =\exp \left[-\beta \sum_{i}-T \log \left[1+\exp \left[-\beta\left(K_{P L} n_{i}^{L}-\mu\right)\right]\right]\right]
\end{aligned}
$$

Das nächste Ziel ist es, den oben berechneten Beitrag zur effektiven Hamiltonfunktion analog zum Ausdruck für das Lipidsystem linear in den Besetzungszahlen $n_{i}^{L}$ zu schreiben, um ihn mit diesem zu verknüpfen:

$$
\begin{aligned}
\mathcal{H}_{\text {Adsorbate }} & =\sum_{i} \log \left[1+\exp \left[-\beta\left(K_{P L} n_{i}^{L}-\mu\right)\right]\right] \\
& =\sum_{i}\left(1-n_{i}^{L}\right) \log [1+\exp \beta \mu]+\sum_{i} n_{i}^{L} \log \left[1+\exp \beta\left(-K_{P L}+\mu\right)\right] \\
& =\sum_{i} \log [1+\exp \beta \mu]+\sum_{i} n_{i}^{L} \log \left[\frac{1+\exp \beta\left(-K_{P L}+\mu\right)}{1+\exp \beta \mu}\right] \\
& =: \sum_{i} \mathcal{N}(\mu, T)+\sum_{i} n_{i}^{L} H^{P}(\mu, T)
\end{aligned}
$$

Das effektive Feld $H^{P}$ ist meist monoton in den Parametern $K_{P L}, \mu$ und $T$. Für den Fall nichtmonotonen Verhaltens $\left(H^{P}\left(T, \mu<0, K_{P L}<0\right)\right)$ ist der Verlauf in Abbildung 3.12 skizziert. 
Die effektive Hamiltonfunktion des Gesamtsystems im Falle kleiner Adsorbate im großkanonischen Ensemble schreibt sich damit wie folgt:

$$
\mathcal{H}_{\text {peripher }}=K_{L L} \sum_{\langle i, j\rangle} n_{i}^{L} n_{j}^{L}+\left(H-T S+H^{P}(\mu, T)\right) \sum_{i} n_{i}^{L}+\sum_{i} \mathcal{N}(\mu, T)
$$

Das Resultat ist, dass die kleinen Adsorbate ein homogenes Feld für die Lipide darstellen und einen zusätzlichen numerischen Term erzeugen. Dieser ist erst bei Ableitungen bezüglich der Temperatur oder des chemischen Potentials zu berücksichtigen. Die Struktur des Modells für die Lipidmembran bleibt unverändert: ein Gittergas mit NächsterNachbar-Wechselwirkung und homogenem Feld. Das bedeutet auch, dass die möglichen Phasen dieselben bleiben. Da es sich bei dem Hauptübergang der Lipide um einen durch das effektive Feld getriebenen Übergang handelt, wird dieser entsprechend durch den Beitrag $H^{P}$ verändert. Beispielrechnungen ergeben, dass der Übergang verschoben und abgeflacht wird. Qualitativ neue Effekte kann man jedoch nicht erwarten. Dieses Verhalten ändert sich drastisch, wenn man von peripheren zu integralen Komponenten übergeht. Kleine Einlagerungen führen im Gegensatz zu Adsorbaten zu ganz neuen Strukturen und einem reichhaltigen Phasendiagramm.

\subsubsection{Bekannte Mittlere-Feld-Lösung des Dreizustands-Modells}

Das Dreizustands-Gittergas ist wohlbekannt und untersucht, vor allem im Hinblick auf ternäre Legierungen. Eine exakte Lösung der Zustandssumme ist in keinem Grenzfall (also auch nicht bei verschwindenden Feldtermen) bekannt. Es gibt eine gute und übersichtliche Darstellung der Mittlere-Feld-Lösung von Furman u. a. (1977). Das dort entwickelte Phasendiagramm zeigt eine Reihe von Koexistenzregionen, Phasenübergangslinien und kritischen Punkten bzw. Linien bis hin zu kritischen Punkten vierter Ordnung und VierphasenKoexistenzgebieten. Symmetrisch und übersichtlich sind die Diagramme nur, solang alle drei Zustände in Abhängigkeit der Wechselwirkungs-Parameter und der chemischen Potentiale betrachtet werden. Die zu Ensembles konstanter Dichte gehörigen Phasendiagramme sind wesentlich unübersichtlicher.

Das von den oben zitierten Autoren entwickelte Phasendiagramm ist hier in Abbildung 3.13(a) etwas vereinfacht skizziert. Es soll an dieser Stelle kurz besprochen werden, um einen Eindruck von der Komplexität des Dreizustands-Modells im Vergleich zum bereits diskutierten Zweizustands-Modell (Ising-Modell) zu gewinnen. Es liest sich wie folgt: Die Lage des Punktes innerhalb des Dreiecks bestimmt die (normierten) KopplungsKonstanten $a, b$ und $c$ der drei Komponenten. Hier ist nur das Dreieck mit positiven Vorzeichen aller Kopplungen gezeigt. Das komplette Phasendiagramm besteht aus acht solchen Dreiecken, das gewählte ist aber das mit den meisten Phasenübergängen und Koexistenzgebieten und darüber hinaus das typische, wenn man nach dem Prinzip der hydrophoben Wechselwirkung eine Abstoßung zwischen Komponenten unterschiedlicher Spezies annimmt. In den Ecken sind zwei der Kopplungen null und die andere eins. Zu jedem Punkt im Diagramm 3.13(a) der Wechselwirkungs-Energien gehört ein dreieckiges Phasendiagramm bezüglich der Aktivitäten (d.h. der chemischen Potentiale).

Die durchgezogenen Linien im Phasendiagramm der Kopplungen sind Linien trikritischer Punkte, sie schneiden sich also in kritischen Punkten vierter Ordnung. Das ist die höchste Ordnung kritischer Punkte in diesem Modell. Das Dreieck mit positiven Kopplungen enthält Gebiete, in denen zwei, drei oder vier Phasen koexistieren. 


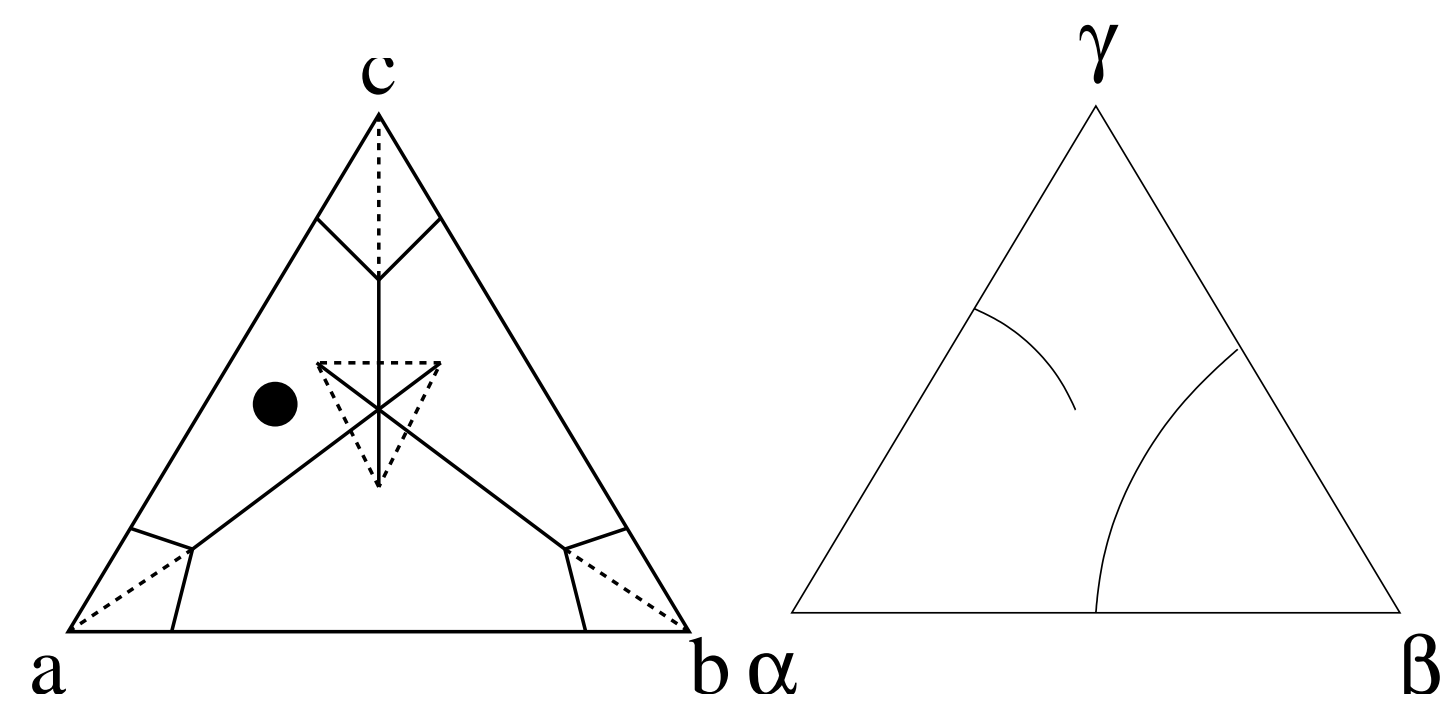

(a) Phasendiagramm in Abhängigkeit der Kopplungs-Konstanten

(b) Phasendiagramm in Abhängigkeit der Aktivitäten

Abbildung 3.13: Schematische Darstellung des Phasendiagramms einer dreikomponentigen Mischung nach Furman u. a. (1977). Die Werte sind so zu lesen, dass in den Ecken der Diagramme der eine Parameter gleich eins und die anderen null sind. Die Linien im Diagramm der Kopplungen sind trikritische Punkte, im Diagramm der Aktivitäten sind damit unstetige Übergänge angezeigt.

Geht man von zufälligen Werten für die Kopplungs-Konstanten aus, so liegt man typischereise in einem Gebiet jenseits dieser trikritischen Linien oder Koexistenzregionen von mehr als zwei Phasen. Experimentellen Untersuchungen zugänglich ist in der Regel nicht der Raum der Kopplungs-Konstanten, sondern die Teilchendichten. Dazu äquivalent und aus theoretischer Sicht einfacher ist der Raum der chemischen Potentiale. Ein typisches Phasendiagramm ist in Abbildung 3.13(b) für einen Punkt skizziert, der auf keiner der kritischen Linien liegt. Die Aktivitäten $\alpha, \beta$ und $\gamma$ sind in gleicher Weise aufgetragen wie die Kopplungen $a, b$ und $c$ in Abbildung 3.13(a). Man erkennt zwei Linien unstetiger Phasenübergänge, von der eine in einem kritischen Punkt endet. Die Übersetzung eines solchen Phasendiagramms in eines von Teilchendichten ist möglich, führt im Allgemeinen jedoch auf wesentlich unübersichtlichere Diagramme.

Zusammenfassend lässt sich feststellen, dass sich im Dreizustands-Modell typischerweise unstetige Phasenübergänge und kritische Punkte finden, die Situation aber für sehr ähnliche Kopplungs-Parameter (mittlere Region des Dreiecks) und sehr extreme (Ecken des Dreiecks) sehr viel komplizierter mit kritischen Punkten höherer Ordnung und mehrkomponentige Phasenkoexistenz wird.

Es gibt Arbeiten, die ein ganz ähnliches wie das hier dargestellte Modell mit zwei Zuständen für die Lipide und einen dritten für "Löcher“ in einer Mittlere-FeldApproximation mit Nachbarschaften untersucht haben (siehe auch Abschnitt 3.2). Das Modell wurde zur Beschreibung des Verhaltens von Langmuir-Monoschichten verwendet (siehe auch Abschnitt 3.2). Eine einführende Darstellung des Ansatzes und die Referenzen zu den Originalarbeiten bietet Lavis und Bell (1999, in Kapitel 7). Es ist zu beachten, dass 
nicht alle Möglichkeiten von Kopplungen und Feldern in diesem Zusammenhang diskutiert wurden, sondern eher auf die Berechnung des spezialisierten Falls von Monoschichten abgezielt wurde. Die Phasendiagramme zeigen die folgenden Charakteristika:

Man erkennt zwei Phasenübergänge in Abhängigkeit von der Temperatur und dem lateralen Druck. Der erste bei niedrigen Drücken wird als der Gas-Flüssigkeit-Übergang identifiziert, der andere bei höheren Drücken als der Übergang von einer expandierten in eine kondensierte Phase. Beide Phasenübergänge sind unstetig, d. h. 1. Ordnung. Bei niedrigen Temperaturen verschmelzen beide Phasenübergänge zu einem unstetigen Übergang. Bei einer bestimmten höheren Temperatur, einem trikritischen Punkt, geht der Phasenübergang expandiert/kondensiert in einen stetigen Phasenübergang 2. Ordnung über. Das unterschiedliche Verhalten bei verschiedenen Temperaturen kann auch durch Variation der Kopplungs-Konstante erreicht werden. Die errechneten Druck-Fläche-Isothermen entsprechen gut den experimentellen Befunden.

\subsection{Beispiel: Multilamellare Vesikel aus DMPC und Cholesterin}

Das Modell für kleine Komponenten ist am ehesten für bestimmte Einlagerungen experimentell realisiert. Adsorbate, die nur die Fläche eines Lipides bedecken sind dem Autor nicht bekannt. Als Einlagerung kommen Lipid-ähnliche Teilchen und kleine Peptide in Betracht. An dieser Stelle sollen Lipidmembranen betrachtet werden, die Cholesterin (siehe Abbildung 3.1) in unterschiedlichen Konzentrationen enthalten. Natürlich muss man bei den Vergleichen die Beschränkungen des Gitter-Modells berücksichtigen, welches die Form der Teilchen nicht genauer als auf eine Gitterkonstante darstellen kann.

Das Modell besitzt zwei neue Wechselwirkungs-Parameter $K_{L I}$ und $K_{I I}$. Aus der Veränderung der Kurven der spezifischen Wärme sollen diese bestimmt werden. Dabei ist auf jeden Fall Vorsicht angebracht, da die experimentellen Daten im Detail zeigen, dass die Situation komplizierter ist als durch das einfache Modell angenommen. So ist insbesondere das Mischungsverhalten nicht ideal. Quantitativ lässt sich am ehesten die Verschiebung der Übergangstemperatur auswerten.

Unabhängig von der chemischen Klasse der Lipide nimmt die Übergangsenthalpie nahezu linear mit der Cholesterin-Konzentration ab (McMullen u. a., 2000). Die Übergangstemperatur verändert sich nur geringfügig, verschiebt sich zumindest für sehr kleine Konzentration von wenigen Prozent hin zu niedrigeren Werten. Es ist bekannt, dass Cholesterin einen starken Einfluss auf die Kettenordnung der Lipide hat (Sankaram und Thompson, 1990).

Experimentelle Fakten, die zur Vorsicht mahnen, sind die konzentrationsabhängige Richtung der Verschiebung des Maximums bei Zugabe von Cholesterin (Mannock u. a., 2003) und strukturell neue Phasen wie Entmischung an Grenzlinien im Tieftemperatur-Bereich.

Für den Vergleich des Modells mit dem Experiment wird nun erstens angenommen, dass die Cholesterin-Moleküle genau einen Gitterplatz besetzen, und zweitens, dass sie keine innere Entropie besitzten, die Moleküle also nur einen Zustand annehmen. Drittens sei die Konzentration von Cholesterin in der Membran fest. Die erste Annahme ist sicher nur eine grobe Näherung, die zweite wegen der Molekülstruktur sicherlich gerechtfertigt und die dritte experimentell bestätigt.

Man vergleicht die Ergebnisse der Mittlere-Feld-Approximation mit Nachbarschaften mit den Messungen von Lemmich u.a. (1997). Aus der spezifischen Wärme des reinen Lipidsystems, bestehend aus DMPC, ergeben sich durch Anpassen der Kurven die drei 


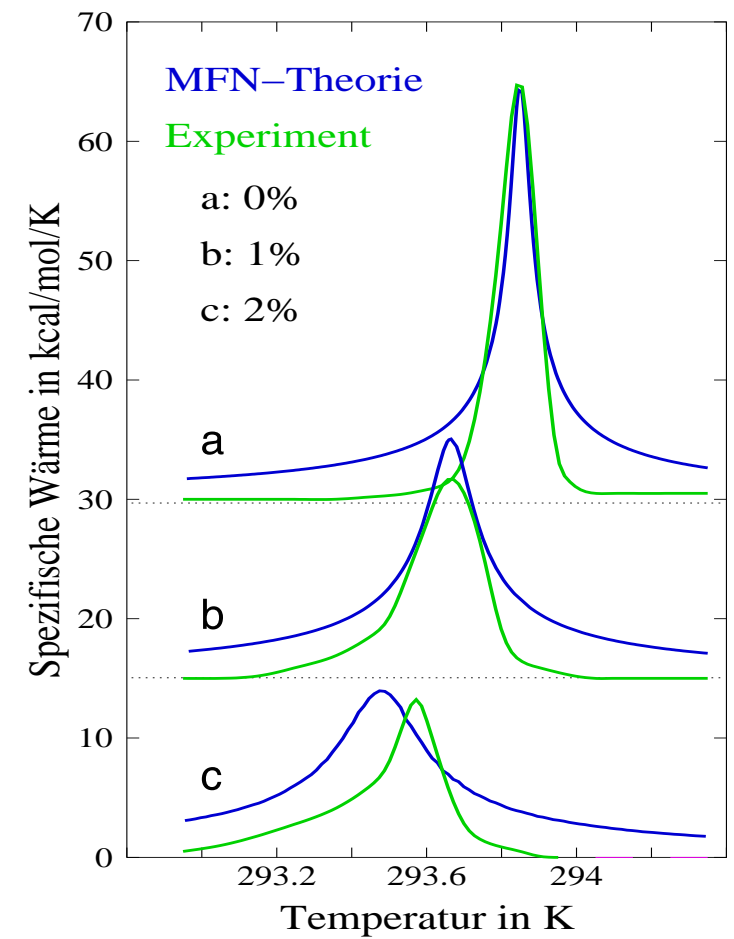

(a) Spezifische Wärme von Lipidmembranen mit Cholesterin

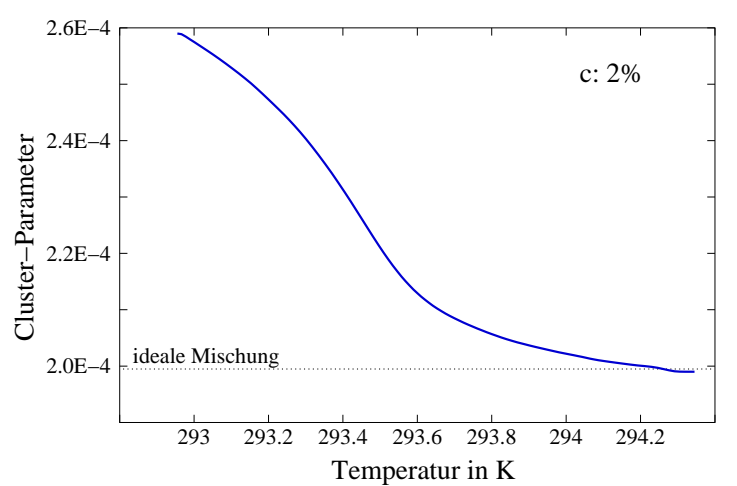

(b) Clusterverhaltens von Cholesterin

Abbildung 3.14: Vergleich der $\mathrm{MF}+\mathrm{N}-$ Approximation mit dem Experiment (Lemmich u. a., 1997). Modellparameter für die MF+N-Approximation, gewonnen durch die möglichst genaue Anpassung an die experimentellen Kurven der spezifischen Wärme: $H=19038 \mathrm{cal} / \mathrm{mol}, S=15$, $K_{L L}=-469 \mathrm{cal} / \mathrm{mol}, K_{I L}=-460 \mathrm{cal} / \mathrm{mol}$

Parameter $K_{L L}, H$ und $S$ des Modells. Die Verschiebung des Maximums zu niedrigeren Temperaturen bei Zugabe von Cholesterin ermöglicht die Anpassung des WechselwirkungsParameters $K_{L I}$. Die experimentellen und theoretischen Kurven sind in Abbildung 3.14(a) zu sehen. Der noch freie Parameter $K_{I I}$ hat wenig Einfluss auf die Kurvenform der spezifischen Wärme. Die experimentellen Daten für die spezifische Wärme lassen sich mit der gleichen Genauigkeit auch durch die Mittlere-Feld-Methode ohne Nachbarschaften anpassen. Die angewandte Methode birgt jedoch qualitativ neue Information.

Wie in Abschnitt 3.4 erläutert, steckt in der Theorie Information über das Clusterverhalten der Komponenten. Abbildung 3.14(b) zeigt den Cluster-Parameter bezüglich der Nachbarschaft aus zwei Cholesterin-Molekülen, der Einblick in die Struktur der Phase erlaubt. Es zeigt sich, dass Cholesterin in der kondensierten Lipid-Phase klumpt. Es muss erwähnt werden, dass der Absolutwert dieses Parameters im Gegensatz zur spezifischen Wärme empfindlich vom unbestimmten Wechselwirkungs-Parameter $K_{I I}$ abhängt. Eine detailliertere Anpassung der Theorie benötigt demnach weitere unabhängige experimentelle Ergebnisse.

Höhere Konzentrationen von Cholesterin induzieren in Lipidmembranen neue Phasen bezüglich der Ordnung der Schwerpunkte. Dies kann durch ähnliche Modelle wie das hier untersuchte unter Aufhebung der Gittersymmetrie durch dynamische Triangu- 
lierung (Nielsen u.a., 1999) theoretisch nachvollzogen werden. Die erfolgreiche Anpassung des Phasendiagramms in der zitierten Arbeit zeigt, dass Cholesterin für das einfache Gitter-Modell zumindest bei höheren Konzentrationen kein gutes Beispiel ist (zum Vergleich des Phasendiagramms siehe z. B. die experimentelle Arbeit von Lemmich u. a., 1996a). Zum Verständnis des Vergleichs in Abbildung 3.14 muss darauf hingewiesen werden, dass die im Rahmen der hier gezeigten Anpassung gefundene Lipid-CholesterinKopplung von $K_{I L}=-460 \mathrm{cal} / \mathrm{mol}$ eine energetische Bevorzugung des gefalteten Lipidzustands bedeutet. Das wird weder durch die oben zitierte Arbeit noch durch Experimente bestätigt. Diese zeigen, dass Cholesterin die Kettenordnung erhöht, also den gestreckten Zustand bevorzugt. Der Grund wird darin liegen, dass der Einfluss von Cholesterin auf die Lipidmembran in erster Linie kein energetischer sondern ein entropischer ist und deshalb durch das Gitter-Modell nur unzureichend wiedergegeben werden kann. 


\section{Lipidmembranen mit großen Komponenten}

Inhaltsangabe

4.1 Teilchen-Formen und Wechselwirkungs-Umgebungen . . . . . 60

4.2 Effektive Systeme aus Lipiden oder Proteinen . . . . . . . . 65

4.2.1 Effektives Lipidsystem mit Mehrteilchen-Wechselwirkung . . . . 65

4.2.2 Effektive Protein-Protein-Wechselwirkung . . . . . . . . . 69

4.3 Phasendiagramm und Analyse der Grenzfläche . . . . . . 76

4.4 Einfluss von Größe und Form der Komponenten . . . . . . 79

4.5 Komponenten mit gerichteter Wechselwirkung . . . . . . . 84

4.6 Beispiel: Unilamellare DMPG-Vesikel mit Cytochrome C . . 86

Wie bereits erwähnt, ist der enorme Größenunterschied zwischen Lipiden und Proteinen eines der auffälligsten Charakteristika von Biomembranen. Die Modellierung soll sich in diesem Kapitel auf diesen Aspekt konzentrieren. Dabei geht es einerseits um die Frage, auf welche Art und Weise große Teilchen in den Gittergas-Formalismus eingearbeitet werden können und zum anderen darum, die resultierenden Effekte anhand von speziellen Fällen des Modellsystems oder bestimmter Approximationen zu verstehen.

Experimentelle Beispiele für große Komponenten gibt es natürlich viele. Dabei ist zu beachten, dass man in der Natur viele sehr verschiedene Bindungsmechanismen findet (siehe z. B. Alberts u. a., 1994; Stryer, 1995). Grundsätzlich kann man in etwa drei Kategorien unterscheiden (wobei aufgrund der Fluidität und der Struktur der Membran die Übergänge im wahrsten Sinne des Wortes fließend sind):

Integrale Proteine Viele Proteine besitzen ein oder mehrere hydrophobe Abschnitte, oft zu $\alpha$-Helizes gefaltet, die die Lipidmembran durchspannen. Damit sind die Teilchen nicht aus der Membran zu lösen, ohne diese zu zerstören. Ihre Funktion besteht z. B. darin, Ladungen oder andere Teilchen von einer Seite zur anderen passieren zu lassen. Bei Modellmembranen müssen solche Einlagerungen bereits im Herstellungsprozess zugegeben werden.

Ankerproteine Manche Proteine liegen und wirken spezifisch auf einer Seite der Membran. Sie haben keinen Abschnitt, der die Membran durchspannt, aber einen hydrophoben Teil, der fest in der einen Schicht der Lipidmembran bindet. Die funktionelle Einheit liegt dabei außerhalb der Membran an der Oberfläche. Im Sinne des in dieser Arbeit verwendeten Modells, das die Doppelschicht-Charakteristik der Lipidmembran außer Acht lässt (d.h. jede eingelagerte Komponente durchspannt vollständig die Membran), werden Ankerproteine als Adsorbate angesehen. 
Periphere Proteine Proteine, die keinen oder keinen deutlichen hydrophoben Bereich besitzen, können auf die Membranoberfläche adsorbieren. Dabei wechselwirken sie mit den Kopfgruppen über elektrostatische Kräfte der Ladungen und/oder Dipole und eventuell auch mit den Ketten der Lipide. Manchmal findet man auch unterschiedlich stark eingelagerte Zustände des Teilchens, die im Extremfall den Ankerproteinen ähneln. Periphere Proteine haben oft eine Vermittlerfunktion mit dem Zellinneren.

In dieser Arbeit kann nur zwischen integralen und peripheren Proteinen unterschieden werden. Ankerproteine sind am ehesten von peripherem Charakter. Die Analyse des Modells zielt besonders auf die adsorbierten Komponenten, beschränkt sich aber nicht darauf.

Ein Beispiel für ein peripheres Protein ist Cytochrome C. Es handelt sich dabei um ein globulares elektrisch geladenes Protein, dessen funktionelle Gruppe durch eine Kette von 104 Aminosäuren umgeben ist. Die hydrophilen Seitengruppen der Aminosäurekette sind nach außen und die hydrophoben nach innen gelagert (siehe Kapitel 5 in Löffler und Petrides, 1988). Im Körper erfüllt es die Aufgabe eines Ladungstransporters (Goodsell, 2002). Die Wechselwirkung von Cytochrome C mit der Lipidmembran kann in künstlichen Systemen aus Vesikelsuspensionen mit Wasser untersucht werden (Heimburg und Biltonen, 1994; Heimburg und Marsh, 1996). Heimburg u. a. (1999) haben aus Adsorptionsisothermen bestimmt, wie viele Lipide durch ein Cytochrome CMolekül im Mittel bedeckt werden. Abhängig vom theoretischen Ansatz erhalten sie einen Wert von 7,8 oder 13. Die effektive Ladung des Proteins beträgt 3,8. (Zum Bindungsverhalten von Cytochrome $\mathrm{C}$ und zu theoretischen Beschreibungen gibt es weitere Arbeiten von T. Heimburg und anderen.) Das gesamte Protein und der funktionelle innere Teil des Cytochrome $\mathrm{C}$ sind in Abbildung 4.1 gezeigt.

Zum peripheren Charakter von Cytochrome C muss angemerkt werden, dass neuere Untersuchungen einen komplexeren Bindungsmechanismus zeigen, der auch den hydrophoben Teil der Membran mit beeinflusst. Als Einlagerungen in Modellmembranen untersucht man meist kleine integrale Proteine wie Gramicidin, welches nur eine Lipidmonoschicht umspannt oder hydrophobe Motive, das sind diejenigen Teile von integralen Proteinen, die durch die Membran ragen.

\subsection{Teilchen-Formen und Wechselwirkungs-Umgebungen}

In Kapitel 3 war das Modell einfach: Ein zweidimensionales Gitter wird besetzt durch verschiedene Komponenten oder Moleküle in verschiedenen Zuständen. Jedes Teilchen wechselwirkt mit seinen Nachbarn auf diesem Dreiecksgitter. Die „Form“ der Moleküle wird durch die Gitterplätze, ihre Wechselwirkung untereinander durch die nächsten Nachbarn (das entspricht den Kanten des Gitters) repräsentiert.

Als groß werden die Teilchen bezeichnet, wenn sie größer als die Gitterkonstante sind und damit mehr als einen Gitterplatz belegen. Die erste Aufgabe bei der Formulierung von solchen Komponenten in einem Gitter-Modell ist die Definition der Form und Wechselwirkung dieser Teilchen. Bei der Modellierung sollen nur die Gitterplätze benutzt werden, die Kanten werden nicht explizit mit einbezogen: 

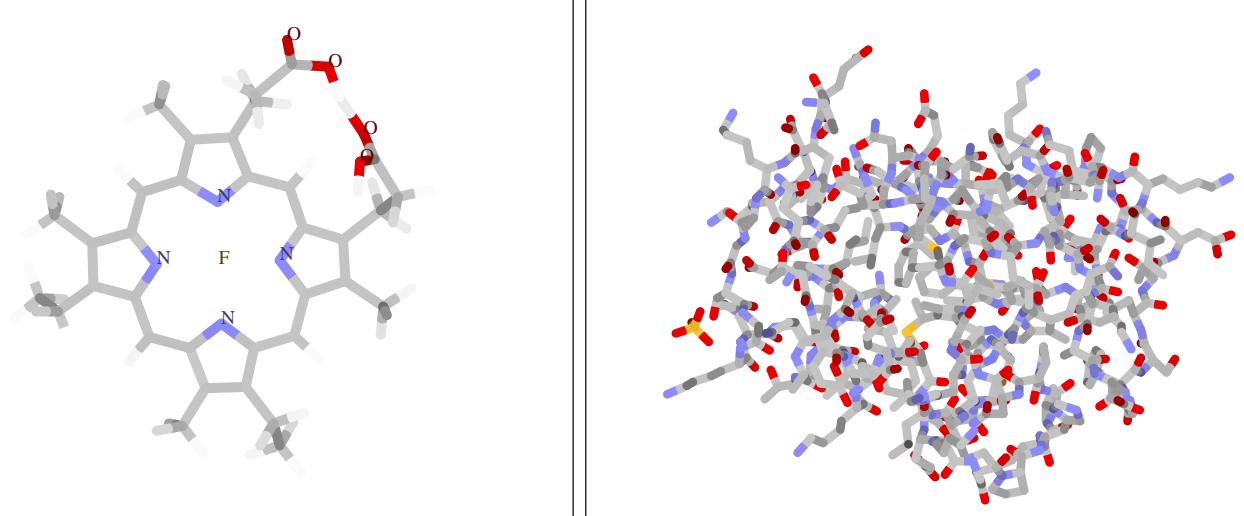

(a) Die funktionelle innere Häm-Gruppe um das Eisenatom trägt die transportierte Ladung.

(b) An die Häm-Gruppe schließt sich eine Kette aus 104 Aminosäuren an.

Abbildung 4.1: Cytochrome C, abgebildet nach Daten von Louie und Brayer (1990) aus der Protein Data Bank (Berman u. a., 2000).

Besetzungszahlen Die Anzahl der Proteine im System wird auch im Fall großer Komponenten durch eine Besetzungszahl $n_{i}^{P}$ ( $n_{i}^{I}$ für integrale Proteine) auf dem Gitter bestimmt:

$$
n_{i}^{P} \text { bzw. } n_{i}^{I}= \begin{cases}1 & \text { Zentrum des Proteins an Platz } i \\ 0 & \text { sonst }\end{cases}
$$

Die Einschränkung auf zwei Werte bedeutet, dass sich zwei Teilchen nicht komplett überlagern können. Die Besetzungszahl reicht zur Beschreibung der Form der Teilchen nicht aus.

Harte Kerne Entsprechend der Modellierung der kleinen Komponenten soll unter der Form eines Teilchens sein harter Kern verstanden werden. Harte Kerne können sich nicht überlappen. Die Gitterplätze, die zum harten Kern des Proteins auf Platz $i$ gehören, sollen in der Menge $o_{i}^{P}$ ( $o_{i}^{I}$ für integrale Komponenten) gelistet sein. Definitionsgemäß muss $i$ selbst in $o_{i}^{P}$ (bzw. $o_{i}^{I}$ ) enthalten sein. Für die Lipide ist zu beachten, dass deren Harte-Kern-Umgebung weiterhin nur ihrem Gitterplatz entspricht.

In anschaulicher Art und Weise ist das Modell in Abbildung 4.2 gezeigt, in dem die Ellipsen die harten Kerne der Teilchen repräsentieren. Die integralen Komponenten verdrängen die Lipide, die Adsorbate hingegen bilden eine eigene Schicht. Abbildung 4.3 zeigt das Modell der Lipidmembran mit großen Adsorbaten, welche sieben Gitterplätze belegen, in der im Folgenden gebräuchlichen zweidimensionalen Aufsicht. Die roten (bzw. dunklen) Bereiche in Bild 4.2(b) der Adsorbatschicht sind 
so zu interpretieren, dass auf dem Platz in der Mitte der sieben die Besetzungszahl $n_{i}^{P}=1$ ist und auf allen sieben Plätzen einschließlich der Mitte $o_{j}^{P}=1$.

Reichweite der Wechselwirkung Die Wechselwirkung wird nun ganz analog zu den harten Kernen über Umgebungen, d.h. Mengen mit den wechselwirkenden Gitterplätzen als Einträgen, beschrieben. Dabei muss man aber unterscheiden zwischen der Protein-Protein- und der Protein-Lipid-Wechselwirkung. Sie können nicht nur in ihrer Stärke, sondern auch in ihrer Reichweite verschieden sein. Für die ProteinProtein-Wechselwirkung soll die Menge $w_{i}^{P P}$ (bzw. $w_{i}^{I I}$ ) für jeden Gitterplatz $i$ eingeführt werden. Die Protein-Lipid-Wechselwirkung wird beschrieben durch $w_{i}^{P L}$ (bzw. $w_{i}^{I L}$ ).

Durch die Einführung einer repulsiven Protein-Protein-Wechselwirkung können „weiche Kerne" modelliert werden. In dieser Arbeit soll ein Teilchen immer dann als weich bezeichnet werden, wenn seine Wechselwirkungs-Umgebungen weiter reichen als sein harter Kern.

Rotationsfreiheitsgrad der Proteine Diese Formulierung beschränkt sich zunächst auf symmetrische Teilchen. Sollen die beschriebenen Umgebungen nicht symmetrisch auf dem Gitter sein, so ist ein weiterer Index zur Beschreibung der Umgebung (z. B. $o_{i, j}^{P}$ oder $\left.w_{i, j}^{P P}\right)$ notwendig, der die Orientierung beschreibt. Dieser Index repräsentiert dann den Rotationsfreiheitsgrad der Komponenten, der neben den Besetzungszahlen auch in der Zustandssumme berücksichtigt werden müsste. Tatsächlich ist dies in der Simulation, die für diese Arbeit geschrieben wurde, implementiert und wird in Abschnitt 4.5 für ein Beispiel angewendet.

Die Wechselwirkung wird nun durch die Überlappung von Umgebungen beschrieben. Dabei können die Wechselwirkungs-Umgebungen $w_{i}^{P P}$ usw. auch Teile der Harte-KernUmgebungen $o_{i}^{P}$ usw. überlappen. Es gibt also für jedes Paar von Molekülspezies zwei unterschiedliche Wechselwirkungs-Konstanten: $K^{w w}$ und $K^{w o}$. Die Kopplung $K^{o o}$ der harten Kerne ist wegen der Definition von $o^{P}$ (nach der eine Überlappung ausgeschlossen ist) quasi unendlich groß.

Nach der Einführung dieser Begriffe schreibt sich die Hamiltonfunktion einer Lipidmembran mit großen Komponenten, also des allgemeinsten in dieser Arbeit untersuchten Systems, wie folgt:

$$
\begin{aligned}
\mathcal{H}_{\text {Biomembran }}= & \frac{K_{L L}}{2} \sum_{i} \sum_{j \in w_{i}^{L L}} n_{i}^{L} n_{j}^{L}+(H-T S) \sum_{i} n_{i}^{L} \\
& +K_{P L} \sum_{i} \sum_{j \in w_{i}^{P L}} n_{i}^{P} n_{j}^{L} \\
& +\frac{K_{P P}^{w o}}{2} \sum_{i} \sum_{\substack{k \in w_{i}^{P P} \\
k \in o_{j}^{P}}} n_{i}^{P} n_{j}^{P}+K_{P P}^{w w} \sum_{i} \sum_{\substack{k \in w_{i}^{P P} \\
k \in w_{j}^{P P}}} n_{i}^{P} n_{j}^{P}
\end{aligned}
$$

Zur Vereinfachung wurden die Terme mit $K_{L L}^{w w}$ und $K_{L P}^{w w}$ der WechselwirkungsUmgebungen miteinander für die Lipide nicht berücksichtigt, da sie für die weiteren Betrachtungen - der Einfluss der Form der Proteine soll in erster Linie untersucht werden - nicht von Belang sind. Die oberen Indizes konnten dadurch bei 


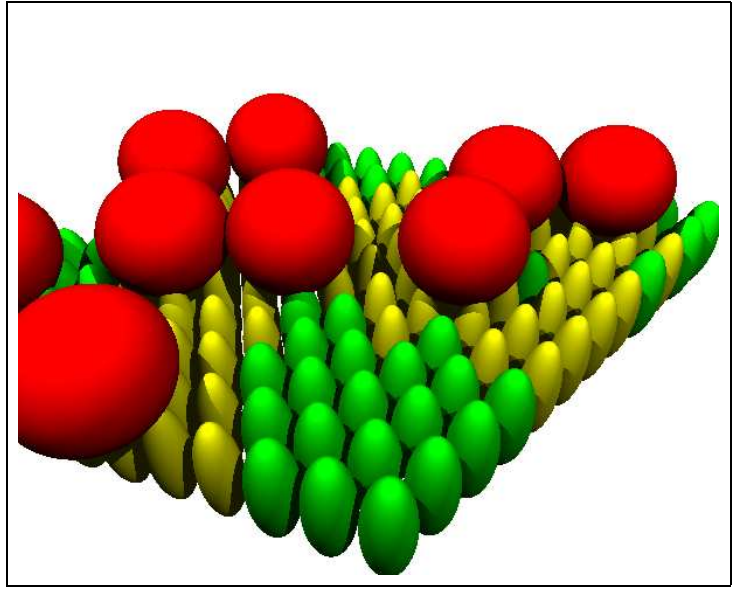

(a) Lipidmembran mit großen Adsorbaten

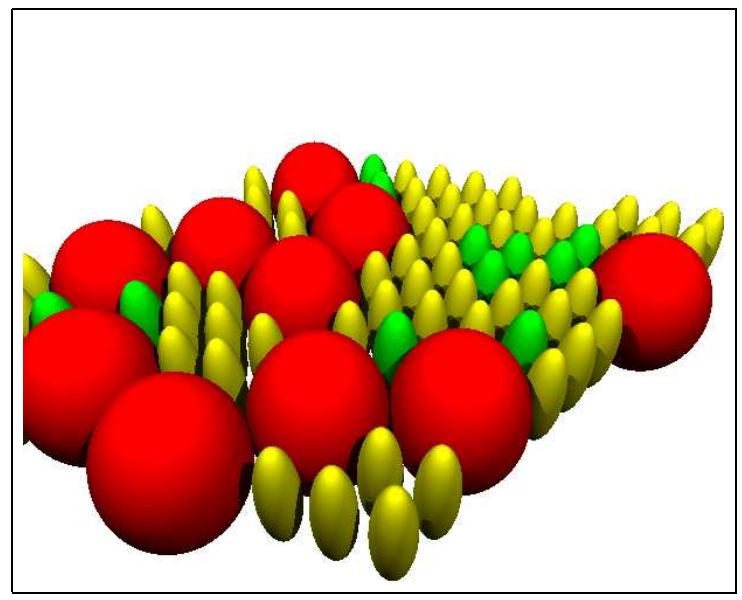

(b) Lipidmembran mit großen Einlagerungen

Abbildung 4.2: Modellbild des kompletten Systems in einer dreidimensionalen Seitenansicht. Die gestreckten Lipide sind gelbe (helle) Ellipsen, die gefalteten grün (dunkel). Die Proteine sind rote (sehr dunkle) Kugeln. Sie liegen entweder auf der Membran oder sind in diese eingebettet.

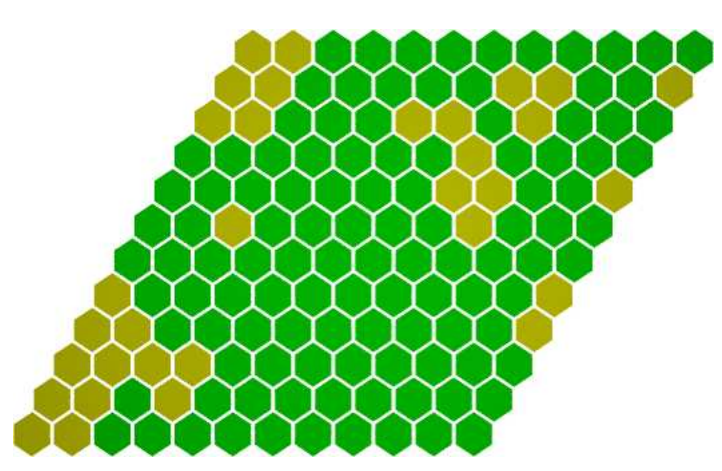

(a) Lipide

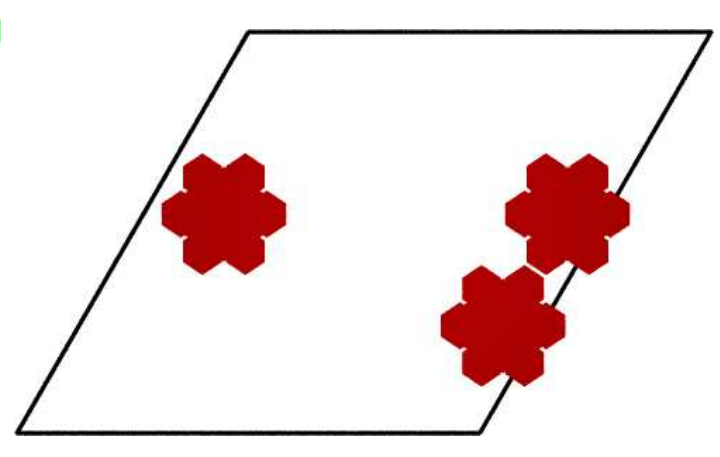

(b) Adsorbate

Abbildung 4.3: Schnappschuss einer Lipidmembran mit großen Adsorbaten in einer zweidimensionalen Aufsicht. Die kleinen gelben (hellen) Hexagone sind gestreckte Lipide, die grünen (dunklen) sind gefaltete. Die aus mehreren kleinen Hexagonen zusammengesetzten Formen zeigen den harten Kern der Proteine. 
den Lipid-Wechselwirkungen entfallen. So enthält diese Hamiltonfunktion nur einen Wechselwirkungs-Parameter mehr als die der kleinen integralen Komponenten aus Gleichung 3.2. Selbstverständlich sind die Umgebungen $w^{P L}, w^{P P}$ und $o^{P}$ auch variable Parameter des Modells. Die positiven Vorzeichen der Protein-Protein-Wechselwirkung deuten an, dass im Allgemeinen abstoßende Wechselwirkungen betrachtet werden sollen. Die Gleichung 4.2 gilt für integrale Komponenten ganz analog mit dem Index $I$ statt $P$.

Gittergas aus harten Hexagonen Ein Nachteil der gewählten Formulierung ist sicherlich, dass sie sehr umfangreich und auf den ersten Blick umständlich wirkt. Der Vorteil ist aber, dass nun wirklich jede durch das Gitter darstellbare Form von Teilchen beschrieben werden kann. Durch bestimmte Wahl der Wechselwirkungs-Konstanten mit Index ww und wo lassen sich auch Formen repräsentieren, die nicht genau eine gewisse Menge von Gitterplätzen überdecken, sondern gewissermaßen die Zwischenräume. Das soll am Beispiel der Harten Hexagone verdeutlicht werden. Das Modell einer zweidimensionalen Schicht aus harten Hexagonen ist exakt gelöst und zeigt einen stetigen Phasenübergang in eine geordnete Struktur bei hohen Dichten von etwa 0,8 (Baxter, 1980, 1982).

Die Form harter Hexagone wird im Rahmen des Modells folgendermaßen dargestellt. Die Harte-Kern-Umgebung $o_{i}^{P}$ ist gleich dem Platz $i$, weil es auf Nachbarplätzen Überlappungen geben kann. Die Wechselwirkungs-Umgebung $w_{i}^{P}$ umfasst $i$ selbst und alle nächsten Nachbarn. Um nur den Aufenthalt von Zentren anderer Proteine auf Nachbarplätzen zu verhindern, muss die Kopplung $K_{P P}^{w o}$ gegen unendlich gehen (praktisch heißt das: viel größer als die thermische Energie) und $K_{P P}^{w w}$ gleich null sein. Für eine Skizze der Hexagonform auf dem Dreiecksgitter siehe Abbildung 4.4.

Der Harte-Hexagon-Übergang ist rein entropischen Ursprungs und nur der Spezialfall des Übergangs, den ausgedehnte Scheiben jeder Form durchlaufen. Der Übergang besteht in folgender Veränderung des Zustandsraumes: Bei geringen Dichten kann jedes Teilchen den ganzen Raum per Diffusion erreichen. Wird die Dichte höher, so gibt es irgendwann einen Punkt, an dem die Lücken zwischen den Teilchen so klein geworden sind, dass eine Diffusion effektiv verhindert wird. Die Teilchen können die Umgebung ihres Aufenthaltsortes nicht mehr verlassen. Die Diffusions-Konstante ist also ein mögliches Maß für den Übergang. Bei ausgedehnten Teilchen (von nun an sollen Hexagone betrachtet werden) auf einem Gitter gibt es noch eine einfachere statische Größe zur Bestimmung des Übergangspunktes. Die Hexagone müssen auf dem Gitter möglichst dicht gepackt werden. In der dichtesten Packung ist ein Untergitter vor den zwei anderen ausgezeichnet (siehe Abbildung 4.4). Der Wert der Dichte, an dem die Symmetrie bezüglich der Untergitter aufgehoben wird, definiert den Phasenübergangspunkt. Als Maß dient die Differenz der Teilchendichten auf den Untergittern. Sie ist null in der ungeordneten Phase und bei geeigneter Normierung eins in der dichtesten Packung.

Das Modell harter Hexagone ist bezüglich vieler Eigenschaften untersucht worden. Beispielsweise berechnen Richey und Tracy (1987) die Zustandsgleichung des Systems in der ungeordneten Phase, Nagai (1991) charakterisiert das Desorptions-Verhalten der harten Hexagone und vergleicht es mit dem anderer Modelle und mit Experimenten an FestkörperOberflächen und Villain und Moreira (1991) wenden das Modell auf die Untersuchung von Adsorptionsschichten aus zwei Atomsorten an. Eine Kopplung des Phasenübergangs harter Hexagone an andere Systeme wie dem Ising-Modell wurde auch untersucht (z. B. von Honda und Horiguchi, 1997), entspricht aber in der dortigen Form nicht dem in dieser Arbeit entwickelten Mehrschicht-Modell. 


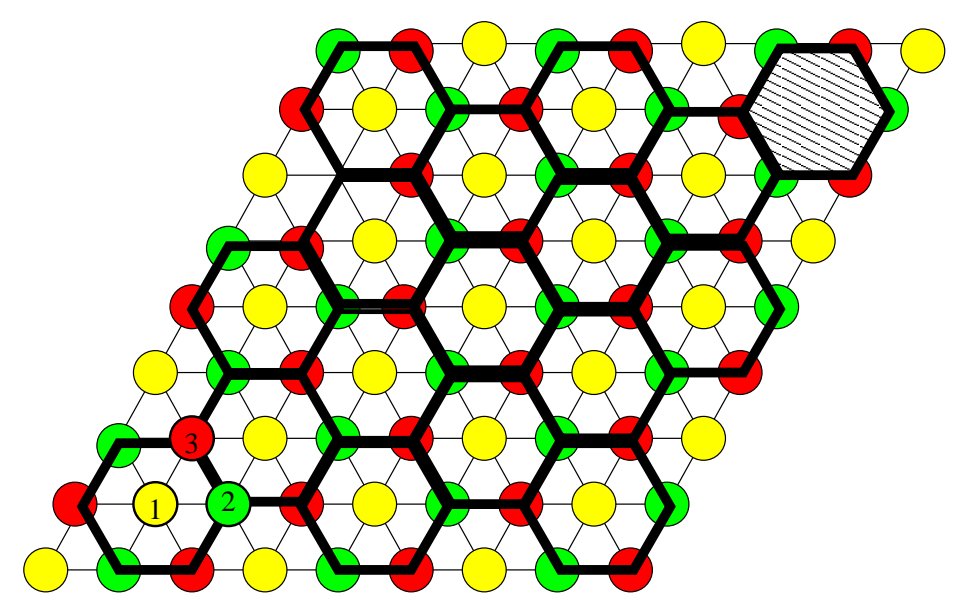

Abbildung 4.4: Untergitter im Falle der Ordnung harter Hexagone zur dichtesten Packung. Es sind drei Untergitter durch die Farben gelb, grün und rot (bzw. drei Grautöne) ausgezeichnet. Das Gitter ist mit Hexagonen voll besetzt, wenn genau ein Untergitter (in diesem Fall das gelbe bzw. helle) besetzt ist. Das schraffierte Hexagon verdeutlicht lediglich die Form der Objekte.

\subsection{Effektive Systeme aus Lipiden oder Proteinen}

In den nächsten beiden Unterabschnitten wird die Biomembran einerseits als effektives System nur aus Lipiden und andererseits als effektives System nur aus Proteinen beschrieben. Die jeweils andere Teilchensorte wird, wie in Abschnitt 2.3 unter dem Stichwort effektive Wechselwirkung grundsätzlich erläutert, aus der Zustandssumme aussummiert. Dabei wird im ersten Fall die Methode der Mittlere-Feld-Näherung und im zweiten die Monte-Carlo-Simulation eingesetzt.

\subsubsection{Effektives Lipidsystem mit Mehrteilchen-Wechselwirkung}

Im Folgenden soll die von peripheren Proteinen bedeckte Lipidmembran als ein effektives reines Lipidsystem aufgefasst werden, d. h. die Proteinfreiheitsgrade sollen komplett aussummiert werden. Solch eine partielle Ausführung der Zustandssumme ist im Allgemeinen, d. h. für jede Form von Adsorbaten, nicht möglich - wohl aber für einen bestimmten Fall.

Der Ausgangspunkt ist die komplette Zustandssumme des Modells der Biomembran, wie sie durch die Hamiltonfunktion in Gleichung 4.2 gegeben ist. Die resultierende Zustandssumme erinnert daran, dass über alle möglichen Konfigurationen der Besetzungszahlen der Lipide und Proteine auf dem Gitter summiert werden muss:

$$
\mathcal{Z}_{\text {Biomembran }}=\sum_{\left\{n^{L}\right\}} \sum_{\left\{n^{P}\right\}} \exp \left[-\beta \mathcal{H}_{\text {Biomembran }}\right]
$$

Die Schwierigkeiten in der Summation liegen im Allgemeinen an nichtlokalen Termen der Hamiltonfunktion, wie z. B. der Nächste-Nachbar-Wechselwirkung der Lipide. In der hier gezeigten Approximation soll deshalb zunächst auf alle nichtlokalen Terme der ProteinProtein-Wechselwirkung verzichtet werden. Das bedeutet, dass die Proteine nur über ihren (kleinen) harten Kern von einem Gitterplatz miteinander wechselwirken. Die ProteinLipid-Wechselwirkung jedoch soll so weit wie möglich exakt berücksichtigt werden. Eine Komponente, deren Reichweite der Wechselwirkung größer ist als ihr harter Kern, wird als 
weich bezeichnet. In diesem Sinne sind die hier betrachteten Proteine große sehr weiche Adsorbate, deren Hamiltonfunktion genau Gleichung 4.2 ohne die beiden letzten Terme entspricht.

Die ersten Schritte der Rechnung unterscheiden sich nicht von dem Fall kleiner Adsorbate aus Abschnitt 3.5.1. Man muss nur den Wechselwirkungs-Term der Proteine mit den Lipiden in Gleichung 3.27 durch die ausgedehnte Wechselwirkung ersetzen und entsprechend durch die Rechnung in Gleichung 3.28 hindurchziehen:

$$
\sum_{i} n_{i}^{P} n_{i}^{L} \longrightarrow \sum_{i, j \in w_{i}^{P L}} n_{i}^{P} n_{j}^{L}
$$

Das bis hierhin exakt resultierende effektive Lipidsystem ist durch folgende Zustandssumme charakterisiert:

$$
\begin{aligned}
\mathcal{Z}= & \sum_{\left\{n^{L}\right\}} \exp \left\{-\beta\left(K_{L L} \sum_{i, j \in w_{i}^{L L}} n_{i}^{L} n_{j}^{L}+(H-T S) \sum_{i} n_{i}^{L}\right)\right\} \times \\
& \exp \left\{-\beta \sum_{i}-T \log \left[1+\exp \left[-\beta\left(K_{P L} \sum_{j \in w_{i}^{P L}} n_{j}^{L}-\mu\right)\right]\right]\right\}
\end{aligned}
$$

$\mathrm{Zu}$ diesem Zwischenergebnis lassen sich einige Anmerkungen machen:

1. Die Proteinfreiheitsgrade $\left\{n^{P}\right\}$ sind exakt berücksichtigt. Die Zustandssumme bezieht sich nur noch auf die Freiheitsgrade $\left\{n^{L}\right\}$ der Lipide.

2. Der neue Term in der effektiven Hamiltonfunktion ist wegen seines entropischen Ursprungs auf komplizierte Art und Weise temperaturabhängig. Die Summation über die Besetzungszahlen der Lipide ist nicht trivial.

3. Im einfachsten Fall, wenn die Protein-Lipid-Wechselwirkungs-Umgebung nur einen Platz umfasst, kann man den Term einfach umschreiben (verwende $f(n=\{0,1\})=$ $n f(1)+(1-n) f(0))$ und erhält einen Beitrag zum homogenen Feld der Lipidmembran (siehe Abschnitt 3.5.1).

4. Der neue Term enthält die Korrelationen der Lipidzustände aufgrund der gemeinsamen Überdeckung. In der Zustandssumme müssen alle möglichen Konfigurationen der Lipide in der Wechselwirkungs-Umgebung berücksichtigt werden.

Die in Abschnitt 3.5.1 dann folgende exakte Auflösung des Wechselwirkungs-Terms in einen neuen Beitrag zum homogenen Feld ist hier wegen der ausgedehnten Umgebung $w_{i}^{P L}$ nicht möglich. Um den Effekt der Proteine auf das Lipidsystem näher studieren zu können, wird an dieser Stelle das Lipidsystem mit der üblichen Mittlere-Feld-Näherung approximiert (siehe Abschnitt 2.6). Aus der Zustandssumme in Gleichung $4.5 \mathrm{kann}$ die freie Energie $\mathcal{F}_{\mathrm{MF}}=-T \log [\mathcal{Z}]$ direkt als Funktion des MF-Parameters $m=\left\langle n^{L}\right\rangle_{\mathrm{MF}}$ angegeben werden. Um diesen Schritt nachzuvollziehen, betrachte man die beiden Faktoren der Zustandssumme getrennt. Der erste Term entspricht genau dem Beitrag des einfachen Gittergases bzw. des Ising-Modells. Aus diesem folgt sofort der erste Beitrag zu Gleichung 4.6. Für den zweiten Teil muss die Anzahl der oben erwähnten Konfigurationen der Lipide in der Wechselwirkungs-Umgebung durch die mittlere Besetzungszahl ausgedrückt werden. 
Dafür zählt man die Möglichkeiten, eine bestimmte Anzahl von gestreckten Lipiden unter ein Protein zu setzen (die Anzahl der gefalteten folgt sofort) und summiert über alle möglichen Anzahlen. Der resultierende Beitrag in der freien Energie wird im Folgenden kurz erläutert:

$$
\begin{aligned}
\mathcal{F}_{\mathrm{MF}}= & -T \log \mathcal{Z} \\
\approx & K_{L L} m^{2}+(H-T S) m+T(m \log m-(1-m) \log (1-m))- \\
& T \sum_{r=0}^{\eta+1}\left(\begin{array}{c}
\eta+1 \\
r
\end{array}\right) m^{\eta+1-r}(1-m)^{r} \log \left[1+\exp \left[-\beta\left((\eta+1-r) K_{P L}-\mu\right)\right]\right]
\end{aligned}
$$

Die Anzahl der durch ein Protein bedeckten Lipide sei $\eta+1$. Für jeden Summanden sei angenommen, dass $r$ Lipide im gestreckten Zustand und folglich $\eta+1-r$ Lipide im gefalteten sind. Die Wahrscheinlichkeit für eine solche Konfiguration ist $m^{\eta+1-r}(1-m)^{r}$, der Binomialkoeffizient zählt die Zahl möglicher Konfigurationen zu einer bestimmten Zahl von gestreckten Lipiden. Der log [...]-Faktor schließlich bestimmt das Gewicht jeder Konfiguration und ist direkt aus der Zustandssumme 4.5 abzulesen. Der Term höchster Ordnung in der Lipid-Wechselwirkung ist von der Ordnung $\eta+1$, welches genau die Anzahl bedeckter Lipide pro Protein ist. Jede einzelne Kopplungs-Konstante in 4.6 ist negativ $(-T \log [1+\exp [\ldots]])$, d. h. ordnend, aber das Vorzeichen der Kopplung für jede Ordnung von $m$ könnte beide Werte annehmen, da verschiedene Terme aus der Summe über $r$ zusammengefasst werden müssen. Der Frage nach dem Vorzeichen und damit nach der Tendenz zur Ordnung soll im Folgenden nachgegangen werden, indem die Terme der MehrteilchenWechselwirkung nach Ordnungen von $m$ sortiert werden. Man schreibt den Term $(1-m)^{r}$ in Gleichung 4.6 mit Hilfe der binomischen Formel um, führt ein Kronecker-Delta zur Festlegung der Potenz von $m$ ein und erhält folgenden Wechselwirkungs-Term $s$-ter Ordnung:

$$
-T m^{s} \sum_{r=0}^{\eta+1}\left(\begin{array}{c}
\eta+1 \\
r
\end{array}\right)\left(\begin{array}{c}
r \\
s+r-\eta-1
\end{array}\right)(-1)^{s+r-\eta-1} \log [1+\exp [\ldots]]
$$

Wegen des alternierenden Vorzeichens lässt sich über den Charakter der Wechselwirkung, ob sie „ferromagnetisch“ ordnend ist oder nicht, nichts Allgemeines aussagen. Eigene Berechnungen aller Ordnungen für bestimmte Größen und Wechselwirkungen der Adsorbate mit dem Computerprogramm Maple ${ }^{\mathrm{TM}}$ bestätigen dieses Bild und zeigen, dass die Wechselwirkungs-Konstanten mancher Ordnungen positiv und die anderer negativ sind (das Programm wird z. B. in Walz, 2002, beschrieben).

Interessant an diesem Ergebnis ist die Abhängigkeit von der Größe $\eta$ der Proteine. Eine vergleichbare Aussage zur Größenabhängigkeit von Adsorbaten findet sich in der Literatur nur in der Arbeit von Netz u. a. (1996). Diese behandeln jedoch die Proteine in einer Ginzburg-Landau-Formulierung, welches einem Mittlere-Feld-Ansatz entspricht. Die neue effektive Mehrteilchen-Wechselwirkung in der freien Energie von Gleichung 4.6 lässt sich auch quantitativ erfassen. Sie enthält als Abhängigkeiten die Größe des Adsorbats, dessen chemisches Potential und die Kopplungs-Konstante pro Platz. Man wählt ein bestimmtes Szenarium für die Lipidmembran (vergleichbare Werte für die Kopplung und das chemische Potential) und variiert die Größe. Als Observable wählt man die Breite des Übergangs, die als Halbwertsbreite des Maximums der spezifischen Wärme definiert wird. Dafür muss man sinnvollerweise im Bereich des Phasendiagramms sein, in dem der Übergang kontinuierlich ist. Die Kopplungs-Konstante der Lipide wird also gegenüber typischen Werten 


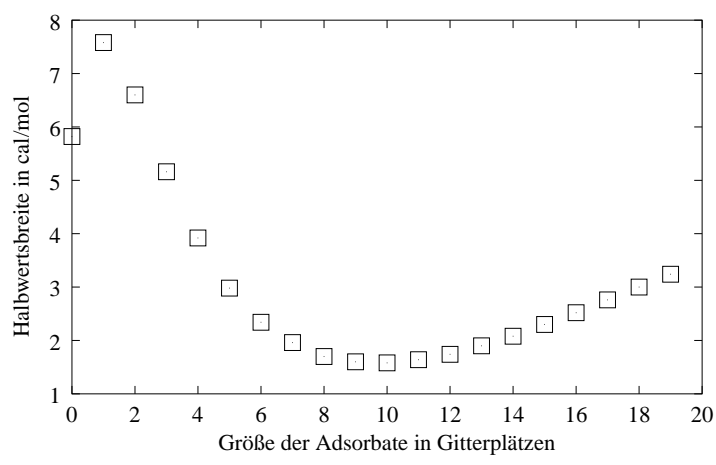

(a) Mittlere-Feld-Approximation

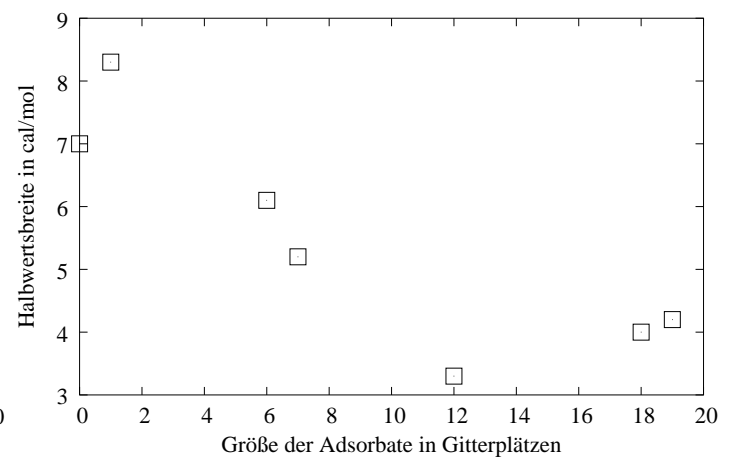

(b) Monte-Carlo-Simulation

\begin{abstract}
Abbildung 4.5: Verstärkung der Kooperativität: Verhalten des effektiven Lipidsystems mit Mehrteilchen-Wechselwirkung in MF-Näherung und Vergleich mit MC-Simulationen (man beachte die etwas unterschiedliche Skalierung der Ordinaten). MC-Parameter: $L=50, K_{L L}=$ $-540 \mathrm{cal} / \mathrm{mol}, K_{P L}=200 \mathrm{cal} / \mathrm{mol}$.
\end{abstract}

von Lipidvesikeln etwas erniedrigt, um den Abstand vom kritischen Punkt zu erhöhen. Das Ergebnis dieser Analyse ist in Abbildung 4.5(a) zu sehen.

Die Lipid-Protein-Kopplung ist so gewählt, dass sie zu einer Verschiebung des Übergangs weiter weg vom kritischen Punkt des Modells führt und den Übergang damit verbreitert. Diese Verbreiterung ist bei einer Größe von einem Platz auch zu erkennen. Bei größeren Adsorbaten wirkt nun die Korrelation der Ausdehnung als neue Kooperativität und verschmälert den Übergang. Der Anstieg der Halbwertsbreite bei sehr großen Proteinen ist darauf zurückzuführen, dass bei vergleichbarem chemischen Potential die großen Adsorbate mit einer wesentlich größeren Rate desorbieren, die Lipidmembran also gar nicht mehr so stark bedeckt ist.

Um einen Übergang zur Methode der Monte-Carlo-Simulationen zu finden, soll zunächst das oben erwähnte Phänomen der effektiven Lipid-Kopplung nachvollzogen werden. Dazu wird genau das System, welches durch die Approximation beschrieben ist, simuliert: die Lipidmembran mit Adsorbaten, die eine ausgedehnte Protein-Lipid-WechselwirkungsUmgebung besitzen, aber nur einen Platz auf dem Gitter besetzen. Die Lipid-Parameter werden ganz analog gewählt, die Kopplungs-Konstante wie üblich so angepasst, dass die Übergangsbreite in etwa stimmt. Nun lassen sich auf dem Gitter nicht symmetrische Formen beliebiger Größe definieren, deshalb besitzt die Abbildung 4.5(b) nicht zu jeder Größe einen Wert. Der Vergleich zeigt, dass die Monte-Carlo-Simulation nicht nur qualitativ die Approximation bestätigt, auch quantitativ sind die Abweichungen erstaunlich gering. Man beachte dabei, dass der Absolutwert der Halbwertsbreite des reinen Lipidsystems sehr empfindlich von der Kopplungs-Konstante $K_{L L}$ abhängt und diese bezüglich der beiden Methoden Mittlere-Feld-Näherung und Monte-Carlo-Simulation grundsätzlich nicht vergleichbar sondern nur anpassbar ist. Die Ähnlichkeit der analytischen Ergebnisse mit den simulierten demonstriert erstens, dass die effektive Lipid-Kopplung kein Artefakt der Approximation ist und zweitens, dass sie für diesen Parameterbereich auch quantitativ richtig durch die Approximation wiedergegeben wird. 


\subsubsection{Effektive Protein-Protein-Wechselwirkung}

Die Computersimulation hat gegenüber der analytischen Approximation den Vorteil, dass das Modell nicht weiter vereinfacht werden muss. Insbesondere kann nun die ProteinProtein-Wechselwirkung, also die Größe und Form der Komponenten variiert werden.

Wie im Rahmen der Modellbildung beschrieben, sollen die Adsorbate außer ihrer HarteKern-Wechselwirkung keine weiteren direkten intermolekularen Wechselwirkungen besitzen. Im vorherigen Abschnitt wurde der Einfluss der peripheren Proteine auf den Übergang der Lipide untersucht und dargestellt. Nun soll die Fragestellung umgekehrt werden und der Einfluss der Lipide auf das Proteinsystem gezeigt werden. Dazu wird zunächst die vermittelte, d.h. die von den Lipiden in das Proteinsystem hineingetragene, Wechselwirkung ausgemessen. Der mögliche Einfluss auf Übergänge in der Adsorbatschicht wird im nächsten Abschnitt untersucht.

In Abschnitt 2.3 wurde das Konzept der effektiven Wechselwirkung allgemein eingeführt und das Potential der mittleren Kräfte definiert. Genau wie bei dem in Abschnitt 4.2.1 berechneten effektiven Lipidsystem basiert die Darstellung des effektiven Proteinsystems auf der Hamiltonfunktion der Biomembran in Gleichung 4.2 und der zugehörigen kanonischen Zustandssumme in Gleichung 4.3.

Die direkte Berechnung der effektiven Hamiltonfunktion über Gleichung 2.4 ist im Rahmen einer Monte-Carlo-Simulation nicht ohne weiteres möglich. Mit der als Potential der mittleren Kräfte interpretierten effektiven Wechselwirkung $\mathcal{H}^{\text {eff. }}(i, j)$ (siehe Gleichung 2.7 und 2.8) ist es möglich, den Beitrag der Paar-Wechselwirkung in der Näherung niedriger Protein-Dichte auf eine Observable (die mittlere Kraft, siehe Gleichung 2.9) abzubilden. In einem Gitter-Modell wie dem vorliegenden ist aber der Ausdruck der Kraft wegen des Gradienten zunächst nicht definiert. Der zum Gradienten auf dem Gitter äquivalente Quotient (die Variable $a$ bezeichne die Gitterkonstante) schreibt sich wie folgt:

$$
\begin{aligned}
\nabla_{j} \mathcal{H}^{\text {eff. }}(i, j) \equiv & \frac{\mathcal{H}^{\text {eff. }}(i, j+a)-\mathcal{H}^{\text {eff. }}(i, j)}{a}= \\
& =-\frac{1}{a} T \log \left\{\frac{\sum_{\left\{n^{L}\right\}} \exp [-\beta \mathcal{H}(i, j+a)]}{\sum_{\left\{n^{L}\right\}} \exp [-\beta \mathcal{H}(i, j)]}\right\} \\
& =-\frac{1}{a} T \log \langle\exp [-\beta(\mathcal{H}(i, j+a)-\mathcal{H}(i, j))]\rangle_{\left\{n^{L}\right\} ; i, j \text { fest }}
\end{aligned}
$$

Die spitzen Klammern symbolisieren den Erwartungswert im Ensemble des Gesamtsystems, bestehend aus der Schicht von Lipiden und je einem Protein auf den Plätzen $i$ und $j$. Die Differenz der Hamiltonfunktion im Exponenten aufgrund der Verschiebung des einen Proteins um eine Gitterkonstante lässt sich folgendermaßen abschätzen:

Man betrachte nur die Protein-Lipid-Wechselwirkung, denn die direkte Protein-ProteinKopplung lässt sich aus der Mittelung herausziehen und ist deshalb unproblematisch. Der Wert $\gamma$ bezeichne die Anzahl von Gitterplätzen, in denen sich die WechselwirkungsUmgebung des Platzes $j$ von der des verschobenen Platzes $j+a$ unterscheidet. Beispielsweise entsprechen für eine symmetrische Wechselwirkungs-Umgebung von sieben Plätzen in Form eines Hexagons drei Gitterplätze der verschobenen Umgebung nicht denen der ursprünglichen. Der Energieunterschied ist maximal, wenn alle Lipidzustände auf den $\gamma$ Plätzen der verschobenen Umgebung verschieden sind von den ebenfalls $\gamma$ freigewordenen.

$$
\Delta \mathcal{H}=\mathcal{H}(i, j+a)-\mathcal{H}(i, j) \leq \gamma K_{P L}
$$


Damit man von den auf dem Gitter definierten Größen auf der rechten Seite von Gleichung 4.8 zur kontinuierlichen auf der linken Seite übergehen kann, muss der Grenzwert $a \rightarrow 0$ existieren. Der einzige Parameter, der hier vom Gitter abhängig sein kann, ist die Kopplungs-Konstante $K_{P L}$, denn die Zahl $\gamma$ ist für eine Protein-Form immer die gleiche, unabhängig von der Auflösung des Gitters. Die Kopplung muss also proportional zur Gitterkonstante sein. Betrachtet man nur das Regime des Gitter-Modells, in dem dies gilt, kann man den Ausdruck in Gleichung 4.8 entwickeln und erhält nach kurzer Rechnung, dass die mittlere Kraft im Kontinuum der Differenz von inneren Energien im Gitter-Modell entspricht und damit die effektive Wechselwirkung direkt aus der inneren Energie zu bestimmen ist:

$$
-\nabla_{j} \mathcal{H}^{\mathrm{eff} .}(i, j) \stackrel{a \rightarrow 0}{\equiv}-\langle\Delta \mathcal{H}\rangle_{\left\{n^{L}\right\} ; i, j \text { fest }}
$$

Im Prinzip ist mit der so bestimmten Wechselwirkung ein neues Modell aus Proteinen analog zu Gleichung 2.5 beschrieben, welches jedoch nicht als solches untersucht wird. Da das Gitter homogen und isotrop ist, hängt die Energie nur vom Abstand $r$ der Punkte $i$ und $j$ ab. Um nur die Effekte zu berücksichtigen, die von der durch die Lipide vermittelten Paar-Wechselwirkung der Proteine hervorgerufen werden, wird in der Monte-CarloSimulation folgende Observable gemessen:

$$
U(r):=\langle\mathcal{H}(i, j)\rangle_{\left\{n^{L}\right\} ; i, j \text { fest }}-2\left(\left\langle\mathcal{H}_{1}(i)\right\rangle_{\left\{n^{L}\right\} ; i \text { fest }}-\left\langle\mathcal{H}_{0}\right\rangle_{\left\{n^{L}\right\}}\right)-\left\langle\mathcal{H}_{0}\right\rangle_{\left\{n^{L}\right\}}
$$

Das bedeutet erstens, dass $U(r)$ (eventuell bis auf eine Konstante) genau $\mathcal{H}^{\text {eff. }}(i, j)$ entspricht und zweitens, dass das Potential in drei Schritten berechnet werden muss: Die Mittelwerte ohne Proteine, mit einem Teilchen und mit einem Paar müssen getrennt voneinander simuliert werden.

Unabhängig von den Überlegungen zur Energiedifferenz ist $U(r)$ auch dann eine gute Näherung an die effektive Wechselwirkung, wenn die entropischen Beiträge zum effektiven Potential relativ klein sind. Dann kann man nämlich den Logarithmus in Gleichung 4.8 in die Mittelung ziehen. In jedem Fall aber beschreibt die Observable den Beitrag der inneren Energie zur Paar-Wechselwirkung der Proteine. Im weiteren Verlauf der Arbeit ist immer $U(r)$ aus Gleichung 4.11 gemeint, wenn von der effektiven Wechselwirkung oder dem effektiven Potential der Proteine die Rede ist.

Konkret wird die Ortsabhängigkeit in Gleichung 4.11 dargestellt, indem das eine Protein auf einem Platz festgehalten und das andere für jede Messung auf einen Platz eines Sechstels der Umgebung des ersten gesetzt wird (siehe Abbildung 4.6). Durch diese Prozedur ergeben sich auch Abstände, die kein Vielfaches der Gitterkonstante sind. Manche Abstände ergeben sich mehrfach. Wegen der Symmetrie des Gitters hat man mit einem Sechstel der Umgebung alle möglichen Abstände ermittelt.

Die Bestimmung der effektiven Protein-Protein-Wechselwirkung ist komplementär zur Summation über die Proteinfreiheitsgrade in Abschnitt 4.2.1. Im erwähnten Abschnitt sind die Proteine eine Störung des Lipidsystems und der Anlass für einen neuen Typ von Kopplung. Hier sind es die Lipide, die eine effektive Wechselwirkung unter den Proteinen verursachen. Da die Lipide aber nur numerisch aussummiert werden, muss man für systematische Aussagen mehrere konkrete Realisierungen zu unterschiedlichen ModellParametern analysieren. 


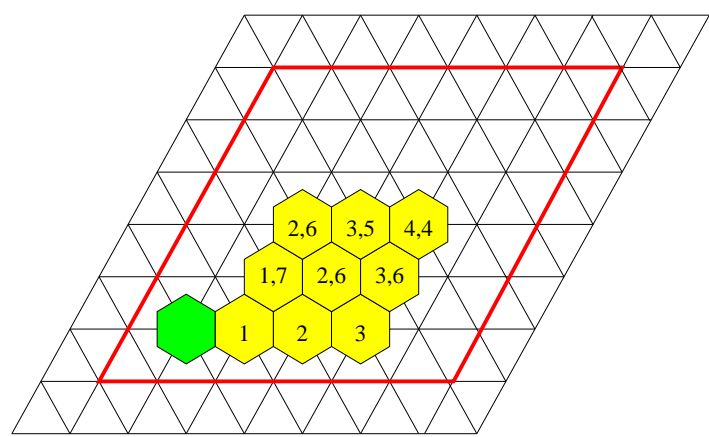

(a)

$\begin{array}{rl}\text { Größe } & \text { Abstand } \\ 1 & 1 \\ 7 & 2,65 \\ 19 & 4,36\end{array}$

(b)

\begin{abstract}
Abbildung 4.6: Darstellung der Abstandsabhängigkeit auf dem Dreiecksgitter am Beispiel eines kleinen Systems. Der „Ursprung“ ist die grüne (dunkle) Plakette, das überdeckte Sechstel der direkten Umgebung ist gelb (hell) eingefärbt. Die jeweiligen Abstände sind eingetragen. In der Tabelle stehen die minimalen Abstände in Abhängigkeit der Größe des Proteins, gemessen in Einheiten der Gitterkonstante.
\end{abstract}

An dieser Stelle sollen nur einige instruktive Beispiele gegeben werden. Im Kapitel 4.6 wird diese Methode angewendet, um mehr über das an das Experiment angepasste System zu erfahren. Die folgende Auflistung zeigt die Temperaturabhängigkeit der effektiven Wechselwirkung. Um dabei den Effekt herauszustellen, der durch die Lipide entsteht, wird die Protein-Protein-Wechselwirkung gleich null gesetzt. Zur Verdeutlichung der Längenskalen wird auf den mit den harten Kernen verbundenen minimalen Abstand (siehe Abbildung 4.6) verwiesen.

In beiden Szenarien, die im Folgenden betrachtet werden, ist der Hauptübergang der Lipidmembran als kontinuierlicher Übergang jenseits des kritischen Punktes gewählt. Die Mitte des Übergangs liegt bei $T_{\mathrm{m}}=600 \mathrm{cal} / \mathrm{mol}$. Zuerst werden Adsorbate betrachtet, die im zweiten Szenarium mit Einlagerungen verglichen werden. Die Adsorbate sollen eine ausgedehnte Wechselwirkungs-Umgebung bezüglich der Protein-Lipid-Kopplung von 19 Plätzen haben und nicht miteinander wechselwirken. Die Kopplungs-Konstante pro Platz beträgt $200 \mathrm{cal} / \mathrm{mol}$. Das positive Vorzeichen bedeutet, dass die Adsorbate gestreckte Lipide und damit die Tieftemperatur-Phase bevorzugen. Im Folgenden werden die effektiven Potentiale der Adsorbate näher beschrieben:

Periphere Proteine in bevorzugter Lipid-Phase Die effektive Wechselwirkung ist fast null und kaum vom Abstand abhängig. Die Proteine begünstigen in dieser Phase nur den Lipiduustand, der auch ohne ihre Anwesenheit thermisch bevorzugt ist, sie finden also eine homogene Lipid-Umgebung vor. Übergänge vom gestreckten in den gefalteten Lipidzustand, die das reine Lipidsystem bei solchen Parametern zeigt, werden durch die Proteine energetisch gehindert, daher resultiert eine schwache Anziehung der Proteine (siehe Abbildung 4.7).

Periphere Proteine am Lipid-Hauptübergang Genau im Bereich des Hauptübergangs der Lipide stoßen sich die Proteine effektiv ab. Die Abstoßung reicht bis etwa zum Dreifachen des Durchmessers der Protein-Lipid-Wechselwirkungs-Umgebung. Ihre 


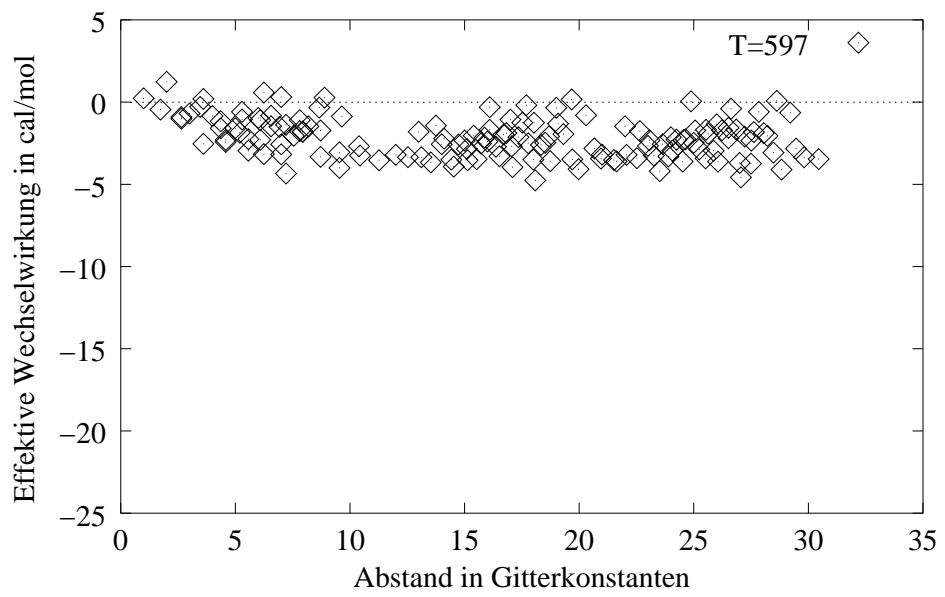

Abbildung 4.7: Lipidmembran mit großen (19 Plätze bedeckenden) Adsorbaten vor dem Hauptübergang bei $T=597 \mathrm{cal} / \mathrm{mol}<T_{m}$.

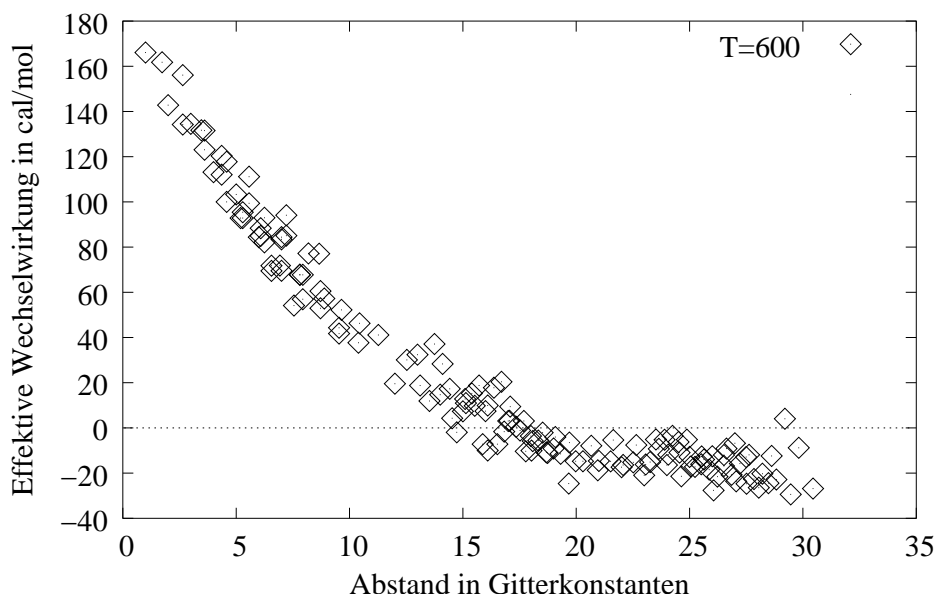

Abbildung 4.8: Lipidmembran mit großen (19 Plätze bedeckenden) Adsorbaten am Hauptübergang bei $T=600 \mathrm{cal} / \mathrm{mol}=T_{m}$.

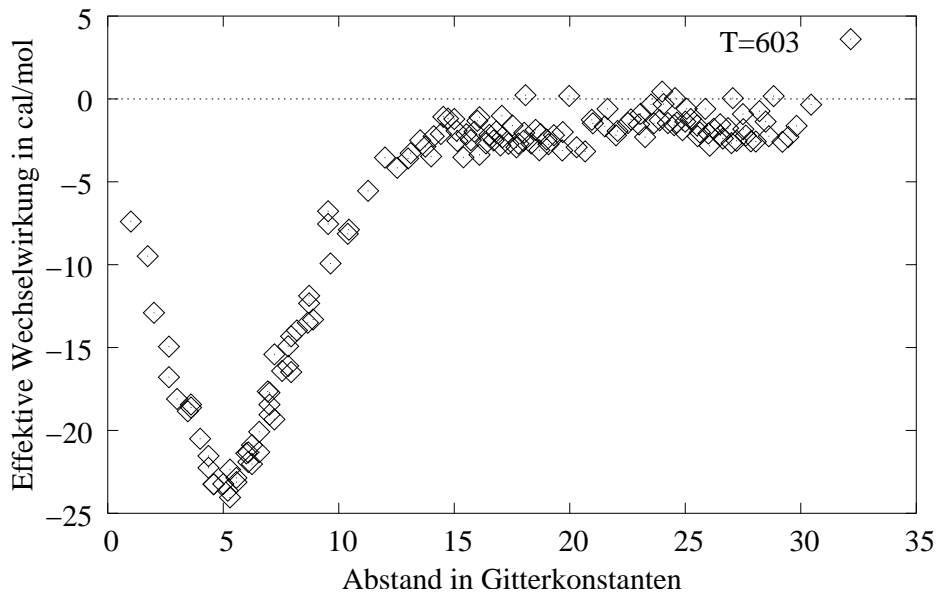

Abbildung 4.9: Lipidmembran mit großen (19 Plätze bedeckenden) Adsorbaten nach dem Hauptübergang bei $T=603 \mathrm{cal} / \mathrm{mol}>T_{m}$. Parameter für die Abbildungen 4.7, 4.8 und 4.9: $L=60$, $T_{m}=600 \mathrm{cal} / \mathrm{mol}, H_{\mathrm{m}}=6000 \mathrm{cal} / \mathrm{mol}, \Delta T_{1 / 2} \approx 1 \mathrm{cal} / \mathrm{mol}, K_{P L}=200 \mathrm{cal} / \mathrm{mol},\left|o^{P}\right|=1,\left|w^{L P}\right|=$ $19, N_{\text {int }} \times N_{\text {ext }}=10^{6}$ (MC-Läufe). 
Stärke von etwa $150 \mathrm{cal} / \mathrm{mol}$, das ist ein Viertel der thermischen Energie, ist sehr groß und bereits im Bereich der direkten Wechselwirkungen zwischen den Plätzen bei einer wesentlich größeren Reichweite. Für sehr große Abstände wird die Wechselwirkung anziehend (da die Längen in diesem Bereich bereits in der Größenordnung der Ausdehnung des Systems liegen, kann man Einflüsse der endlichen Größe dort nicht ausschließen).

Die Ursache ist in der Heterogenität des Lipidsystems am Übergang zu sehen. Im Bereich des kontinuierlichen Übergangs bilden sich räumliche Strukturen mit einer charakteristischen endlichen Ausdehnung und einer ebenfalls endlichen Korrelationszeit. Da diese Strukturen wesentlich kleiner sind als die Ausdehnung des Systems (die Parameter sind so gewählt, dass der Übergang etwa $9 \%$ vom kritischen entfernt liegt), ist eine Klumpung der Adsorbate unvorteilhaft (siehe Abbildung 4.8).

Periphere Proteine in nicht bevorzugter Lipid-Phase Die Proteine ziehen sich nun effektiv an. Das Minimum im effektiven Potential ist deutlich ausgeprägt und in Lage und Tiefe von der Temperatur abhängig. Es wandert bei zunehmender Temperatur und damit zunehmendem Abstand vom Hauptübergang von größeren Abständen zu kleineren und verschwindet schließlich beim Abstand null. Für höhere Temperaturen ähnelt das effektive Potential dem Bild von peripheren Proteinen in der bevorzugten Phase, denn das unterliegende Lipidsystem ist wieder homogen.

Die Ausbildung eines Minimums und der damit verbundenen Anziehung auf einer bestimmten Längenskala kann wie folgt verstanden werden: Die Proteine sorgen durch ihre lokale Wechselwirkung mit den Lipiden dafür, dass unter ihnen die Lipide bevorzugt denjenigen Zustand annehmen, der der Protein-Lipid-Kopplung entspricht. Dieser ist aber bei der gewählten Temperatur global nicht stabil. Das System tendiert dazu, die Bereiche erstens möglichst klein zu halten (wegen des globalen Feldes) und zweitens die Grenzlinie möglichst kurz zu halten (wegen der lokalen LipidLipid-Wechselwirkung). Da das entropisch dominierte Feld der Lipide $H-T S$ mit steigender Temperatur immer ungünstiger für den von den Proteinen bevorzugten gestreckten Zustand wird, verkleinern sich die Bereiche, in denen sich die Proteine ansammeln können, um dadurch Energie über die Wechselwirkung zu gewinnen (siehe Abbildung 4.9).

Es stellt sich die Frage, warum der Effekt, den die Proteine durch ihre Wechselwirkung mit den Lipiden in das Gesamtsystem hineintragen, bei ausgedehnten Adsorbaten kooperativ und bei kleinen nicht kooperativ ist. Das liegt an der Korrelation, die eine ausgedehnte Wechselwirkungs-Umgebung mit sich bringt. Sie ist dreierlei Natur: Zunächst vermeidet das System ungünstige Lipidnachbarschaften durch die Tatsache, dass sich die Lipide im global ungünstigen Zustand nebeneinander unter einem Protein befinden. Darüber hinaus wird dieser Effekt verstärkt, wenn die Adsorbate klumpen und so die ungünstigen Nachbarschaften zum nächsten Adsorbat verschwinden. Zuletzt kann durch eine Überlappung der Wechselwirkungs-Umgebungen die gleiche Energie mit weniger global ungünstigen Lipiden gewonnen werden. Auf kleine Adsorbate trifft nur der zweite Effekt zu, der jedoch nur die bereits im Lipidsystem vorhandene Nächste-Nachbar-Wechselwirkung beeinflusst. Der erste und dritte Punkt bringen neue Kooperativität in das System, die über PaarWechselwirkung hinausgeht.

Die im ersten Szenarium verwendeten Parameterwerte des Modells stammen aus Anpassungen der MC-Daten an experimentelle Kurven (siehe Abschnitt 4.6). Im Ergebnis 
ergibt sich dort das Bild, dass das Adsorbat von seiner Ausdehnung her etwa 7 Lipidköpfe bedeckt, jedoch mit 19 wechselwirkt. Man stelle sich nun vor, dass man dieses Protein in die Membran einlagert. Es würde 7 Plätze belegen und mit den 12 Nachbar-Lipiden wechselwirken. Die Kopplungs-Konstante soll nun so gewählt werden, dass die energetische Präferenz des Proteins für einen der beiden Lipidzustände pro Kontakt gleich groß ist im Falle des Adsorbates und der Einlagerung. Aufgrund der unterschiedlichen Nebenbedingungen ist die Kopplung $K_{I L}$ nicht gleich $K_{L P}$, sondern $K_{I L}=-112,5 \mathrm{cal} / \mathrm{mol}$ bei einer Präferenz des gestreckten Zustands von $K_{i f}=200 \mathrm{cal} / \mathrm{mol}$ und einer Präferenz für Paare aus gleichen Lipidzuständen von $K_{s f}=625 \mathrm{cal} / \mathrm{mol}$ (siehe dazu Gleichung 3.4 und 3.6). Die effektiven Potentiale der Einlagerungen stellen sich wie folgt dar:

Integrale Proteine in bevorzugter Lipid-Phase Das Szenarium ausgedehnter integraler Proteine unterscheidet sich bezüglich der effektiven Wechselwirkung zunächst kaum von dem der Adsorbate. In der vom Protein durch Wechselwirkung bevorzugten Lipidphase ziehen sich die Proteine schwach über das ganze System an. Der Grund liegt auch hier darin, dass die Einlagerungen Lipidfluktuationen in den gefalteten $\mathrm{Zu}-$ stand behindern und es deshalb eine schwache Präferenz zur Klumpung gibt (siehe Abbildung 4.10 und vergleiche mit 4.7).

Integrale Proteine am Lipid-Hauptübergang Die Proteine stoßen sich effektiv ab, und zwar mit einer Stärke von etwa einem Viertel der thermischen Energie, welches genau dem Fall peripherer Proteine entspricht. Im Unterschied zu diesen jedoch findet sich keine Anziehung auf längeren Skalen (siehe Abbildung 4.11 und vergleiche mit 4.8).

Integrale Proteine in nicht bevorzugter Lipid-Phase Auch bei integralen Proteinen findet man ein anziehendes Minimum des effektiven Potentials bei einem bestimmten Abstand. Bei steigender Temperatur verschiebt es sich zu kleinen Abständen und wird schwächer. Im Vergleich zum Fall der Adsorbate liegt das ganze Potential erhöht, welches eine Abstoßung auf sehr langen und sehr kurzen Skalen zur Folge hat (die Abstoßung auf kurzen Skalen findet sich aber ähnlich auch bei Adsorbaten im Übergangsbereich zwischen dem Verhalten von Abbildung 4.8 und 4.9). Die Erklärung für die effektive Anziehung über einen bestimmten Abstand kann von der Erläuterung der Adsorbate übernommen werden. Der einzige Unterschied ist in der Form der Wechselwirkungs-Umgebungen zu sehen. Die Fläche von 19 Plätzen der Adsorbat-Umgebung hat offensichtlich eine kooperativere Wirkung als der Ring aus 12 Plätzen um die Einlagerungen (siehe die Abbildung 4.12 und vergleiche mit 4.9).

In diesem Abschnitt wurde die effektive Wechselwirkung peripherer oder integraler Proteine im Rahmen dieses Modells berechnet. Die wesentlichen Approximationen bestehen zum einen in den Modellannahmen und zum anderen in der Beschränkung auf PaarPotentiale. Die Vernachlässigung aller Mehrteilchen-Wechselwirkungen ist üblich, um in einem ersten Schritt die effektiven Potentiale zu beschreiben. Es sind aber auch Beispiele bekannt, in denen die Terme höherer Ordnung qualitative Veränderungen wie Potentialwälle oder Minima verursachen. Die Entscheidung, ob solche Effekte hier eine Rolle spielen, bleibt Gegenstand zukünftiger Untersuchungen. Das verwendete Modell fokussiert auf die innere Struktur (die Flexibilität) der Lipide. Die modellierte Nächste-NachbarWechselwirkung der Lipide vermittelt die Wechselwirkung zwischen den Proteinen unter Umständen über eine Länge von der Größenordnung der Systemgröße. Das bedeutet, dass eine zunächst kurzreichweitige Wechselwirkung im einem bestimmten Parameterbe- 


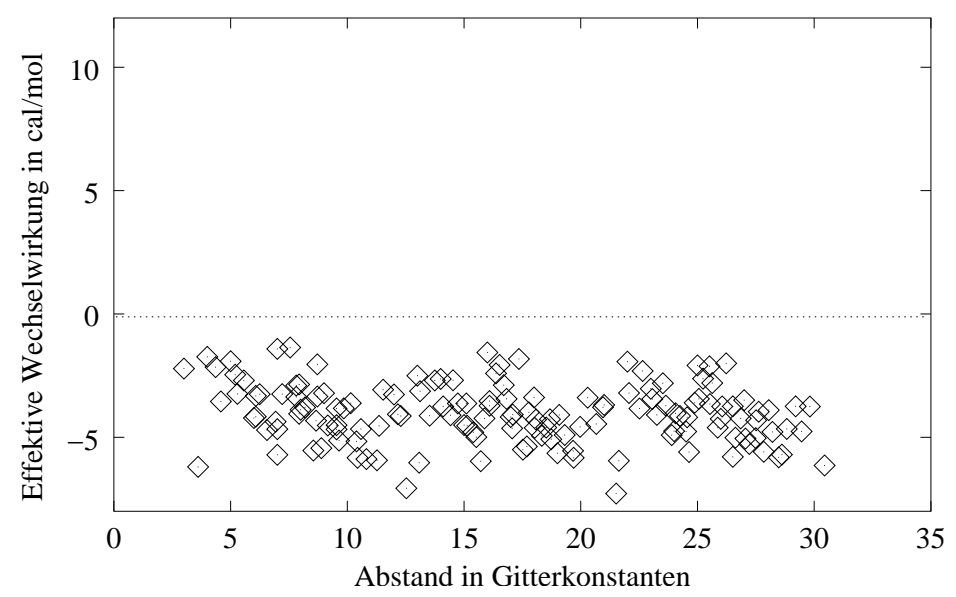

Abbildung 4.10: Lipidmembran mit großen (7 Plätze einnehmenden und mit 12 Lipiden wechselwirkenden) Einlagerungen vor dem Hauptübergang bei $T=597 \mathrm{cal} / \mathrm{mol}<T_{m}$.

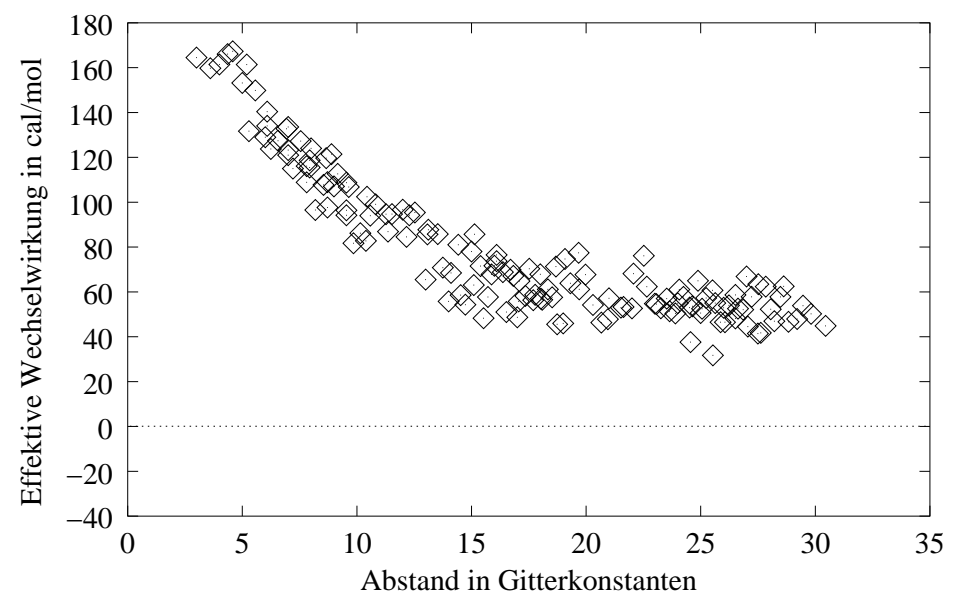

Abbildung 4.11: Lipidmembran mit großen (7 Plätze einnehmenden und mit 12 Lipiden wechselwirkenden) Einlagerungen am Hauptübergang bei $T=600 \mathrm{cal} / \mathrm{mol}=T_{m}$.

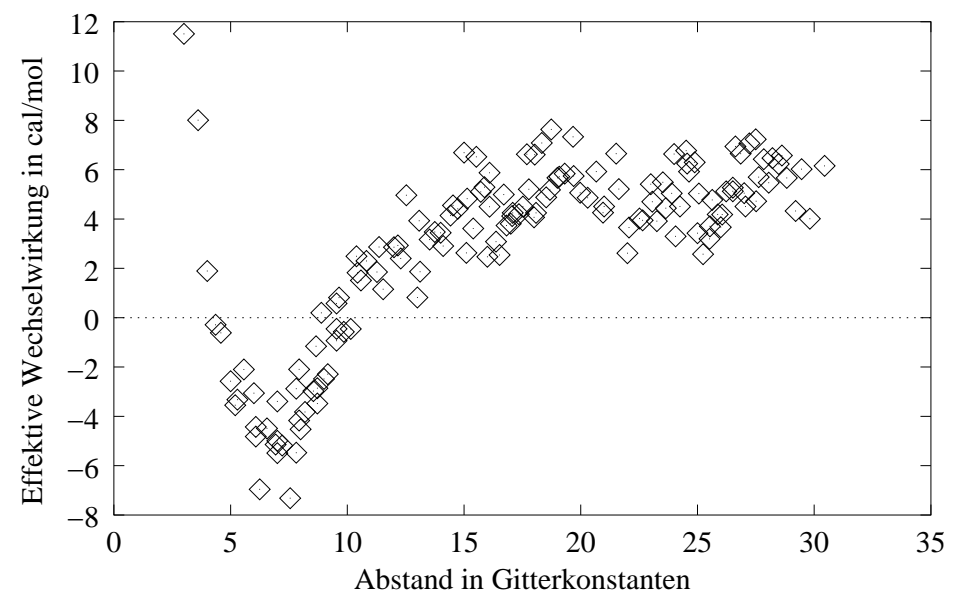

Abbildung 4.12: Lipidmembran mit großen (7 Plätze einnehmenden und mit 12 Lipiden wechselwirkenden) Adsorbaten nach dem Hauptübergang bei $T=603 \mathrm{cal} / \mathrm{mol}>T_{m}$. Parameter für die Abbildungen 4.10, 4.11 und 4.12: $L=60, T_{m}=600 \mathrm{cal} / \mathrm{mol}, H_{\mathrm{m}}=6000 \mathrm{cal} / \mathrm{mol}$, $K_{L L}=-625 \mathrm{cal} / \mathrm{mol}, K_{I L}=-112,5 \mathrm{cal} / \mathrm{mol}, K_{I I}=0, N_{\text {int }} \times N_{\text {ext }}=10^{6}$ (MC-Läufe). 
reich Anlass für eine sehr langreichweitige gibt (siehe z. B. Abbildungen 4.8 und 4.11). Einschränkend muss angemerkt werden, dass in diesem Zusammenhang mit dem Begriff langreichweitig keine bestimmte Gesetzmäßigkeit verbunden wird. Quantitativ wurde die Reichweite nicht ausführlich genug untersucht, um darüber eine Aussage machen zu können. Trotzdem ist dieser Ansatz zu unterscheiden von einem anderen zur Beschreibung effektiver Wechselwirkungen von Proteinen in einer Lipidmembran: die Vermittelung von Kräften durch die Verbiegung der Oberfläche (siehe z. B. Chou u. a., 2001). Die mechanischen Kräfte einer elastischen Fläche, in diesem Zusammenhang immer beschrieben in der Formulierung nach Helfrich (1973), sind aus intrinsischen Gründen von einer größeren Reichweite als die Nächste-Nachbar-Wechselwirkung der Lipide im hier untersuchten Modell.

\subsection{Phasendiagramm und Analyse der Grenzfläche}

In den vorherigen Abschnitten war bereits von Clusterbildung - sowohl in der Lipidschicht als auch im Proteinsystem - die Rede. Es stellt sich natürlich sofort die Frage nach der Stabilität dieser Cluster. Sind es Fluktuationen, die mit der Zeit wieder zerfallen, oder thermodynamische Phasen, also stabile Bereiche?

Einen ersten Aufschluss geben Monte-Carlo-Schnappschüsse. An ihnen kann man oft auf einen Blick erkennen, ob sich Strukturen bilden und aus dem Vergleich von vielen Bildern zu unterschiedlichen (Computer-) Zeiten lässt sich ablesen, ob diese Strukturen stabil sind. Eine genauere Cluster-Analyse der Daten ist im Prinzip möglich, wird hier aber nicht durchgeführt.

Um auf die Protein-Lipid-Wechselwirkung zu fokussieren, sollen zunächst solche Proteine untersucht werden, die eine ausgedehnte Wechselwirkungs-Umgebung mit den Lipiden besitzen, selbst aber nur einen Platz besetzen, sie also als weich zu bezeichnen sind. Exemplarisch wird die Wechselwirkungs-Umgebung auf 19 Plätze festgesetzt, das entspricht dem Platz unter dem Protein und zwei Schalen darum herum. Die Auswirkungen der Protein-Protein-Kopplung wird später untersucht.

Das in Abbildung 4.13 dargestellte Phasendiagramm ist durch die oben beschriebene Beobachtung von Schnappschüssen entstanden. Die Lipidparameter sind so gewählt, dass bei $600 \mathrm{cal} / \mathrm{mol}$ der Hauptübergang der puren Lipidmembran stattfindet, und zwar kontinuierlich mit einer typischen Breite von etwa $1 \mathrm{cal} / \mathrm{mol}$. Neben der Temperatur wurde die Teilchendichte der Proteine variiert. Man beachte, dass der Bedeckungsgrad, also die Anzahl von Lipiden, die mit Proteinen wechselwirken, den neunzehnfachen Wert der Teilchendichte hat (mögliche Überlappungen der Umgebungen mit einbezogen). Auf der Spitze stehende Quadrate bedeuten, dass ein gemischtes System vorliegt, die Proteine also in etwa gleichverteilt auf der Lipidmembran liegen. Quadrate auf der Kante bedeuten, dass klare Entmischung der Phasen in eine proteinreiche Phase mit vorzugsweise gestreckten Lipiden und eine proteinarme mit gefalteten Lipiden zu beobachten ist. Kann keine klare Entscheidung getroffen werden, so sind beide Symbole dargestellt. Man erkennt, dass bei Temperaturen jenseits des Hauptübergangs und mit zunehmender Dichte das System entmischt. Es muss angemerkt werden, dass bei sehr hohen Temperaturen das Lipidsystem homogen in der expandierten Phase vorliegt und die Proteine darauf ideal durchmischt sind, das Entmischungsgebiet also begrenzt ist.

Die Behauptung, dass es sich bei dem beobachteten Phänomen wirklich um stabile Entmischung handelt, kann durch eine Analyse der Grenzfläche zwischen den verschie- 


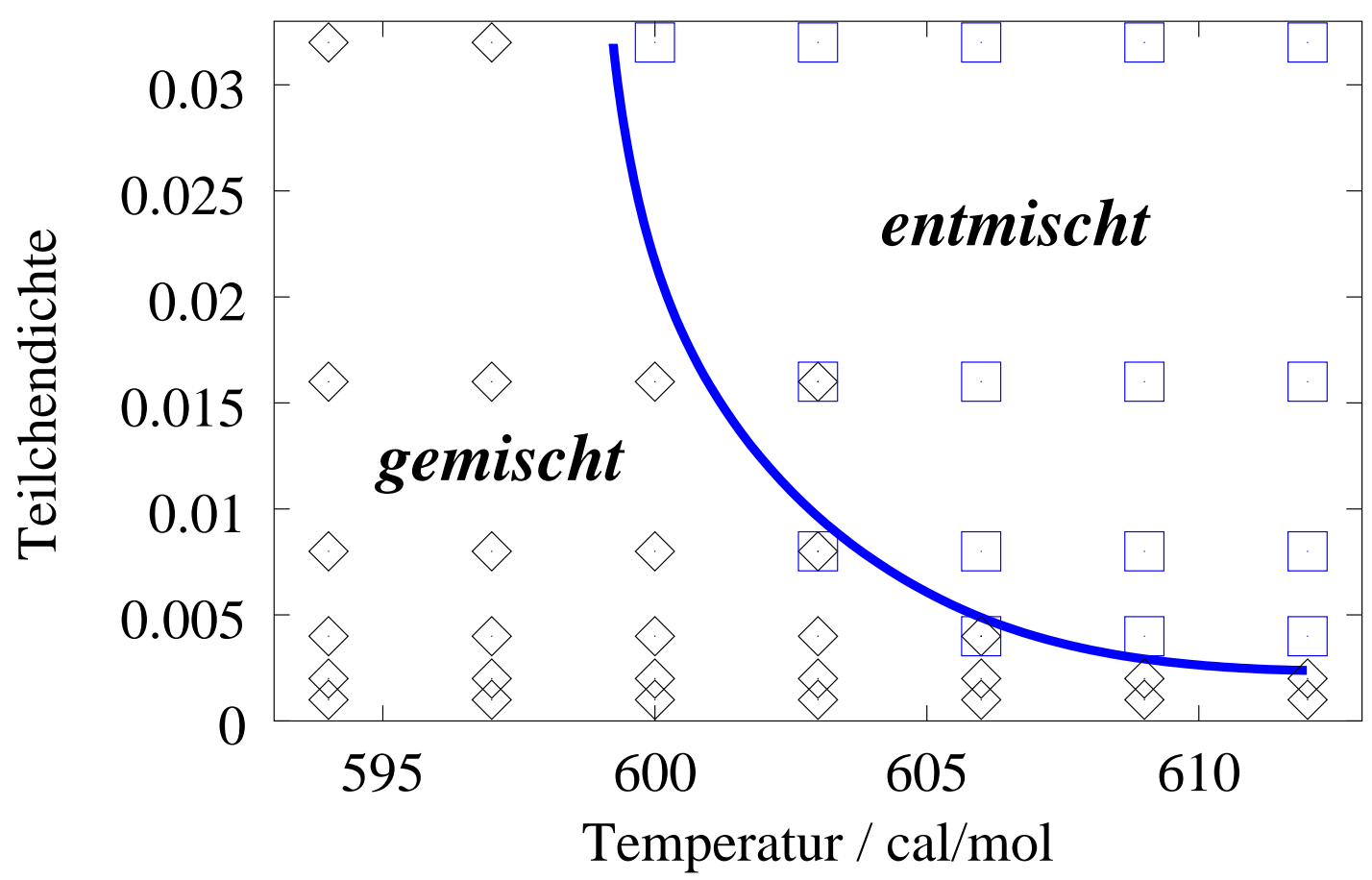

Abbildung 4.13: Phasendiagramm weicher ausgedehnter Adsorbate, die mit 19 Lipiden wechselwirken und den gestreckten Lipidzustand mit einer Energiedifferenz von $200 \mathrm{cal} / \mathrm{mol}$ bevorzugen. Auf der Spitze stehende Symbole bedeuten, dass keine Entmischung in den Simulationen beobachtet wird. Die auf der Kante liegenden Symbole zeigen Entmischung an. Sind beide Symbole an einem Punkt eingezeichnet, war die Frage nach stabiler Entmischung durch die Beobachtung nicht eindeutig zu klären. Ein möglicher Verlauf der Phasenübergangs-Linie ist eingezeichnet. Dass das System für große Dichten und hohe Temperaturen natürlich wieder gemischt ist, ist nicht mehr dargestellt.

denen Phasen untermauert werden. Zur Analyse von Grenzflächen siehe z. B. das Buch von Barabasi und Stanley (1995) und die beiden Artikel von Werner u. a. (1997, 1999).

Die Grenzfläche zwischen Phasen unterscheidet sich in zwei Aspekten von der Grenze zwischen Fluktuationen:

1. Die Lage der Grenzfläche ist stabil, d.h. die Korrelationszeit ist unendlich.

2. Ihre Dicke ist konstant und klein gegen die Ausdehnung der Phasen bzw. des Systems.

Um die Grenzfläche in der Simulation besser untersuchen zu können, wird in das System eine Asymmetrie eingeführt. Diese soll dafür sorgen, dass die Grenzfläche eine Richtung bevorzugt. Dazu werden die Lipidzustände auf zwei gegenüberliegenden Seiten des Systems fest auf entgegengesetzten Werten gehalten, die Ränder also in den beiden homogenen Phasen eingefroren. Um eine Vorstellung von dem untersuchten System mit festen Randbedingungen in der einen Richtung und periodischen in der anderen zu bekommen, ist in Abbildung 4.14 ein typischer Schnappschuss des Gesamtsystems gezeigt. Wie üblich sind die Lipid- und die Proteinschicht getrennt abgebildet.

Zwischen den Phasen entwickelt sich eine Grenzfläche, deren Position $h(x)$ wie folgt definiert wird:

$$
h^{B}(x):=m^{B}(x) \times L
$$




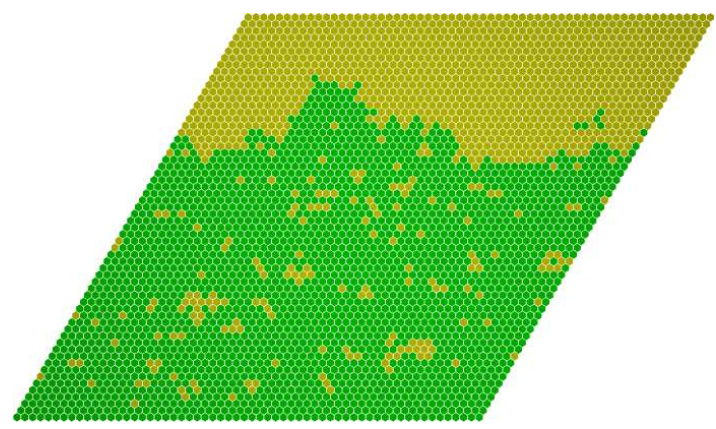

(a) Lipidschicht

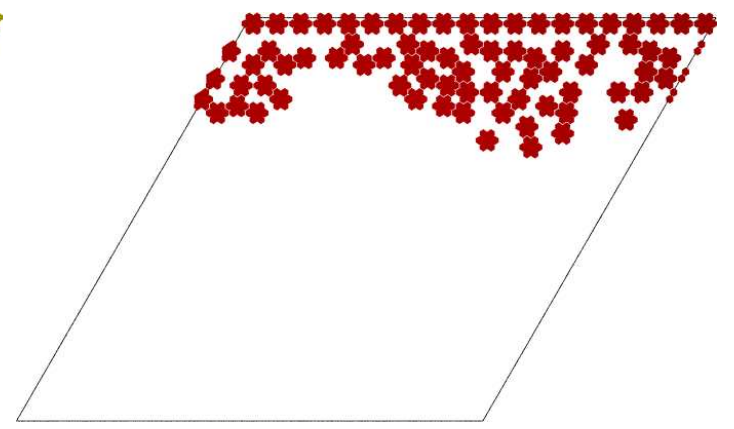

(b) Proteinschicht

Abbildung 4.14: Monte-Carlo-Schnappschüsse des Systems, wie es zur Bestimmung der Breite der Grenzflächen präpariert wird. Der untere und obere Rand des Systems sind jeweils in einer homogenen Phase (hier kondensiert-bedeckt und expandiert-unbedeckt) fixiert, der linke und rechte Rand unterliegen periodischen Randbedingungen.

Dabei ist $L$ die lineare Systemgröße, eingeteilt in Streifen der Breite $B$, senkrecht zu den Rändern mit festen Randbedingungen. Der Lipid-Ordnungsparameter $m^{B}(x)$ wird in einem solchen Streifen an der Stelle $x$ bestimmt. Das bedeutet, dass die Lipidzustände die Membran-Phasen definieren und die Lage der Grenzfläche genau dort ist, wo die Dichte der Lipidbesetzungszahl den Wert 1/2 überschreitet. Der Index $B$ wird im Folgenden häufig weggelassen, wenn mit dem Standardwert $B=1$ gerechnet wird.

Die Grenzfläche wird im Mittel charakterisiert durch den Erwartungswert $h_{0}$ und dessen zweites Moment $h_{\mathrm{w}}$, welches ein Maß für die Dicke der Grenzfläche ist.

$$
\begin{aligned}
h_{0} & :=\overline{\langle h(x)\rangle} \\
h_{\mathrm{w}} & :=\overline{\left\langle\left(h(x)-h_{0}\right)^{2}\right\rangle}
\end{aligned}
$$

Dabei ist zu beachten, dass neben dem Ensemblemittel auch über die Ausdehnung des Systems gemittelt werden muss, angedeutet durch den Querstrich.

Die Messmethode zur Charakterisierung der Grenzlinie ist in Abbildung 4.15 verdeutlicht. Gezeigt ist einerseits die Verteilung der Größe $h(x)$ und andererseits der ortsabhängige Erwartungswert $\langle h(x)\rangle$. Die zweite Abbildung soll zeigen, dass der Erwartungswert eben nicht mehr explizit vom Ort abhängt. Die Interpretation des zweiten Moments der in der ersten Abbildung gezeigten Verteilung als Breite der Grenzlinie geht davon aus. An der Verteilung ist auch zu erkennen, dass sie nicht immer ganz symmetrisch ist.

Unter der Voraussetzung, dass sich eine Grenzlinie bildet, sich also zwei Phasen trennen, gelten häufig Skalenrelationen für die Längen- oder Zeitskalen (Barabasi und Stanley, 1995). Praktisch bedeutet das, dass man im ersten Schritt die Schnappschüsse in computerzeitlicher Abfolge betrachtet, um zu entscheiden, ob die Korrelationen stabil sind. Quantifiziert wird dies dann im zweiten Schritt durch die Skalenanalyse und die Bestimmung des Exponenten.

In dieser Arbeit sollen nur die statischen Eigenschaften der Grenzfläche quantifiziert werden und nicht die Dynamik der Relaxation in das Gleichgewicht. Die Grenzfläche selbst 


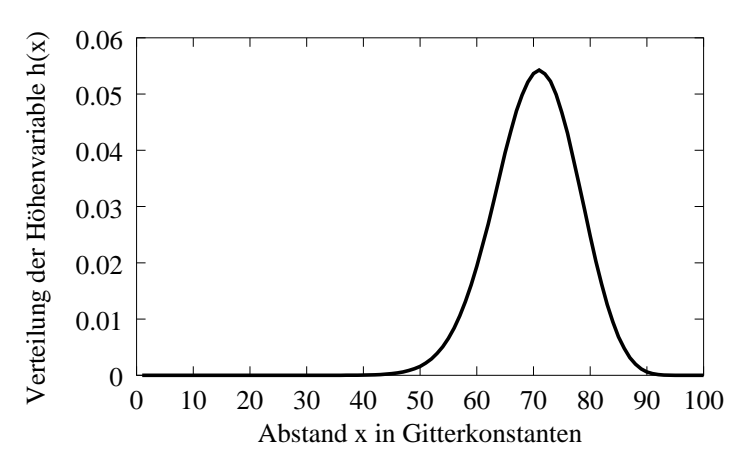

(a) Verteilung

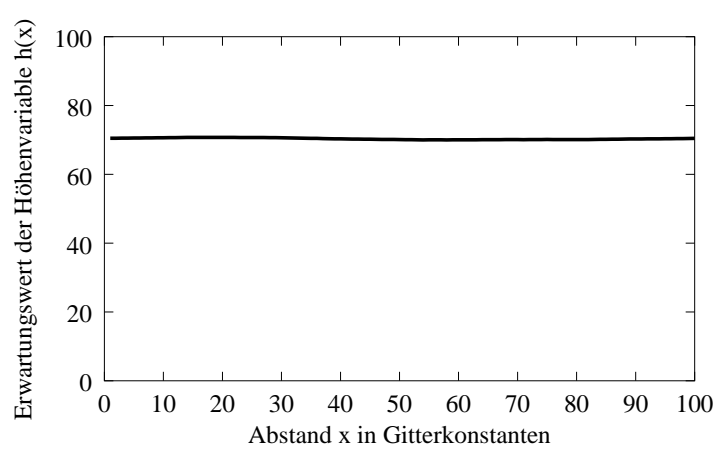

(b) Erwartungswert

Abbildung 4.15: Zur Bestimmung der Breite der Grenzfläche wird die Verteilung der Höhenvariablen gemessen und deren zweites Moment bestimmt. Die Höhenvariable hängt im Mittel nicht vom Ort ab. Parameter: $T=606 \mathrm{cal} / \mathrm{mol}, H_{\mathrm{m}}=6 \mathrm{kcal} / \mathrm{mol}, T_{\mathrm{m}}=600 \mathrm{cal} / \mathrm{mol}$, $\mathrm{K}_{L L}=-625 \mathrm{cal} / \mathrm{mol}, K_{L P}=200 \mathrm{cal} / \mathrm{mol}, \theta=0,016,\left|w^{L P}\right|=19,\left|o^{P P}=1\right|$.

und ihre Breite sind in Gleichung 4.13 und 4.14 definiert. Der statische Skalenexponent $\alpha$ ist über das Verhalten der Breite mit der linearen Systemgröße $L$ definiert:

$$
h_{\mathrm{w}} \propto L^{\alpha}
$$

An dieser Stelle wird eine Lipidmembran mit großen Adsorbaten simuliert (siehe Abbildung 4.16). Die Lipid-Protein-Wechselwirkungs-Umgebung umfasst 19 Plätze, die harten Kerne der Proteine haben lediglich die minimale Ausdehnung von einem Platz. Die lineare Systemgröße variiert zwischen $L=10$ und 100. Abweichungen vom Skalenverhalten für kleine Systeme können mit einer intrinsischen Breite der Grenzflächen zusammenhängen.

Der ermittelte Exponent von etwa 0,61 bis 0,69 je nach Temperatur ist typisch für die hier untersuchten Adsorbate auf Lipidmembranen und findet sich auch für andere Größen und Formen von Proteinen. Der Wert ist signifikant höher als der generische Wert einer Grenzlinie in zwei Dimensionen. Auf diesen Wert von 0,5 führen alle einfachen Modelle zur Charakterisierung einer Phasengrenzlinie (Barabasi und Stanley, 1995). Daraus kann man schließen, dass genau die Effekte, welche durch die einfachen Modelle vernachlässigt werden, offensichtlich hier von Belang sind: Die Überhänge der Grenzlinie und kleine Fluktuationen der einen Phase innerhalb der anderen. Die hier untersuchte Grenzlinie entmischter Proteine ist also vergleichsweise rau.

\subsection{Einfluss von Größe und Form der Komponenten}

Der Einfluss der Protein-Lipid-Wechselwirkungs-Umgebung auf das Mischungsverhalten ist in Abbildung 4.17 exemplarisch gezeigt. Darin sind drei Szenarien unterschiedlicher Protein-Lipid-Wechselwirkung miteinander verglichen und jeweils ein Schnappschuss des Lipid- und des Proteinsystems dargestellt. Alle sonstigen Parameter wie Temperatur oder Konzentration sind in allen Bildern identisch.

Die ersten Abbildungen ( $\mathrm{a}$ und $\mathrm{b}$ ) zeigen die ungekoppelten Untersysteme. Die Lipidmembran ist in der expandierten Phase (grün bzw. dunkel), bei Temperaturen jenseits des 


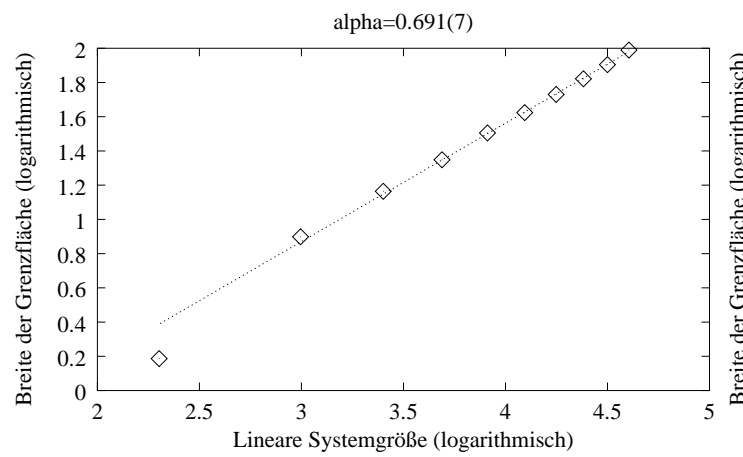

(a) $T=606 \mathrm{cal} / \mathrm{mol}, \theta=0,016$

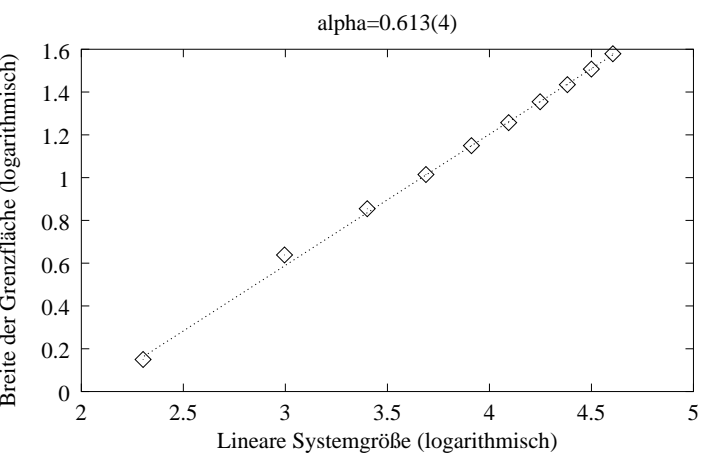

(b) $T=612 \mathrm{cal} / \mathrm{mol}, \theta=0,016$

Abbildung 4.16: Skalierung der Breite der Grenzfläche mit der linearen Systemgröße. Je nach Membranparameter findet man einen Skalenexponenten von $\alpha=0,6 \ldots 0,7$. Parameter: $H_{\mathrm{m}}=$ $6 \mathrm{kcal} / \mathrm{mol}, T_{\mathrm{m}}=600 \mathrm{cal} / \mathrm{mol}, K_{L P}=200 \mathrm{cal} / \mathrm{mol}, \theta=0,016,\left|w^{L P}\right|=19,\left|o^{P P}=1\right|, L=$ $10 \ldots 100$.

Hauptübergangs. Die Proteine bilden eine Schicht aus harten Scheiben (mit einer Ausdehnung von $\left|o^{P}\right|=7$ ). Die Teilchendichte von $\theta=0,016$ entspricht einem Bedeckungsgrad von $11 \%$, was weit entfernt von einem Phasenübergang ist, der bei hohen Bedeckungen von etwa $80 \%$ auftritt. Beide Systeme sind demnach homogen und weit entfernt von den jeweils möglichen Phasenübergängen.

In den mittleren Abbildungen (c und d) wurde eine lokale Protein-Wechselwirkung (nur an einem Platz $\left|w^{L P}\right|=1$ ) eingeführt. Um einen mit dem nächsten Fall vergleichbaren Energieeintrag zu bewerkstelligen, wurde die Kopplungs-Konstante sehr hoch (mit $K_{L P}=3,8 \mathrm{kcal} / \mathrm{mol}$ ) angesetzt. Trotzdem sind nur etwas verstärkte Bereiche von gestreckten Lipiden (gelb bzw. hell) in der expandierten Phase zu erkennen. Diese zerfallen nach einigen Monte-Carlo-Läufen wieder und bilden sich an einer anderen Stelle neu. Sowohl das Lipid- als auch das Proteinsystem ist weiterhin in einer homogenen Phase. Es gibt keine stabile Ordnung.

Für die untersten Abbildungen (e und $\mathrm{f}$ ) wurde die Wechselwirkungs-Umgebung bei gleichbleibendem Energieeintrag vergrößert $\left(\left|w^{L P}=19\right|\right.$ und $\left.K_{L P}=200 \mathrm{cal} / \mathrm{mol}\right)$. Jetzt ist eine deutliche Entmischung in zwei Phasen zu erkennen. Die Lipide in der expandierten Phase (grün bzw. dunkel) sind fast gar nicht durch Proteine bedeckt. Demgegenüber bilden die gestreckten Lipide eine von Proteinen bedeckte kondensierte Phase (gelb bzw. hell). Entscheidend ist die Beobachtung, dass die Bereiche gestreckter und bedeckter Lipide im Laufe der Monte-Carlo-Simulationen zu immer größeren verschmelzen, bis zum Schluss eine große Domäne stabil auf allen beobachtbaren Zeitskalen der Simulation existiert. Genau dieses Verhalten charakterisiert Entmischung und grenzt sie von Fluktuationen ab.

Neben der Tatsache, dass die ausgedehnten Wechselwirkungs-Umgebungen neue Korrelationen in das System einbringen, ist für deren Einfluss entscheidend, ob sich die Gebiete überlappen können. Die geometrischen Verhältnisse bezüglich der WechselwirkungsUmgebungen und ihrer Überlappungen wird durch die Abbildung 4.18 skizziert.

Nach dem Einfluss der Protein-Lipid-Wechselwirkung auf das Phasenverhalten des Gesamtsystems soll im nächsten Fall die Protein-Protein-Abstoßung aufgrund der Ausdeh- 


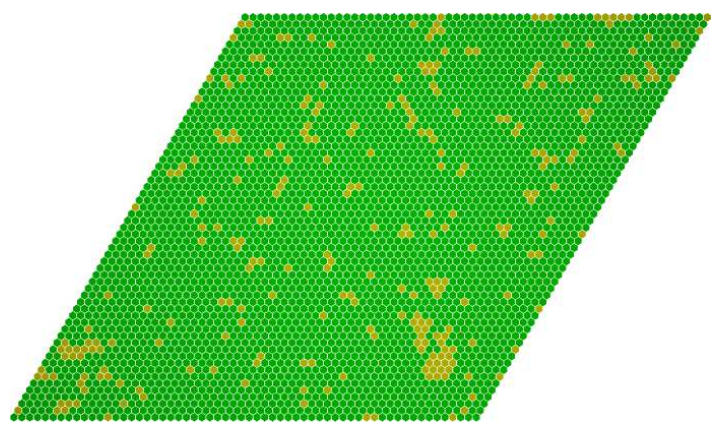

(a) Lipide (keine Kopplung)

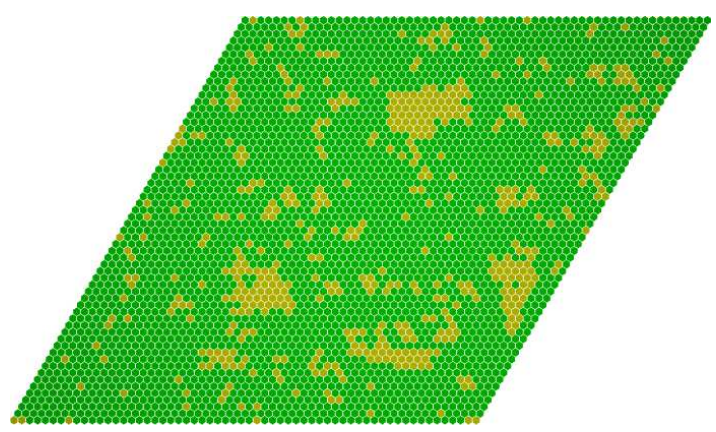

(c) Lipide mit lokaler (1 Platz) Kopplung

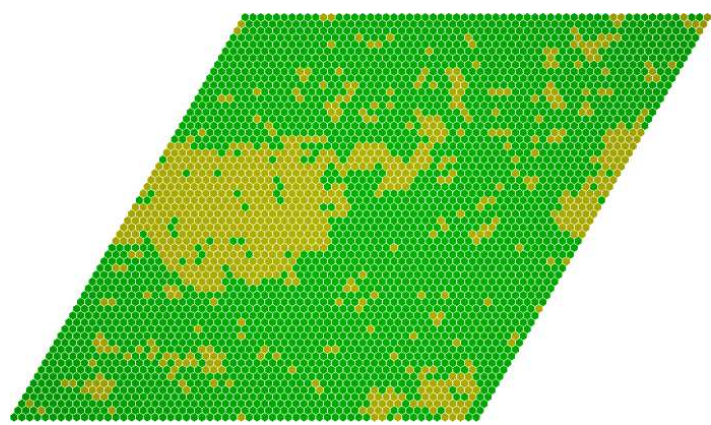

(e) Lipide mit ausgedehnter (19 Plätze) Kopplung

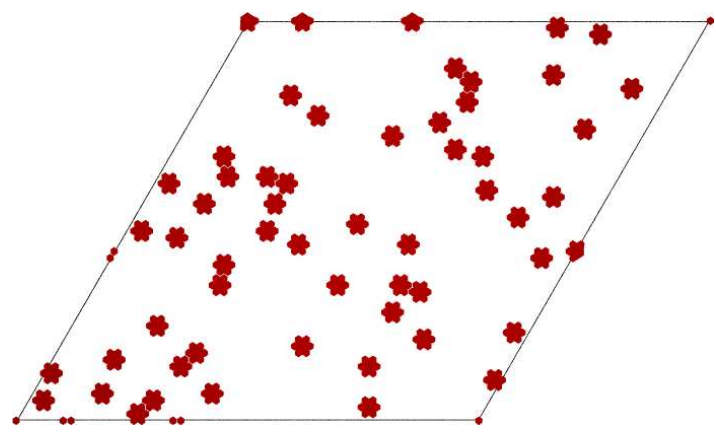

(b) Proteine (keine Kopplung)

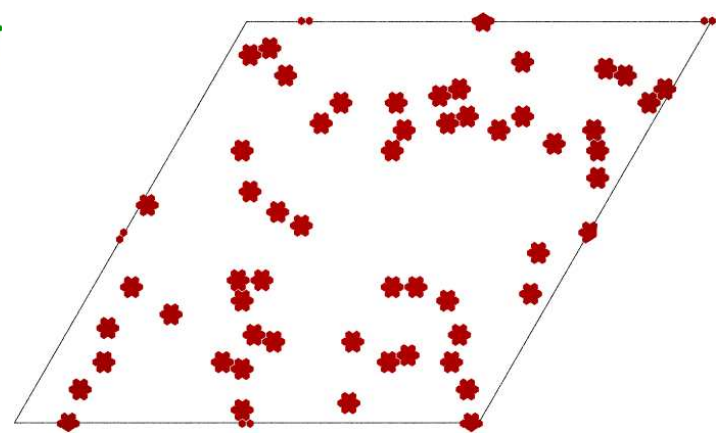

(d) Proteine mit lokaler (1 Platz) Kopplung

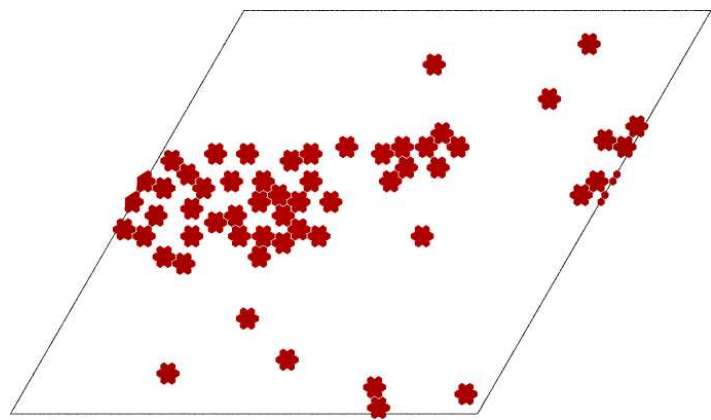

(f) Proteine mit ausgedehnter (19 Plätze) Kopplung

Abbildung 4.17: Lipidmembran mit ausgedehnten Adsorbaten bei einer Temperatur $T=$ $612 \mathrm{cal} / \mathrm{mol}$ weit oberhalb des Phasenübergangs und einer geringen Proteinteilchendichte $\theta=0,016$ weit entfernt von einem ordnenden Übergang. Von oben nach unten ist die Protein-LipidWechselwirkungs-Umgebung vergrößert von null über einen auf auf 19 Plätze. In den beiden Fällen von Wechselwirkung ist der Gesamtenergieeintrag durch die Proteine gleich. Parameter: $K_{L L}=-625 \mathrm{cal} / \mathrm{mol}, H_{\mathrm{m}}=6 \mathrm{kcal} / \mathrm{mol}, T_{\mathrm{m}}=600 \mathrm{cal} / \mathrm{mol},\left|w^{P P}\right|=7, L=60$ (a) $K_{L P}=0$, $\left|w^{L P}\right|=0$ (b) $K_{L P}=3800 \mathrm{cal} / \mathrm{mol},\left|w^{L P}\right|=1$ (c) $K_{L P}=200 \mathrm{cal} / \mathrm{mol},\left|w^{L P}\right|=19$. 


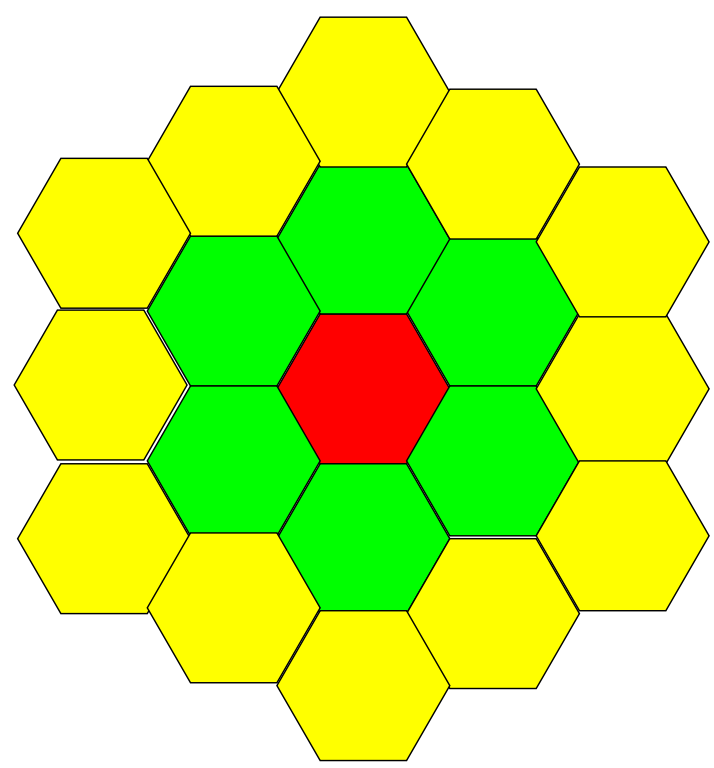

(a) Symmetrische WechselwirkungsUmgebungen: Kleiner Kern (rot bzw. dunkel grau), mittelgroßer Kern (kleiner Kern plus grün bzw. mittel grau) und großer Kern (rot, grün und gelb bzw. alle Grautöne).

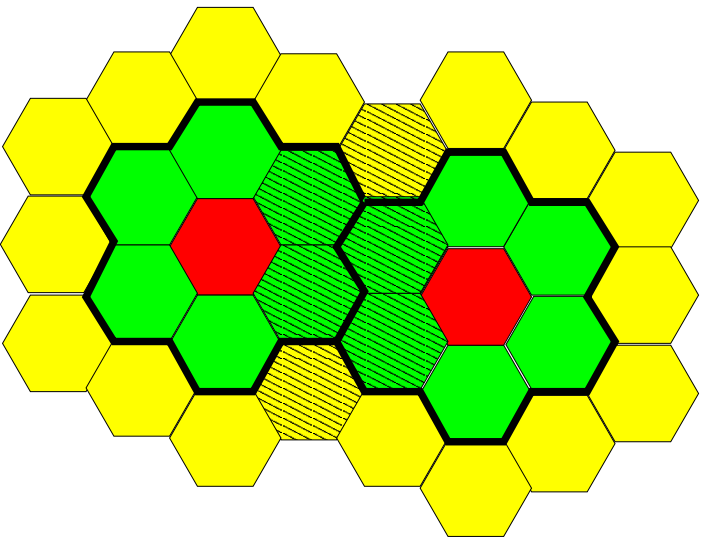

(b) Dichteste Packung von großen weichen Adsorbaten mit einem Kern von 7 Plätzen: Mittelgroße harte Kerne (rot und grün bzw. dunkel grau) und ProteinLipid-Wechselwirkung (alle Grautöne) mit Überlappungsbereich (schraffiert).

Abbildung 4.18: Skizze der Wechselwirkungs-Umgebungen und möglichen Überlappungen.

nung und Form der Adsorbate betrachtet werden. Abbildung 4.19 zeigt wiederum drei Fälle mit jeweils Bildern des Lipid- und Proteinsystems, wobei bis auf die Form der Proteine alle Parameter unverändert sind. Im Vergleich zu Abbildung 4.17 wurden andere Werte verwendet, die einen wesentlich schmaleren Hauptübergang, typisch z. B. für multilamellare Vesikel, beschreiben. Jedes Protein wechselwirkt mit sieben Lipiden.

Die Ausgangssituation in den ersten Abbildungen ( $\mathrm{a}$ und b) entspricht den letzten Abbildungen in 4.17. Die Wechselwirkungs-Umgebungen der Proteine mit den Lipiden sind ausgedehnt und überlappen. Die Korrelationen führen zu neuer Kooperativität und das Gesamtsystem entmischt in einen bedeckten und einen unbedeckten Teil.

Im Folgenden werden die Proteine immer größer, ohne etwas an der Protein-LipidWechselwirkung zu ändern. Zunächst betrachtet man harte Hexagone (Bilder c und d), die einen Platz und die Verbindungslinien zu den Nachbarn besetzen, so dass erst auf den übernächsten Nachbarn wieder Proteine liegen können (siehe Abschnitt 4.1). Immer noch ist deutlich eine Entmischung zu beobachten. Jedoch macht sich die Verminderung des Überlapps insofern bemerkbar, als dass die entmischten Gebiete rauer sind und am Rand mehr fluktuieren.

Dass die Entmischung durch die Vergrößerung der Proteine ganz unterdrückt werden kann, zeigen die letzten Abbildungen (e und f), genau genommen eine Abfolge von solchen Bildern. Denn betrachtet man die Entwicklung der Cluster, die auch in diesem Fall von 7 Plätze bedeckenden Adsorbaten zu sehen sind, so beobachtet man keine fortlaufende Vereinigung zu immer größeren Domänen, sondern einen Zerfall in einer endlichen Zeit (wenn 


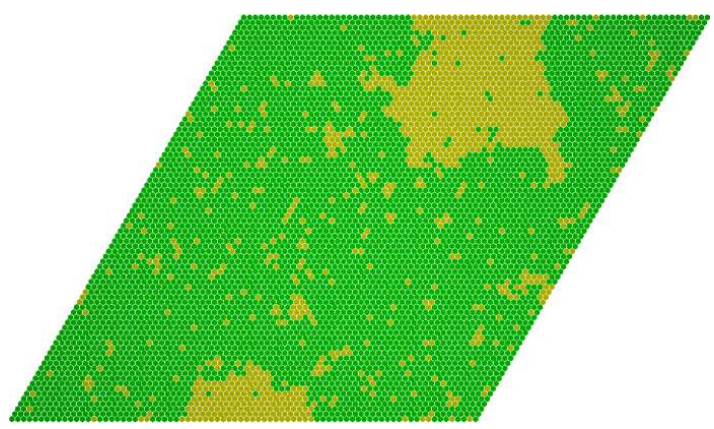

(a) Lipide

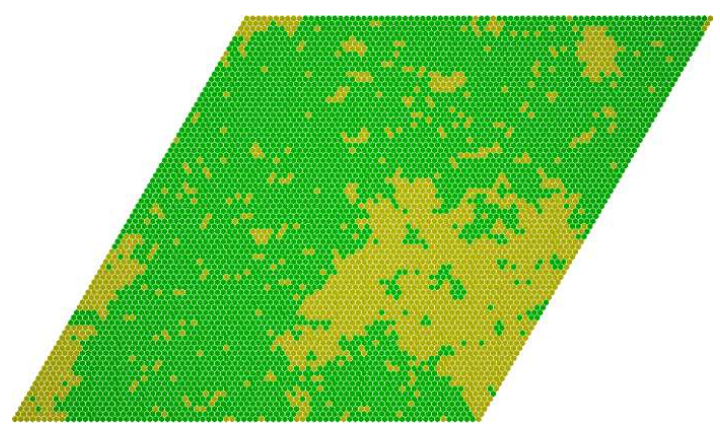

(c) Lipide

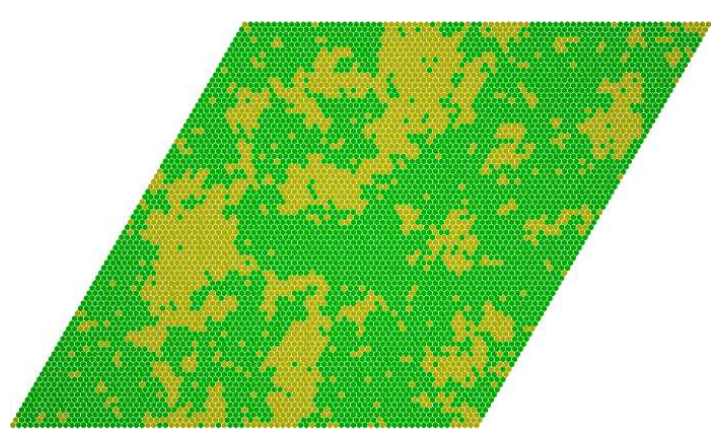

(e) Lipide

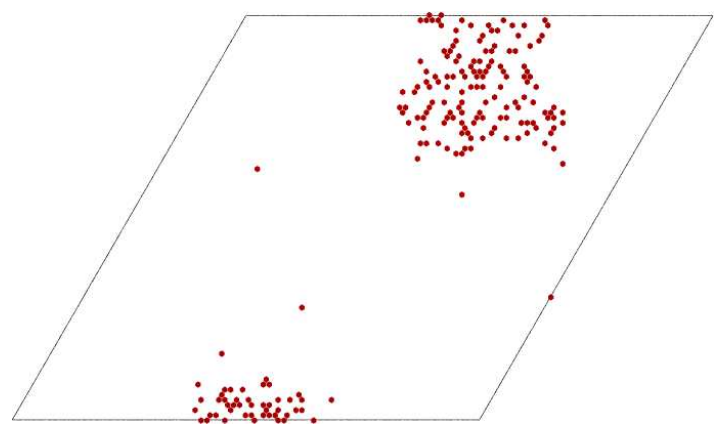

(b) Kleine Proteine (1 Platz)

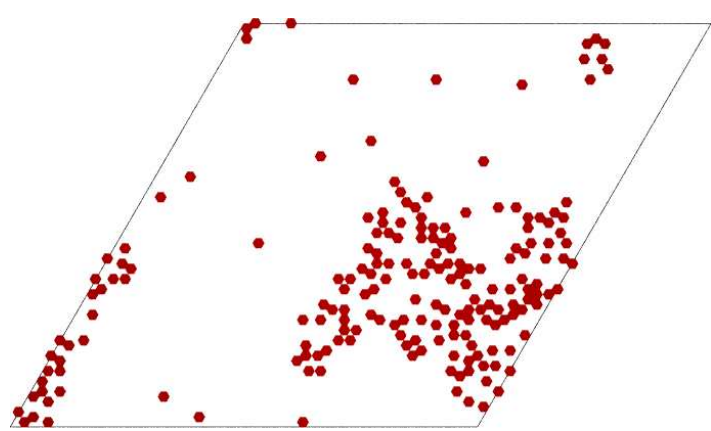

(d) Mittlere Proteine (Harte Hexagone)

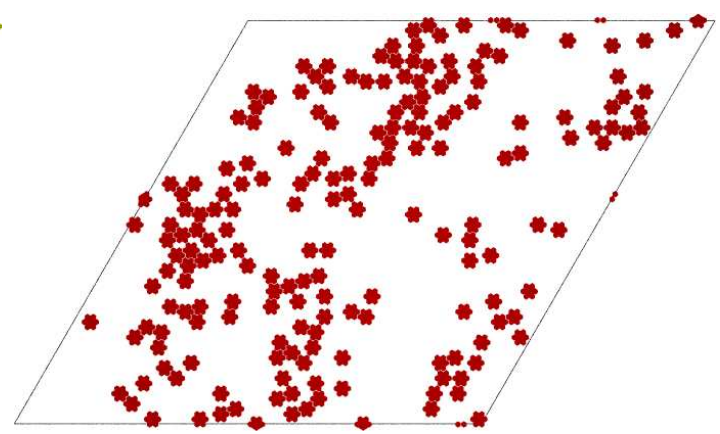

(f) Große Proteine (7 Plätze)

Abbildung 4.19: Auflösung der Strukturen mit Vergrößerung des harten Kerns. Stabile Strukturen bilden sich nur bei Überlappung der Protein-Lipid-Wechselwirkungs-Umgebungen, d. h. wenn diese größer sind als die harten Kerne der Adsorbate. Parameter: $T=612 \mathrm{cal} / \mathrm{mol}>T_{\mathrm{m}}$, $K_{L L}=-600 \mathrm{cal} / \mathrm{mol}, H=10,2 \mathrm{kcal} / \mathrm{mol}, S=14, K_{L P}=600 \mathrm{cal} / \mathrm{mol}, \theta=0,03, L=80$, $\left|w^{L P}\right|=7$. 
auch relativ lang mit etwa $10^{4}$ Monte-Carlo-Läufen). Die allein durch die Ausdehnung der Proteine eingebrachte Kooperativität reicht ohne Überlappung der WechselwirkungsUmgebungen in den betrachteten Fällen nicht aus, um stabile Entmischung zu induzieren.

Nicht unbedingt überraschend aber bemerkenswert ist die Tatsache, dass globale thermodynamische Größen wie die spezifische Wärme nicht merklich auf den Entmischungsübergang reagieren. In allen drei Fällen zeigt sich eine etwa um das gleiche Maß verschobene, abgeflachte und etwas verzerrte Übergangskurve ohne charakteristische Unterschiede.

Zusammenfassend soll die Ursache für das beobachtete Entmischungsphänomen noch einmal erläutert und mit den analytischen und numerischen Analysen verknüpft werden. Für die Kooperativität ist es zunächst wichtig, dass die Proteine mit mehr als einem Lipid wechselwirken (vergleiche Abbildung 4.17). Qualitativ sieht man den Effekt sowohl in der freien Energie des effektiven Lipidsystems als auch im effektiven Potential der Proteine. In letzterem Bild des effektiven Proteinsystems sieht man auch, dass es auf mehr als eine ausgedehnte Wechselwirkungs-Umgebung ankommt. Wenn der harte Kern der Proteine, also die Abstoßung der Teilchen, das anziehende Minimum des effektiven Potentials verdeckt, so lösen sich die Strukturen wieder auf (vergleiche Abbildung 4.19). Das Verdecken des anziehenden Minimums durch den harten Kern im Fall größerer Proteine erkennt man, indem man die in Abbildung 4.6 angegebenen Abstände mit der Lage des Minimums in Abbildung 4.9 vergleicht. Am Ausdruck für das effektive Lipidsystem kann man das nicht sehen, da die Protein-Protein-Wechselwirkung in der Rechnung vernachlässigt wurde.

\subsection{Komponenten mit gerichteter Wechselwirkung}

Proteine bilden in Biomembranen häufig funktionelle Komplexe. Dabei kommen gleiche, ähnliche oder auch sehr verschiedene Proteine räumlich eng zusammen und bilden einen mehr oder weniger stabilen Komplex. Die Bindungen können sehr stark sein wie bei den Bestandteilen eines Ionenkanals, der sich praktisch wie ein einziges Teilchen in der Biomembran bewegt, oder viel schwächer durch Anlagerungen, die thermisch auch wieder gelöst werden können (siehe z. B. Stryer, 1995). Die Einzelteile für sich haben keine oder eine andere Funktion für das biologische System als der Komplex. Insofern spielt neben der Frage, welche Proteine in einer Biomembran überhaupt vorkommen, die nach den Bindungsverhältnissen eine entscheidende Rolle zum Verständnis biologischer Funktionen.

Diese Betrachtungen sollen zum Anlass genommen werden, Proteinkomplexe im Rahmen des in dieser Arbeit entwickelten Modells zu untersuchen. Wegen der Vielzahl an Möglichkeiten beschränkt sich die Darstellung hier auf eine exemplarische Diskussion von einwertigen Bindungen.

Es soll der einfachst mögliche Komplex, das Dimer, betrachtet werden. Dafür wird eine Proteinform konstruiert, die genau eine Bindungsstelle besitzt, d. h. es gibt eine mögliche Zusammenlagerung von zwei Proteinen, bei der das System Energie gewinnt. Wegen der geringen Bindungsenergie kann die Dimerisierung eventuell durch die (durch das Lipidsystem vermittelte) effektive Wechselwirkung der Proteine getrieben werden. Genau diese Frage ist Gegenstand der Untersuchung.

Das Modell, das durch die Hamiltonfunktion in Gleichung 4.2 definiert wurde, enthält bereits alle Bestandteile, um Proteine mit Bindungsstellen zu beschreiben. Es müssen lediglich die Wechselwirkungs-Umgebungen und die Kopplungs-Konstanten angegeben werden. Die Bindungsstelle soll durch eine kleine Wechselwirkungs-Umgebung beschrieben 


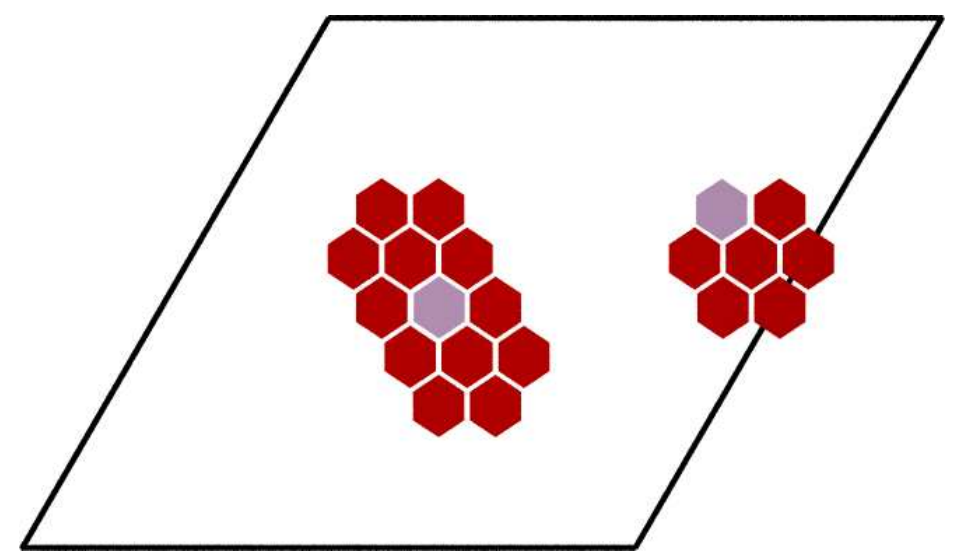

Abbildung 4.20: Modellskizze der Adsorbate mit Bindungsstellen. Rot (dunkel) sind die Plätze, die zu den harten Kernen der Proteine gehören, grau (hell) sind die Bindungsstellen. Zwei Proteine sind durch Überlappung ihrer Bindungsstellen zu einem Dimer verbunden.

werden, die bei Überlappung mit einer anderen Energie gewinnt. Bindungen mit mehr als zwei Proteinen sollen nicht möglich sein, deshalb muss die Form des harten Kerns so gewählt werden, dass sich aus geometrischen Gründen nur je zwei Umgebungen überlappen können. Das Protein selbst soll möglichst klein und symmetrisch sein.

Man wählt hier eine Form, die vom sieben Plätze bedeckenden Protein (vergleiche Abbildung 4.3) ausgeht, einen Platz vom Rand des harten Kerns entnimmt und diesen zur Bindungsstelle macht. Dieser Randplatz kann sich nur mit genau einem anderen Randplatz überlappen. Eine Konfiguration mit drei Adsorbaten, wovon zwei gebunden sind, ist in Abbildung 4.20 gezeigt.

Unter dem Dimerisierungsgrad verstehe man die Wahrscheinlichkeit, dass ein Protein Teil eines Dimers ist. In der Simulation bestimmt man diese Größe aus dem ClusterParameter bezüglich der bindenden Wechselwirkungs-Umgebung. Nach der Definition des Cluster-Parameters als Wahrscheinlichkeit für ein bestimmtes Paar von Gitterplätzen muss man diesen folgendermaßen normieren, um den Dimerisierungsgrad zu erhalten:

$$
p(\text { Dimer })=\frac{p(\text { Cluster })}{\theta / 3}
$$

Geht man von einem bestimmten Lipidsystem aus, so sind im oben formulierten Modell nur die Dichte der Adsorbate $\theta$ und die Stärke der bindenden Wechselwirkung $K_{P P}$ variabel. Der Term, der die Wechselwirkung mit dem Kern $K_{P P}^{w o}$ beschreibt, ist hier nicht nötig. Als Lipidparameter wählt man - wie schon einige Male zuvor - die Werte aus Gleichung 4.19. Die Protein-Lipid-Kopplung sei genau so, wie in der Anpassung an die Daten von Cytochrome C ermittelt, d. h. 200 cal/mol stark bei 19 Plätzen Bedeckung. Unabhängig von der Kopplungsstärke ergibt sich qualitativ das in Abbildung 4.21 gezeigte Verhalten mit steigender Dichte. Mit steigender Kopplung erhöht sich lediglich der Absolutwert des Dimerisierungsgrads. Für die hier gezeigte Abbildung binden die Proteine einfach mit der gleichen Stärke aneinander wie an die Lipide im gestreckten Zustand.

Bei geringer Proteindichte folgt der Grad der Dimerisierung dem Übergang mit einem schwach ausgeprägten Maximum im Übergangsbereich selbst. Mit steigender Dichte stabilisieren die Dimere in der von den Proteinen ungeliebten expandierten Lipid-Phase. 


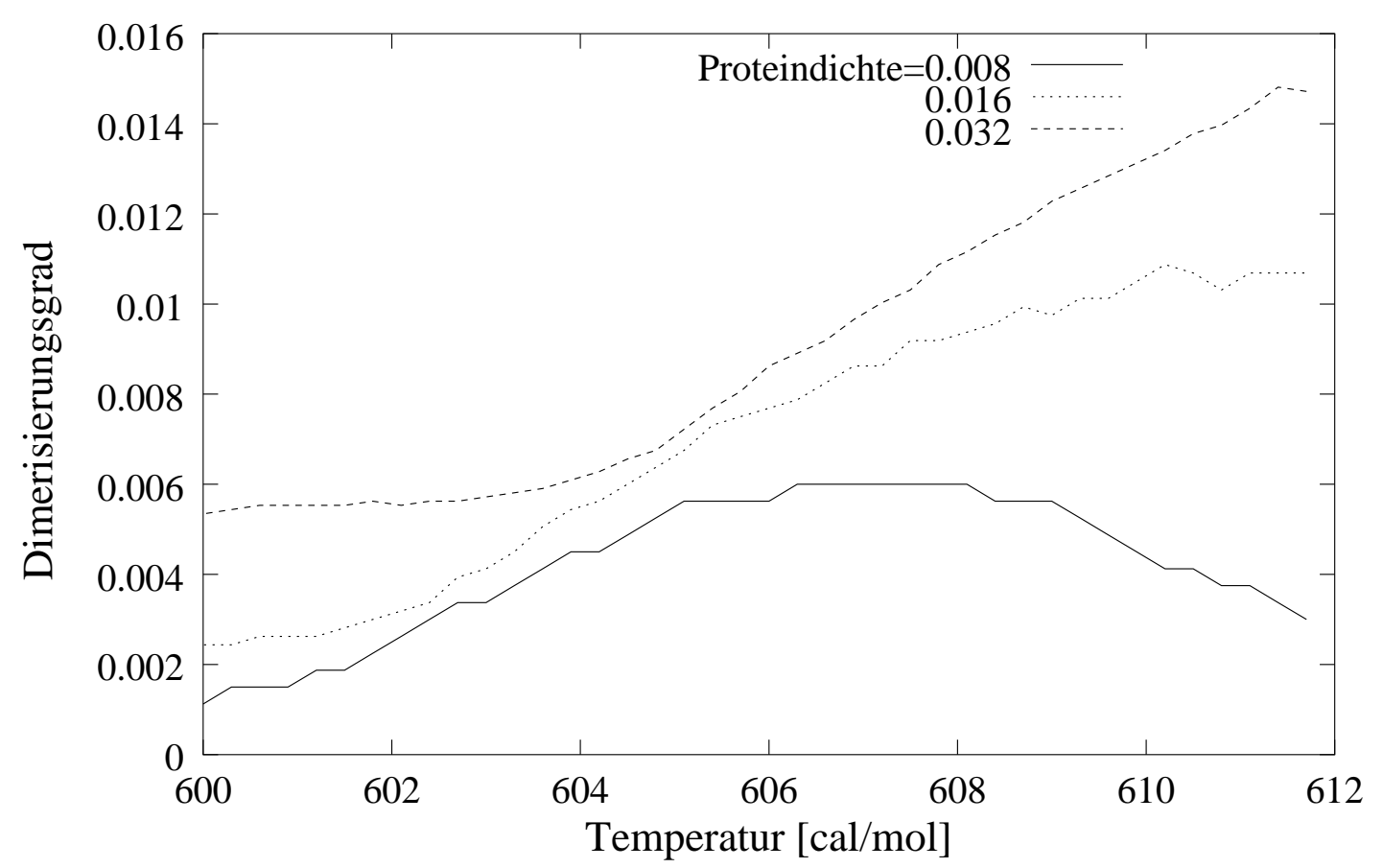

Abbildung 4.21: Dichteabhängigkeit der Dimerisierung. Die Teilchendichte auf dem Gitter beträgt 0,008, 0,016 und 0,032. Der Dimerisierungsgrad ist die Wahrscheinlichkeit, dass ein Protein Teil eines Dimers ist. $\left[L=80, K_{L P}=200 \mathrm{cal} / \mathrm{mol}, K_{P P}=-200 \mathrm{cal} / \mathrm{mol}\right]$

Dies korreliert mit der Entstehung und Stabilisierung von Protein-Clustern in einer LipidPhase, wie sie im letzten Kapitel beschrieben wurde. Es ist also gezeigt, dass die durch die Lipidfluktuationen getriebene Protein-Klumpung zu einer deutlich sichtbaren Dimerisierung führt.

Der Vorgang der Dimerisierung ist nicht kooperativ. Er folgt mehr oder weniger dem Übergang im Lipidsystem. In Bezug auf Bindungsphänomene ist dies eine Ausnahme, die nur für einwertig bindende Proteine wie hier betrachtet gilt. Hätte jedes Teilchen zwei oder mehr Bindungsstellen, so könnten sich ausgedehnte Cluster bilden, die erstens eine Orientierungsordnung und zweitens eine Kooperativität, aufgrund zunehmender Restriktionen beim Aufbrechen ausgedehnter Cluster, erwarten lassen.

\subsection{Beispiel: Unilamellare DMPG-Vesikel mit Cytochrome C}

Der einfachste Fall im Hinblick auf die Anpassung der Modellparameter an experimentelle Kurven ist der peripherer Komponenten, deren Wechselwirkung untereinander vernachlässigt wird (also der weicher Adsorbate). Neben den Lipidparametern gilt es nur, die Kopplungs-Konstante $K_{P L}$ zu finden. Mit dem gleichen Argument für die Übergangstemperatur wie in Abschnitt 2.7 gilt nun für deren Verschiebung $\delta T_{\mathrm{m}}$ bei einem Bedeckungs$\operatorname{grad} \operatorname{von} \theta$ :

$$
H-T_{m} S+\theta K_{P L}=3 K_{L L} \Rightarrow \theta K_{P L}=\delta T_{\mathrm{m}} S
$$

Die Modellparameter werden an experimentelle Daten aus der Literatur angepasst, die von Heimburg und Biltonen (1996) veröffentlicht wurden. Die Vesikel der wässrigen Sus- 


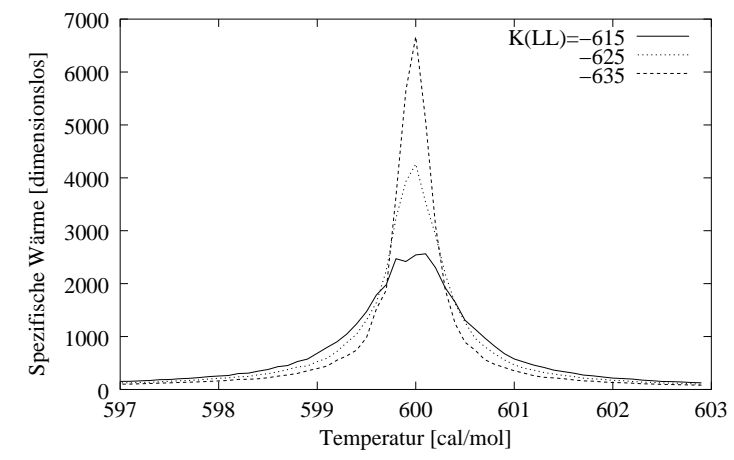

(a) Lipid-Kopplungs-Konstante $K_{L L}$

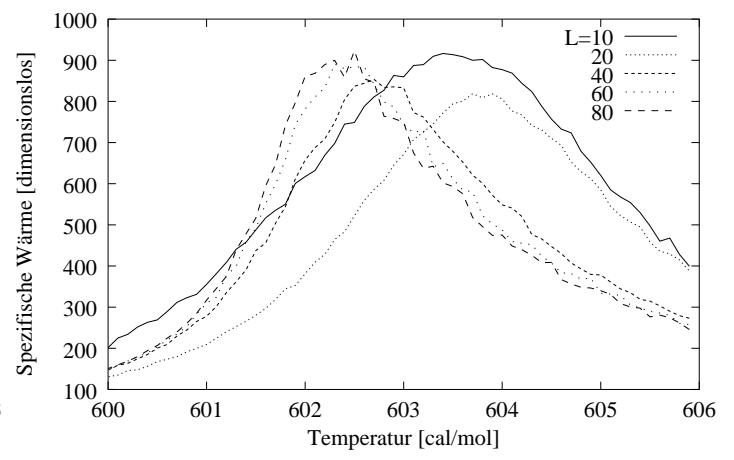

(b) Systemgröße $L$ (mit Proteinen)

Abbildung 4.22: Erste Anpassung der Parameter der MC-Simulation an experimentelle Daten der spezifischen Wärme. Physikalische Einheiten: Kopplungs-Konstanten und Temperatur in $\mathrm{cal} / \mathrm{mol}$, damit ist die spezifische Wärme dimensionslos.

pension bestanden in der zitierten Arbeit aus Lipiden der chemischen Bezeichnung DMPG und waren mit dem hydrophilen Protein Cytochrome C bedeckt (siehe Abbildung 4.1). In den Experimenten wird die spezifische Wärme im Temperaturbereich des Hauptübergangs der Lipide bestimmt. Die Autoren vergleichen ihre experimentellen Ergebnisse ebenfalls mit Monte-Carlo-Simulationen eines ähnlichen Modells. Aber erstens passen ihre Modellparameter nur qualitativ zu den eigenen Experimenten und zweitens wird nur eine Größe und Form von Adsorbaten untersucht. Um genau diese Abhängigkeit von der Form und Größe soll es im Folgenden gehen.

Beim Vergleich von Experimenten mit theoretischen Ergebnissen muss darauf geachtet werden, das richtige Ensemble zu wählen. An dieser Stelle wird davon ausgegangen, dass die Zahl der adsorbierten Proteine auf der Membran konstant ist (die Teilchen also ein kanonisches Ensemble bilden). Das ist für Proteine, die - wie Cytochrome C - keinen Anker in der Lipidmembran besitzen, nicht selbstverständlich.

Zuerst müssen die Lipidparameter bestimmt werden. Aus der oben zitierten Arbeit entnimmt man die folgenden gemessenen Werte für die Übergangsenthalpie $H_{\mathrm{m}}$, die Übergangstemperatur $T_{\mathrm{m}}$ und die Übergangsbreite $\Delta T_{1 / 2}$ der Suspension aus Wasser und Lipiden:

$$
\begin{aligned}
H_{\mathrm{m}} & =6 \mathrm{kcal} / \mathrm{mol} \\
T_{\mathrm{m}} & =297 \mathrm{~K} \approx 600 \mathrm{cal} / \mathrm{mol} \\
\Delta T_{1 / 2} & \leq 1 \mathrm{~K} \approx 2 \mathrm{cal} / \mathrm{mol}
\end{aligned}
$$

Die auf den ersten Blick etwas grob erscheinende Näherung für die Übergangstemperatur ist nicht zu beanstanden, da die sonstigen Energiewerte wie die Übergangsenthalpie nicht mit einer vergleichbaren Genauigkeit messbar sind.

Die im Rahmen der vorliegenden Arbeit simulierten Kurven, die an die experimentellen Daten aus der Literatur angepasst werden sollen, um die Kopplungs-Konstante der Lipide zu bestimmen, sind in Abbildung 4.22(a) zu sehen. Mit Hilfe der Zusammenhänge aus 
Gleichung 2.26 und 2.27 erhält man die folgenden Werte für die Modellparameter $H, S$ und $K_{L L}$ :

$$
\begin{aligned}
H & =7875 \mathrm{cal} / \mathrm{mol} \\
S & =10 \\
K_{L L} & =625 \mathrm{cal} / \mathrm{mol}
\end{aligned}
$$

Die Entropie ist dimensionslos, weil die Temperatur in Energieeinheiten ausgedrückt wird. Die Tatsache, dass die Breite des Übergangs - und damit der ermittelte Wert für die Kopplungs-Konstante - abhängig von der Präparationsmethode der Lipidvesikel ist (siehe z. B. Ivanova u. a., 2003), sei der Vollständigkeit halber und zur Vorsicht mahnend erwähnt.

Im Phasendiagramm des Gittergas-Modells befindet sich das System jenseits des kritischen Punktes an einem Punkt, an dem das Verhältnis von Temperatur und KopplungsKonstante den kritischen Wert um etwa $10 \%$ übersteigt. In Abbildung 4.22(b) ist gezeigt, dass die Kurven in diesem Bereich etwa ab einer linearen Systemgröße von $L=30$ nicht mehr von der Systemgröße abhängen.

Man kann Heimburg und Biltonen (1996) entnehmen, dass die Energie der ProteinLipid-Kopplung unabhängig von der spezifischen Wärme gemessen wurde. Aber auch anhand der Verschiebung des Übergangs lässt sich die Wechselwirkungs-Energie abschätzen. Die beiden resultierenden Werte unterscheiden sich um einen Faktor zwei, einerseits $K_{L P}=$ $100 \mathrm{cal} / \mathrm{mol}$ und andererseits $K_{L P}=200 \mathrm{cal} / \mathrm{mol}$. Zunächst soll der erste Wert für $K_{P L}$ angenommen werden.

Damit sind die Energie-Parameter des Modells bestimmt. Nun werden die Wechselwirkungs-Umgebungen gesucht. Zunächst vernachlässigt man die Protein-ProteinWechselwirkung bis auf die durch die Besetzungszahlen realisierten harten Kerne und variiert die Protein-Lipid-Wechselwirkungs-Umgebung. Man probiert systematisch symmetrische Umgebungen auf dem Gitter aus, indem man dem genau unter dem Protein liegenden Platz der Größe 1 die erste Schale von Plätzen, die ein Hexagon bilden und zusammen 7 Plätze ausmachen, hinzufügt und im dritten Schritt eine weitere Schale, um auf insgesamt 19 Plätze zu kommen.

Das Resultat dieser Variationen ist in Abbildung 4.23(a) zu sehen. Die Kurven werden mit zunehmender Größe der Umgebung flacher, verschieben sich ein wenig und es ist eine gewisse Asymmetrie zu erkennen. Mit den stark verbreiterten und abgeflachten Kurven des Experiments stimmt am ehesten die Kurve mit der größten Protein-Lipid-Umgebung von 19 Plätzen überein.

Variiert man nun aber die Protein-Protein-Wechselwirkung, indem man den harten Kern genauso von 1 Platz auf 7 Plätze und dann auf 19 Plätze vergrößert, so erkennt man in Abbildung 4.23(b) wieder eine geringe Verschiebung und diesmal ein Aufbäumen der Kurven. Den größten Effekt zeigen also große weiche Adsorbate. Aus unabhängigen Experimenten berichten Heimburg u. a. (1999) eine Ausdehnung des Cytochrome C, welches einer Bedeckung von mindestens 7 Lipiden entspricht. Deshalb wird der bezüglich der simulierten Umgebungen mittlere Wert von 7 Plätzen für die Protein-Protein-Umgebung gewählt.

Das Resultat dieser ganzen Anpassung sieht man in Abbildung 4.24(a), in der die spezifische Wärme von unterschiedlich stark bedeckten Lipidsystemen mit Proteinen gezeigt ist, die mit 19 Lipiden wechselwirken, aber nur 7 Plätze belegen. Für die Protein-LipidKopplung wurde zunächst ein Wert von $K_{P L}=100 \mathrm{cal} / \mathrm{mol}$ angenommen. Die Kurven 


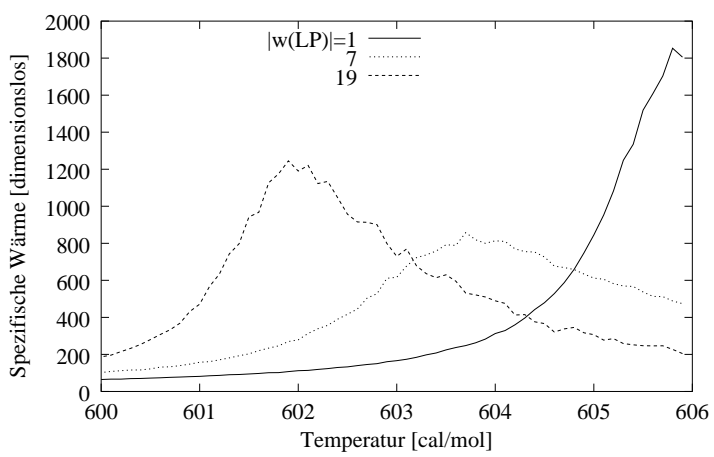

(a) Protein-Lipid-Wechselwirkung $\left|w^{P L}\right|$ (Bedeckungsgrad 0,3, Kopplung $K_{L P}=$ $200 \mathrm{cal} / \mathrm{mol}$ fest)

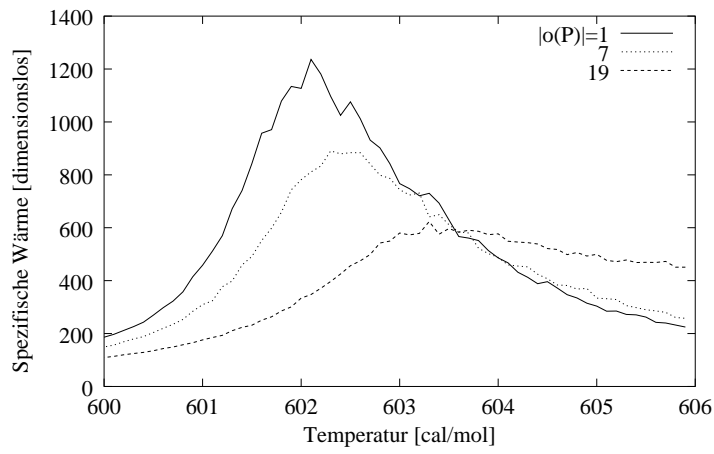

(b) Protein-Protein-Wechselwirkung $\left|o^{P}\right|$ (Bedeckungsgrad 0,3, Kopplung $K_{L P}=$ $200 \mathrm{cal} / \mathrm{mol}$ fest)

Abbildung 4.23: Weitere Anpassung der Parameter der MC-Simulation an experimentelle Daten der spezifischen Wärme. Physikalische Einheiten: Kopplungs-Konstanten und Temperatur in $\mathrm{cal} / \mathrm{mol}$, damit ist die spezifische Wärme dimensionslos.

stimmen sowohl qualitativ als auch quantitativ in einem gewissen Rahmen mit dem Experiment überein. In der Abbildung 4.24(b) darunter ist das Ergebnis der Simulationen mit der doppelten Wechselwirkungs-Energie von $200 \mathrm{cal} / \mathrm{mol}$ dargestellt. Die Verbreiterung des Übergangs ist beim zweiten (höheren) Wert von $K_{P L}$ stärker ausgeprägt und damit näher am experimentellen Ergebnis.

Die experimentell bestimmten spezifischen Wärmen lassen sich also relativ zwanglos durch simulierte Kurven des Gitter-Modells anpassen. Im Folgenden soll über die bekannten Experimente hinaus dargestellt werden, welche Observablen prinzipiell noch vergleichbar sind, denn aus der Simulation lassen sich wesentlich aussagekräftigere Daten gewinnen als die spezifische Wärme.

Zunächst betrachte man die effektive Wechselwirkung. Geht man von der Anpassung der Modellparameter durch kalorimetrische Experimente aus, so gibt es keine Freiheiten mehr in dem Modell. Die resultierenden effektiven Potentiale der Protein-ProteinWechselwirkung sind in Abbildung 4.25 zu einer Reihe von unterschiedlichen Temperaturen dargestellt. Prinzipiell ergibt sich das aus Abschnitt 4.2.2 bekannte Bild, jedoch ist die Auflösung bezüglich der Temperatur höher. Man erkennt in den kleinen Abbildungen 4.25(a) und 4.25(b), wie sehr sich die Potentiale im Bereich des Hauptübergangs qualitativ unterscheiden. Anhand der Abbildung 4.25(c), die das effektive Potential im wichtigen Temperaturbereich jenseits des Hauptübergangs vergrößert zeigt, lässt sich verstehen, wie sich die Ausdehnung der Proteine auswirkt: Mit ihrem harten Kern überdecken die Adsorbate das anziehende Minimum je nach Größe und Temperatur zu einem bestimmten Teil. Die Tatsache, dass sich bei der Anpassung der kalorimetrischen Daten eine mittlere Größe von 7 Plätzen als praktikabel erwiesen hat, zeigt, dass die Tendenz zur Entmischung vorhanden, aber auch teilweise durch die Überdeckung des Minimums gehindert ist.

Angesichts der fehlenden Experimente, die die Frage nach Entmischung im Fall von Cytochrome C auf Lipidmembranen klären könnten, bleibt es Spekulation, ob dieses spezielle Protein in Wirklichkeit entmischt. Die hier dargestellte Anpassung der Daten legt 


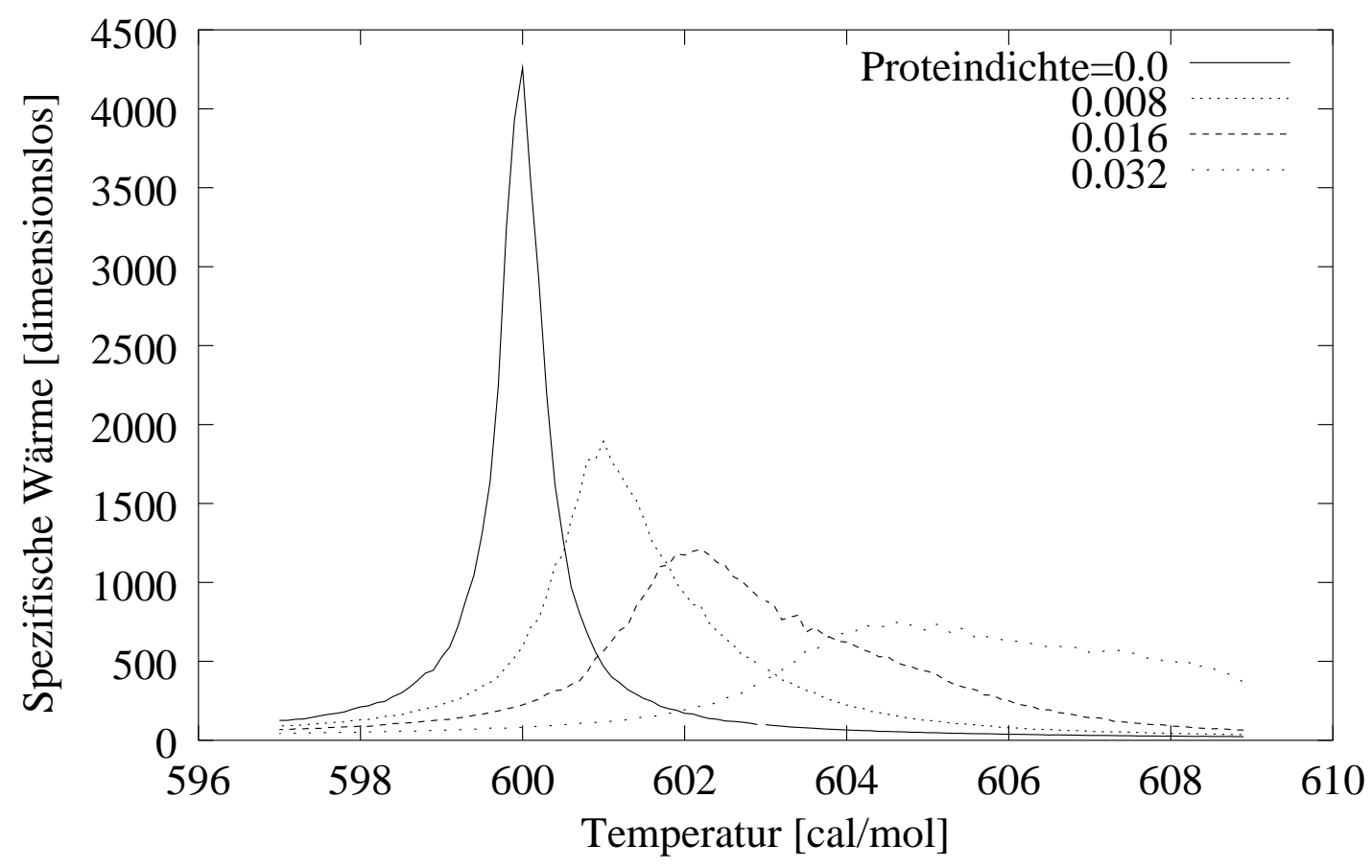

(a) Bedeckungsgrad 0, 15, 30, 60\% $\left(\left|w^{P L}\right|=19\right)$ bei $K_{P L}=100 \mathrm{cal} / \mathrm{mol}$

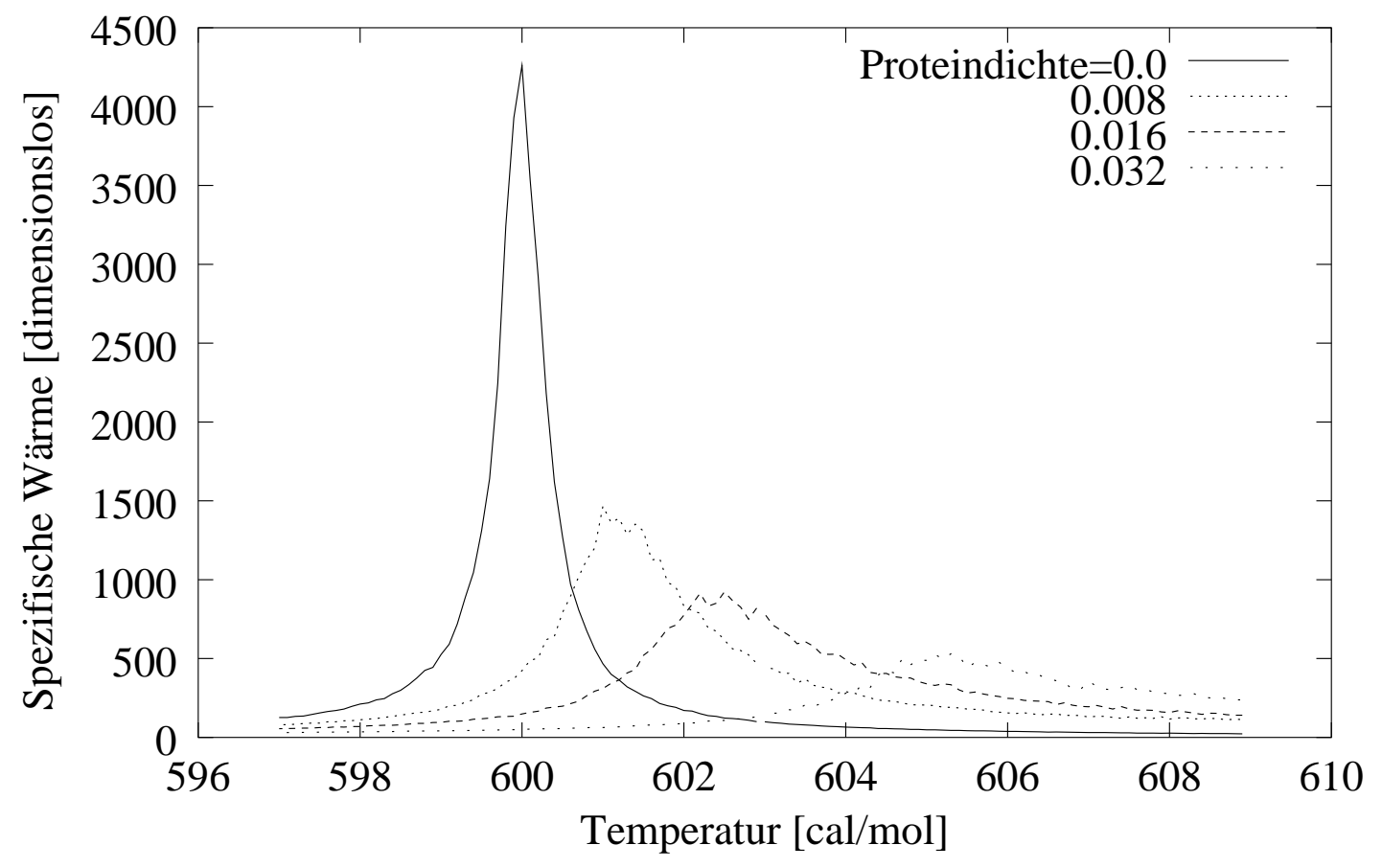

(b) Bedeckungsgrad 0, 15, 30, $60 \%\left(\left|w^{P L}\right|=19\right)$ bei $K_{P L}=200 \mathrm{cal} / \mathrm{mol}$

\footnotetext{
Abbildung 4.24: Ergebnis der Anpassung an experimentelle Daten der spezifischen Wärme (Physikalische Einheiten: Temperatur in cal/mol und folglich spezifische Wärme dimensionslos). Parameter: siehe Gleichung 4.19.
} 


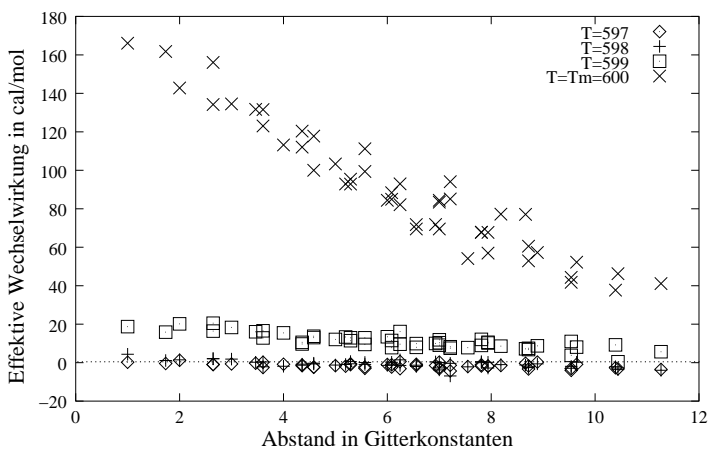

(a) Temperaturen wenig unterhalb des Hauptübergangs. Am Übergangspunkt erkennt man ein stark abstoßendes Potential.

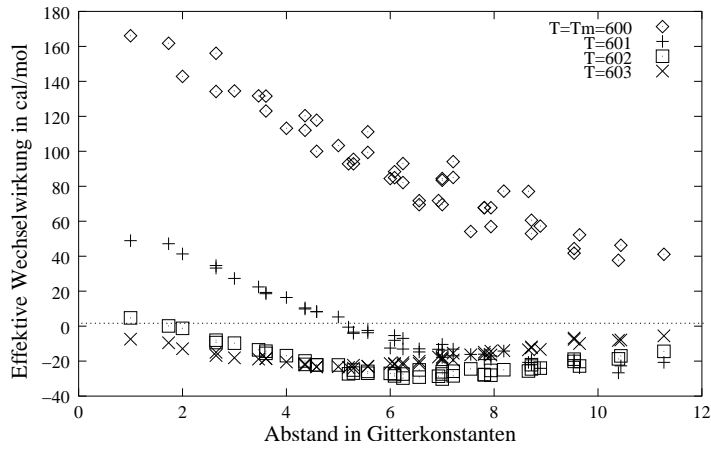

(b) Temperaturen wenig oberhalb des Hauptübergangs. Jenseits des Übergangs existiert ein Minimum mit anziehender Wechselwirkung.

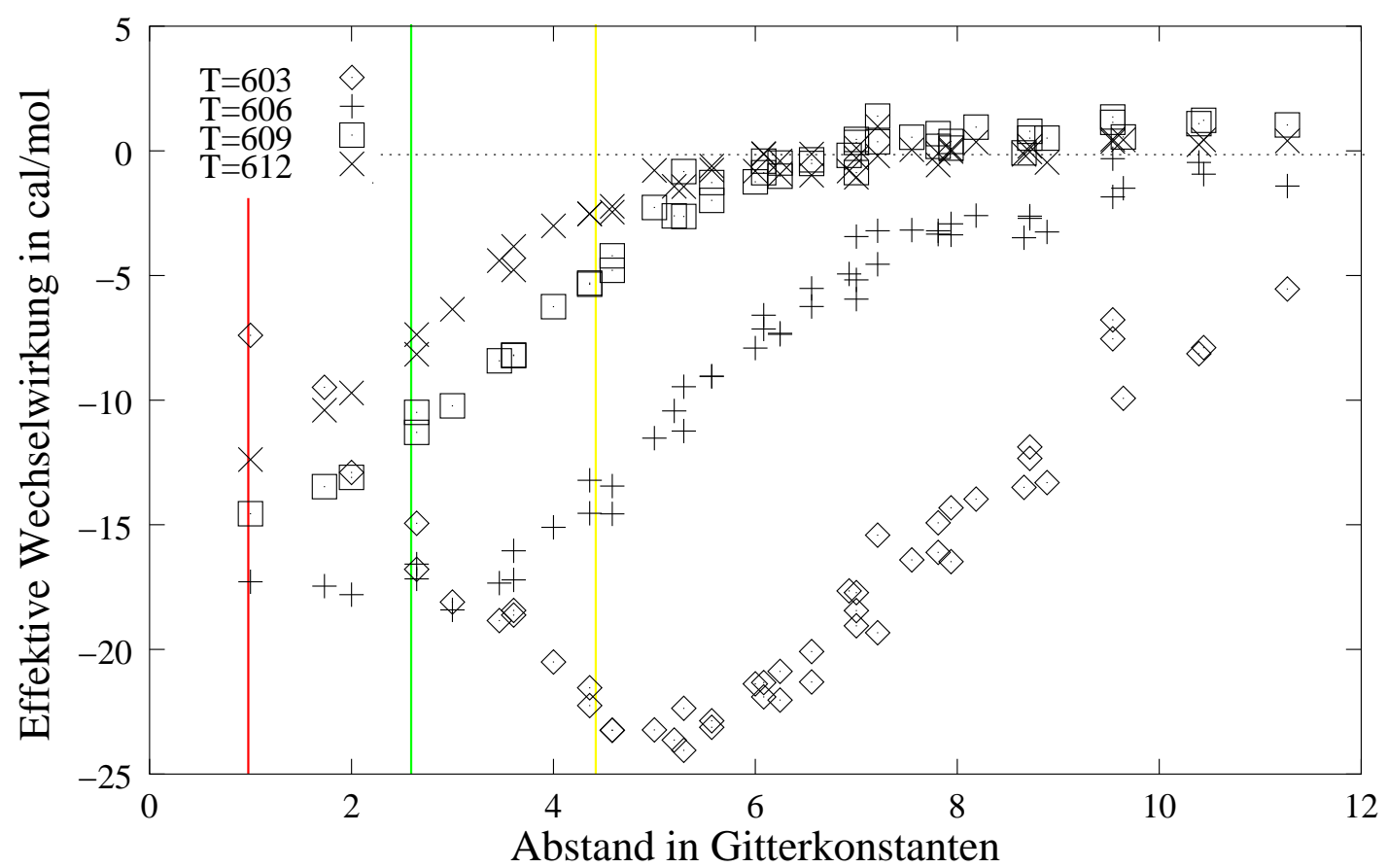

(c) Temperaturen weit oberhalb des Hauptübergangs. Das Minimum verschiebt sich zu kleineren Abständen, bleibt aber auch bei hohen Temperaturen ausgeprägt. Als senkrechte Linien sind die Ausdehnungen der harten Kerne für Umgebungen der Größe 1, 7 und 19 Plätze eingezeichnet. Aus den spezifischen Wärmen für Cytochrome $\mathrm{C}$ wurde der mittlere Wert 7 herausgelesen.

Abbildung 4.25: Effektive Protein-Protein-Wechselwirkung in Abhängigkeit des ProteinAbstandes bei verschiedenen Temperaturen. Parameter: $K_{P L}=200 \mathrm{cal} / \mathrm{mol},\left|w^{P L}\right|=19$. Das Minimum im effektiven Potential der Proteine (hervorgehoben durch die große Abbildung in der Mitte) bei Temperaturen oberhalb des Hauptübergangs der Lipide führt zu einer Aggregation der Adsorbate. Parameter: siehe Gleichung 4.19. 


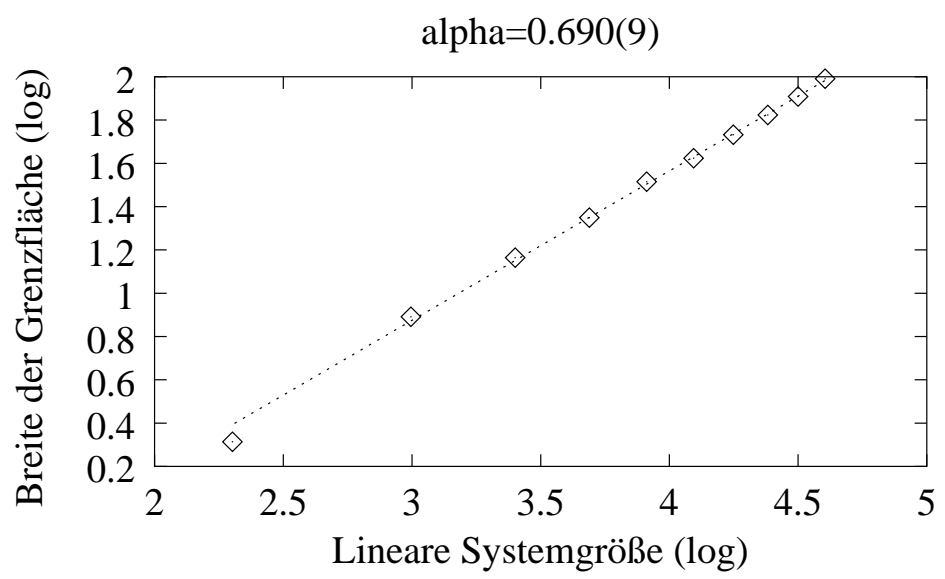

$$
\begin{array}{c|cc} 
& \theta=0,008 & \theta=0,016 \\
\hline T=606 \mathrm{cal} / \mathrm{mol} & \alpha=0,679(7) & \alpha=0,74(1) \\
T=612 \mathrm{cal} / \mathrm{mol} & \alpha=0,1690(9) & \alpha=0,69(1)
\end{array}
$$

Abbildung 4.26: Skalenverhalten der Breite der Grenzfläche mit der linearen Systemgröße $L$. Parameter: $T=612 \mathrm{cal} / \mathrm{mol}, \theta=0,008$ (Bedeckungsgrad 15\%), angepasst an Cytochrome C. Tabelle: Unterschiedliche Werte des Skalenexponenten $\alpha$ für verschiedene Werte der Temperatur und des Bedeckungsgrades. Parameter: siehe Gleichung 4.19.

dies aber nahe. Weil man aus Beobachtungen der Computersimulationen weiß, dass Adsorbate mit dieser Form $\left(\left|o^{P}\right|=7\right.$ und $\left.\left|w^{L P}\right|=19\right)$ bei gewissen Temperaturen jenseits des Hauptübergangs entmischen, wird der Vollständigkeit halber auch die Grenzfläche der Phasen charakterisiert.

Zunächst zeigt Abbildung 4.26 das Skalenverhalten der Grenzlinie zwischen bedeckter und unbedeckter Membran bei einem gemittelten Bedeckungsgrad von $15 \%$ und einer Temperatur weit jenseits des Hauptübergangs. Der Skalenexponent beträgt $\alpha=0,69$, das heißt die Grenzlinie ist sehr rau. Es zeigt sich, dass der Wert des Exponenten in einem gewissen Rahmen von der Temperatur und dem Bedeckungsgrad abhängt (siehe Tabelle in Abbildung 4.26).

Zusammenfassend lässt sich festhalten, dass die Möglichkeiten zur Anpassung der Modellparameter gut sind, aber in Zukunft durch andere Experimente validiert werden sollten. Die Variationsmöglichkeiten in den Modellparametern sind anhand nur einer Größe wie der spezifischen Wärme allein zu groß. Zusätzliche Experimente sollten sensitiv bezüglich der Paar-Korrelationsfunktion der Proteine sein, die sich direkt in die hier berechneten effektiven Potentiale überführen lässt (beispielsweise Streuexperimente mit Röntgen- oder Neutronen-Strahlen), oder die Kräfte direkt messen (z. B. durch Bewegung der Proteine mit einem Atomkraftmikroskop oder einer optischen Pinzette). 


\title{
5 Diskussion und Einordnung der Arbeit
}

\author{
Inhaltsangabe
}

5.1 Gibt es ein Standardmodell der Biophysik? . . . . . . . . . . 93

5.1.1 Verschiedene Ebenen der Modellierung . . . . . . . . . . . . . 94

5.1.2 Abgrenzung zu anderen Arbeiten . . . . . . . . . . . . . 97

5.2 Verständnis des Hauptübergangs von Lipidmembranen . . . 98

5.3 Entmischung peripherer Proteine durch Lipidfluktuationen . . 99

5.4 Anwendungspotenzial des formulierten Modells . . . . . . . . 101

5.5 Ein Gitter-Modell der gekrümmten Membran . . . . . . . . . . 103

In diesem Kapitel wird die vorliegende Arbeit zunächst in den globalen Kontext biophysikalischer Wissenschaft eingebettet. Daraufhin stellt sich die Frage, wie sich das beschriebene und analysierte Modell in die aktuelle Forschungslandschaft einordnet. Dabei werden konkrete Arbeiten besprochen, um die vorliegende Arbeit abzugrenzen und ihren neuen Beitrag herauszustellen. Zum Schluss des Kapitels und der Arbeit wird diskutiert, was man aus den theoretischen Modellen über die Biomembran lernen kann, und ein Ausblick auf die mögliche weitere Forschungsarbeit gegeben.

\subsection{Gibt es ein Standardmodell der Biophysik?}

Die Physik biologischer Materie ist kein Standardgebiet der theoretischen Physik, in dem ausgehend von etablierten ersten Prinzipien ein klarer Weg der Modellierung vorgezeichnet ist. Aber auch wenn das Thema zwischen den klassischen Disziplinen angesiedelt ist, werden die Prinzipien der physikalischen Forschung - die mathematische und experimentelle Validierung - nicht vernachlässigt (eine treffende Beschreibung, was Physik eigentlich ist, findet sich in der Einleitung zu Schulz, 2001).

Zunächst wird das biologische System behandelt wie jedes physikalische System auch, der Begriff Leben spielt für die Biophysik im Allgemeinen keine Rolle. Die Frage, ob ein lebendes System möglicherweise grundsätzlich anders zu betrachten ist, stellen sich Physiker zur Zeit kaum. Aus ihrer Sicht ist ein biologischer Organismus ein komplexes VielteilchenSystem, bestehend aus ganz unterschiedlichen Molekülen, die oft sehr groß sind und viele innere Freiheitsgrade besitzen. Typisch ist der mehr oder weniger weiche Charakter der Stoffe und die Tatsache, dass die Organismen als Ganzes sicher nicht im thermischen Gleichgewicht sind.

Auf mesoskopischer Skala ist die biologische Materie meist flüssig, die molekularen Aggregate können aber eine erstaunliche Festigkeit erreichen, die das Gesamtsystem stabilisieren (z. B. das Cytoskelett oder sogenannte Mikrotubuli). Subsysteme können durchaus im thermischen Gleichgewicht sein, jedoch fällt die Identifizierung equilibrierter Teile oft 
schwer, da man kaum in der Lage ist, Raum-, Zeit- oder Energieskalen im System klar zu trennen. Bei der Beschäftigung mit Modellen biologischer Systeme begegnet einem ständig ein „sowohl als auch“ bezüglich der Skalen.

In dieser reduktionistischen Sicht erscheint die biologische Materie als ein Spezialfall weicher Materie oder komplexer Fluide. Viele Eigenschaften lassen sich durch technische Modellsysteme und theoretische Modelle nachvollziehen. Die statistische Physik liefert einen etablierten und mächtigen Formalismus zur Beschreibung struktureller, thermischer und dynamischer Eigenschaften ausgehend vom molekularen Bild (siehe neben vielen anderen Büchern z. B. Reif und Muschik, 1987).

Typische Eigenschaften von biologischen Materialien sind unter anderem:

- Große Moleküle mit inneren Freiheitsgraden und komplizierte, ev. indirekte Wechselwirkungen

- Metastabile Strukturen, die keinen Gleichgewichts-Zustand repräsentieren

- Selbstorganisation auf allen Ebenen, von Molekülen (z. B. Ionenkanäle) bis zu ganzen Ökosystemen

Als weitere typische Eigenschaft wird oft angeführt, dass die relevanten Energien meist im Bereich der thermischen (bei einer typischen Temperatur von etwa 300 Kelvin) liegen. Das stimmt sicher genauso wie die oben aufgeführten Punkte, soll aber zeigen, dass die Eigenschaften von biologischer Materie konzeptionell nicht von ihrer Funktion zu trennen sind. Wie sollte denn ein dynamischer und zugleich im Ganzen sehr stabiler Prozess wie das Leben auf der Erde entstehen, wenn die Freiheitsgrade nicht durch die Energie der Umgebung anregbar wären? Doch solche funktionellen Argumente weisen über die Diskussion innerhalb der Physik hinaus. Die Evolution - der Begriff für die eben erwähnte Dynamik und Stabilität - ist für die Physik etwas ganz Neues (siehe auch Zaccai, 2002). Sie findet nur insofern Beachtung, als dass statistische Modelle für die Entwicklung von Populationen untersucht werden, die eine qualitative Veränderung der Eigenschaften der Individuen zulassen. Der Zusammenhang mit biologischer Materie fehlt diesen Ansätzen.

Die Diskussion biophysikalischer Modellierung führt also von der Frage nach einem theoretischen physikalischen Bild biologischer Materie hin zum Gebiet der statistischen Physik weicher Materie. Von dort geht eventuell ein Weg zurück zu den Fragen des lebenden Systems. Doch weil diese Aspekte der Natur zur Zeit ausgeklammert werden, muss man als theoretischer Physiker in der Diskussion der „biologischen Funktion eines Systems“ vorsichtig werden.

Beschränkt man sich auf die reduktionistische Sicht der Dinge, so könnte man vermuten, dass es eine systematische Vergröberung der Modellierung vom Molekül zum biologischen Subsystem gibt. Das ist momentan noch nicht der Fall. Die Identifizierung wichtiger Freiheitsgrade gestaltet sich gerade bei biologischer Materie als sehr schwierig. Die Kombination verschiedener Ansätze, sowohl experimentell als auch theoretisch, ist äußert wichtig. Die Herausforderung der täglichen Arbeit besteht darin, die Verknüpfung von Modell, Methode und Fragestellung zu überblicken. Das Teilsystem, zu dessen Verständnis die hier vorliegende Arbeit einen Beitrag leisten will, ist die Biomembran.

\subsubsection{Verschiedene Ebenen der Modellierung}

Die Biomembran ist für sich genommen ein dermaßen komplexes System, dass sich die Modellierung nur auf Teilaspekte oder generische Eigenschaften beziehen kann. Für die 
groben Bilder der Biomembran als dielektrische Barriere mit selektivem Teilchentransport sei nur kurz auf die Literatur verwiesen (z. B. Alberts u. a., 1994; Adam u. a., 1995). Einen historischen Abriss und eine gute Einführung in die Diskussion zur Modellierung von Biomembranen gibt ein Sammelband von Mouritsen und Andersen (1998). In verschiedenen Beiträgen wird in erster Linie auf die mikroskopische Struktur und die Vorstellungen, die sich aus unterschiedlichen Experimenten und Sichtweisen ergeben, eingegangen.

Die Weichheit der Membran, die zusammen mit der geringen Oberflächenspannung zur Folge hat, dass Krümmungs-Energien die Form der Fläche bestimmen, führt auf die erste Kategorie von Modellen, die kurz besprochen werden soll. Hierbei handelt es sich um phänomenologische Modelle, d. h. die freie Energie wird aus allgemeinen Argumenten heraus postuliert und nicht oder nur indirekt mikroskopisch begründet. Der Startpunkt zur Beschreibung von gekrümmten Membranen ist üblicherweise die Formulierung von Helfrich (1973): Die Krümmungs-Energie wird in Abhängigkeit der Biegesteifigkeit als Materialkonstante und der (ortsabhängigen) Krümmungsradien als Variablen der äußeren Form bis zur quadratischen Ordnung entwickelt. Die innere Struktur wird durch Kopplung eines Ordnungsparameters in der Ginzburg-Landau-Formulierung an die Krümmung dargestellt. Durch Minimierung der freien Energie erhält man dann sowohl die Form der Membran als auch die Verteilung des Ordnungsparameters und eine Abschätzung für die Werte der elastischen Konstanten der Lipidmembran (Chacón u. a., 1998). Die Formvariationen von Vesikeln (Deuling und Helfrich, 1976), sogar die Entstehung von nicht symmetrischen und topologisch veränderten Formen (Seifert u. a., 1991), und beispielsweise das Abschnüren von Vesikeln aufgrund der Entmischung von zwei Komponenten lassen sich sehr genau mit diesem theoretischen Ansatz beschreiben, siehe Jülicher und Lipowsky (1993) oder den ausführlicheren Beitrag von Lipowsky (1992).

Von einer ganz anderen Richtung der Modellierung setzt die Molekular-DynamikSimulation an. Mit plausiblen Annahmen für die Potentiale zwischen den Atomen wird die Bewegung einer Menge von Lipiden, Wasser und anderen Membran-Bestandteilen auf dem Computer simuliert. Die Energieparameter sind aber auch hier nicht ad hoc bestimmt, sondern werden an experimentelle Daten angepasst. Der Vorteil dieser Simulationen liegt auf der Hand: Man besitzt die komplette mikroskopische Information und simuliert das System in seiner wirklichen Dynamik. Ein Anwendungsbeispiel ist die Untersuchung des Vorgangs der Einlagerung eines Proteins in eine Lipidmembran (Okazaki u. a., 2001). Die Grenzen liegen in der Kapazität: Es lassen sich nur kleine Systeme aus hunderten von Lipiden und sehr wenigen Proteinen berechnen und das Zeitintervall ist auf einige Nanosekunden begrenzt. So ist es sehr schwer, aus dem mikroskopischen Wissen makroskopische thermodynamische Observablen und Aussagen über das Phasenverhalten des Systems zu gewinnen.

Der auch in dieser Arbeit beschrittene Mittelweg versucht, die Modelle mikroskopisch zu begründen und die Moleküle als Entitäten des Modells zu erhalten. Gleichzeitig sollen makroskopische Phänomene wie das Phasenverhalten gemischter Systeme untersucht werden. Das geht einerseits durch analytische Approximationen, die im Ergebnis auf ähnliche Formulierungen wie die der phänomenologischen Modelle führen, oder andererseits durch statistische Simulationen der thermischen Eigenschaften der Modelle. Die Systeme, die durch Monte-Carlo-Simulationen zugänglich sind, können wegen der geringeren Detailliertheit des Modells mit etwa $10^{4}$ Molekülen wesentlich größer sein als in Molekular-DynamikSimulationen. Die Methode liefert üblicherweise Aussagen über den Gleichgewichtszustand des Systems, kann aber auch zur Beschreibung dynamischer Größen herangezogen werden. 
Die Modellierung der einfachen Lipidmembran als Gittergas, dargestellt in Abschnitt 2.4, vernachlässigt zunächst die äußeren Freiheitsgrade (wie die Translation) der Lipide und vergröbert die inneren Zustände auf zwei, die sich in ihrer Energie und Entartung signifikant unterscheiden. Ausgehend von diesen beiden Paradigmen der Modellierung gibt es eine Reihe von Arbeiten, die gezeigt haben, dass dieser Ansatz zur Beschreibung der Thermodynamik von Lipidmembranen und deren Wechselwirkung mit Proteinen prinzipiell geeignet ist (siehe z. B. Gil u. a., 1998). Die vielen offenen Fragen zu den Details der Phasen und Übergänge führen dazu, dass gezielte Erweiterungen des Modells untersucht werden. Bezüglich der Translationsfreiheitsgrade und damit der Frage, wie die Ordnung der Schwerpunkte der Lipide mit in das Zweizustands-Modell einbezogen werden kann, gibt es zwei unterschiedliche Ansätze. Entweder man führt einen variablen Ort und eine ausgedehnte Form (z. B. eine Kreisscheibe) der Teilchen ein und simuliert ein zweidimensionales System aus harten Scheiben mit inneren Freiheitsgraden (Fraser u. a., 1991), oder man führt eine Dynamik auf dem Gitter der Teilchen ein, d.h. man lässt die Kanten des Gitters fluktuieren (Nielsen u.a., 1996). In beiden Ansätzen konnten die Phasenübergänge in der Ordnung der Schwerpunkte und der inneren Ordnung der Ketten erfolgreich verknüpft werden. Ist man an genaueren strukturellen Eigenschaften interessiert, z.B. der möglichen Ordnung zusätzlicher Membran-Komponenten in einer Gitterformation (Sabra u.a., 1998b) oder dem Einfluss kleinerer Komponenten wie Cholesterin auf die Ordnung der Lipidmoleküle (Nielsen u.a., 1999), so führt an solch einer Erweiterung des Modellansatzes für die Lipide kein Weg vorbei. Diese Richtung ist aber in der hier vorliegenden Arbeit bewusst nicht eingeschlagen worden. Hier wird sich damit zufrieden gegeben, dass das Gittergas-Modell die Struktur der Lipidmembran in groben Zügen wiedergibt. Das Zusammenspiel großer ausgedehnter Membran-Komponenten mit den relativ kleinen Lipidmolekülen und die daraus resultierende, möglicherweise strukturbildende, Wechselwirkung steht bei diesem Ansatz im Vordergrund. Dafür wird das Gitter-Modell unter Wahrung der oben beschriebenen Paradigmen erweitert.

Die in dieser Arbeit untersuchte Modellerweiterung ist schon aus Sicht der GitterModelle interessant. Es handelt sich beim Lipidsystem um ein Ising-Modell mit temperaturabhängigem Feld. Über dieses sind einige Eigenschaften exakt und viele in unterschiedlichen Näherungen bekannt. Das Proteinsystem ist ein Gittergas aus ausgedehnten Teilchen. Dieses ist längst nicht so ausführlich untersucht, allgemeine Ergebnisse liegen nicht vor. In gewissen Näherungen finden sich aber bekannte Modelle wie das der harten Hexagone. Das Modell der Biomembran (siehe Gleichung 4.2) geht noch einen Schritt weiter und koppelt diese beiden Modelle. Dabei ist es sehr wichtig, dass die Protein-LipidWechselwirkung von ihrer Reichweite her nicht der Ausdehnung des Proteins entsprechen muss. Dafür gibt es mindestens zwei anschauliche Erklärungen: Erstens kann das Protein weich sein und deshalb weniger Platz bezüglich anderer Proteine beanspruchen als es Lipide bedeckt, zweitens kann das Protein partiell in die Membran eindringen und dadurch die Lipide in einer gewissen Umgebung beeinflussen.

Das Konzept der effektiven Wechselwirkung bzw. des Potentials der mittleren Kräfte dient in dieser Arbeit zunächst zur qualitativen und quantitativen Begründung für das beobachtete Phänomen der Entmischung aufgrund der Protein-Lipid-Wechselwirkung. Sowohl die analytische Formulierung eines effektiven Modells (Gleichung 4.6) als auch die numerische Berechnung mittlerer Zweiteilchen-Potentiale (Gleichung 4.11) kann als Ansatzpunkt für neue Untersuchungen dienen. 
Die Beschreibung der effektiven Wechselwirkung zwischen zwei Proteinen (siehe Abschnitt 4.2.2) kann mit einer ganz anderen Klasse von Arbeiten verglichen werden, die weniger auf die Protein-Lipid-Wechselwirkung in Membranen als vielmehr auf die speziellen Eigenschaften der Proteine fokussieren. So wurde beispielsweise die effektive Wechselwirkung zwischen DNS-Molekülen in ionischer Lösung untersucht (Allahyarov und Löwen, 2000) und eine starke Abhängigkeit von der Orientierung der DNS-Moleküle zueinander und der Ionen-Konzentration in der Lösung festgestellt, die sich durch eine lineare Theorie des Elektrolyten nicht nachvollziehen lässt. Der in der vorliegenden Arbeit beschrittene Weg ist zwischen der möglichst genauen Modellierung der Proteine und einer kontinuierlichen Theorie des Mediums angesiedelt.

\subsubsection{Abgrenzung zu anderen Arbeiten}

Das in dieser Arbeit beschriebene Modell ist in anderer Form bereits untersucht worden. Insbesondere die Namen O.G. Mouritsen und T. Heimburg verbinden sich mit vielen Veröffentlichungen, in denen ein solches Modell mit Hilfe der Monte-Carlo-Methode ausgewertet wurde. Was ist also neu an dieser Arbeit?

Ziel dieser Arbeit ist es, die Einflüsse ausgedehnter Komponenten auf den Phasenübergang der Lipide und die effektive Rückkopplung auf das Proteinsystem systematisch in seiner Abhängigkeit von der Größe und Form der Komponenten und der äußeren Parameter wie der Temperatur zu untersuchen. Die analytische Summation über die Proteinzustände führt auf ein Lipidsystem mit effektiven Mehrteilchen-Kopplungen. Dieser Aspekt, insbesondere die Abhängigkeit von der Größe der Adsorbate, wurde bisher nicht untersucht. Ebenfalls zum ersten Mal werden effektive Potentiale zwischen Proteinen in solch einem Modell quantifiziert. Neu ist auch die Beschreibung der Entmischung peripherer Proteine aufgrund der Protein-Lipid-Wechselwirkung.

Als Spezialfall der hier untersuchten Modellvarianten finden sich manche bereits veröffentlichten Ergebnisse anderer Autoren wieder, insbesondere die Monte-CarloSimulation des Protein-Lipid-Systems. Dabei handelt es sich in der Literatur immer um eine Näherung des hier untersuchten Modells, in der zwischen der Form der Proteine und der Wechselwirkungs-Umgebung mit den Lipiden nicht unterschieden wird. Eine systematische Analyse des Einflusses von Größe und Form fehlt bisher. In diesem Zusammenhang führt die in dieser Arbeit angewandte Kombination von analytischen Methoden (Mittlere-Feld-Näherung) und (Monte-Carlo-) Simulationen zu einer neuen Einsicht in die Eigenschaften von Lipidmembranen mit Proteinen.

Verschiedene Autoren zielen in ihren Arbeiten darauf ab, anhand der spezifischen Wärme, die sie aus Monte-Carlo-Simulationen gewinnen und mit experimentellen Daten vergleichen, das Mischungs- und Cluster-Verhalten der Peptide vorhersagen zu können. Das Phasenverhalten wird in erster Linie anhand von Schnappschüssen der Simulation abgeleitet. Zunächst muss aus theoretischer Sicht jedoch angemerkt werden, dass eine globale Größe wie die spezifische Wärme nicht eins-zu-eins die molekularen Strukturen eindeutig beinhalten kann. Darüber hinaus kann allein die Betrachtung von Schnappschüssen die Frage nach Entmischung und vor allem die nach der Stabilität und der Natur der räumlichen Strukturen nicht beantworten (siehe dazu die Betrachtungen in Abschnitt 3.5 dieser Arbeit).

Aus der einfachen Struktur des Zweizustands-Modells folgen einige Äquivalenzen. So sind verschiedene Antwortfunktionen wie die spezifische Wärme und die Kompressibilität 
proportional zueinander. Im Dreizustands-Modell gilt dies aber nicht mehr. Es gibt Experimente, die eine erstaunlich weitreichende Proportionalität beider Größen bei Suspensionen aus Lipidvesikeln zeigen (Heimburg, 1998) und damit das Zweizustands-Modell in dieser Hinsicht bestätigen. Das darf man aber nicht ohne weiteres auf komplexere Systeme verallgemeinern.

Im Rahmen der vorliegenden Arbeit wurde eine gerichtete Wechselwirkung zwischen den Proteinen eingeführt, die spezifische Bindungsstellen oder ganz allgemein Asymmetrien des Teilchens modellieren kann (siehe Abschnitt 4.5). Dieser Ansatz findet sich in verwandter Form auch in der Literatur wieder (Sperotto, 1997). Die in der zitierten Arbeit untersuchte Form der Wechselwirkung erlaubt viele verschiedene gebundene Zustände und lässt sich deshalb nicht direkt mit einem einfachen und anschaulichen Phänomen wie der Dimerisierung verknüpfen. Die Klumpung der dort simulierten integralen Proteine wird durch die unmittelbare Protein-Protein-Wechselwirkung getrieben, wohingegen die Dimerisierung der Adsorbate in Abbildung 4.21 dieser Arbeit auf die durch die Lipide vermittelte effektive Wechselwirkung zurückzuführen ist.

\subsection{Verständnis des Hauptübergangs von Lipidmembranen}

Studiert man die Literatur bezüglich des Hauptübergangs von Lipidmembranen, unterhält sich mit verschiedenen Wissenschaftlern auf diesem Gebiet und sammelt selbst Erfahrung bei der Modellierung von Biomembranen, so stellt man fest, dass einige grundlegende Fragen unentschieden bleiben. So ist vor allem die Ordnung des Übergangs einzelner Lipidschichten, aggregiert z. B. zu Vesikeln, nicht eindeutig festzustellen. In Abschnitt 2.5 wurde aufgezeigt, dass einige Anzeichen eines Phasenübergangs 1. Ordnung, viele Beobachtungen großer Fluktuationen und sogar kritisches Verhalten zu verzeichnen sind. Des Weiteren lassen kalorische Experimente sogar bezweifeln, ob es überhaupt einen scharfen Übergang für einzelne Membranen gibt.

Das Zweizustands-Modell besitzt zwar Bereiche mit jeweils solchen Charakteristika, kann aber das Gemenge an Beobachtungen verschiedener Messgrößen nicht erklären. Aufgrund seiner wenigen Freiheitsgrade ist es wahrscheinlich ungeeignet, einen wesentlichen Beitrag zur Klärung der widersprüchlich erscheinenden Observablen zu leisten. Deshalb wird in dieser Arbeit auch keiner der in der Literatur diskutierten Standpunkte selbst eingenommen, es werden nur die verschiedenen Aspekte beleuchtet.

Insbesondere ist der Fokus der vorliegenden Arbeit auf den Einfluss von ausgedehnten Komponenten auf das Phasenverhalten der Membran gerichtet. In diesem Sinne ist das zugrunde liegende Lipidmembran-Modell das einfachste, welches überhaupt einen Phasenübergang zeigt. Dieser weist einige - aber längst nicht alle - Charakteristika des Hauptübergangs auf. Unter anderem um die strukturierende Wirkung zusätzlicher Komponenten herauszustellen, wird für die Lipidmembran angenommen, dass sie sich im Phasenraum jenseits eines unstetigen Übergangs befindet. Im Hinblick auf Biomembranen bleibt darüber hinaus die Vorstellung, dass es aufgrund der Komplexität und Inhomogenität des Systems für die qualitativen Effekte nicht auf die spezielle Struktur eines Übergangs ankommt, sondern allein auf die Tatsache, dass die Membran innere Freiheitsgrade besitzt, die mit den funktionellen Teilen (den Proteinen) wechselwirken, und so Effekte treiben können, die auch biologisch relevant sind. 


\begin{tabular}{|c|c|}
\hline $\begin{array}{l}\text { Lipidmembran: I } \\
\text { ne Strukturierun }\end{array}$ & $\begin{array}{l}\text { g-Modell } \rightarrow \text { Kei- } \\
\text { oberhalb } T_{c}\end{array}$ \\
\hline $\begin{array}{l}\text { Kleine Einlagerungen: 3-Zustands- } \\
\text { Modell mit komplexem Phasendia- } \\
\text { gramm } \Rightarrow \text { Entmischung und Ord- } \\
\text { nung }\end{array}$ & $\begin{array}{l}\text { Große weiche Adsorbate: Ising mit } \\
\text { Mehrteilchen-Wechselwirkung } \Rightarrow \\
\text { Entmischung und Clusterbildung }\end{array}$ \\
\hline$\downarrow$ & $\downarrow$ \\
\hline $\begin{array}{l}\text { Kleine Adsorbate: Ising im } \\
\text { Gleichgewichts-Zufallsfeld } \Rightarrow \text { Keine } \\
\text { Strukturierung aber Clusterbildung }\end{array}$ & $\begin{array}{l}\text { Große harte } \quad \text { Adsorbate: } \\
\text { Mehrzustands-Modell mit WW- } \\
\text { Umgebungen } \Rightarrow \text { Destabilisierung } \\
\text { der Strukturierung }\end{array}$ \\
\hline
\end{tabular}

Abbildung 5.1: Strukturbildung in den verschiedenen untersuchten Modellvarianten. Das Diagramm zeigt die beiden wichtigsten Wege der Analyse: den Vergleich integraler mit peripheren Komponenten auf der linken Seite und die Abhängigkeit von der Größe und Form der Adsorbate auf der rechten Seite. Die Auswahl der Methoden (Mittlere-Feld-Approximation mit Nachbarschaften und Monte-Carlo-Simulation) richtet sich nach ihren Möglichkeiten, zur Untersuchung dieser Fragestellungen nützlich zu sein.

\subsection{Entmischung peripherer Proteine durch Lipidfluktuationen}

Das Bild bezüglich der Strukturbildung in Lipidmembranen mit kleinen oder großen Komponenten, das aus den Analysen dieser Arbeit folgt, ist in Abbildung 5.1 gezeigt. Man geht zunächst vom Zweizustands-Modell der Lipidmembran aus, von dem viele exakte Ergebnisse bekannt sind. Bei variabler mittlerer Besetzungszahl des Lipidzustands (variabler Ordnungsparameter) ist insbesondere klar, dass es ein Phasendiagramm mit einer Linie 1. Ordnungsübergänge gibt, die in einem kritischen Punkt endet (vergleiche Ising-Modell des Ferromagnetismus). Unterhalb des kritischen Punkte gibt es die bekannten Strukturen, die aus Domänenwachstum (Stichwort „Weißsche Bezirke“) resultieren. Oberhalb gibt es aber nur Fluktuationen mit endlichen Zeit- und Längenskalen. Bei fester mittlerer Besetzungszahl entmischen die Komponenten unterhalb des kritischen Punktes für bestimmte Zusammensetzungen und mischen oberhalb (Stichwort „Binäre Legierungen“). Wie sich dieses Bild verändert, wenn man integrale oder periphere Komponenten hinzugibt, ist Gegenstand der Untersuchung.

Eine zentrale Aussage der Arbeit ist: In gewissen Näherungen lassen sich entweder die Proteine aus der Zustandssumme analytisch oder die Lipide numerisch per Simulation aussummieren. Im ersten Fall erhält man einen neuen Ausdruck für die Lipidmembran, der eine effektive Wechselwirkung höherer Ordnung (mehr als die Kopplung von Paaren) enthält und im zweiten ein zweidimensionales Gas ausgedehnter Teilchen mit Paar-Wechselwirkungen, die temperaturabhängig entweder kein Profil, eine ausgeprägte Abstoßung oder ein deutliches anziehendes Optimum besitzen (Abbildungen 4.7 bis 4.12).

Die Anpassung der Parameter der Computersimulation an experimentelle Daten und die Auswertung der Systemeigenschaften bei Temperaturen in der Nähe des Hauptübergangs hat folgendes Bild ergeben: Am Hauptübergang selbst gibt es keine stabile Strukturierung, wenn nicht die Lipide selbst entmischen. Aber jenseits des Hauptübergangs in einem gewis- 
sen Temperaturbereich entmischt das System aus Lipiden und Proteinen, auch wenn das Lipidsystem selbst dies nicht tut (siehe das Phasendiagramm in Abbildung 4.13). Die Proteine strukturieren also ein System, dass ohne sie homogen ist. Dieses Phänomen zeigt sich zum einen in den Schnappschüssen (Abbildungen 4.17 und 4.19) und deren genaueren Analyse, zum anderen aber auch deutlich in der effektiven Protein-Protein-Wechselwirkung. Diese wird nämlich anziehend für gewisse Temperaturen jenseits des Übergangs der Li-

pide, wohingegen sie genau am Übergang stark abstoßend ist. Zusammengefasst führt das auf die Aussage: Nicht der Hauptübergang selbst hat biologisch relevante Auswirkungen auf die Proteine, sondern allein die Fähigkeit der Lipide zur Zustandsänderung bewirkt funktionell wichtige Wechselwirkungen!

Das Bild, das sich aus der freien Energie des effektiven Lipidsystems in Gleichung 4.6 ergibt, ist mit den obigen Aussagen verträglich. So zeigt sich eine zusätzliche, durch die ausgedehnten Proteine in das System eingebrachte, Kooperativität des Systems. Dass der Effekt auch quantitativ mit Monte-Carlo-Simulationen vergleichbar ist, zeigt Abbildung 4.5. Das Phasenverhalten des effektiven Modells wurde jedoch nicht eingehender untersucht.

Es gibt einige Veröffentlichungen zur Frage der effektiven durch die Lipide vermittelten Wechselwirkung von Proteinen. In diesen ist aber ausschließlich von integralen Proteinen die Rede. Ein häufig bemühtes Modellbild besteht darin, dass die Einlagerungen die Oberfläche der Lipidmembran lokal verbiegen, weil die Länge ihrer hydrophoben Bereiche eventuell nicht zu denen der Lipide passen (englisch hydrophobic mismatch genannt). Als Resultat dieser Verbiegungen wechselwirken die Proteine miteinander und zwar aufgrund des elastischen Charakters der Wechselwirkung im Allgemeinen über eine große Distanz (siehe z. B. Weikl u. a., 1998; Sens und Safran, 2000).

Ein anderer Ansatz ist in den Arbeiten von Lagüe u. a. (2000, 2001) dargestellt. Die Autoren arbeiten mit einer integralen Darstellung des effektiven Wechselwirkungs-Potentials. Die Proteine sind als einfache zylindrische Objekte in der Membran und die Lipide mit atomarer Auflösung modelliert. Aussummiert werden die Lipidfreiheitsgrade, indem über die Daten aus Schnappschüssen von Molekular-Dynamik-Simulationen gemittelt wird. Als Ergebnis erhält man das effektive Potential der Zylinder im fluktuierenden Medium aus Lipiden. Dieser Ansatz wird genutzt, um die effektive Wechselwirkung in Abhängigkeit von der Zylindergröße zu untersuchen. Man findet, dass es ein abstoßendes Potentialmaximum gibt, dessen Abstand vom Protein mit zunehmender Zylinergröße abnimmt und dessen Betrag dabei ansteigt. Für nicht zu große Proteine gibt es bei geringen Abständen ein anziehendes Minimum. Das Lipidsystem befindet sich jeweils in der expandierten Phase, eine Temperaturabhängigkeit wird jedoch nicht untersucht.

Der Schwerpunkt der hier vorliegenden Arbeit liegt aber gerade auf dieser Abhängigkeit (siehe Abbildungen 4.10 bis 4.12). Auch in diesem Modell findet man ein Minimum bei geringen Abständen und ein ausgeprägtes abstoßendes Maximum, jedoch nicht zum selben Wert der Temperatur. Ein detaillierter Vergleich der Ergebnisse ist mit dem derzeitigen Datenbestand leider nicht möglich. Aus einem solchen könnte sich ergeben, inwieweit das sehr einfache Zweizustands-Modell der Lipide ausreicht, um die durch die Lipidmembran vermittelte Wechselwirkung von Proteinen untereinander zu beschreiben.

In einer Arbeit von Netz u. a. (1996), die vom Ansatz her den Mittlere-Feld-Näherungen der vorliegenden Arbeit ähnelt, wurde das Mischungsverhalten von ausgedehnten Adsorbaten in Lipidmembranen untersucht. Unter der Voraussetzung, dass die expandierte und die kondensierte Lipidphase koexistieren (man sich also im Bereich eines unstetigen Hauptübergangs befindet), finden die Autoren, dass sich die Proteine in der Grenzregion an- 
reichern, wenn die Proteine keine der beiden Lipidphasen energetisch bevorzugen. Die Adsorbate folgen dem Phasenverhalten der Lipide, beeinflussen dieses aber nicht.

Die Beobachtung stabiler Entmischung (siehe die Abschnitte 4.3 und 4.4) peripherer und mit einer Lipidmembran wechselwirkender Proteine in dieser Arbeit ist neu. Dabei ist stabile Entmischung von der Bildung metastabiler Cluster zu unterscheiden. Hat man einen Entmischungsvorgang identifiziert, so stellt sich sogleich die Frage nach der Charakterisierung der beiden Phasen und des Übergangs. Zunächst muss der Phasenübergang qualitativ beschrieben und die Ursache für dieses Phänomen in den effektiven Formulierungen des Lipid- bzw. Proteinsystems gesucht werden. Die effektiven Modelle liefern jeweils eine anschauliche und miteinander konsistente Erklärung und lassen sich quantitativ fassen. Die Charakteristika des Übergangs selbst wurden nicht näher untersucht. Jedoch wurde ein Anfang zur Analyse der Struktur der Phasen gemacht, indem das Skalenverhalten der Grenzflächen quantifiziert wurde. Das Skalenverhalten unterscheidet sich signifikant vom typischen Verhalten in zwei Dimensionen. Wie bereits in der Beschreibung der Ergebnisse erwähnt, bedeutet der Skalenexponent mit einem Wert von $\alpha \approx 0,6 . .0,7$, dass die Grenzfläche der entmischten Phase vergleichsweise rau ist. Typisch für zwei Dimensionen ist nämlich ein Wert von nur $\alpha=0,5$ (Barabasi und Stanley, 1995). Im makroskopischen Limes ist die Breite der Grenzfläche aber trotzdem relativ zum Volumen der Phasen verschwindend gering, denn der Exponent ist deutlich kleiner als eins. Wie diese Analyse weiterentwickelt werden kann, erkennt man z. B. in einem Beitrag zur Simulation von Grenzflächen bei Polymer-Mischungen (Müller und Schmid, 1999).

\subsection{Anwendungspotenzial des formulierten Modells}

Die Formulierung des sogenannten Kettenschmelzens der Lipide als ZweizustandsGittergas kann man eventuell auf ganz unterschiedliche Eigenschaften von LipidDoppelschichten anwenden (Heimburg, 2003). Doch bereits beim Studium des Hauptübergangs (siehe Abschnitt 2.5) zeigt sich, dass diese sehr vereinfachende Sicht auf die Lipidmembran im Detail diskussionswürdig ist und viele experimentelle Ungereimtheiten nicht aufzuklären vermag. Deshalb konzentriert sich diese Arbeit auf das Verhalten zusätzlicher Komponenten, die wesentlich größer sind als die Lipide und nicht auf die Details des Kettenschmelzens.

Die Formalisierung der Wechselwirkung durch die Überlappung von Umgebungen ist äußerst flexibel. Anhand der beiden Beispiele harte Hexagone (Abschnitt 4.1) und Proteine mit Bindungsstellen (Abschnitt 4.5) wurde bereits gezeigt, dass beliebige durch das Dreiecksgitter darstellbare Formen realisierbar sind. Durch die Trennung von Protein-Lipidund Protein-Protein-Wechselwirkung sind auch komplizierte Sachverhalte modellierbar. Am Beispiel der Anpassung des Modells an experimentelle Daten von Lipidvesikeln mit Cytochrome C zeigt sich, dass das Protein wahrscheinlich mit mehr Lipiden wechselwirkt als es rein geometrisch gesehen bedeckt (Abschnitt 4.6). Aber auch der umgekehrte Fall ist realistisch: Integrale Proteine besitzen häufig einen externen hydrophilen Teil, der in manchen Fällen wesentlich größer sein kann als der die Membran durchspannende. Die Abstoßung zwischen den Proteinen wäre in solch einem Fall von einer größeren Reichweite als die Wechselwirkung mit den Lipiden.

Die Lipidzustände werden im Rahmen dieser Arbeit immer als innere Freiheitsgrade einer chemischen Sorte von Molekülen aufgefasst. Man kann sie aber auch als Teilchensorte, und das Modell damit als binäre Mischung von Lipiden, interpretieren. Das En- 
semble der Lipidzustände müsste angepasst werden: das Verhältnis der Dichten beider Membran-Komponenten müsste konstant, das Ensemble also kanonisch sein. Die mittlere Besetzungszahl wäre eine Erhaltungsgröße (das entspricht dem Ising-Modell bei fester Magnetisierung).

Die Formulierung des Modells beschränkt sich nicht auf das thermische Gleichgewicht. Die Monte-Carlo-Simulation lässt sich auch dynamisch interpretieren, wenn man für die Metropolis-Schritte äquivalente Freiheitsgrade im experimentellen System finden kann und deren typische Zeitskalen auf die Übergangswahrscheinlichkeiten des Computerprogramms abbildet. Je komplizierter die Situation wird, d. h. je mehr Freiheitsgrade simuliert werden, desto schwieriger wird diese Identifikation. Für einfache Lipidmembranen, modelliert durch ein Zweizustands-Gittergas, haben Grabitz u. a. (2002) die Relaxation nach einem Drucksprung experimentell und in Computersimulationen nachvollzogen. Sabra u. a. (1998a) haben in einem Zweizustands-Modell einer binären Mischung mit zusätzlichen integralen Komponenten die Strukturierung in Abhängigkeit eines äußeren Energieeintrags durch die Einlagerungen untersucht. Man stellt sich dabei Proteine vor, die Energie von außen z. B. durch Lichtabsorption aufnehmen. Die Dynamik der Proteinaggregation, wie sie in der vorliegenden Arbeit in Abschnitt 4.3 beschrieben wurde, ist gerade im Hinblick auf biologische Anwendungen von Interesse, da in der wirklichen Biomembran ganz unterschiedliche Kräfte, unter Umständen auch von außen, in Konkurrenz zueinander treten. Eine Abschätzung der relevanten Zeitskalen könnte hier helfen, die für die Biomembran wichtigen Prozesse zu identifizieren.

Auch wenn in dieser Arbeit integrale und periphere Proteine getrennt untersucht werden, ist es keine große Erweiterung, integrale und periphere Komponenten gleichzeitig in die Lipidmembran zu geben. Für solch eine Analyse fehlt bisher das experimentelle Vorbild. Von theoretischer Seite spricht zudem gegen eine solche Untersuchung, dass das resultierende Modell weitere Parameter und ein noch viel reichhaltigeres Phasendiagramm besitzen würde, so dass eine systematische Analyse ohne weitere Anknüpfungspunkte sehr schwierig erscheint.

Die Untersuchung dieser Arbeit fokussiert auf die effektive Wechselwirkung im Proteinbzw. Lipidsystem, die durch die Protein-Lipid-Kopplung vermittelt wird. Dabei wird als treibende Kraft in erster Linie die Flexibilität der Lipidmoleküle und die damit verbundene Möglichkeit zum Phasenübergang identifiziert. Ein weiteres Ziel der Analyse dieses Modells könnte der Einfluss auf den Phasenübergang der Proteine selbst sein: Für das System ausgedehnter Scheiben existiert ein kooperativer Übergang, der durch die Dichte der Teilchen in der Fläche getrieben wird. Zum Phasenübergang harter Hexagone siehe Baxter (1982), zu dem harter kreisrunder Scheiben siehe Kapitel 2.1 in Chaikin und Lubensky (1995). Der Einfluss der Lipide auf diesen Übergang könnte untersucht werden. Zunächst ist aber zu beachten, dass die Art des Übergangs von der genauen Form des Teilchens und der Struktur des Gitters abhängt, und damit nur begrenzt als generisches Prinzip auf Proteine übertragbar ist. Des Weiteren haben erste Messungen des Übergangs der harten Hexagone keinen qualitativen Einfluss der Protein-Lipid-Wechselwirkung gezeigt.

Um Fragen der physiologischen Funktion von Biomembranen untersuchen zu können, wäre eine Erweiterung des Modells auf mehrere Proteinsorten nützlich, denn die Funktionen beruhen meist auf sehr spezifischen Wechselwirkungen der Komponenten. Rein zufällige Reaktionsereignisse in einem homogen gemischten Medium können die beobachteten funktionellen Reaktionen jedoch nicht erklären. Ein Membran-Modell, das sowohl spezifische Bindungen zulässt als auch globale Phänomene wie die Entmischung von Kom- 
ponenten berücksichtigt, kann auf Basis des in dieser Arbeit vorgestellten Modells entwickelt werden (siehe dazu den Abschnitt 4.5 über Proteine mit Bindungstellen).

Grundsätzlich soll festgehalten werden, dass das Modell der Biomembran (siehe Gleichung 4.2) nur so weit verallgemeinert wurde, wie es für die konkreten Betrachtungen in dieser Arbeit notwendig war. Der Grundgedanke, der sich auch in den Modellskizzen in Abbildung 4.2 zeigt, beruht auf der Vorstellung, dass die Membran aus mehreren Schichten besteht. Um den Aufbau der Biomembran in seiner ganzen Komplexität zu erfassen, müsste man zwei derartige Modelle von Lipidschichten mit integralen und peripheren Komponenten aneinander koppeln.

\subsection{Ein Gitter-Modell der gekrümmten Membran}

Das in dieser Arbeit vorgestellte Modell einer Biomembran (Gleichung 4.2) ist molekular aufgelöst, aber "flach“. Die Teilchen sind per Nebenbedingung in ihrer Anzahl und in ihrer Lokalisierung innerhalb der zweidimensionalen Schicht festgehalten. Fluktuationen in der räumlichen Anordnung der Moleküle, die sich aus den Zustandsänderungen ergeben und dadurch eventuell eine Krümmung der Oberfläche bewirken könnten, sind im Modell ausgeschlossen. Intuitiv empfindet man dies als sehr starke Einschränkung, deren Auswirkung auf die Thermodynamik des Systems im Gegensatz zur Vergröberung des Zustandsraums schlecht abzuschätzen ist. Gibt es eine Möglichkeit, die Formfluktuationen der Membran mit in ein (möglichst „Ising-artiges“) zweidimensionales molekulares Gitter-Modell einzubeziehen? Dabei soll vor allem die geometrische Form der Membran aus den inneren Zuständen der Komponenten folgen und nicht phänomenologisch als neue Freiheitsgrade des Modells eingeführt werden.

Die Beantwortung der Frage sollte damit beginnen, den Stand der Modellierung von Krümmungen in molekularen Membran-Modellen zu skizzieren. Hier werden nur Arbeiten angesprochen, die einen molekularen Ansatz der Modellierung wählen. Die Literatur im Umfeld der Modellierung nach Helfrich (1973) mit kontinuierlichen Größen bleibt an dieser Stelle ausgeblendet.

Heimburg (2000) z. B. hat den Monte-Carlo-Simulationen des Zweizustands-Modells eine Höhenvariable für die Lipide der Doppelschicht hinzugefügt und bezüglich dieser einen globalen Energiebeitrag angenommen, der große Undulationen unterdrückt. Die Simulation beschreibt jedoch nur einen eindimensionalen Schnitt durch eine Membran und lässt sich nicht auf zwei Dimensionen ausdehnen. Als Resultat findet sich ein Vorübergang, bei dem ein geringer Teil der Lipide in den gefalteten Zustand übergeht und sich „Ripples" ausbilden (zur Struktur der "Ripple-Phase"', wie sie sich experimentell darstellt, siehe Sengupta u. a., 1999). Kumar u.a. (2001) diskretisieren die Fläche mit Hilfe einer dynamischen Triangulierung, so dass beliebige topologisch sphärische Formen möglich sind. Auf dieser Fläche sind die Teilchen als Zustände auf den Plaketten definiert und wechselwirken nach Art eines Ising-Modells miteinander. Die Anzahl nächster Nachbarn ist aufgrund der Konstruktion trotz des fluktuierenden Gitters auf drei festgelegt. In einer älteren Formulierung besetzen die Teilchen die Knoten des Gitters (Kumar und Rao, 1997). Die Krümmungs-Energie wird in einer diskreten Form (auf dem Dreiecksgitter) mitberücksichtigt und über die Annahme, dass die Zustände unterschiedliche spontane Krümmungen erzeugen, an diese gekoppelt. Die Autoren untersuchen binäre LipidMischungen und finden, dass sich Bereiche des Vesikels auf unterschiedliche Weise abschnüren können, wenn die Komponenten entmischen. Die Faltung eines Dreiecksgit- 
ters aufgrund von lokalen und zufällig aber fest verteilten Krümmungs-Energien wird von Francesco u. a. (1997) mit Hilfe eines Cluster-Variationsverfahrens untersucht. Der Unterschied zu den zuvor zitierten Arbeiten liegt einerseits in der festen Unordnung (engl. quenched) und andererseits in der analytischen Methode. Die Autoren berechnen das Phasendiagramm (bezüglich der Eigenschaften "flach" und „gefaltet") in Abhängigkeit der Krümmungs-Energie. Das Modell mit zufälligen festen Verteilungen positiver und negativer Krümmungen auf dem Gitter entspricht einem Ising-Modell mit zufälligen Vorzeichen der Nächste-Nachbar-Kopplung. Die beschriebenen Ansätze beruhen alle auf der Formulierung eines eventuell erweiterten Ising-Modells, in dem die lokale Krümmung der Fläche mit den Spin-Freiheitsgraden des Modells in Verbindung gebracht wird.

Goldhirsch und Goldenberg (2002) diskutieren, inwieweit sich die Theorie elastischer Medien überhaupt mikroskopisch ohne die Einführung eines Gitters begründen lässt. Sie finden in ihrer systematischen Vergröberung, dass auf kleinen Längenskalen Abweichungen von der Theorie auftreten. Auch wenn ihre Arbeit auf die Effekte in granularen Medien zielt, kann man eine Relevanz für Biomembranen, die mit ihren Proteinen auch größere asymmetrische Teilchen enthalten, vermuten.

Ein Blick in ein weiteres Gebiet der theoretischen Physik offenbart einen ganz anderen Zugang, der mit nur sehr wenigen Modellannahmen und Freiheitsgraden auskommt und konsistent in zwei Dimensionen formuliert werden kann. Inspiriert ist der folgende Gedanke durch den Formalismus des Regge-Gitters zur möglichen Beschreibung der Quantengravitation. Die Originalarbeit ist von Regge (1961), die Formulierung des Modells wird von Fleming u. a. (1994) übernommen.

Das Modell soll anhand der einfachen Lipidmembran vorgestellt werden. Dabei ähneln die Gedanken sehr denen in Kapitel 2 dargestellten. Die Paradigmen der Modellierung ändern sich kaum. Eine spätere Erweiterung um zusätzliche Komponenten erscheint genauso unkompliziert wie im Modell flacher Membranen.

Wieder geht man davon aus, dass die Lipide aufgrund ihrer hydrophoben Wechselwirkung mit Wasser zweidimensionale ausgedehnte Aggregate bilden. Die Form dieser Aggregate wird aber nicht vorgegeben. Bezüglich der inneren Freiheitsgrade vergröbert man auch hier bis auf zwei Zustände, gestreckt und gefaltet, die sich in ihrer inneren Energie und dem Entartungsgrad, der inneren Entropie, unterscheiden. Bezüglich der Wechselwirkung nun nutzt man die Kenntnis des Regge-Gitters und ordnet die Lipide dementsprechend an: Die Moleküle bilden die Verknüpfungslinien eines zweidimensionalen Dreiecksgitters (siehe Abbildung 5.2). Für die Hamiltonfunktion enthält man natürlicherweise Terme linear in den Besetzungszahlen, solche in denen zwei Lipide respektive Verknüpfungen miteinander wechselwirken und zuletzt solche, in denen drei Lipide koppeln, die gemeinsam eine Plakette des Gitters bilden. Für das Modell flacher Membranen in Kapitel 2 wurde angenommen, dass die Lipide in ihrer Form bezüglich der Oberfläche der Membran als symmetrisch angesehen werden kann. Das ist aber sicher wegen des Aufbaus der Moleküle aus zwei verbundenen Ketten nur eine erste Näherung und zumindest im gestreckten Zustand keine besonders gute. Die hier diskutierte Erweiterung von der symmatrischen zur ellipsenförmigen Gestalt entspricht dem zweiten Term einer Entwicklung der MassenVerteilung (dem Quadrupol-Moment) und ist in diesem Sinne die systematische Fortsetzung des Ansatzes. Die Fixierung der Teilchen auf den Kanten des Gitters vernachlässigt aber weiterhin die Rotationsfreiheitsgrade der Lipide.

In der Literatur zur Regge-Formulierung findet man folgenden generischen Ausdruck zur Diskretisierung der Krümmungs-Energie auf einen Satz von Zweizustands-Variablen 


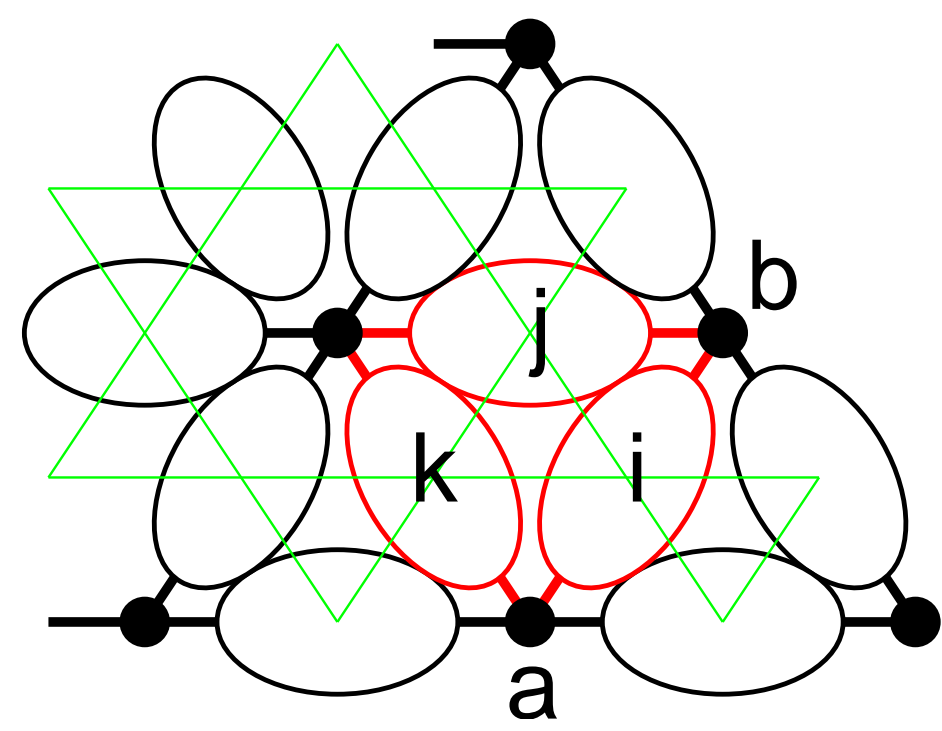

Abbildung 5.2: Formulierung der Lipidmembran als Regge-Gitter. Die Lipide sind (von oben gesehen) ellipsenförmig und seien so angeordnet, dass die langen Halbachsen die Kanten eines Dreiecksgitters bilden. Eine Zustandsänderung in den gefalteten Zustand bedeutet dann eine Ausdehnung dieser Achse und damit eine Verlängerung der Kante. Die Schwerpunkte der Lipide bilden ein Kagomé-Gitter (grün bzw. hellgrau angedeutet). Jeweils bis zu drei Lipide, die eine Plakette des Gitter bilden, wechselwirken miteinander (rot bzw. dunkelgrau und mit den Indizes $i, j, k$ bezeichnet). Die Gitterpunkte des Dreiecksgitters (Indizes $a, b$ ) werden zur Bestimmung der Flächenform herangezogen.

(Spins). Die Idee der Modellierung ist, dass die zweidimensionale Mannigfaltigkeit dargestellt wird durch ein Dreiecksgitter mit fester Koordinationszahl und fluktuierenden Kantenlängen, wobei diese nur zwei verschiedene Werte annehmen können. Diese Kantenlängen bilden also die Spinvariablen $s_{i}$ (vergleiche Abbildung 5.2):

$$
\mathcal{H}_{\text {Krümmung }}=C_{3} \sum_{\langle i, j, k\rangle} s_{i} s_{j} s_{k}+C_{2} \sum_{\langle i, j\rangle} s_{i} s_{j}+C_{1} \sum_{i} s_{i}
$$

Summiert wird in der Hamiltonfunktion über die Menge der Plaketten $\langle i, j, k\rangle$, der Paare $\langle i, j\rangle$ und der Plätze $i$ des Gitters. Die Kanten werden als die Lipide der Membran identifiziert. Die obige Hamiltonfunktion muss also um den Entartungsfaktor im Feld der Lipide erweitert werden (vergleiche Abschnitt 2.4):

$$
C_{1} \rightarrow C_{1}-T S
$$

Gleichung 5.1 ist die Energie einer zweidimensionalen gekrümmten Fläche, ausgefüllt durch Teilchen mit zwei sich in Entartungsgrad und Platzbedarf unterscheidenden Zuständen. Das resultierende Modell ist im Kontext von Lipidmembranen ungewöhnlich und neu, aber aufgrund der Annahmen der Modellierung konsequent. Interessant und hilfreich ist eventuell die Feststellung, dass Spins auf den Kanten eines Dreiecksgitters genau den Spins auf den Knoten eines Kagomé-Gitters entsprechen. Davon soll an dieser Stelle aber kein Gebrauch gemacht werden.

Entscheidend für die Interpretation des Gitters als gekrümmte Fläche ist die Identifizierung der Abstände zwischen den Gitterpunkten. Dafür werden die Indizes $a$ und $b$ zur 
Nummerierung der Knoten des Dreiecksgitters eingeführt (siehe Abbildung 5.2). Die neue Variable $s_{a b}$ bezeichnet den Abstand in beliebigen Einheiten zwischen den Gitterplätzen $a$ und $b$ :

$$
s_{a b}=1+\epsilon s_{i} \quad \text { mit } \quad i=\overline{a b}
$$

Die Konstante $\epsilon$ darf dabei nicht zu groß werden, weil sonst die Dreiecksungleichung verletzt würde. Der Wert, und damit der relative Unterschied in der Ausdehnung der Lipide im gestreckten und gefalteten Zustand, darf nicht größer als 1/3 sein.

Betrachtet man nur eine Plakette des Gitters, so stellt Gleichung 5.1 (erweitert um eine Konstante $C_{0}$ ) neben der Energie auch den allgemeinsten möglichen Ausdruck für deren Fläche dar. Diese kann aber nur vier verschiedene Werte annehmen, je nachdem ob keines, eines, zwei oder drei der Lipide auf den Kanten der Plakette sich im gefalteten Zustand befinden. Daraus folgen vier Gleichungen für die vier Konstanten $C_{0}$ bis $C_{3}$ in Abhängigkeit der relativen Differenz der Kantenlängen $\epsilon$. Damit bleibt dieser Parameter neben der inneren Entropie $S$ der einzige des Modells.

Das so formulierte System lässt sich wie gewöhnlich mit der Monte-Carlo-Methode simulieren und bezüglich seiner thermodynamischen Eigenschaften auswerten. Die entscheidende Eigenschaft des Spin-Modells der Krümmungsfläche besteht darin, dass zu jedem Mikrozustand der Menge der Spins auch eine Mannigfaltigkeit existiert (Fleming u.a., 1994). Die Kopplung von bis zu drei Spin-Variablen führt zu einem kooperativen Phasenübergang, der, vernachlässigt man die Wechselwirkung dritter Ordnung, genau dem Ising-Ferromagneten auf dem Kagomé-Gitter entspricht.

Um von der neuen Interpretation des Modells als gekrümmte Fläche profitieren zu können, braucht man eine Methode zur Darstellung dieser Fläche. Dazu kann ein ganz pragmatischer Weg beschritten werden, indem eine Kostenfunktion definiert wird, die Abweichungen von den thermodynamisch bestimmten Gitterabständen bestraft:

$$
\mathcal{H}_{\text {Optimum }}=\sum_{\langle a, b\rangle}\left(s_{a b}-\left|\vec{r}_{a}-\vec{r}_{b}\right|\right)^{2}
$$

Aus dem Wissen der gewählten Mikrozustände der Lipidmembran lässt sich ihre Form durch Minimierung obiger Funktion berechnen. Konzeptionell zeichnet es diesen Ansatz der Modellierung aus, dass aus der Statistik der Lipidzustände die äußere Form direkt folgt, ohne dass die Fläche als solche wieder in die Berechnung der Zustände eingeht. Die Tatsache, dass es sich bei der Membran um eine gekrümmte Fläche handelt, steckt ausschließlich in der Formulierung der Hamiltonfunktion in Gleichung 5.1. Das unterscheidet die hier vorgestellte Formulierung auch von anderen Ansätzen, die bisher in der Literatur über die Modellierung von Biomembranen beschrieben wurden.

Im Rahmen dieser Arbeit ist das Modell der gekrümmten Lipidmembran entwickelt, aber nicht weiter untersucht worden. Technisch gesehen kann ein ganz ähnlicher Weg beschritten werden wie in den vorangegangenen Kapiteln auch. Die zusätzliche Aufgabe der Analyse besteht in der Darstellung und Charakterisierung der Fläche. Dabei spielen die Randbedingungen eine wichtige Rolle, die für sich genommen noch diskutiert werden müsste. Da die statistische Analyse nicht besonders verkompliziert wurde und die Erweiterung auf eine Lipidmembran mit integralen und peripheren Komponenten genauso möglich erscheint wie im Modell mit flachem Gitter, kann man sich einen qualitativen 
Sprung in der Interpretation solcher theoretischer Modelle erhoffen. Alle Fragen, die mit der äußeren Beschaffenheit der Membran zu tun haben, wie die globale Krümmung oder lokale Fluktuationen und Knicke, können damit im Rahmen eines molekularen Modells untersucht werden. 



\section{Zusammenfassung der Ergebnisse}

Biomembranen sind ein komplexes Gemisch aus Lipiden und Proteinen in wässriger Lösung. In dieser Arbeit werden möglichst einfache Modelle zur Beschreibung der Thermodynamik und eventueller lateraler Strukturbildung formuliert und untersucht. Dabei liegt der Ansatz in der statistischen molekularen Modellierung und der Berechnung mit Hilfe von approximativen Näherungen oder Computersimulationen. Das zentrale Element der Biomembran ist die Lipid-Doppelschicht. Ausgehend von dieser werden zunehmend komplexere Komponenten in Form von Einlagerungen und Adsorbaten beschrieben. Der wesentliche Teil der vorliegenden Arbeit handelt von weichen ausgedehnten Adsorbaten, die bei geeigneten äußeren Bedingungen stabile Strukturen in der Membran induzieren, die potenziell für biologische Prozesse relevant sind.

Ausgehend vom molekularen Aufbau der Lipidmoleküle (Stichwort: lineare Kette) und ihrem Mischungsverhalten mit Wasser (Stichwort: hydrophober Effekt) wird ein minimales Modell für den Hauptübergang von Lipid-Doppelschichten formuliert. Es handelt sich dabei um ein Zweizustands-Modell auf einem Dreiecksgitter mit Wechselwirkung nächster Nachbarn. Wegen der hohen Entartung des einen Zustands ist das thermische Verhalten der Membran durch einen entropischen Beitrag zum äußeren Feld dominiert. Das Phasendiagramm entspricht dem eines Ising-Ferromagneten. Aufgrund der ungewöhnlichen Temperaturabhängigkeit kommt der kritische Ising-Phasenübergang für die Interpretation des Hauptübergangs der Lipidmembran nicht in Frage, sondern nur der Feldübergang. Die beiden möglichen Phasen werden kondensiert (die Lipide sind im gestreckten Grundzustand) und expandiert (die Lipide sind im hoch entarteten gefalteten Zustand) genannt.

Die zum Teil widersprüchlichen experimentellen Befunde zur Charakterisierung des Hauptübergangs werden gegenübergestellt, ohne eine Entscheidung bezüglich der Natur des Übergangs treffen zu können. Es bleibt die Feststellung, dass das sogenannte Kettenschmelzen, also der Übergang der Lipide von einem geordneten in einen ungeordneten Konformationszustand, die thermische Signatur des Phasenübergangs bestimmt. Zur Anpassung der Modellparameter an Experimente von Lipidvesikeln wird der Hauptübergang als kontinuierlich jenseits des kritischen Punktes angenommen.

Zusätzliche Komponenten der Membran werden im ersten Schritt als klein angenommen, d. h. sie besetzen wie die Lipide einen Platz des Gitters. Das Phasenverhalten von nicht miteinander wechselwirkenden Adsorbaten und kleinen Einlagerungen wird miteinander verglichen. Die Freiheitsgrade der kleinen Adsorbate kann man exakt in der Zustandssumme berücksichtigen und erhält ein effektives Lipidsystem mit zusätzlichem homogenen äußeren Feld. Das bedeutet, dass es keine neuen Phasen geben kann. Demgegenüber zeigt das Dreizustands-Modell der Lipidmembran mit Einlagerungen ein reichhaltiges Phasendiagramm.

Anhand der kleinen Komponenten lässt sich die Güte der Mittlere-Feld-Approximation mit Nachbarschaften anhand der Monte-Carlo-Simulation des Modells abschätzen. Dafür 
werden die Cluster-Parameter, welche Information über die mikroskopische Struktur der Phasen beinhalten, herangezogen. Sie zeigen, dass die Approximation mit Nachbarschaften gegenüber der einfachen Mittlere-Feld-Approximation einen qualitativen Forschritt darstellt, der auch quantitativ durch die Computersimulation bestätigt wird.

Das Modell wird weiterentwickelt zur Beschreibung einer Lipidmembran mit ausgedehnten Einlagerungen bzw. Adsorbaten. Wesentliches Charakteristikum ist dabei, dass die Wechselwirkungs-Umgebungen der verschiedenen Membran-Komponenten unabhängig voneinander und beliebig geformt sind. Das Modell entspricht dem IsingFerromagneten mit sehr komplexen miteinander wechselwirkenden thermisch verteilten Störungen.

Zur Untersuchung des kompletten Modells der Lipidmembran mit beliebig großen ausgedehnten Proteinen kann die einfache Mittlere-Feld-Approximation einen bemerkenswerten Beitrag liefern: Die Näherung zeigt, dass die ausgedehnten Adsorbate eine zusätzliche Korrelation in das Lipidsystem tragen, die sich wie eine Mehrteilchen-Wechselwirkung auswirkt. Im effektiven Modell koppeln genau so viele Lipide miteinander, wie von einem Protein bedeckt werden. Diese durch die Proteine vermittelte Kooperativität der Lipide führt zu einem völlig neuen Membran-Modell und ist potentiell die Ursache für neue Phasen. Die analytische Approximation, die alle von einem Protein bedeckten Plätze gleich behandelt, kann im Ergebnis quantitativ durch die Monte-Carlo-Simulation nachvollzogen werden.

Mit Hilfe der Simulationen lässt sich ein komplementärer Weg beschreiten, indem man die Lipide numerisch aussummiert und daraufhin ein reines Proteinsystem mit effektiven Wechselwirkungen erhält. Das effektive Potential zeigt ein deutliches anziehendes Minimum bei Temperaturen jenseits des Hauptübergangs der Lipide. Tatsächlich findet man in der Simulation, dass das von Proteinen bedeckte Lipidsystem bei geeigneten Parametern jenseits des Hauptübergangs entmischt. Eine Phase ist von Proteinen bedeckt und besteht aus Lipiden im gestreckten, von den Proteinen energetisch bevorzugten Zustand, die andere besteht aus unbedeckten gefalteten Lipiden.

Der Einfluss der Größe und Form der Proteine selbst lässt sich nur mit Hilfe der Computersimulation untersuchen. Es zeigt sich, dass für die Entmischung entscheidend ist, ob sich die Protein-Lipid-Wechselwirkungs-Umgebungen überlappen können. Das ist für integrale Proteine immer der Fall, für periphere nur dann, wenn die Ausdehnung der Teilchen geringer ist als die Reichweite der Protein-Lipid-Wechselwirkung. Quantifizieren lässt sich das, indem die Lage des Potentialminimums mit der Größe der Proteine verglichen wird.

Das Phasenverhalten der Proteine wird näher untersucht. Zunächst wird ein Phasendiagramm ermittelt, welches das Entmischungsgebiet in der Temperatur/DichteAuftragung zeigt. Des Weiteren wird die Grenzlinie zwischen den Phasen auf ihr Skalenverhalten hin untersucht. Es findet sich ein statischer Skalenexponent von 0,6 bis 0,7. Dieser Wert ist signifikant höher als der, den man für einfache Modelle in zwei Dimensionen erwartet. Das bedeutet, dass die Grenzen zwischen den entmischten Phasen besonders rau sind und wahrscheinlich Überhänge für die Struktur der Grenzlinie eine wesentliche Rolle spielen.

Am Beispiel von Lipidvesikeln mit dem peripheren Protein Cytochrome $\mathbf{C}$ zeigt sich, dass die Vorstellung von einem Protein, dessen Wechselwirkungs-Umgebung mit den Lipiden größer ist als die Ausdehnung des Teilchens selbst, nicht unrealistisch ist. Die beste Anpassung erhält man für eine Proteinform, die 7 Gitterplätze besetzt, aber mit 19 
Lipiden wechselwirkt. Augrund der durchgeführten Analyse des Modell erwartet man für ein solches System, dass es bei geeigneten Temperaturen und Dichten entmischt.

Das Modell ist in verwandter Form bereits von anderen Autoren mit Hilfe von MonteCarlo-Simulationen untersucht worden. Neu an der vorliegenden Arbeit sind in diesem Zusammenhang die Verknüpfung von analytischer Theorie und Computersimulation, die systematische Analyse der Abhängigkeit der Protein-Lipid-Wechselwirkung von der Größe und Form der Adsorbate und die Charakterisierung der Entmischung des Gesamtsystems in eine bedeckte und eine unbedeckte Phase.

In weitergehenden Modellen sollte die äußere Form der Membran mit einbezogen werden. Auf Basis des Regge-Gitters zur Beschreibung der Quanten-Gravitation wird in der Diskussion dieser Arbeit ein neues Modell für die Lipidmembran vorgeschlagen. Der entscheidende Aspekt an dieser Formulierung ist die Möglichkeit, allein aus dem IsingModell der inneren Zustände Lipide eine gekrümmte Form der Membran zu konstruieren, ohne die Modellierung durch zusätzliche Freiheitsgrade oder komplizierte Randbedingungen zu verkomplizieren.

Beginnend mit der reinen Lipidmembran, erweitert auf kleine integrale und periphere Komponenten, ausführlich untersucht und quantifiziert für große ausgedehnte Adsorbate und schließlich ausblickend auf gekrümmte Membranen übertragen, werden möglichst einfache Modelle untersucht, um generische Eigenschaften biologischer Membranen aufzuzeigen. Die Entmischung ausgedehnter Proteine aufgrund der Fluktuationen im Lipidsystem erweist sich als zentraler Effekt der Untersuchungen. Methodisch werden diese sowohl durch analytische Rechnungen als auch durch Computersimulationen gestützt. 



\section{A Programm zur Berechnung der Mittlere-Feld-Approximation}

Inhaltsangabe

A.1 Programmstruktur . . . . . . . . . . . . 113

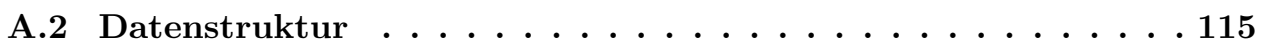

A.3 Algorithmus .................... 116

Für die freie Energie der beiden folgenden Modellvarianten wurden in dieser Arbeit approximative analytische Ausdrücke gefunden:

- Kleine integrale oder periphere Komponenten mit fester oder variabler Teilchenzahl in einer Lipidmembran. Approximation durch Mittlere-Feld-Näherung mit Nachbarschaften (Gleichung 3.24 gemeinsam mit Gleichung 3.23 und 3.17).

- Große ausgedehnte, aber nicht miteinander wechselwirkende Adsorbate auf einer Lipidmembran. Approximation durch eine Mittlere-Feld-Näherung (Gleichung 4.6).

Das Programm kikmean ermittelt den Gleichgewichtswert der freien Energie durch Minimierung bezüglich der MF- bzw. Cluster-Parameter. Es ist eigens für diese Arbeit entwickelt worden und in der Programmiersprache C (Kernighan und Ritchie, 1990) implementiert. Die Parameter des Modells werden an das Programm als Optionen beim Funktionsaufruf übergeben (dafür existiert das Steuerskript kikrun.sh). Nach Beendigung der Berechnungen gibt kikmean die Rohdaten als Satz von Messpunkten in eine ASCII-Datei aus. Die beiden wichtigsten Aufgaben des Programms sind die Berechnung der spezifischen Wärme und der Cluster-Parameter in Abhängigkeit der Temperatur (Mittlere-FeldNäherung mit Nachbarschaften) sowie die Halbwertsbreite des Übergangs in Abhängigkeit der Adsorbatgröße (Mittlere-Feld-Näherung).

Dafür ermittelt das Programm an jedem Messpunkt das Minimum der analytisch explizit gegebenen freien Energie. Der Ort des Minimums im Parameterraum definiert die Gleichgewichtswerte der MF- und Cluster-Parameter. Da alle Ableitungen der freien Energie explizit gegeben sind, können daraus alle Observablen berechnet werden. Für die Optimierung wird das Programm frprmn aus den „Numerical Recipes“ (Press u. a., 1992) genutzt. Dabei handelt es sich um eine Implementierung des „Conjugate Gradient"-Verfahrens.

\section{A.1 Programmstruktur}

Um unterschiedliche Fragen (wie die Berechnung einer Übergangskurve in Abhängigkeit der Temperatur oder der Übergangsbreite in Abhängigkeit der Proteingröße) in einem Programm zu implementieren, sind die Kernfunktionen zu verschiedenen Aufgabenblöcken 


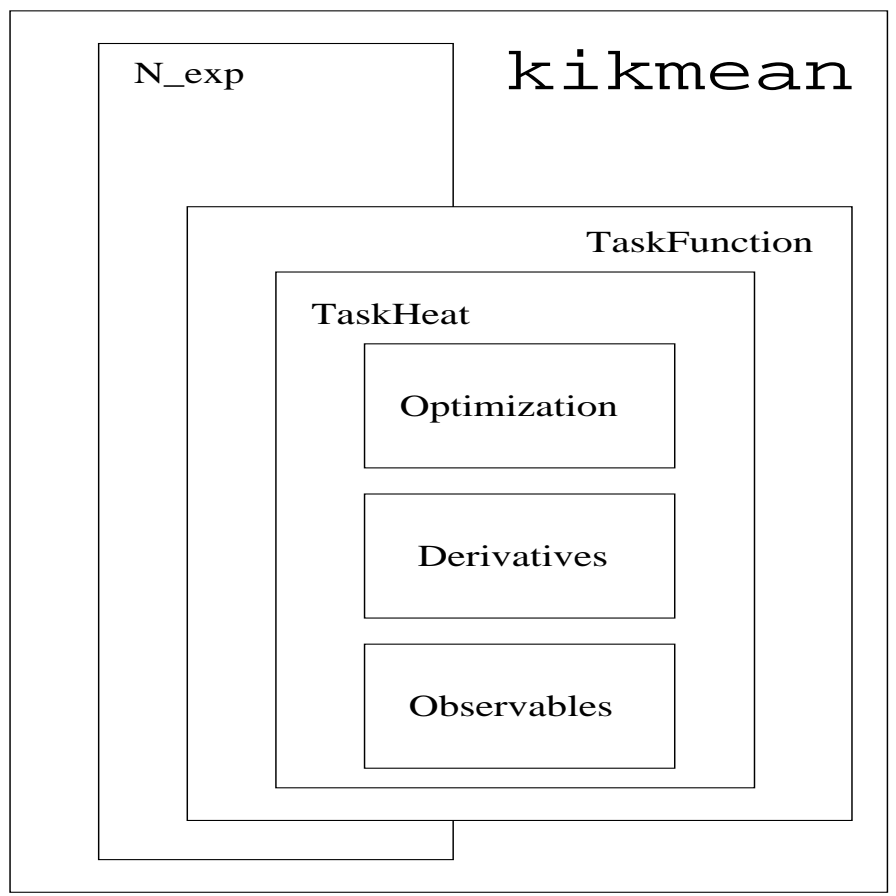

\begin{abstract}
Abbildung A.1: Ablaufdiagramm des Programms kikmean mit den wichtigen Programmbausteinen, die in der Implementierung aus mehreren Funktionen bestehen können. Die äußerste Schleife variiert den Kontrollparameter, meist die Temperatur, in $N_{\text {ext }}$ Durchläufen und bildet so das entsprechende Experiment ab. Aus den Werten für die Cluster-Parameter am Minimum der freien Energie lassen sich direkt alle Observablen wie die spezifische Wärme berechnen. Die Abbildung stellt nur die wesentlichen Aspekte des Programmablaufs dar und entspricht nicht genau den Modulen.
\end{abstract}

zusammengefasst, die alternativ aufgerufen werden. In Abbildung A.1 ist die Struktur des Programms dargestellt, die angesprochenen Blöcke sind mit dem Begriff TaskFunction bezeichnet. Zur Vereinfachung ist nur der wichtigste Block zur Berechnung der spezifischen Wärme und der Cluster-Parameter eingezeichnet. Numerische Berechnungen stecken ausschließlich in der Optimierungsroutine, alle anderen Schritte sind exakt. Die Quelltexte des Programms gliedern sich in vier Teile:

kikmean.c Das Hauptprogramm bindet den Kopf kikmean.h ein, initialisiert die Ausgabedateien, liest die Eingabeparameter als Parameter an den Programmaufruf, initialisiert alle Hilfsgrößen und ruft in einer Schleife über den aüßeren Kontrollparameter (meist die Temperatur) je nach gestellter Aufgabe die geforderte Funktion aus kiktask.c auf.

kikmean.h Im Kopf des Programms werden die benötigten Bibliotheken, insbesondere Programme aus den „Numerical Recipes“ eingebunden. Die von allen Programmteilen benutzen Variablen, u. a. die Eingabeparameter und Variablen der Approximation (Cluster-Parameter) sind global definiert (näheres in Abschnitt A.2).

kiktask.c Dieses Modul enthält neben den Aufgabe-Funktionen zur Berechnung einer oder mehrerer bestimmter Observablen die Kapselung der Optimierungsroutine frprmn (siehe Abschnitt A.3). 
kikutil.c In diesem Modul stecken die Funktionen zur Initialisierung der ClusterParameter und zur Berechnung der folgenden analytisch bekannten Ausdrücke:

- Freie Energie (Funktion FreeCalc)

- Gradient der freien Energie bezüglich der Cluster-Parameter (Funktion DerCalc)

- Hesse-Matrix der freien Energie, d.h. die zweiten Ableitungen bezüglich der Cluster-Parameter (Funktion HesseCalc)

- Die Inverse der Hesse-Matrix (Funktion HesseInv)

- Spezifische Wärme (Funktion HeatCalc)

\section{A.2 Datenstruktur}

Die Eingabeparameter werden als Optionen an den Programmaufruf in eine globale Struktur eingelesen. Sie enthält alle Modellparameter für den Fall kleiner integraler oder peripherer Komponenten in $\mathrm{MF}+\mathrm{N}-\mathrm{Näherung}$ und großer nicht miteinander wechselwirkender Adsorbate in MF-Näherung:

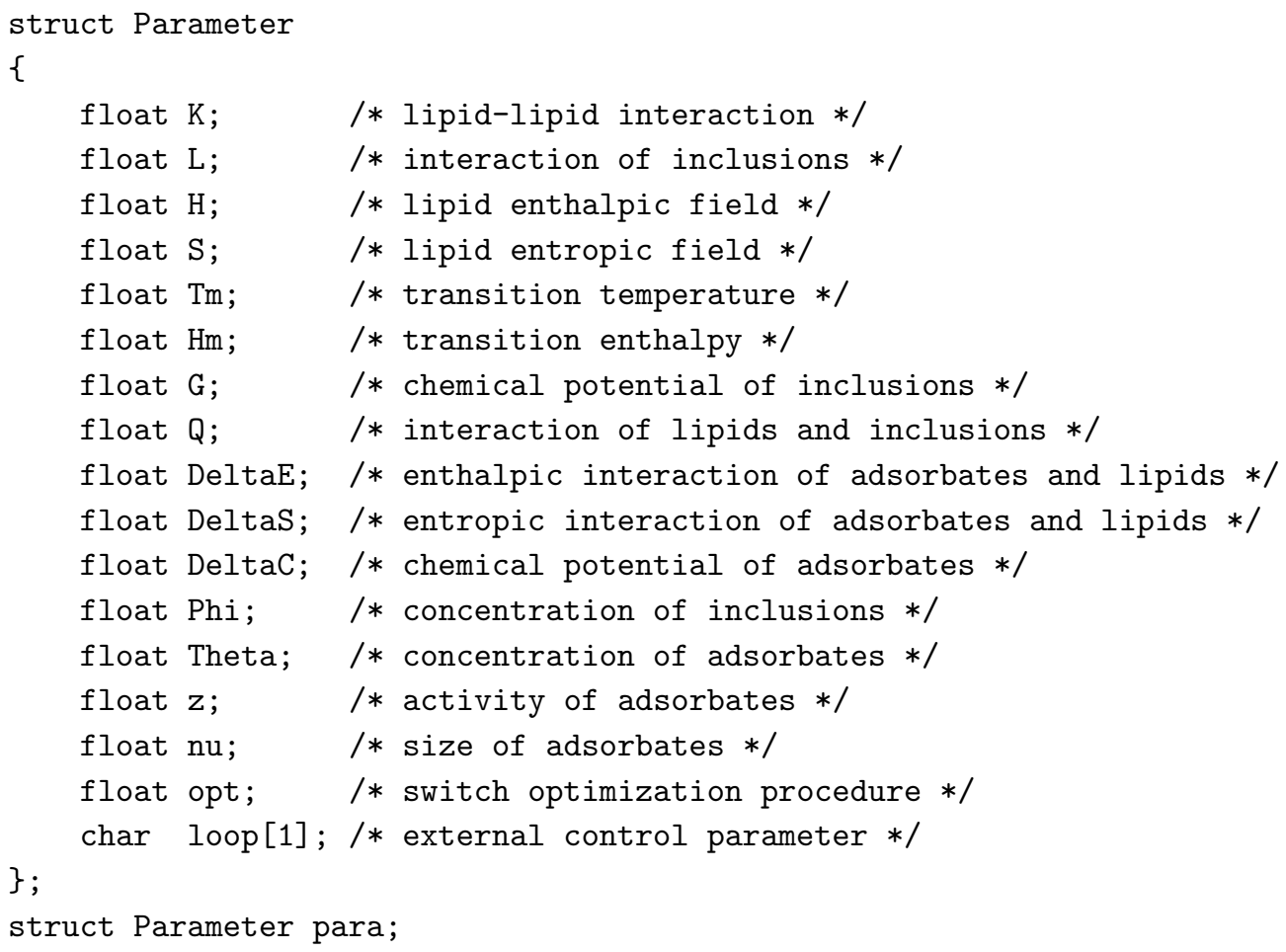

Zur Definition des thermodynamischen Zustands des Systems ist neben den Modellparametern nur der Satz von Cluster-Parametern notwendig. Diese werden in einem global im Programmteil kikmean.h definierten Vektor p0 [i] gespeichert und zur Berechnung aller Ausdrücke an die jeweiligen Funktionen übergeben.

Die Ausgabedatei ist im ASCII-Format. Sie wird von den Aufgabefunktionen (siehe kiktask.c) geschrieben und enthält Zeilen mit allen relevanten Parametern in der folgenden Reihenfolge (beispielhaft für die Aufgabe 'heat' zur Berechnung der spezifischen Wärme):

- Externer Kontrollparameter (meist die Temperatur) 
- Spezifische Wärme

- Alle (bis zu acht) Cluster-Parameter

- Freie Energie

- Anzahl der Iterationsschritte des Optimierers

\section{A.3 Algorithmus}

Die Minimierungsprozedur zur Berechnung der freien Energie stellt eine Anwendung der Routine frprmn der "Numerical Recipes“ dar. Diese Routine stellt eine Variante des in Kapitel 10.6 von Press u. a. (1992) beschriebenen „Conjugate Gradient“-Verfahrens dar. Der Raum der Abhängigkeiten, bezüglich derer das Minimum gesucht wird, bilden die Cluster-Parameter $p^{\alpha}$ und $p^{\alpha \beta}$ (siehe Gleichung 3.12 und 3.13, gespeichert als p0 [i]). Das Verfahren beruht auf einer Iteration von eindimensionalen Nullstellensuchen, deren Richtungen direkt durch den lokalen Wert des Gradienten berechnet werden und jeweils senkrecht aufeinander stehen.

Die wichtigste Hürde für den Algorithmus besteht darin, dass der Raum zulässiger, d.h. der mit den Nebenbedingungen (siehe Tabelle 3.1 und 3.2) verträglichen, ClusterParameter eng begrenzt ist. Die Konsistenzprüfung geschieht durch die Funktion Check, die im Programmteil kiktask.c definiert ist.

Auf der beiliegenden CD-ROM befindet sich ein Verzeichnis programs/kikuchi/. Dieses enthält den kompletten und kommentierten Quelltext, im Unterverzeichnis nrc/ die aus den „Numerical Recipes“ benutzten Programme und unter data/ die Rohdaten zu den in dieser Arbeit gezeigten Abbildungen. 


\section{B Programm zur Monte-Carlo-Simulation nach Metropolis}

Inhaltsangabe

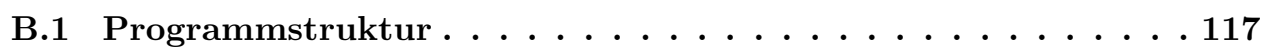

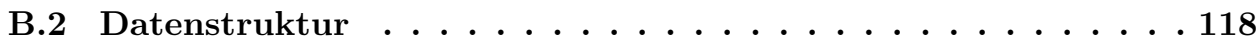

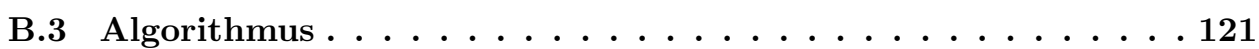

Das Programm lipflip simuliert das Biomembran-Modell aus Gleichung 4.2 in seiner allgemeinsten Form. Es ist im Rahmen dieser Arbeit entwickelt worden und in der Programmiersprache C (Kernighan und Ritchie, 1990) implementiert. Die thermodynamischen Erwartungswerte werden mit Hilfe der Monte-Carlo-Methode geschätzt, siehe auch Abschnitt 2.6 und z. B. Binder und Heermann (1997). Die Modellparameter und Angaben zur Laufzeit der Simulation werden als Optionen an den Programmaufruf übergeben (dies wurde durch das Steuerskript liprun.sh automatisiert).

\section{B.1 Programmstruktur}

Die wesentliche Struktur des Programms ist in Abbildung B.1 zusammengefasst. Die Blöcke entsprechen dem groben funktionellen Ablauf und sind nicht durch Module eindeutig repräsentiert. Die Gliederung des Quelltextes in Module gestaltet sich wie folgt:

lipflip.c Dieses Modul bindet den Kopf lipflip.h ein und erhält als Hauptprogramm unter anderem den Aufruf der Funktionen zum Einlesen und Initialisieren der internen Strukturen (u. a. GetPara, InitState, SetState), zur Auswertung und Ausgabe der Observablen (u. a. OutputAverage, WriteAverage, POVrayState) und die äußerste Schleife über die Messungen, die $N_{\exp }$ mal durchlaufen wird. In ihr wird die zentrale Funktion MetropolisLoop aufgerufen, die die eigentliche Simulation des Systems ausmacht.

lipflip.h Hier werden alle benötigten Bibliotheken und Programmteile aus den „Numerical Recipes" eingebunden, alle Funktionen von lipflip deklariert und die folgenden fünf Module eingebunden:

lipstruct.c Hier werden die Eingabedaten (struct Input), die Daten zur Charakterisierung des Systemzustandes (struct State) und die Ausgabedaten (struct Output) definiert und jeweils eine Instanz deklariert. Es handelt sich bei allen Instanzen um globale Variablen.

lipio.c Die Funktionen zur Eingabe und Ausgabe von Daten (u. a. WriteAverage und GetPara) werden hier definiert. 


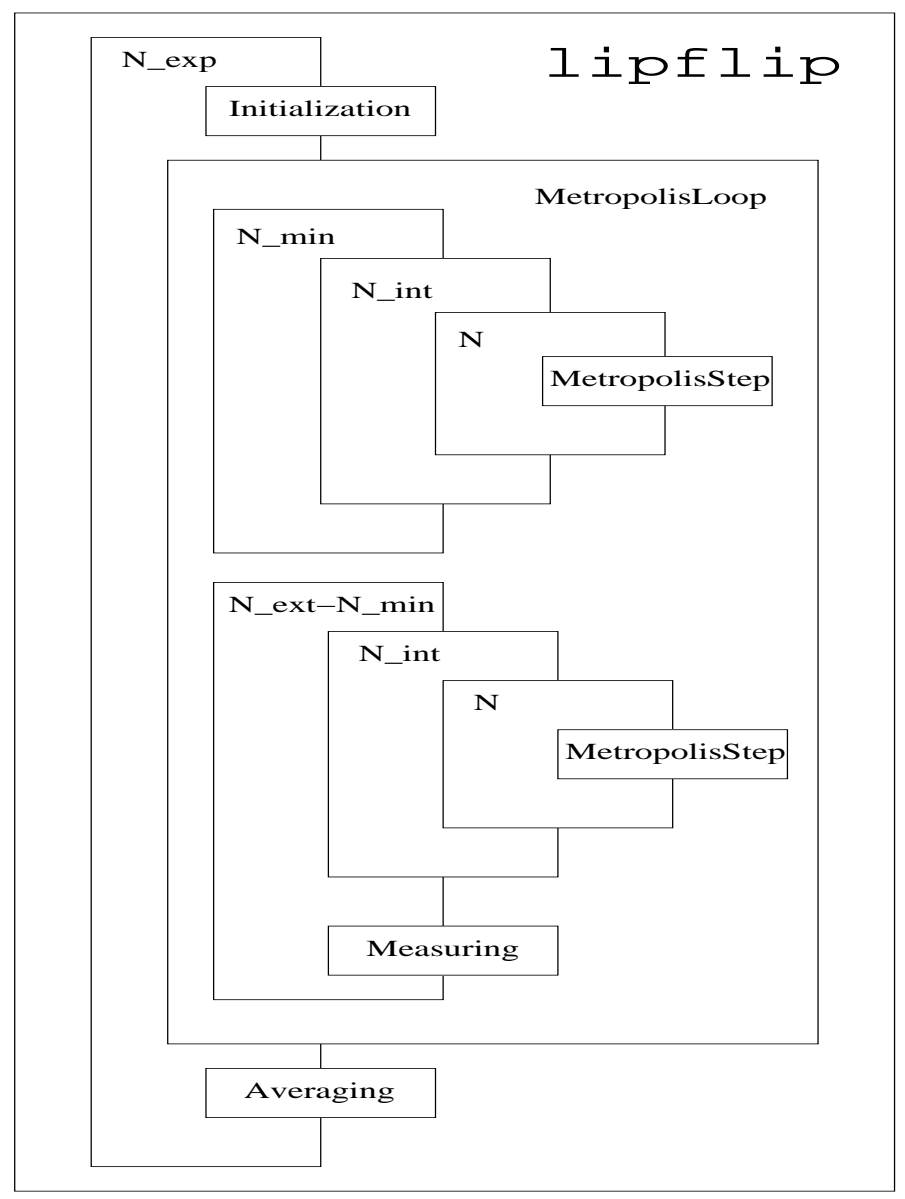

\begin{abstract}
Abbildung B.1: Struktur des Programms lipflip mit allen Schleifen und wichtigen Programmbausteinen, die in der Implementierung jeweils aus mehreren Funktionen bestehen. Ein Experiment mit $N_{\exp }$ Messpunkten entspricht der äußersten Schleife. Im ersten Teil der Simulation wird das System durch $N_{\min }$ Durchläufe equilibriert, um danach über $N_{\text {ext }}-N_{\min }$ Läufe mitteln zu können. Ein Durchlauf besteht aus $N$ (gleich der Anzahl von Lipiden) Metropolis-Schritten zur Veränderung des Systemzustands, die $N_{\text {int }}$ mal wiederholt werden, um Korrelationen zwischen den Zuständen zu vermeiden. Der eigentliche Metropolis-Schritt versucht sowohl ein Lipid als auch ein Protein im Zustand zu verändern (siehe Abschnitt B.3).
\end{abstract}

lipinit.c Wichtig für die Datenhaltung sind die next [i]-Felder, die die NachbarschaftsVerhältnisse und Wechselwirkungs-Umgebungen auf dem Gitter speichern. Neben ihnen wird der Zustand struct State initialisiert.

liputil.c Außer nützlichen kleinen Funktionen finden sich die Metropolis-Schritte und die Hauptschleife MetropolisLoop selbst in diesem Modul.

liptest.c Im letzten Modul sind eine Reihe von Test-Funktionen definiert. Die Darstellung von Schnappschüssen des Systems mit PoVray-Bildern, wie sie an vielen Stellen dieser Arbeit zu sehen ist, gründet auf Funktionen dieses Moduls.

\title{
B.2 Datenstruktur
}

Alle wichtigen Variablen des Programms sind in drei globale Strukturen zusammengefasst. Eine Struktur (Input) repräsentiert alle Eingabedaten, die über die Kommandozeile als 
Optionen an das Programm übergeben werden, eine andere (State) organisiert die Verarbeitung des Modells und eine letzte (Output) speichert die Daten, die vom Programm zum Schluss in eine Datei ausgegeben werden.

\section{Eingabedaten}

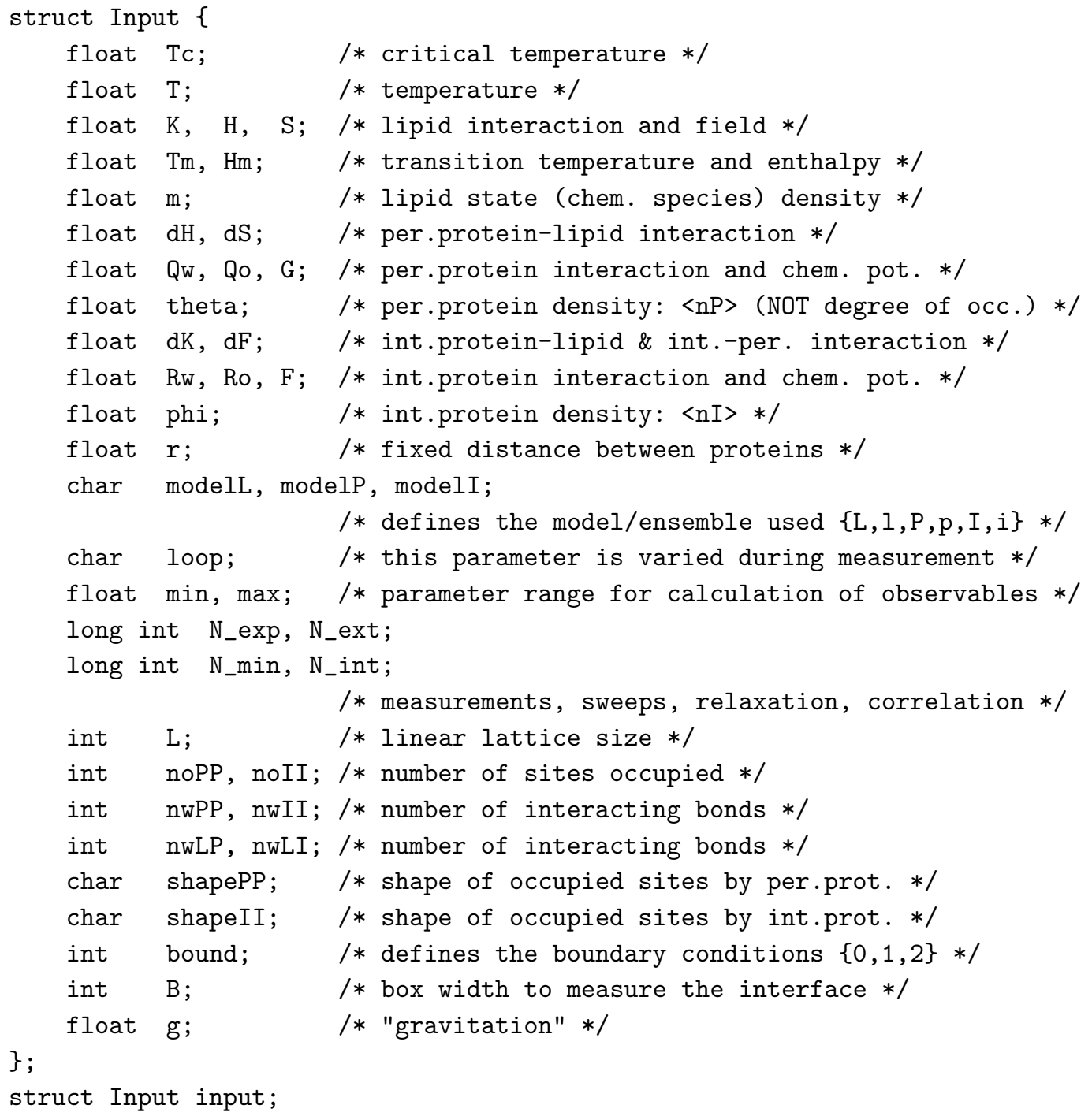

\section{Systemzustand}

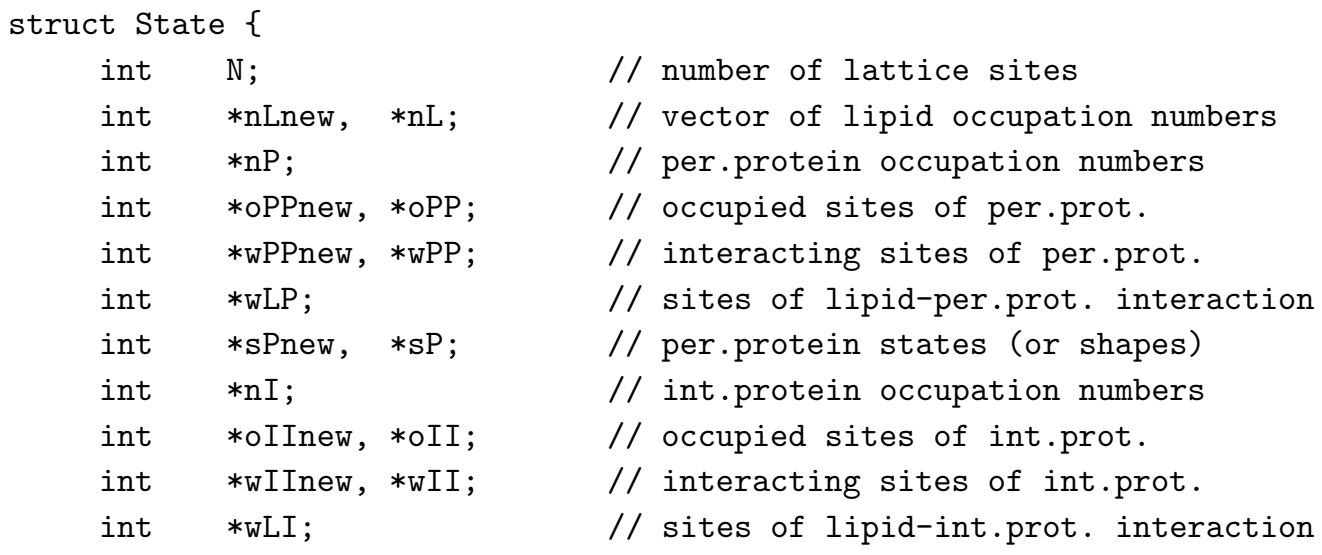




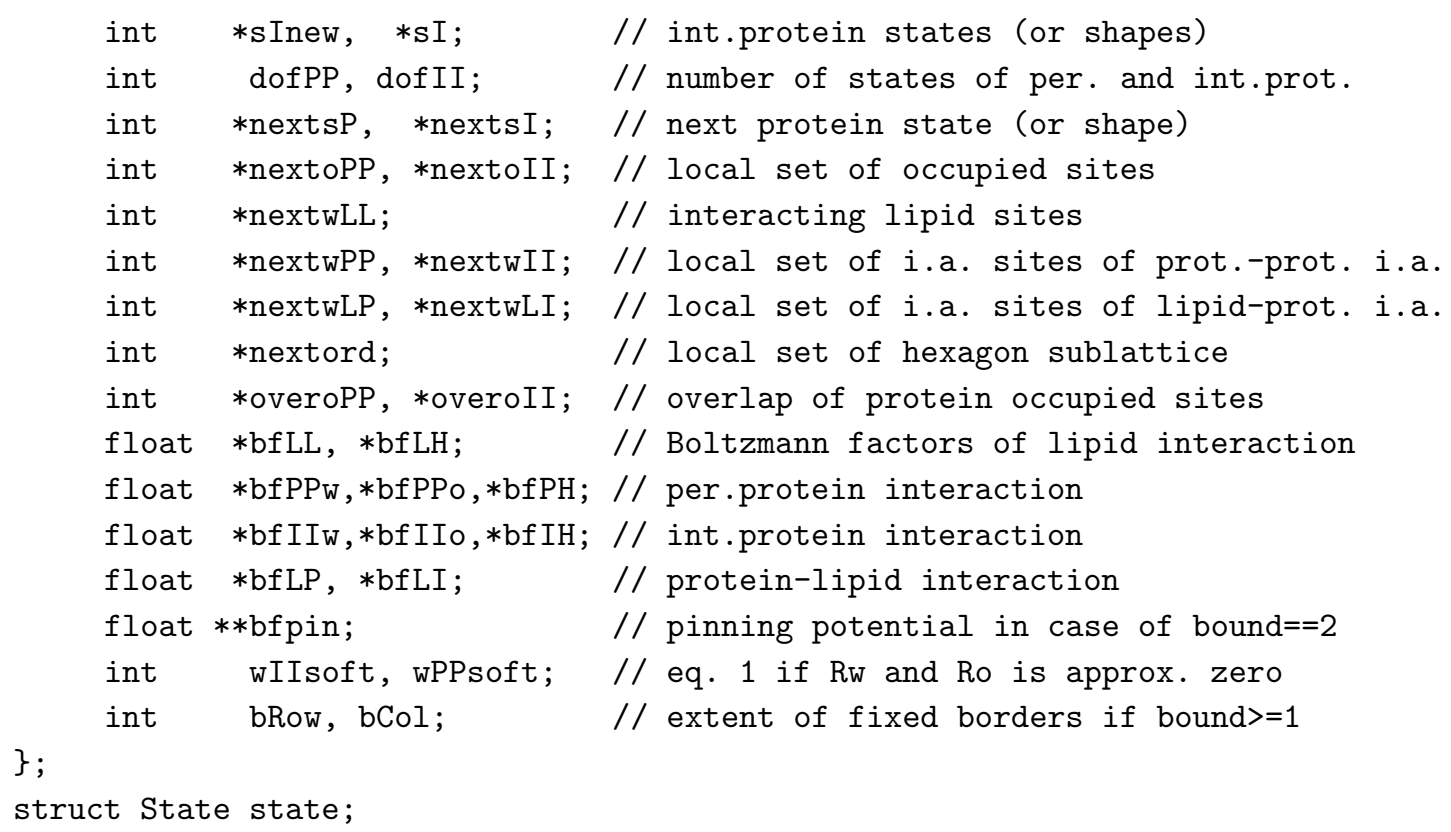

Die Nachbarschaften und Wechselwirkungs-Umgebungen werden durch sogenannte next [i]-Felder abgebildet (zur Idee siehe Hartmann und Rieger, 2001). Dabei werden für jeden Punkt des Gitters alle seine Nachbarn (bzw. alle Plätze, mit denen er wechselwirken kann) abgespeichert (siehe Funktion InitNeighbour). Erstens wird damit die gesamte Information über die Konnektivität auf den Gitter nur einmal berechnet und kann in allen folgenden Schritten zeitsparend in den Feldern nachgeschlagen werden (engl. lookup tables). Zweitens lassen sich die periodischen Randbedingungen ohne Zeitverlust bei der Definition der Nachbarschaften implementieren. Gekapselt werden diese Felder durch NEXT-Makros, die es erlauben, komfortabel auf das k-te Element der WechselwirkungsUmgebung des Proteins am Platz x im Zustand s zuzugreifen (im Folgenden am Beispiel der Wechselwirkungs-Umgebung peripherer Proteine gezeigt).

\#define $\operatorname{NEXTWPP}(\mathrm{x}, \mathrm{k}, \mathrm{s}) \backslash$

state.nextwPP [s*( (state. $N+1) *$ input. $n w P P)+x *$ input . nwPP+k]

Daten in der Ausgabedatei Die Ausgabedatei heißt lipout .dat und enthält $N_{\exp }$ Zeilen, wobei jede Zeile die folgenden Observablen beinhaltet:

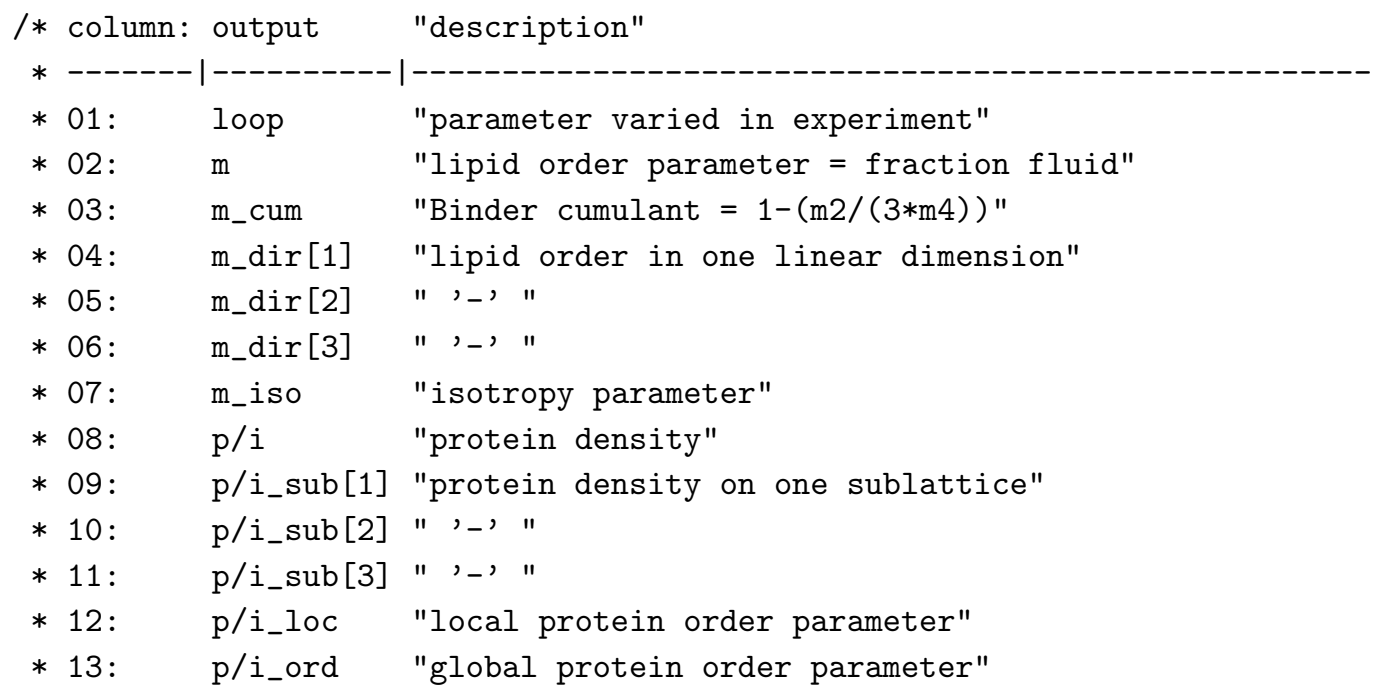




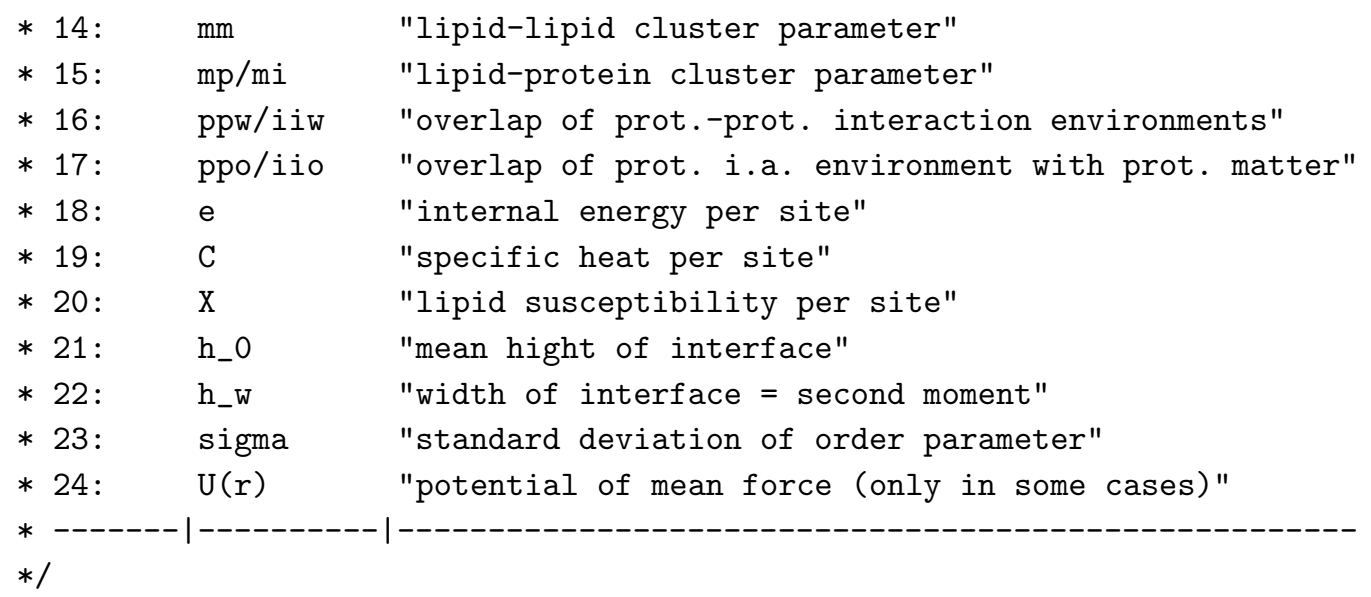

\section{B.3 Algorithmus}

Der Kern jeder Monte-Carlo-Simulation ist die Berechnung von (Pseudo-) Zufallszahlen. Das Programm wurde so aufgebaut, dass auf einfache Art und Weise der Zufallszahlengenerator gewechselt werden kann. Es wurden die beiden Generatoren ran0 und ran3 der „Numerical Recipes“ (Press u. a., 1992) abwechselnd herangezogen und die Ergebnisse der Simulationen miteinander verglichen, um einen Einfluss des Generators ausschließen zu können.

Die gewichtete Überdeckung des Zustandsraums durch die Simulation beruht auf lokalen Schritten im Konfigurationsraum des Systems. Die drei zentralen Metropolis-Schritte sollen kurz skizziert werden.

Lipide Die Lipide können ihren Zustand einzeln lokal ändern (sogenanntes „Spin-Flip“). Die Wechselwirkungen werden im einfachen Fall nächster Nachbarn einfach über das NEXTFeld abgefragt. Um die möglicherweise komplizierten Formen der Proteine zu kapseln, wird die Wechselwirkung mit ihnen grundsätzlich durch Umgebungen dargestellt, die bei Veränderung des Proteinzustandes aktualisiert werden (z. B. gibt der Wert von state.wLP [x] an, wie viele periphere Proteine mit dem Lipid auf Platz x wechselwirken). Zum Vergleich der Energien vor und nach dem Schritt für die Berechnung der Übergangswahrscheinlichkeit werden die Zustandsvektoren grundsätzlich in zwei Versionen abgespeichert (z. B. state. $\mathrm{nL}[\mathrm{x}]$ und state.nLnew $[\mathrm{x}])$. Der Vorteil dieses Verfahrens wird in den nächsten komplizierteren Metropolis-Schritten verständlich.

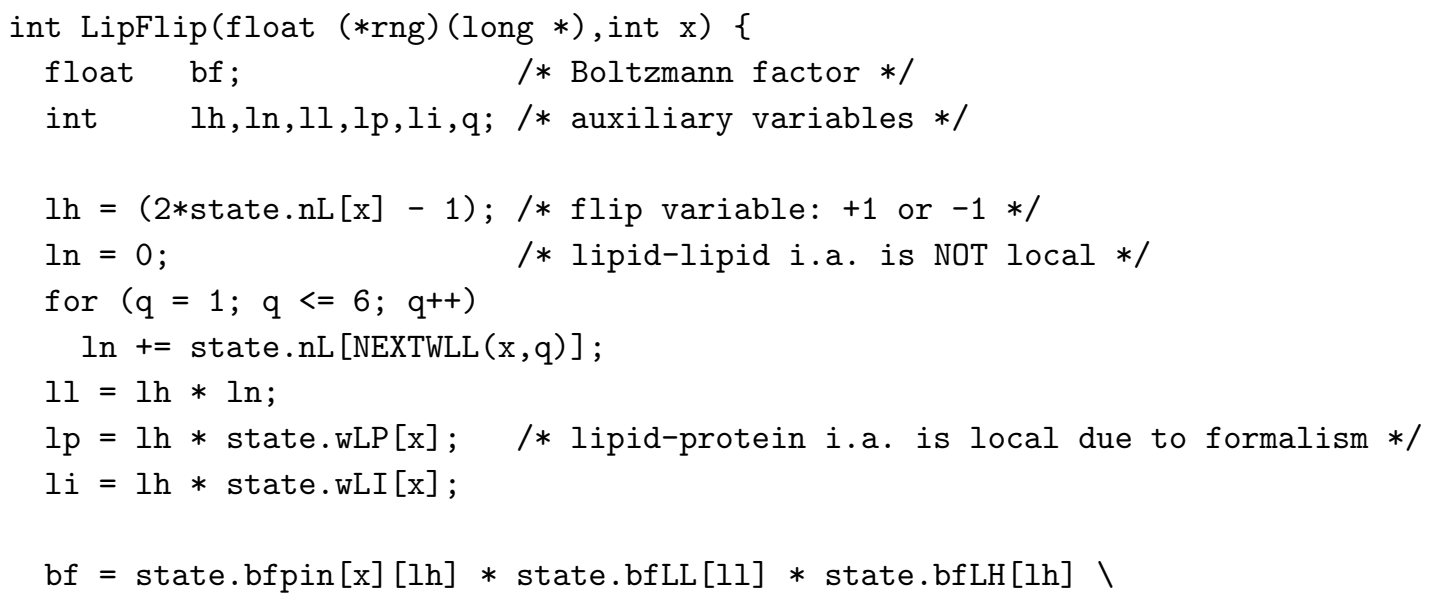




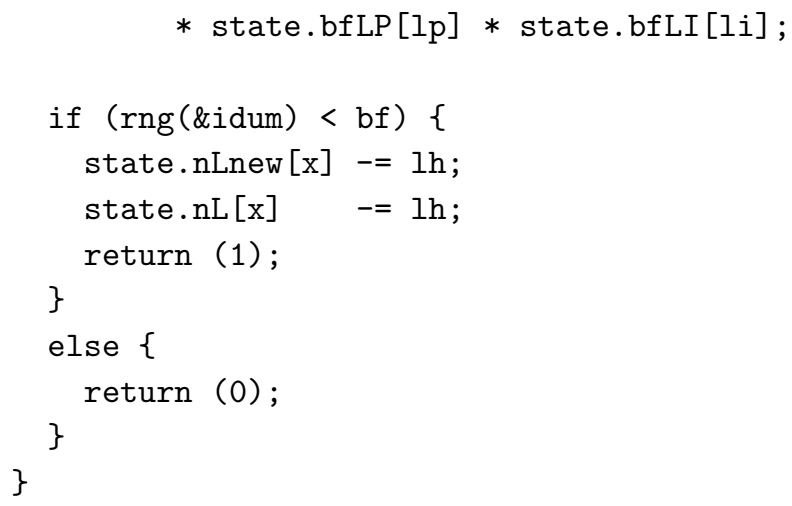

Proteine im Adsorptions-/Desorptions-Gleichgewicht Um den Quelltext verständlicher zu halten, sind der Adsorptions- und Desorptions-Vorgang voneinander getrennt worden. Mit der Formulierung in der Ising-Symmetrie der Spins wäre das sicher nicht nötig gewesen, kostet so aber auch keine Rechenzeit. Der grundsätzliche Gedanke ist wie folgt: Ist am ausgesuchten Platz kein Protein, so berechne die Metropolis-Wahrscheinlichkeit für die Adsorption, welche zuerst durch die harten Kerne anderer Proteine eingeschränkt und dann durch die Wechselwirkung mit anderen Umgebungen bestimmt ist. Befindet sich ein Protein am Platz, so berechne die Desorptionswahrscheinlichkeit. Die Entscheidung, ob der Schritt angenommen wird oder nicht, trifft man durch die Berechnung einer Zufallszahl: Ist diese niedriger als der Boltzmann-Faktor, so erneuere die Zustandsvektoren des Systems.

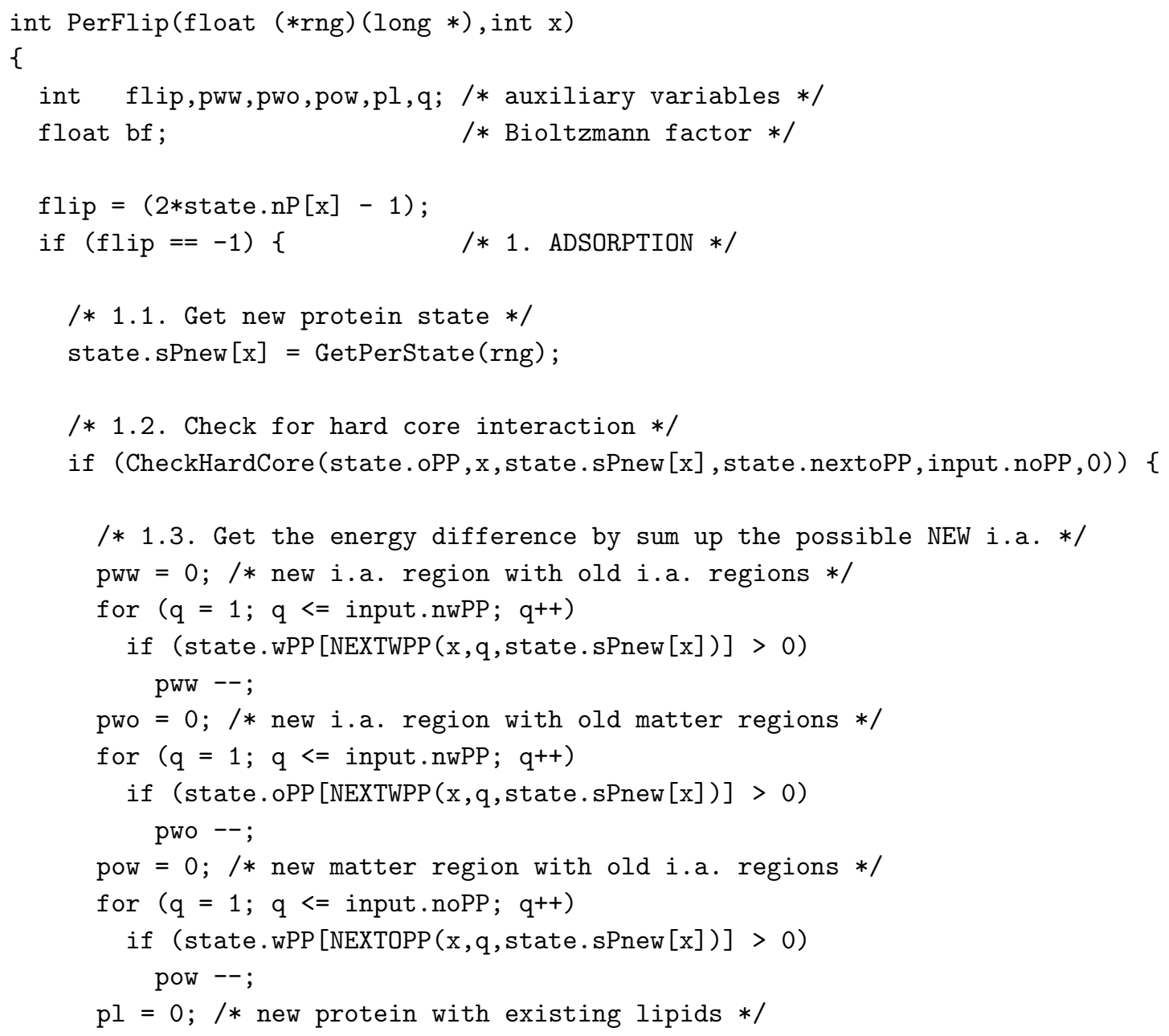




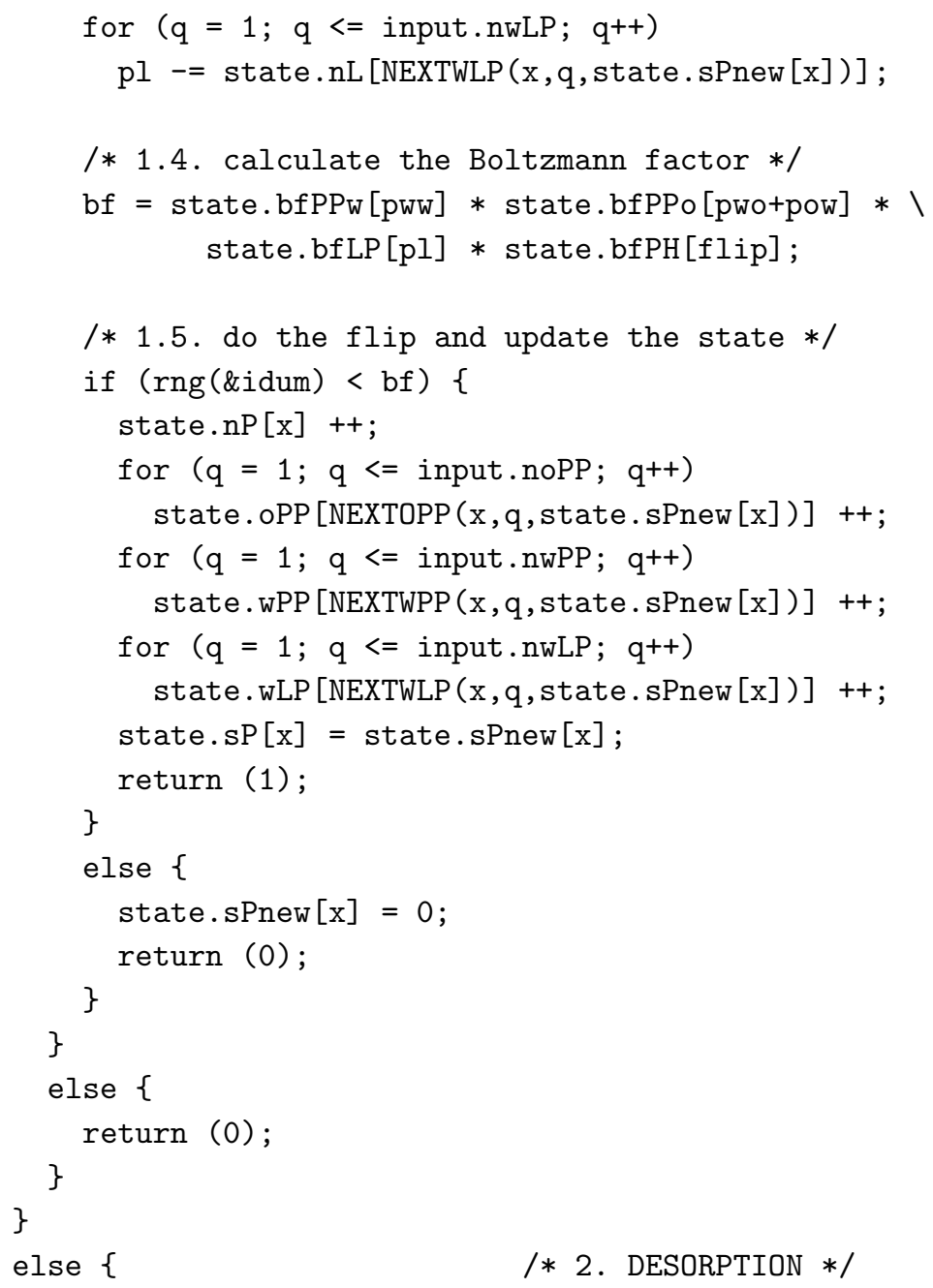




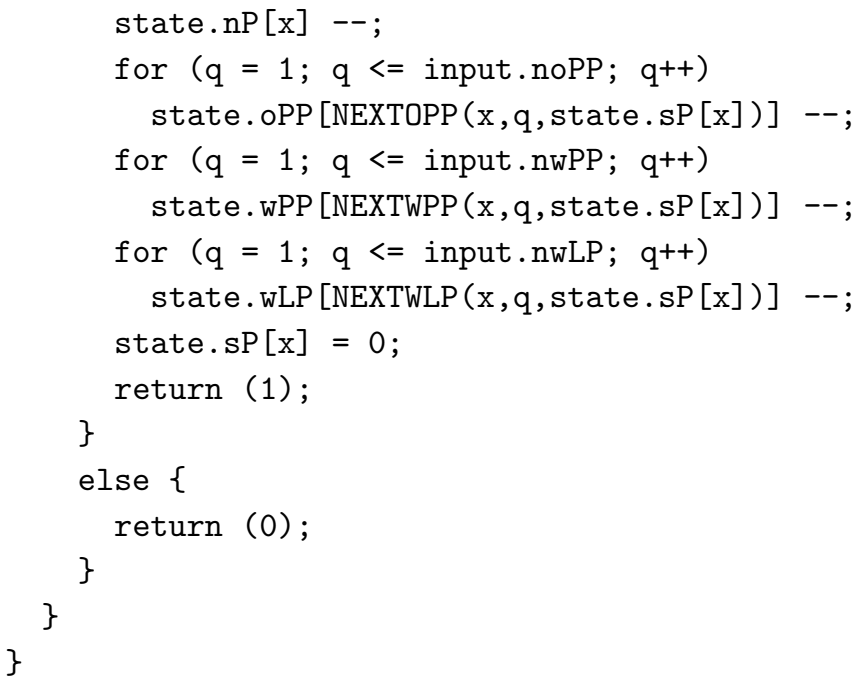

Proteine bei fester Teilchenzahl Die Bewegung von Proteinen in der Membran ist der aufwändigste Schritt und entspricht der Simulation eines kanonischen Ensembles von Adsorbaten oder Einlagerungen. Die Berechnung des Boltzmann-Faktors ist in eine eigene kleine Funktion ausgegliedert. Die Schleifen entsprechen den Summen über die Wechselwirkungs-Umgebungen in Gleichung 4.2.

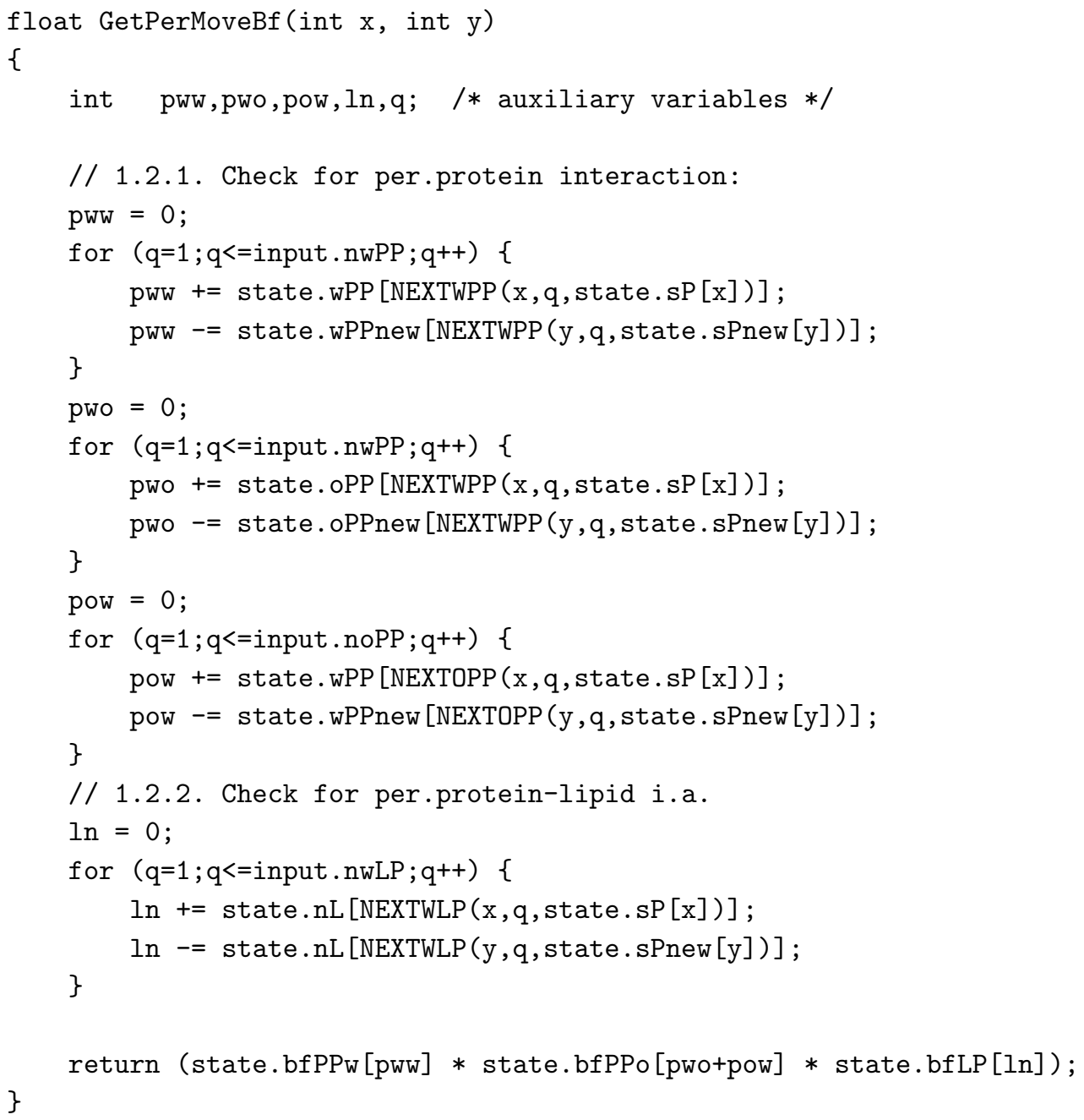


Es folgt die Berechnung des eigentlichen Schrittes. Für den Schritt ist zu beachten, dass es für nicht symmetrische Proteinformen acht Möglichkeiten der Bewegung gibt: sechs Richtungen für die Schwerpunktsbewegung (die Nachbarn auf dem Gitter) und zwei für die Rotation (links und rechts herum) um den Schwerpunkt. Die erste ist einfach durch den Ort $\mathrm{x}$ gekennzeichnet, an dem die Besetzungszahl state.nP $[\mathrm{x}]$ gleich eins ist. Die zweite wird durch den Zustandsvektor state.sP $[\mathrm{x}]$ kodiert, dessen Wert bis zu sechs verschiedene Einstellungen besitzt, die die möglichen Rotationswinkel auf dem Gitter repräsentieren.

Die Auswahl einer der möglichen Bewegungen und die Vorbereitung der ZustandsVektoren ist noch einmal in eine eigene Funktion ausgegliedert. Im Anschluss folgt der eigentliche Schritt.

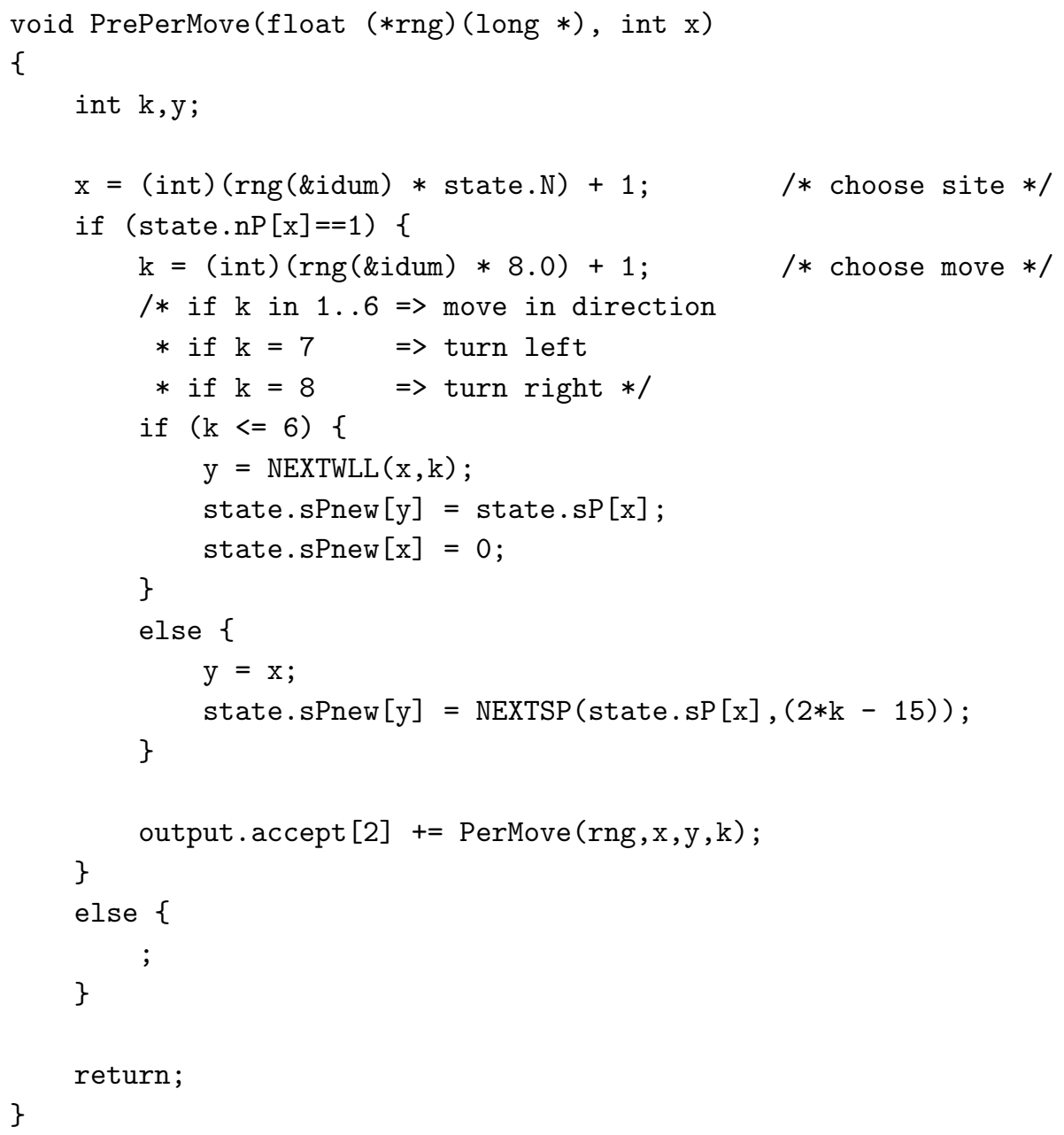




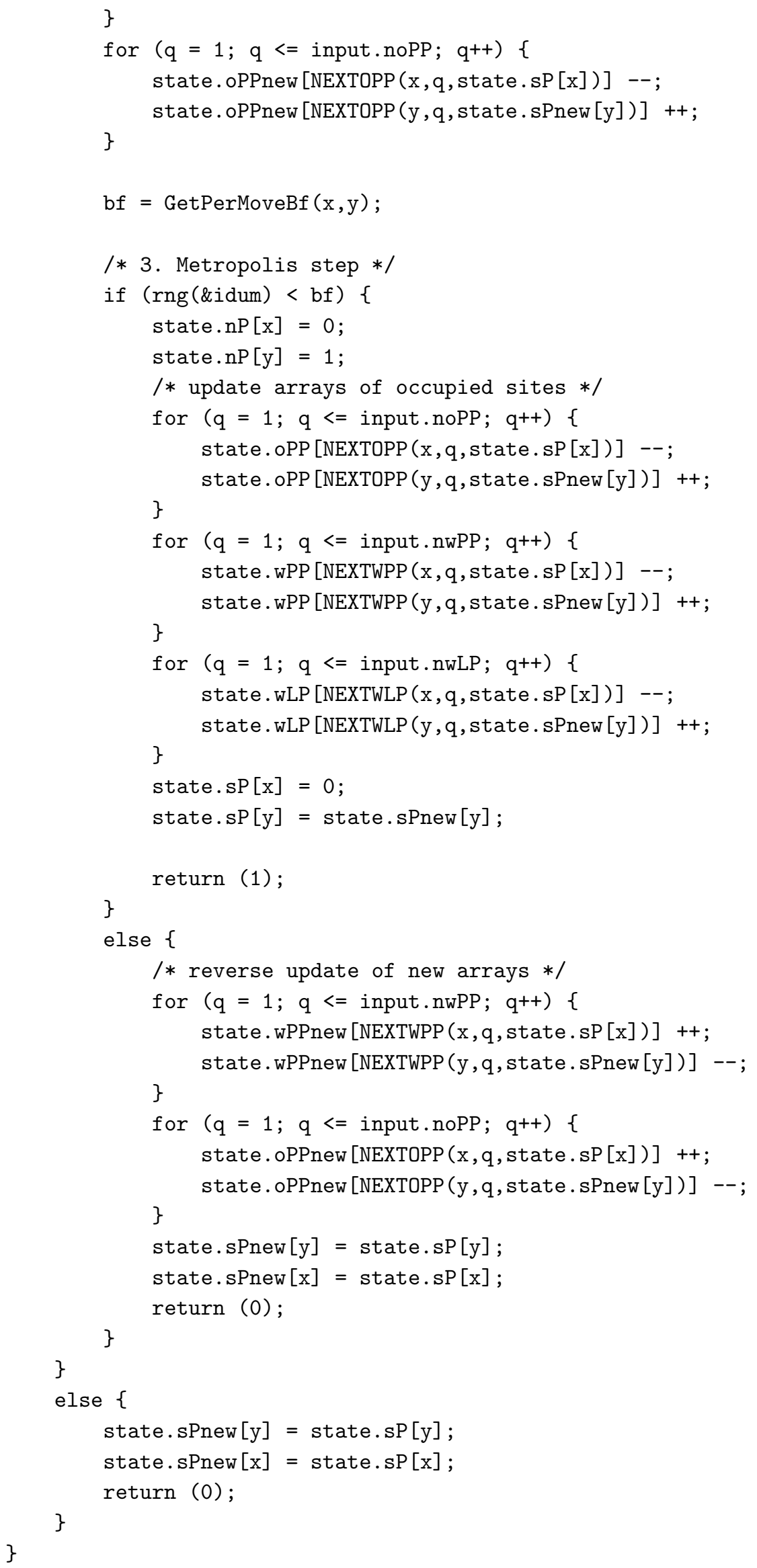


Auf der beiliegenden CD-ROM in Verzeichnis programs/lipflip/ finden sich die QuellDateien des Programms, die Rohdaten für alle Abbildungen (in Verzeichnis data/) und eine ausführliche Dokumentation des Programms. Die Dokumentation wurde mit dem Werkzeug „ZehDok“ von Rudolf Opalla automatisch aus dem kommentierten Quell-Text erzeugt und findet sich im Unterverzeichnis cdoc/ im LATEX-Format mit einer druckfähigen PostScript-Version. 



\section{Literaturverzeichnis}

[Adam u. a. 1995] Adam, G.; LÄUger, P. ; StARK, G.: Biophysikalische Chemie und Biophysik. 3. Springer Verlag, 1995 9, 20, 95

[Akashi u. a. 1996] Akashi, K. ; Miyata, H. ; IтOH, H. ; Kinosita, Jr. K.: Preparation of giant liposomes in physiological conditions and their characterization under an optical microscope. In: Biophysical Journal 71 (1996), December, S. 3242-3250 10

[Alberts u. a. 1994] Alberts, B. ; Bray, D. ; Lewis, J. ; RAfF, M. ; Roberts, K. ; Watson, J.D.: Molecular Biology of the Cell. 3. Garland Publishing, 1994 1, 59, 95

[Albrecht u. a. 1978] Albrecht, O. ; Gruler, H. ; Sackmann, E.: Polymorphism of phospholipid monolayers. In: Le Journal de Physique 39 (1978), March, S. 301-313 11, 23

[Allahyarov und Löwen 2000] Allahyarov, E. ; Löwen, H.: Effective interaction between helical biomolecules. In: Physical Review E 62 (2000), October, Nr. 4, S. 5542-5556 97

[Allen und Tildesley 1986] Allen, M.P. ; Tildesley, D.J.: Computer Simulation of Liquids. Oxford University Press, 198628

[Aloia 1983] Aloia, R.C. (Hrsg.): Membrane Fluidity in Biology, Volume 1: Concepts of Membrane Structure. Academic Press, 1983 132, 134

[Amey und Chapman 1984] Amey, R.L. ; Chapman, D.: Infrared spectroscopy studies of model and natural biomembranes. In: Biomembrane Structure and Function. (Chapman, 1984), Kap. 4, S. $199-25619$

[Bach 1984] BACH, D.: Calorimetric studies of model and natural biomembranes. In: Biomembrane Structure and Function. (Chapman, 1984), Kap. 1, S. 1-41 27, 33

[Barabasi und Stanley 1995] Barabasi, A.-L. ; Stanley, H.E.: Fractal Concepts in Surface Growth. Cambridge University Press, 1995 77, 78, 79, 101

[Baxter 1980] Baxter, R.J.: Hard hexagons: Exact solution. In: J. Phys. A: Math. Gen. 13 (1980), S. L61-L70 64

[Baxter 1982] BAXter, R.J.: Exactly Solved Models in Statistical Mechanics. Academic Press, $198222,64,102$

[Berman u. a. 2000] Berman, H.M. ; Westbrook, J. ; Feng, Z. ; Gilliland, G. ; Bhat, T.N. ; Weissig, H. ; Shindyalov, I.N. ; Bourne, P.E.: The Protein Data Bank. In: Nucleic Acids Research 28 (2000), S. 235-242. - http://www.pdb.org 61

[Bernardes 1996] Bernardes, A.T.: Monte Carlo simulation of vesicle self-organisation. In: Journal de Physique II France 6 (1996), February, S. 169-174 9

[Bertoli u. a. 1987] Bertoli, E. ; Chapman, D. ; Cambria, A. ; Scapagnini, U.: Fida Research Series. Bd. 7: Biomembrane and Receptor Mechanisms. Springer Verlag, 1987137

[Bethe 1935] Bethe, H.A.: Statistical theory of superlattices. In: Proceedings of the Royal Society 150 (1935), S. 552-575 40 
[Binder und Heermann 1997] Binder, K. ; Heermann, D.W.: Monte Carlo Simulation in Statistical Physics. Springer, 1997 29, 117

[Bloom u.a. 1991] Bloom, M. ; Evans, E. ; Mouritsen, O.: Physical properties of the fluid lipid-bilayer component of cell membranes: A perspective. In: Quarterly Reviews of Biophysics 24 (1991), Nr. 3, S. 293-397 9

[Boltzmann 1909] Boltzmann, Ludwig: Über die Beziehung zwischen dem zweiten Hauptsatze der mechanischen Wärmetheorie und der Wahrscheinlichkeitsrechnung respektive den Sätzen über das Wärmegleichgewicht. In: HASEnÖHrL, Fritz (Hrsg.): Wissenschaftliche Abhandlungen II. J. A. Barth, 1909, S. 164-223. - original: Wien. Ber. 76, 373-435 (1877) 14, 30

[Bronstein und Semendjajew 1991] Bronstein, I.N. ; SemendjAJew, K.A.: Taschenbuch der Mathematik. 25. B.G. Teubner Verlagsgesellschaft, 199144

[Burger 1997] Burger, K.N.J.: Morphology of membrane fusion. In: Lipid Polymorphism and Membrane Properties. (Epand, 1997), Kap. 11, S. 403-445 2

[Caille u.a. 1978] Caille, A. ; Rapini, A. ; Zuckermann, M.J. ; Cros, A. ; Doniach, S.: A simple model for phase transition in monolayers and bilayers of lipid molecules. In: Canadian Journal of Physics 56 (1978), S. 348-357 21

[Chacón u.a. 1998] Chacón, E. ; Somoza, A.M. ; Tarazona, P.: Elastic constants from a microscopic model of bilayer membrane. In: Journal of Chemical Physics 109 (1998), August, Nr. 6, S. 2371-2379 95

[Chaikin und Lubensky 1995] Chaikin, P.M. ; Lubensky, T.C.: Principles of Condensed Matter Physics. Cambridge University Press, 1995 4, 102

[Chapman 1984] Chapman, D.: Biomembrane Structure and Function. Verlag Chemie, 19843 , $129,136,138$

[Chou u. a. 2001] Chou, T. ; KIm, K.S. ; Oster, G.: Statistical thermodynamics of membrane bending-mediated protein-protein attractions. In: Biophysical Journal 80 (2001), Nr. 3, S. 1075108776

[Costigan u.a. 2000] Costigan, S.C. ; Boоth, P.J. ; Templer, R.H.: Estimations of lipid bilayer geometry in fluid lamellar phases. In: Biochimica et Biophysica Acta 1468 (2000), S. $41-5412$

[Deuling und Helfrich 1976] Deuling, H.J. ; Helfrich, W.: The curvature elasticity of fluid membranes: A catalogue of vesicle shapes. In: Journal de Physique 37 (1976), November, S. $1335-1345 \quad 95$

[Dhont u.a. 2002] Dhont, J.K.G. (Hrsg.) ; Gompper, G. (Hrsg.) ; Richter, D. (Hrsg.): Soft Matter: Complex Materials on Mesoscopic Scales (33. IFF-Ferienkurs). Forschungszentrum Jülich GmbH, 2002 134, 135, 139

[Doi und Edwards 1988] DoI, M. ; Edwards, S.F.: The Theory of Polymer Dynamics. Oxford University Press, 198818

[Doniach 1978] Doniach, S.: Thermodynamic fluctuations on phospholipid bilayers. In: Journal of Chemical Physics 68 (1978), June, Nr. 11, S. 4912-4916 21

[Doniach 1980] Doniach, S.: Melting in phospholipids and in smectics - A comparison. In: Sinha, Sunil K. (Hrsg.): Ordering in Two Dimensions, Elsevier, 1980, S. 67-72 11, 13, 24

[Epand 1997] Epand, R.M.: Current Topics in Membranes. Bd. 44: Lipid Polymorphism and Membrane Properties. Academic Press, 1997 3, 11, 130, 133, 138, 139 
[Fleming u. a. 1994] Fleming, T. ; Gross, M. ; Renken, R.: Ising-link Regge gravity. In: Physical Review D 50 (1994), December, Nr. 12, S. 7363-7371 104, 106

[Fließbach 1995] Fliessbach, T.: Lehrbuch zur Theoretischen Physik. Bd. 4: Statistische Physik. 2. Spektrum Akademischer Verlag, 199514

[Flory 1992] Flory, P.J.: Principles of Polymer Chemistry. 15. Cornell University Press, 1992 18

[Francesco u.a. 1997] Francesco, P.D. ; Guitter, E. ; Mori, S.: Folding of the triangular lattice with quenched random bending rigidity. In: Physical Review E 55 (1997), January, Nr. 1, S. 237-251 104

[Fraser u. a. 1991] Fraser, D.P. ; Zuckermann, M.J. ; Mouritsen, O.G.: Theory and simulations for hard-disk models of binary mixtures of molecules with internal degrees of freedom. In: Physical Review A 43 (1991), June, Nr. 12, S. 6642-6656 96

[Fujiwara u. a. 2002] Fujiwara, T. ; Ritchie, K. ; Murakoshi, H. ; Jacobson, K. ; Kusumi, A.: Phospholipids undergo hop diffusion in compartmentalized cell membrane. In: Journal of Cell Biology 157 (2002), June, Nr. 6, S. 1071-1081 2

[Furman u. a. 1977] Furman, D. ; Dattagupta, S. ; Griffiths, R.B.: Global phase diagram for a three-component model. In: Physical Review B 15 (1977), January, Nr. 1, S. 441-464 54, 55

[Gennis 1989] Gennis, R.B.: Biomembranes - Molecular Structure and Function. Springer Verlag, 1989 3, 18, 19

[Gil u.a. 1998] Gil, T. ; Ipsen, J.H. ; Mouritsen, O.G. ; SAbra, M.C. ; Sperotto, M.M. ; Zuckermann, M.J.: Theoretical analysis of protein organization in lipid membranes. In: Biochimica et Biophysica Acta 1376 (1998), S. 245-266 96

[Goetz und Lipowsky 1998] Goetz, R. ; Lipowsky, R.: Computer simulations of bilayer membranes: Self-assembly and interfacial tension. In: Journal of Chemical Physics 108 (1998), May, Nr. 17, S. 7397-7409 9

[Goldhirsch und Goldenberg 2002] Goldhirsch, I. ; GoldenberG, C.: On the microscopic foundations of elasticity. In: European Physical Journal E 9 (2002), Nr. 3, S. 245-251. - condmat/0203360 104

[Goodsell 2002] Goodsell, D.S.: Molecule of the Month: Cytochrome C. http://www.rcsb.org/pdb/molecules/pdb36_1.html. 200260

[Grabitz u. a. 2002] Grabitz, P. ; Ivanova, V.P. ; Heimburg, T.: Relaxation kinetics of lipid membranes and its relation to the heat capacity. In: Biophysical Journal 82 (2002), January, S. 299-309 102

[Halstenberg u. a. 2003] Halstenberg, S. ; Schrader, W. ; Das, P. ; Bhattacharjee, J.K. ; KAATzE, U.: Critical fluctuations in the domain structure of lipid membranes. In: Journal of Chemical Physics 118 (2003), March, Nr. 12, S. 5683-5691 13, 26

[Hartmann und Rieger 2001] Hartmann, A.K. ; Rieger, H.: Optimization Algorithms in Physics. Wiley-VCH, 2001120

[Heimburg 1998] Heimburg, T.: Mechanical aspects of membrane thermodynamics. Estimation of the mechanical properties of lipid membranes close to the chain melting transition from calorimetry. In: Biochimica et Biophysica Acta 1415 (1998), S. 147-162 98 
[Heimburg 2000] Heimburg, T.: A model for the lipid pretransition: Coupling of ripple formation with the chain-melting transition. In: Biophysical Journal 78 (2000), March, S. 1154-1165 103

[Heimburg 2003] Heimburg, T.: Coupling of chain melting and bilayer structure: Domains, rafts, elasticity and fusion. In: Tien, H.T. (Hrsg.) ; Ottova-Leitmannova, A. (Hrsg.): Planar Lipid Bilayers and their Applications. Elsevier, 2003, Kap. 8, S. 269-293 101

[Heimburg u.a. 1999] Heimburg, T. ; Angerstein, B. ; Marsh, D.: Binding of peripheral proteins to mixed lipid membranes: Effect of lipid demixing upon binding. In: Biophysical Journal 76 (1999), May, S. 2575-2586 60, 88

[Heimburg und Biltonen 1994] Heimburg, T. ; Biltonen, R.L.: Thermotropic behavior of Dimyristoylphosphatidylglycerol and its interaction with Cytochrome C. In: Biochemistry 33 (1994), S. 9477-9488 60

[Heimburg und Biltonen 1996] Heimburg, T. ; Biltonen, R.L.: A Monte Carlo simulation study of protein-induced heat capacity changes and lipid-induced protein clustering. In: Biophysical Journal 70 (1996), January, S. 84-96 45, 86, 88

[Heimburg und Marsh 1996] Heimburg, T. ; Marsh, D.: Thermodynamics of the interaction of proteins with lipid membranes. In: Biological Membranes - A Molecular Perspective from Computation and Experiment. Birkhäuser, 1996, S. 403-462 60

[Helfrich 1973] Helfrich, W.: Elastic properties of lipid bilayers: Theory and possible experiments. In: Zeitschrift für Naturforschung C 28 (1973), S. 693-703 76, 95, 103

[Heller u. a. 1993] Heller, H. ; Schäfer, M. ; Schulten, K.: Molecular dynamics simulation of a bilayer of 200 lipids in the gel and in the liquid-crystal phases. In: J. Phys. Chem. 97 (1993), S. 8343-8360 7, 8

[Hoenger u. a. 1994] Hoenger, T. ; Mortensen, K. ; Ipsen, J.H. ; Lemmich, J. ; Bauer, R. ; Mouritsen, O.G.: Anormalous swelling of multilamellar lipid bilayers in the transition region by renormalization of curvature elasticity. In: Physical Review Letters 72 (1994), June, Nr. 24, S. 3911-3914 12

[Honda und Horiguchi 1997] HondA, Y. ; Horiguchi, T.: Critical phase of a magnetic hard hexagon model on a triangular lattice. In: Physical Review E 55 (1997), January, Nr. 1, S. 194$198 \quad 64$

[Huster und Gawrisch 2001] Huster, D. ; Gawrisch, K.: New insights into biomembrane structure from two-dimensional Nuclear Overhauser Enhancement Spectroscopy. In: (Katsaras und Gutberlet, 2001), S. 109-126 50

[Ising 1925] IsING, E.: Beitrag zur Theorie des Ferromagnetismus. In: Zeitschrift für Physik 31 (1925), S. 253-258 21

[Ivanova u. a. 2003] Ivanova, V.P. ; Makarov, I.M. ; T.E., Schäffer ; Heimburg, T.: Analyzing heat capacity profiles of peptide-containing membranes: Cluster formation of Gramicidin A. In: Biophysical Journal 84 (2003), April, S. 2427-2439 88

[Jain 1983] JAIN, M.K.: Nonrandom lateral organization in bilayers and biomembranes. In: (Aloia, 1983), Kap. 1, S. 1-37 12

[Jain und White 1977] JAIN, M.K. ; White, H.B.: Long-range order in biomembranes. In: Advances in Lipid Research 15 (1977), S. 1-60 1, 2, 17

[Jülicher und Lipowsky 1993] Jülicher, F. ; Lipowsky, R.: Domain-induced budding of vesicles. In: Physical Review Letters 70 (1993), May, Nr. 19, S. 2964-2967 95 
[Kaganer u. a. 1999] Kaganer, V.M. ; MöHwald, H. ; Dutta, P.: Structure and phase transitions in Langmuir monolayers. In: Reviews of Modern Physics 71 (1999), April, Nr. 3, S. 779-819 10

[Katsaras und Gutberlet 2001] Katsaras, J. (Hrsg.) ; Gutberlet, T. (Hrsg.): Lipid Bilayers: Structure and Interactions. Springer, 2001 (Biological Physics Series) 132, 133, 135

[Kernighan und Ritchie 1990] Kernighan, B.W. ; Ritchie, D.M.: Programmieren in C. Carl Hanser, 1990 113, 117

[Kikuchi 1951] KIKUCHI, R.: A theory of cooperative phenomena. In: Physical Review 81 (1951), March, Nr. 6, S. 988-1003 40

[Kinzel und Reents 1998] Kinzel, W. ; Reents, G.: Physics by Computer: Programming Physical Problems Using Mathematica and C. Springer, 199829

[Klösgen 2001] Klösgen, B.: Conformations of fluid lipid membranes. In: (Katsaras und Gutberlet, 2001), S. 47-88 11

[Knobler 1990] Knobler, C.M.: Recent developments in the study of monolayers at the air-water interface. In: Adv. Chem. Phys. 77 (1990), S. 397-450 10

[Knobler und Schwartz 1999] Knobler, C.M. ; Schwartz, D.K.: Langmuir and self-assembled monolayers. In: Current Opinion in Colloid $\mathscr{E}$ Interface Science 4 (1999), February, Nr. 1, S. $46-51 \quad 10$

[Kosterlitz und Thouless 1973] Kosterlitz, J.M. ; Thouless, D.J.: Ordering, metastability and phase transitions in two-dimensional systems. In: Journal of Physics C: Solid State Physics 6 (1973), S. 1181-1203 14

[Koynova und Caffrey 1998] Koynova, R. ; CAffrey, M.: Phases and phase transitions of the phosphatidylcholines. In: Biochimica et Biophysica Acta 1376 (1998), June, Nr. 1, S. 91-145 25

[Koynova und Caffrey 2002] Koynova, R. ; CAffrey, M.: An index of lipid phase diagrams. In: Chemistry and Physics of Lipids 115 (2002), S. 107-219 25

[de Kruijff u. a. 1997] Kruijff, B. de ; Killian, J.A. ; Rietveld, A.G. ; Kusters, R.: Phospholipid structure and Escherichia coli membranes. In: Lipid Polymorphism and Membrane Properties. (Epand, 1997), Kap. 13, S. 477-515 27

[Kumar u.a. 2001] Kumar, P.B.S. ; Gompper, G. ; Lipowsky, R.: Budding dynamics of multicomponent membranes. In: Physical Review Letters 86 (2001), April, Nr. 17, S. 3911-3914 103

[Kumar und Rao 1997] Kumar, P.B.S. ; RAO, M.: Shape instabilities in the dynamics of a two-component fluid membrane. In: Physical Review Letters 80 (1997), Nr. 11, S. 2489-2492. cond-mat/9704171 103

[Lagüe u. a. 2000] LagüE, P. ; Zuckermann, M.J. ; Roux, B.: Lipid-mediated interactions between intrinsic membrane proteins: A theoretical study based on integral equations. In: Biophysical Journal 79 (2000), December, S. 2867-2879 100

[Lagüe u. a. 2001] Lagüe, P. ; Zuckermann, M.J. ; Roux, B.: Lipid-mediated interactions between intrinsic membrane proteins: Dependence on protein size and lipid composition. In: Biophysical Journal 81 (2001), July, S. 276-284 100

[Landau und Lifschitz 1987] Landau, L.D. ; Lifschitz, E.M.: Statistische Physik (Teil 1). Akademie-Verlag Berlin, 198714 
[Langmuir 1917] LANGmuiR, I.K.: The constitution and fundamental properties of solids and liquids, II. Liquids. In: Journal of the American Chemical Society 39 (1917), S. 1848-1906 10

[Lavis und Bell 1999] Lavis, D.A. ; Bell, G.M.: Statistical Mechanics of Lattice Systems. Bd. 1: Closed-Form and Exact Solutions. Springer, 1999 22, 40, 55

[Lemmich u. a. 1996a] Lemmich, J. ; Hoenger, T. ; Mortensen, K. ; Ipsen, J.H. ; Bauer, R ; Mouritsen, O.G.: Solutes in small amounts provide for lipid-bilayer softness: cholesterol, short-chain lipids, and bola lipids. In: European Biophysical Journal 25 (1996), S. 61-65 58

[Lemmich u. a. 1996b] Lemmich, J. ; Mortensen, K. ; Ipsen, H. ; Hoenger, T. ; Bauer, R. ; Mouritsen, O.G.: Small-angle neutron scattering from multilamellar lipid bilayers: Theory, model, and experiment. In: Physical Review E 53 (1996), May, Nr. 5, S. 5169-5180 12

[Lemmich u. a. 1997] Lemmich, J. ; Mortensen, K. ; Ipsen, J.H. ; Hoenger, T. ; Bauer, R ; Mouritsen, O.G.: The effect of cholesterol in small amounts on lipid-bilayer softness in the region of the main phase transition. In: European Biophysical Journal 25 (1997), S. 293-304 56,57

[Lewis und McElhaney 2000] Lewis, R.N.A.H. ; MCElhaney, R.N.: Calorimetric and spectroscopic studies of the thermotropic phase behaviour of lipid bilayer model membranes composed of a homologous series of linear saturated phosphatidylserines. In: Biophysical Journal 79 (2000), October, S. 2043-2055 33

[Lexikonredaktion 1995] Lexikonredaktion, Meyers (Hrsg.): Schülerduden: Chemie. 3. Dudenverlag, 19957

[Likos 2001] Likos, C.N.: Effective interactions in soft condensed matter physics. In: Physics Reports 348 (2001), July, Nr. 4-5, S. 267-439 15

[Lipowsky 1992] LiPowsky, R.: Budding of membranes induced by intramembrane domains. In: Journal de Physique II 2 (1992), October, S. 1825-1840 95

[Löffler und Petrides 1988] LÖffler, G. ; Petrides, P.E.: Physiologische Chemie. 4. Springer Verlag, 198860

[Louie und Brayer 1990] Louie, G.V. ; Brayer, G.D.: High-resolution refinement of yeast ISO-1-Cytochrome C and comparisons with other eukaryotic Cytochromes C. In: Journal of Molecular Biology 214 (1990), S. 52761

[Löwen 2002] Löwen, H.: Coarse-Graining Colloids and Polymers. In: (Dhont u. a., 2002), Kap. B17 15

[Luftig und McMillan 1983] Luftig, R.B. ; McMillan, P.N.: Correlation of membrane models with transmission electron microscopic images. In: (Aloia, 1983), Kap. 4, S. 143-170 1

[Mannock u.a. 2003] Mannock, D.A. ; McIntosh, T.J. ; Jiang, X. ; Covey, D.F. ; McElhaNEY, R.N.: Effects of natural and enantiomeric cholesterol on the thermotropic phase behavior and structure of egg sphingomyelin bilayer membranes. In: Biophysical Journal 84 (2003), February, S. 1038-1046 56

[Marčelja 1974] MARČELJA, S.: Chain ordering in liquid crystals II. structure of bilayer membranes. In: Biochimica et Biophysica Acta 367 (1974), S. 165-176 20, 21

[McConnell 1991] MCConnell, H.M.: Structures and transitions in lipid monolayers at the air-water interface. In: Annu. Rev. Phys. Chem. 42 (1991), S. 171-195 10 
[McKiernan u. a. 1997] McKiernan, A.E. ; MacDonald, R.I. ; MacDonald, R.C. ; Axelrod, D.: Cytoskeletal protein binding kinetics at planar phospholipid membranes. In: Biophysical Journal 73 (1997), S. 1987-1998 11

[McKiernan u. a. 2000] McKiernan, A.E. ; Ratto, T.V. ; Longo, M.L.: Domain growth, shapes, and topology in cationic lipid bilayers on mica by fluorescence and atomic force microscopy. In: Biophysical Journal 79 (2000), November, S. 2605-2615 13

[McMullen u. a. 2000] McMullen, T.P.W. ; Lewis, R.N.A.H. ; McElhaney, R.N.: Differential scanning calorimetric and Fourier transform infrared spectroscopic studies of the effects of cholesterol on the thermotropic phase behaviour and organization of a homologous series of linear saturated phosphatidylserine bilayer membranes. In: Biophysical Journal 79 (2000), October, S. 2056-2065 56

[Metropolis u. a. 1953] Metropolis, N. ; Rosenblut, A. ; Rosenblut, M. ; Teller, A. ; TEller, E.: Equation of state calculations by fast computing machine. In: Journal of Chemical Physics 21 (1953), S. 109730

[Möhwald 1990] MöHwald, H.: Phospholipid and phospholipid-protein monolayers at the air/water interface. In: Annu. Rev. Phys. Chem. 41 (1990), S. 441-476 10

[Morse und Milner 1995] Morse, D.C. ; Milner, S.T.: Statistical mechanics of closed fluid membranes. In: Physical Review E 52 (1995), December, Nr. 6, S. 5918-5945 10

[Mouritsen 1991] Mouritsen, O.G.: Theoretical models of phospholipid phase transitions. In: Chemistry and Physics of Lipids 57 (1991), S. 179-194 11

[Mouritsen und Andersen 1998] Mouritsen, O.G. (Hrsg.) ; Andersen, O.S. (Hrsg.) ; The Royal Danish Academy of Sciences and Letters (Veranst.): In Search of a New Biomembrane Model. Bd. 49. Munksgaard, August 1998. (Biologiske Skrifter) 95

[Müller und Schmid 1999] Müller, M. ; Schmid, F.: Monte Carlo simulation of interfaces in polymer blends. In: StAuffer, D. (Hrsg.): Annual Reviews of Computational Physics VI Bd. 6. World Scientific, 1999, S. 59-127 101

[Nagai 1991] NAgAI, K.: Thermal desorption spectrum of the hard hexagon model. In: Surface Science Letters 244 (1991), S. L147-L151 64

[Nägele 2002] NäGELE, G.: Ornstein-Zernike theories of fluid microstructures. In: (Dhont u. a., 2002), Kap. B16 17

[Nagle u. a. 1998] Nagle, J.F. ; Petrache, H.I. ; Gouliaev, N. ; Tristram-Nagle, S. ; Liu, Y. ; Suter, R.M. ; Gawrisch, K.: Multiple mechanisms for critical behavior in the biological relevant phase of lecithin bilayers. In: Physical Review E 58 (1998), December, Nr. 6, S. 7769$7776 \quad 12$

[Nagle und Tristram-Nagle 2000] Nagle, J.F. ; Tristram-Nagle, S.: Structure of lipid bilayers. In: Biochimica et Biophysica Acta 1469 (2000), S. 159-195 12

[Nagle und Tristram-Nagle 2001] Nagle, J.F. ; Tristram-Nagle, S.: Structure and interactions of lipid bilayers: Role of fluctuations. In: (Katsaras und Gutberlet, 2001), S. 1-24 12

[Netz u.a. 1996] Netz, R.R. ; Andelman, D. ; Orland, H.: Protein adsorption on lipid monolayers at their coexistence region. In: Journal de Physique II France 6 (1996), July, S. $1023-1048 \quad 67,100$

[Nielsen u.a. 2000] Nielsen, L.K. ; Buørnholm, T. ; Mouritsen, O.G.: Fluctuations caught in the act. In: Nature 404 (2000), March, S. 35213 
[Nielsen u.a. 1996] Nielsen, M. ; Miao, L. ; Ipsen, J.H. ; Mouritsen, O.G. ; ZuckerMANN, M.J.: Random-lattice models and simulation algorithms for the phase equilibria in twodimensional condensed systems of particles with coupled internal and translational degrees of freedom. In: Physical Review E 54 (1996), December, Nr. 6, S. 6889-6905 96

[Nielsen u. a. 1999] Nielsen, M ; Miao, L. ; Ipsen, J.H. ; Zuckermann, M.J. ; Mouritsen, O.G.: Off-lattice model for the phase behavior of lipid-cholesterol bilayers. In: Physical Review E 59 (1999), May, Nr. 5, S. 5790 58, 96

[Okazaki u. a. 2001] Okazaki, M. ; Watanabe, T. ; Urakami, N. ; Yamamoto, T.: Molecular dynamics simulation of protein translocation across a membrane. In: Genome Informatics 12 (2001), S. 330-331. - cond-mat/0204546 95

[Onsager 1944] Onsager, L.: Crystal statistics. I. A two-dimensional model with an orderdisorder transition. In: Physical Review 65 (1944), February, Nr. 3, S. 117-149 22

[Parisi 1998] PARIsi, G.: Statistical Field Theory. Perseus Books, 1998 (Advanced Book Classics) 28

[Pathria 1996] Pathria, P.K.: Statistical Mechanics - Second Edition. Butterworth-Heinemann, 199614

[Peierls 1935] PEIERLs, R.: Statistical theory of superlattices with unequal concentrations of the components. In: Proceedings of the Royal Society 154 (1935), S. 207-222 40

[Pike 2003] PIKE, L.J.: Lipid rafts: bringing order to chaos. In: Journal of Lipid Research 44 (2003), S. 655-667 2

[Pink 1984] PINK, D.A.: Theoretical models of monolayers, bilayers and biological membranes. In: (Chapman, 1984), Kap. 6, S. 319-354 17

[Pink u.a. 1980] Pink, D.A. ; Georgallas, A. ; Zuckermann, M.J.: Phase transition and critical indices of a phospholipid bilayer model. In: Zeitschrift für Physik B - Condensed Matter 40 (1980), S. 103-110 21

[Pink u.a. 1981] Pink, D.A. ; Green, T.J. ; Chapman, D.: Raman scattering in bilayers of saturated Phosphatidylcholines and Cholesterol. Experiment and theory. In: Biochemistry 20 (1981), S. 6692-6698 19

[Press u.a. 1992] Press, W.H. ; Teukolsky, S.A. ; Vetterling, W.T. ; Flannery, B.P.: Numerical Recipes in C. 2. Cambridge University Press, 1992 28, 113, 116, 121

[Qiu u.a. 1991] QIU, X. ; Ruiz-Garcia, J. ; Stine, K.J. ; Knobler, C.M. ; Selinger, J.V.: Direct observation of domain structure in condensed monolayer phases. In: Physical Review Letters 67 (1991), August, Nr. 6, S. 703-706 13, 24

[Regge 1961] REgGe, T.: General relativity without coordinates. In: Nuovo Cimento 19 (1961), S. 558-571 104

[Reif und Muschik 1987] ReIf, F.; Muschik, W.: Statistische Physik und Theorie der Wärme. 3. Walter de Gruyter, 1987 14, 29, 94

[Richey und Tracy 1987] Richey, M.P. ; Tracy, C.A.: Equation of state and isothermal compressibility for the hard hexagon model in the disordered regime. In: J. Phys. A: Math. Gen. 20 (1987), S. L1121-L1126 64

[Riske u. a. 2002] Riske, K.A. ; Döbereiner, H.-G. ; LAmy-Freund, M.T.: Gel-fluid transition in dilute versus concentrated DMPG aqueous dispersions. In: Journal of Physical Chemistry B 106 (2002), Nr. 2, S. 239-246 13 
[Roelofsen und Op den Kamp 1987] Roelofsen, B. ; Kamp, J.A.F. Op den: Transbilayer organization of phospholipids in the plasma membranes of proerythroblasts and normal and abnormal red cells. In: Biomembrane and Receptor Mechanisms. (Bertoli u. a., 1987), S. 57-68 17

[Rudhardt u. a. 1998] Rudhardt, D. ; Bechinger, C. ; Leiderer, P.: Direct measurement of depletion potentials in mixtures of colloids and nonionic polymers. In: Physical Review Letters 81 (1998), August, Nr. 6, S. 1330-1333 17

[Sabra u.a. 1998a] Sabra, M.C. ; GilhoJ, H. ; Mouritsen, O.G.: Steady-state organization of binary mixtures by active impurities. In: Physical Review E 58 (1998), September, Nr. 3, S. $3547-3551 \quad 102$

[Sabra u. a. 1998b] SAbra, M.C. ; UitdehaAg, J.C.M. ; Watts, A.: General model for lipidmediated two-dimensional array formation of membrane proteins: Application to bacteriorhodopsin. In: Biophysical Journal 75 (1998), September, S. 1180-1188 96

[Sackmann 1978] SaCKMAnN, E.: Dynamic molecular organization in vesicles and membranes. In: Berichte der Bunsen-Gesellschaft: Physical Chemistry 82 (1978), S. 891-909 17

[Sackmann 1995] Sackmann, E.: Biological Membranes: Architecture and Function. In: Lipowsky, R. (Hrsg.) ; Sackmann, E. (Hrsg.): Handbook of Biological Physics Bd. 1. Elsevier, 1995, S. 1-63 1

[Sackmann u.a. 1987] Sackmann, E. ; Sen-Fang, S. ; Wirthensohn, K. ; Urumow, T.: Lipid-protein interaction: selectivity and receptor binding. In: Biomembrane and Receptor Mechanisms. (Bertoli u. a., 1987), S. 98-111 2

[Sankaram und Thompson 1990] Sankaram, M.B. ; Thompson, T.E.: Modulation of phospholipid acyl chain order by cholesterol: A solid-state $2 \mathrm{H}$ nuclear magnetic resonance study. In: Biochemistry 29 (1990), S. 10676-10684 56

[Schrader u. a. 2002] Schrader, W. ; Ebel, H. ; Grabitz, P. ; Hanke, E. ; Heimburg, T. ; Hoeckel, M. ; Kahle, M. ; Wente, F. ; KaAtze, U.: Compressibility of lipid mixtures studied by calorimetric and ultrasonic velocity measurements. In: Journal of Physical Chemistry B 106 (2002), S. 6581-6586 13

[Schulz 2001] Schulz, H.: Physik mit Bleistift. Das analytische Handwerkszeug des Naturwissenschaftlers. 4. Harri Deutsch, 200193

[Seddon und Templer 1995] Seddon, J.M. ; Templer, R.H.: Polymorphism of Lipid-Water Systems. In: Handbook of Biological Physics Bd. 1A. Elsevier, 1995, Kap. 3, S. 97-160 9

[Seifert u. a. 1991] Seifert, U. ; Berndl, K. ; Lipowsky, R.: Shape transformations of vesicles: Phase diagram for spontaneous-curvature and bilayer-coupling models. In: Physical Review A 44 (1991), July, Nr. 2, S. 1182-1202 95

[Sengupta u. a. 1999] Sengupta, K. ; Raghunathan, V.A. ; Katsaras, J.: Structure of the ripple phase in chiral and racemic dimyristoylphosphatidylcholine multibilayers. In: Physical Review E 59 (1999), Nr. 2, S. 2455-2457. - cond-mat/9907016 103

[Sens und Safran 2000] Sens, P. ; SAfran, S.A.: Inclusions induced phase separation in mixed lipid film. In: European Physical Journal E 1 (2000), S. 237-248. - cond-mat/9903365 100

[da Silva 1987] SiLva, P.P. da: Freeze fracture: seeing and thinking biological membranes. In: Biomembrane and Receptor Mechanisms. (Bertoli u. a., 1987), S. 11-33 2

[Simons und Ikonen 1997] Simons, K. ; Ikonen, E.: Functional rafts in cell membranes. In: Nature 387 (1997), June, S. 569-572 2 
[Simons und van Meer 1988] Simons, K. ; MeER, G. van: Lipid sorting in epithelial cells. In: Biochemistry 27 (1988), August, Nr. 17, S. 6197-6202 2

[Singer und Nicolson 1972] Singer, S.J. ; Nicolson, G.L.: The fluid mosaic model of the structure of cell membranes. In: Science 175 (1972), February, S. 720-731 1, 2, 3

[Sperotto 1997] Sperotro, M.M.: A theoretical model for the association of amphiphilic transmembrane peptides in lipid bilayers. In: European Biophysical Journal 26 (1997), S. 405-416 98

[Stryer 1995] Stryer, L.: Biochemie. 4. Spektrum Akademischer Verlag, 1995 1, 59, 84

[Sturm 1991] Sturm, K.: Konformationen. In: Hölzle, R. (Hrsg.): Physik der Polymere. Forschungszentrum Jülich GmbH, 1991, Kap. 318

[Suzuki u. a. 2000] Suzuki, K. ; SterbA, R.E. ; Sheetz, M.P.: Outer membrane monolayer domains from two-dimensional surface scanning resistance measurements. In: Biophysical Journal 79 (2000), July, S. 448-459 2

[Suzuki 1986] Suzuki, M.: Statistical Mechanical Theory of Cooperative Phenomena. I. General Theory of Fluctuations, Coherent Anomalities and Scaling Exponents with Simple Applications to Critical Phenomena. In: Journal of the Physical Society of Japan 55 (1986), December, Nr. 12, S. $4205-423040$

[Suzuki und Katori 1986] Suzuki, M. ; Katori, M.: New Method to Study Critical Phenomena - Mean-Field Finite-Size Scaling Theory. In: Journal of the Physical Society of Japan 55 (1986), January, Nr. 1, S. 1-4 40

[Tanford 1973] TANFORD, C.: The Hydrophobic Effect: Formation of Micelles and Biological Membranes. John Wiley and Sons, 197320

[Tempel u. a. 1996] Tempel, M. ; Isenberg, G. ; Sackmann, E.: Temperature-induced sol-gel transition and microgel formation in alpha-actinin cross-linked actin networks: A rheological study. In: Physical Review E 54 (1996), August, Nr. 2, S. 1802-1810 1

[Thurmond und Lindblom 1997] Thurmond, R.L. ; Lindblom, G.: NMR studies of membrane lipid properties. In: Lipid Polymorphism and Membrane Properties. (Epand, 1997), Kap. 3, S. $103-16623$

[Varma und Mayor 1998] VARMA, R. ; MAYOR, S.: GPI-anchored proteins are organized in submicron domains at the cell surface. In: Nature 394 (1998), August, S. 798-801 2

[Vereb u. a. 2003] Vereb, G. ; SzÖllösi, J. ; Matko, J. ; Nagy, P. ; Farkas, T. ; Vigh, L. ; Matyus, L. ; Waldmann, T.A. ; Damjanovich, S.: Dynamic, yet structures: the cell membrane three decades after the Singer-Nicolson model. In: PNAS 100 (2003), July, Nr. 14, S. 8053-8058 2

[Verma und Wallach 1984] Verma, S.P. ; Wallach, D.F.H.: Raman spectroscopy of lipids and biomembranes. In: Biomembrane Structure and Function. (Chapman, 1984), Kap. 3, S. 167-198 19

[Villain und Moreira 1991] Villain, J. ; MoreIRA, J.G.: Miscibility and phase diagram of mixed submonolayers: Mean field and hard hexagon approximation. In: Journal of Physics: Condensed Matter 3 (1991), S. 4587-4606 64

[Walz 2002] WAlz, A.: Maple 7: Rechnen und Programmieren. 2. Oldenbourg, 200267

[Watts und Spooner 1991] Watts, A. ; Spooner, P.J.R.: Phospholipid phase transitions as revealed by NMR. In: Chemistry and Physics of Lipids 57 (1991), S. 195-211 27 
[Weikl u. a. 1998] WeIKL, T.R. ; KozLov, M.M. ; HelFRICH, W.: Interaction of conical membrane inclusions: Effect of lateral tension. In: Physical Review E 57 (1998), June, Nr. 6, S. 6988-6995. - cond-mat/9804187 100

[Weiss 1948] WeIss, P.R.: The Application of the Bethe-Peierls Method to Ferromagnetism. In: Physical Review 74 (1948), November, Nr. 10, S. 1493-1504 40

[Werner u. a. 1997] Werner, A. ; Schmid, F. ; Müller, M ; Binder, K.: Anomalous sizedependence of interfacial profiles between coexisting phases of polymer mixtures in thin-film geometry: A Monte Carlo simulation. In: Journal of Chemical Physics 107 (1997), November, Nr. 19, S. $8175-818877$

[Werner u. a. 1999] Werner, A. ; Schmid, F. ; Müller, M. ; Binder, K.: "Intrinsic" profiles and capillary waves at homopolymer interfaces: A Monte Carlo study. In: Physical Review E 59 (1999), January, Nr. 1, S. 728-738 77

[White u.a. 2000] White, G.F. ; Racher, K.I. ; Lipski, A. ; Hallett, F.R. ; Wood, J.M.: Physical properties of liposomes and proteoliposomes prepared from Escherichia coli polar lipids. In: Biochimica et Biophysica Acta 1468 (2000), S. 175-186 27

[Yeomans 2000] Yeomans, J.M.: Phase ordering in fluids. In: Stauffer, D. (Hrsg.): Annual Reviews of Computational Physics VII Bd. 7. World Scientific, 2000, S. 61-84 24

[Zaccai 2002] ZACCAI, G.: Biopolymers: The macromolecules of life. In: (Dhont u. a., 2002), Kap. B13 94

[Zidovetzki 1997] ZidovetzKI, R.: Membrane properties and the activation of Protein Kinase C and Phospholipase $\mathrm{A}_{2}$. In: Lipid Polymorphism and Membrane Properties. (Epand, 1997), Kap. 7, S. 255-283 2

\section{Bemerkung}

Jedem Eintrag im Literaturverzeichnis folgt ein Verweis auf die jeweiligen zitierenden Stellen im vorliegenden Text in Form von Seitenzahlen. Die letzten Zahlen jedes Eintrags gehören demnach nicht mehr zum Zitat selbst. 



\section{Symbolverzeichnis}

$\beta \quad$ Inverse Temperatur, Seite 19

$\Delta T_{1 / 2}$ Übergangsbreite, Seite 32

$\langle\ldots\rangle_{P}$ Erwartungswert in der Verteilung $P$, Seite 28

$\langle\mathcal{H}\rangle \quad$ Innere Energie, Seite 28

$\mathcal{F} \quad$ Freie Energie, Seite 28

$H_{\mathrm{m}} \quad$ Übergangsenthalpie, Seite 32

$h_{\mathrm{w}} \quad$ Mittlere Dicke der Grenzfläche, Seite 78

$\mathcal{H} \quad$ Hamiltonfunktion, Seite 28

$\mathcal{Z} \quad$ Zustandssumme, Seite 19

$\pi \quad$ Lateraler Druck, Seite 40

$\mathcal{S} \quad$ Entropie, Seite 28

$T_{\mathrm{m}} \quad$ Übergangstemperatur, Seite 32

$A \quad$ Flächenbedarf des Zustands, Seite 20

C Spezifische Wärme, Seite 30

D $\quad$ Entartung des Zustands, Seite 19

E $\quad$ Energie des Zustands, Seite 19

H Enthalpisches Feld des Zustands, Seite 20

$h_{0} \quad$ Mittlere Lage der Grenzfläche, Seite 78

$n^{I} \quad$ Besetzungszahl der integralen Komponenten, Seite 37

$n^{L} \quad$ Besetzungszahl der Lipide, Seite 19

$n^{P} \quad$ Besetzungszahl der peripheren Komponenten, Seite 36

$o^{I} \quad$ Harter Kern integraler Komponenten, Seite 61

$o^{P} \quad$ Harter Kern peripherer Komponenten, Seite 61

$p^{\alpha} \quad$ Mittlere-Feld-Parameter, Seite 41

$p^{\alpha \beta} \quad$ Cluster-Parameter, Seite 41 
S $\quad$ Entropie des Zustands, Seite 19

T Temperatur, Seite 19

$U(r) \quad$ Energetischer Beitrag zur effektiven Wechselwirkung, Seite 70

$w^{I I} \quad$ Wechselwirkungs-Umgebung integraler Komponenten, Seite 62

$w^{P P} \quad$ Wechselwirkungs-Umgebung peripherer Komponenten, Seite 62

DMPC Dimyristoyl-Phosphatidylcholine, Seite 56

DMPG Dimyristoyl-Phosphatidylglycerol, Seite 87

DPPC Dipalmitoyl-Phosphatidylcholine, Seite 12

MC Monte-Carlo-Simulation, Seite 28

MD Molekular-Dynamik-Simulation, Seite 3

MF Mittlere-Feld-Approximation, Seite 28

$\mathrm{MF}+\mathrm{N}$ Mittlere-Feld-Approximation mit Nachbarschaften, Seite 40 


\section{Stichwortverzeichnis}

A

Adsorbat...................36, 102

Aggregation

- Protein...........................2

Algorithmus

- Conjugate Gradient.............. 116

- Metropolis ........................ 30

Aminosäure...................1, 35

Approximation

- Mittlere-Feld ........... 28, 54, 113

- Mittlere-Feld mit Nachbarschaften .40, 113

B

Bedeckungsgrad 76,86

Besetzungszahl

- Adsorbat.......................36

- Einlagerung....................... 37

- große Komponenten ...............61 61

- Lipid......................... 19

- mittlere.... siehe Ordnungsparameter

Biomembran .............. 1, 27, 94

Biophysik..................... 93

Boltzmann-Faktor ......... 14, 30, 122

Boltzmann-Konstante .............. 15

Boltzmann-Verteilung ............. 28

C

Cholesterin.................. 35, 57

Cluster-Parameter....41, 46, 57, 85, 113

Computersimulation

- Molekular-Dynamik........3, 95, 100

- Monte-Carlo.............28, 95, 117

Cytoskelett.................. 1, 93

D

Data Blocking.................... 31

Detaillierte Balance ................ 29

Dimerisierung ................... 85

Doppelschicht............. 1, 9, 17

Druck
- lateral......................20, 40

- osmotisch ....................25

E

E. Coli ........................ 27

Einlagerung...............37, 102

Energie

- freie .................28, 67, 115

- innere ................ 28, 40, 42

Entmischung.....13, 56, 76, 80, 89, 101

- kritische .................... 13

Entropie...............28, 40, 88

F

Feld

- äußeres ........................ 23

- effektives......................55

- enthalpisches...................20

- zufälliges.......................36

Fettsäure....................... 7

Flächenbedarf.............12, 20, 39

Floß...........................

Fluid .......... siehe Phase -expandiert

Fluktuation ..................... 76

Freie Energie..................... 15

Freiheitsgrad ..................... 14

- Diffusion........................ 17

- Flip-Flop......................17

- Konformation..............4, 7, 17

- Rotation..................18, 20,62

G

Gel .......... siehe Phase -kondensiert

Gittergas ............... siehe Modell

Grenzfläche.............76, 92, 101

- hydrophob/hydrophil.............20

- Wasser/Luft ..................... 10

Grenzlinie........... siehe Grenzfläche

\section{$\mathbf{H}$}

Hamiltonfunktion..............14, 28 
- Biomembran ...................6 62

- effektive ............... 15, 19, 53

- Gittergas........................41

- integrale Komponente............. 37

- periphere Komponente ............ 36

Harter Kern ...................... 61

Hartes Hexagon . . . . . . . . . . . . . . . . . 64

Hauptübergang ................ 11, 32

hydrophil ...................... 20

hydrophob .................... 20

Hydrophober Effekt ........... 39, 100

\section{I}

Ising-Modell

21, 102, 103, 106

K

Kagomé-Gitter .................... 105

Kalorimetrie..................12, 25

Kettenschmelzen .............. 12, 13

kikmean..................44, 113

Kohlenwasserstoff-Kette ............. 7

Kohlenwasserstoff-Ring .............. 35

Komponente

- integral............ siehe Einlagerung

- Loch ............................ 39

- peripher............. siehe Adsorbat

Konformation

- gauche ....................... 18

- trans.......................... 18

Kopfgruppe.................. 7,20

Kopplung.... 23, 30, 34, 67, 79, 86, 102

- Bindung ....................... 84

- Dreizustands-Modell .............. 54

- ferromagnetisch ................. 21

- Vergleich integral/peripher .... 39, 50

- Vergleich MF/MC................44

Korrelation....................... 44

Korrelationsfunktion ................ 16

Krümmung .............26, 95, 103

Kritische Mizellen-Konzentration . . . . 17

Kritischer Punkt......23, 26, 28, 54, 99

L

Lamellare Stapel .................. 10

Langmuir-Monoschicht...........10, 40

Laterale Strukturen ................. 2

Lineare Kette ................... 18

lipflip..................30, 117
Lipid $\ldots \ldots \ldots \ldots \ldots \ldots \ldots \ldots \ldots \ldots \ldots \ldots$, 7

- DMPC ......................56

- DMPG...................... 87

- DPPC ....................... 12

Lipidmembran...................2, 17

\section{M}

Materie

- biologische .................... 93

- weiche....................4, 94

Mischung

- ideal ....................... 46

Mittlere-Feld ..... siehe Approximation

Mizelle ..........................99

Modell

- Dreizustand....................54

- Flüssig-Mosaik .................. 2

- Gittergas...................20, 22

- Ising ............ siehe Ising-Modell

- Lipidmembran .................. 21

- phänomenologisch ................. 3

- Regge............ siehe Regge-Modell

- Zweizustand ............. 19, 21, 103

Molekular-Dynamik .............. siehe Computersimulation

Monte-Carlo.. siehe Computersimulation

$\mathrm{N}$

Nebenbedingung

- Besetzungszahl................... 39

- Cluster-Parameter.............41, 116

$\mathrm{O}$

Observable................. 30, 120

- Mittelwert ..................... 31

Ordnungsparameter ... 13, 14, 22, 78, 95

$\mathbf{P}$

Parameter

- angepasste .................... 88

- experimentelle ................ 87

- typische....................... 33

Peptid .......................... 35

Phase ........................... 76

- Aggregate...................... 9

- expandiert .................... 11

- Form...........................95

- Koexistenz........... 12, 23, 25, 54 
- kondensiert ................... 11

- lyotrop ......................... 9

Phasendiagramm

- Dreizustands-Gittergas ............ 54

- Ising-Modell .................... 23

- Lipidmembran...............23, 25

- Lipidvesikel .................... 32

- weiche Adsorbate ............... 76

Phasenübergang

- 1. Ordnung

- 2. Ordnung. .23

- kontinuierlich

$14,23,32$

Phosphatidylcholine . 25

Phospholipid siehe Lipid

Platzbedarf........ siehe Flächenbedarf Polymer ...................... 1, 18

Potential der mittleren Kräfte ... . 16, 69

Protein...................... 1, 35

- Cytochrome C..........60, 87, 101

- Dimer......................... 84

- integral ...................... 59

- Komplex...................... 84

- peripher..................59, 96

\section{$\mathbf{R}$}

Raft siehe Floß

Randbedingung

- fest ...................... 77

- periodisch.................30, 120

Regge-Modell ....................... 104

Ripple-Phase ............11, 25, 103

\section{$\mathrm{S}$}

Sampling ........... siehe Stichproben

Schichtdicke....................... 12

Sekundärstruktur ................... 35

Selbstkonsistenz .................... 28

Skalieren ................... 79, 101

Spezifische Wärme..........30, 32, 115

Stichproben .....................29

- gewichtet ................... 29

Systemgröße .................... 79

\section{$\mathrm{T}$}

Temperatur 14,23

- kritische ...... siehe Kritischer Punkt

Tertiärstruktur.................... 35

Triangulierung 103
$\mathrm{U}$

Übergang

- Breite......................... 32

- Enthalpie ...................... 32

- Temperatur ..................... 32

Übergangswahrscheinlichkeit.... 29, 121

V

Variationsprinzip .................28

Vergröberung .......... 14, 17, 94, 104

Verteilung

- Gleichgewicht ..................28

Vesikel .........................2

- GUV ......................... 10

- multilamellar......................9

- unilamellar ................... 9, 32

Vorübergang......... siehe Ripple-Phase

\section{W}

Wärmekapazität................ siehe Spezifische Wärme

Wechselwirkung

- Bindungsstelle.............. 84, 98

- effektive.............16, 70, 71, 84

- elektrostatische..............37,60

- harter Kern ...................... 20

- hydrophob .................... 20

- Mehrteilchen ....................667

- molekular ....................... 4

- Nächste Nachbarn................21

- Umgebung ................ 62, 120

- weiche Komponente ......... 66, 76

\section{$\mathrm{Z}$}

Zufallszahl .................. 29, 121

Zustand

- gefaltet..............12, 104, 106

- gestreckt............12, 18, 104, 106

- Lipid ..................... 18, 21

Zustandsänderung..................29

Zustandssumme................... 14

- Biomembran .................... 65

- großkanonisch ...................51

- kanonisch..................19, 51 



\section{Danksagung}

Auch eine Dissertation, für deren Inhalt man allein verantwortlich ist, entsteht nicht ohne die Mitwirkung anderer. Für Anregungen, Diskussionen und Hilfestellungen von Menschen aus meinem Umfeld bin ich sehr dankbar. Im Einzelnen bedanke ich mich bei

- Prof. Dr. Reiner Kree für die umfangreiche und motivierende Betreuung meiner Arbeit,

- Prof. Dr. Annette Zippelius für die Unterstützung meines wissenschaftlichen Werdegangs,

- den Kollegen der Villa-Gruppe für die angenehme Arbeitsatmosphäre,

- Matthias Kölbel, Marco Krohn und Jörg Mertins für die aufmerksame Durchsicht des Manuskripts,

- meiner Lebensgefährtin Dagmar Wachtmann, die mit mir ein großartiges Team bildet,

- und meinen Freunden und meiner Familie für ihre Unterstützung in allen Lebenslagen.

Die Arbeit eines Wissenschaftlers hat sich in den vergangenen Jahrzehnten grundlegend gewandelt. So ist neben der wissenschaftlichen Vorarbeit, die im Literaturverzeichnis zitiert wird, auch die technische unverzichtbar geworden. Viele Programmierer haben sich an der Entwicklung der (ausschließlichen freien) Software beteiligt, die ich im Laufe meiner Promotion genutzt habe. Einige sollen hier explizit erwähnt werden ...

- Alle Arbeiten wurden auf verschiedenen Linux-Betriebssystemen ausgeführt, die auf Linus Torwalds zurückgehen.

- Der Text der Arbeit wurde mit $\mathrm{LAT}_{\mathrm{E} X} \mathrm{x}$ von Leslie Lamport, einem Aufsatz auf $\mathrm{T}_{\mathrm{E}} \mathrm{X}$ von Donald E. Knuth, und diversen Zusatzpaketen gesetzt.

- Die Abbildungen von Molekülen wurden mit RasMol von Herbert J. Bernstein erstellt.

- Die Prinzipskizzen der Modelle und die Schnappschüsse der Monte-Carlo-Simulationen wurden mit dem Raytracing-Programm POVray erstellt, das auf ein ganzes Team von Autoren zurückgeht.

- Die Graphen wurden mit Gnuplot von Thomas Williams und Colin Kelley erstellt und mit dem Vektor-Zeichen-Programm Xfig von Paul King und anderen weiterverarbeitet. 



\section{Lebenslauf des Autors}

Dipl.-Phys. Hergen Schultze

Kurze-Geismar-Straße 40

37073 Göttingen

E-Mail: mail@HergenSchultze.de

Homepage: www.HergenSchultze.de

\section{Persönliche Daten}

Geboren am 7. Juli 1974 in Hannover,

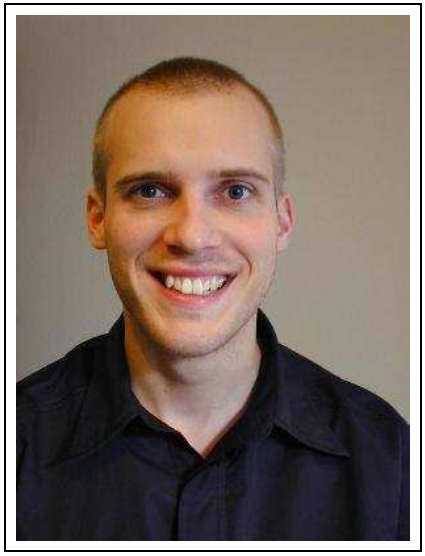

Staatsangehörigkeit: deutsch

\section{Bildungsweg}

\begin{tabular}{ll}
\hline $1981-1985$ & Grundschule Georgstraße in Garbsen \\
$1985-1987$ & Orientierungsstufe Berenbostel in Garbsen \\
$1987-1994$ & Gymnasium Berenbostel in Garbsen \\
& Abschluss Abitur \\
& Universität Hannover \\
$1994-1996$ & Vordiplom \\
& Georg-August-Universität Göttingen \\
$1996-1999$ & Abschluss Diplom \\
& Georg-August-Universität Göttingen \\
$1999-2003$ & Promotion voraussichtlich Oktober 2003 \\
&
\end{tabular}

Göttingen, den 12. September 2003 